\title{
Application and integration of the International Classification of Functioning, Disability and Health (ICF) in vocational rehabilitation
}

Citation for published version (APA):

Finger, M. (2014). Application and integration of the International Classification of Functioning, Disability and Health (ICF) in vocational rehabilitation. [Doctoral Thesis, Maastricht University]. Datawyse / Universitaire Pers Maastricht. https://doi.org/10.26481/dis.20140515mf

Document status and date:

Published: 01/01/2014

DOI:

10.26481/dis.20140515mf

Document Version:

Publisher's PDF, also known as Version of record

Please check the document version of this publication:

- A submitted manuscript is the version of the article upon submission and before peer-review. There can be important differences between the submitted version and the official published version of record.

People interested in the research are advised to contact the author for the final version of the publication, or visit the DOI to the publisher's website.

- The final author version and the galley proof are versions of the publication after peer review.

- The final published version features the final layout of the paper including the volume, issue and page numbers.

Link to publication

\footnotetext{
General rights rights.

- You may freely distribute the URL identifying the publication in the public portal. please follow below link for the End User Agreement:

www.umlib.nl/taverne-license

Take down policy

If you believe that this document breaches copyright please contact us at:

repository@maastrichtuniversity.nl

providing details and we will investigate your claim.
}

Copyright and moral rights for the publications made accessible in the public portal are retained by the authors and/or other copyright owners and it is a condition of accessing publications that users recognise and abide by the legal requirements associated with these

- Users may download and print one copy of any publication from the public portal for the purpose of private study or research.

- You may not further distribute the material or use it for any profit-making activity or commercial gain

If the publication is distributed under the terms of Article 25fa of the Dutch Copyright Act, indicated by the "Taverne" license above, 


\section{Application and integration of the International Classification of Functioning, Disability and Health (ICF) in vocational rehabilitation}


(C) Copyright Monika Elisabeth Finger, Maastricht 2014

ISBN 9789461593313

Production: Datawyse | Universitaire Pers Maastricht 


\title{
Application and integration of the International Classification of Functioning, Disability and Health (ICF) in vocational rehabilitation
}

\author{
DISSERTATION \\ to obtain the degree of Doctor at Maastricht University, \\ on the authority of the Rector Magnificus, Prof .dr. L.L.G. Soete \\ in accordance with the decision of the Board of Deans, \\ to be defended in public on \\ Thursday $15^{\text {th }}$ of May 2014, at 16:00 hours \\ by \\ Monika Elisabeth Finger
}

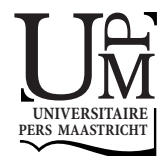




\section{Supervisor}

Prof. dr. R.A. de Bie

\section{Co-supervisors}

Dr. R. Escorpizo, Louisiana State University Health Science Center New Orleans, USA Prof. dr. A. Cieza, University of Southampton, United Kingdom

\section{Assessment committee}

Prof. dr. Mrs. A. Boonen, chair

Prof. dr. IJ. Kant

Dr. J. Kool, PhD

Prof. dr. F. Nijhuis

Prof. dr. M. F. Reneman 


\section{Contents}

$\begin{array}{lll}\text { Chapter } 1 & \text { General Introduction } & 7\end{array}$

Chapter 2 Identification of Relevant ICF Categories in Vocational 25

Rehabilitation: A Cross Sectional Study Evaluating the Clinical

Perspective.

Chapter 3 An examination of concepts in vocational rehabilitation that cannot be linked to the ICF using a qualitative analysis of secondary data

Chapter 4 ICF Core Set for vocational rehabilitation: results of an international consensus conference

Chapter 5 Work Rehabilitation Questionnaire (WORQ): Development and Preliminary Psychometric Evidence of an ICF-Based Questionnaire for Vocational Rehabilitation

Chapter 6 Using ICF in physiotherapy in multidisciplinary vocational rehabilitation: A case study of low back pain

Chapter 7 General Discussion

Addendum English Summary

Deutsche Zusammenfassung

Acknowledgements

About the author

Publications 

Chapter 1

General Introduction 


\section{Introduction}

In 1990 when I took up my work as a physiotherapist in a specialist rehabilitation center for patients with traumatic injuries, I started to experience and understand how important the knowledge of multiple health professionals in the multidisciplinary team was to support the patient at its best in his or her rehabilitation process.

Although in this center, weekly team meetings were common, joint goal definition and the coordination of interventions between professions were an ongoing challenge. Differing professional perspectives and assumptions often lead to individual, profession-specific goal setting and intervention planning. Interprofessional communication between team members was greatly dependent on personal connections and therefore uncertain.

In the mid1990's Dr. Heinz, the former medical director of, a rehabilitation center specialized on the rehabilitation of trauma patients (the Rehaklinik Bellikon), and at the time head of the Swiss Association of Rehabilitation (SAR), emphasized the need to base rehabilitation on a more bio-psychosocial model, moving away from the traditional biomedical focus. In this context he emphasized the need for an agreed model of disability as a basis towards a common understanding of rehabilitation. He proposed to the rehabilitation community in Switzerland to look closer into the ICIDH-2, the International Classification of Impairment, Disability and Health-2, the test version of the International Classification of Functioning Disability and Health (ICF)[1,2].

Finally in 2001, the International Classification of Functioning Disability and Health (ICF) of the World Health Organization (WHO) was endorsed by the World Health Assembly [2]. Shortly after its endorsement, the new medical director of the rehabilitation center in Bellikon, where I was working at the time, introduced the ICF officially as the new frame on which future rehabilitation processes should be based. An exciting process started towards defining an ICF- based rehabilitation process. This ICF approach finally included a comprehensive assessment, common inter-professional definition of rehabilitation goals including the patient perspective, coordination of interventions and discharge planning. In the course of this development, team communication and documentation became transparent and daily practice started to improve.

In the same time in the late 1990s, the body of evidence was growing that early return-to-work interventions were crucial to successfully support individuals on sick leave due to musculoskeletal injuries and diseases to reintegrate into work-force. The value of being at work was not only underlined for the perspective of the individual worker, e.g. life satisfaction, social integration and economic self-sufficiency, but also cost effectiveness due to reduced days of sick leave and disability pensions became evident for insurance companies and the social systems. The Suva, (Swiss accident insurance company) owner of the Rehaklinik Bellikon expressed great interest in returnto-work as a primary outcome of rehabilitation. 
In this context a new intervention program called "Ergonomie" was set up. It was intended to close the gap between medical rehabilitation of patients with musculoskeletal injuries and diseases and the department of professional reintegration, where vocational assessments and professional retraining were provided to clients after their medical rehabilitation was finished. The "Ergonomie" program was mostly based on the findings of Masterson and Isernhagen [3,4], including the process of functional capacity evaluation, work conditioning and work hardening interventions.

With this new program physical therapists were for the first time directly confronted with the importance of return-to-work as the overall goal for patients undergoing rehabilitation. In the meantime all health professionals in the team, physiotherapists and physicians in particular, were forced to realize that rehabilitation was not finished for patients undergoing inpatient rehabilitation after their discharge at home. Another effect of the interest of the Suva into the "Ergonomie"-program was that "health"rehabilitation professionals realized that any successful vocational rehabilitation intervention involved multiple stakeholders (e.g. health- and rehabilitation specialist, payer, employer and social security agent) with different expectations concerning the rehabilitation intervention and outcome. To meet the needs of the patient within this context a comprehensive assessment of his or her abilities and problems and the relevant contextual factors was needed.

The ICF provided a sensible frame to structure vocational rehabilitation interventions within this context. But only the health professionals of the "Ergonomie"-program agreed on using the bio-psychological model of the ICF. The professionals of the department of "Vocational Reintegration" considered the ICF as a foreign concept, too medically oriented, as to be helpful in evaluating professional abilities. They particularly missed the classification of personal factors and complained about the environmental factors in the ICF as being not suitable in the field of workplace accommodation.

This contradiction and growing evidence from outside of Switzerland that recommended to base disability evaluation on bio-psychosocial models [5-8], led in 2009 to the theme of this thesis: to introduce and evaluate the ICF as a reference framework of functioning in the field of vocational rehabilitation.

\title{
International Classification of Functioning, Disability and Health (ICF)
}

\author{
International Classification of Functioning, Disability and Health (ICF) and the \\ International Classification of Disease (ICD)
}

The International Classification of Functioning, Disability and Health (ICF)[1] was endorsed by the World Health Assembly [2] in May 2001 as the world standard for conceptualizing and classifying functioning and disability [9]. It provides a standard language and conceptual basis for the definition and measurement of disability. By shifting 
the focus from cause of disease to impact of disease, the ICF describes the consequences of health conditions in an equal way allowing comparison across health conditions, settings and countries. By integrating the traditional medical and the social model of disability in a "bio-psychosocial synthesis", the ICF acknowledges the role of environmental factors in the creation of disability as well as the role of the health condition [10].

As the second of the World Health Organization's (WHO) family of international classifications, the ICF was intended to complement the information that is collected worldwide and documented within the International Classification of Disease (ICD)[11], the first WHO classification. ICD is to record diagnostic information for clinical, epidemiological and quality purposes. These records also provide the basis for the compilation of national mortality and morbidity statistics by WHO member states. ICD records are also widely used for reimbursement and resource allocation, as well as decisionmaking concerning health policy [12]. Today the ICD-10 Revision (US: ICD-9) is in use while the ICD-11 revision is scheduled for 2015.

\section{Bio-psychosocial model and ICF classification}

The ICF as a classification system is based on a conceptual bio-psychosocial model that consists of two parts. Part 1 of the model refers to human functioning and disability while part 2 covers contextual factors (environmental and personal factors). Human functioning is seen as an umbrella term encompassing body functions, body structures, activities and participation. Thereby the functioning of an individual in a specific domain may be influenced by interactions between the health condition and the contextual factors. As stated in the introduction to the ICF [1], not an individual per se is classified; it is its functioning situation that can be recorded.

The ICF model (Figure 1) reflects the complex, dynamic and often unpredictable relationships among its components by bi-directed arrows, indicating that it is not correct to draw direct conclusions from information on one component to another e.g. inferring overall disability from a diagnosis, activity limitations from impairments, or participation restrictions from impairments or participation restrictions [9]. Consequently it is crucial to collect data on each component separately and then explore the connections between them individually. 
Figure 1: Bio-psychosocial Model of the ICF

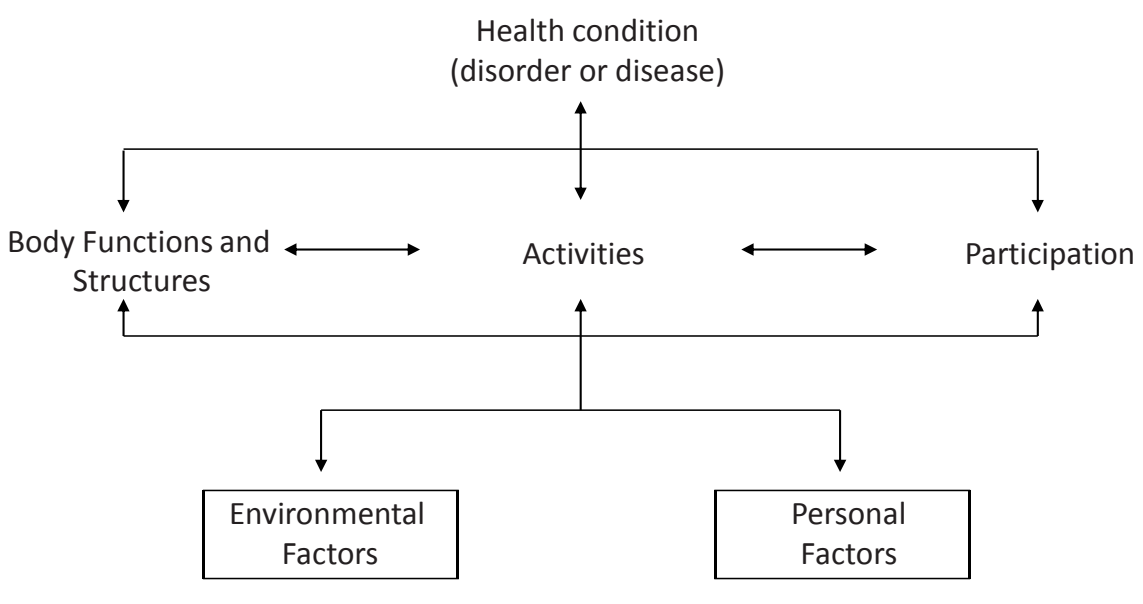

Contextual factors

The ICF classification system (Figure 2) provides a common language, terms and concepts that are intended to be used in various ways across many areas of application, such as in clinical care and research, health and social policy programs, population statistics and education, regardless of the health condition, the setting, culture, and context. One major aim thereby is to enhance communication across professions and settings as a basis to compare health information across regions and countries.

The classification system of the ICF has two parts, each with two components that are subdivided into chapters. The unit of classification in the ICF is the category within health and health related domains. 
Figure 2: Structure of the ICF Classification

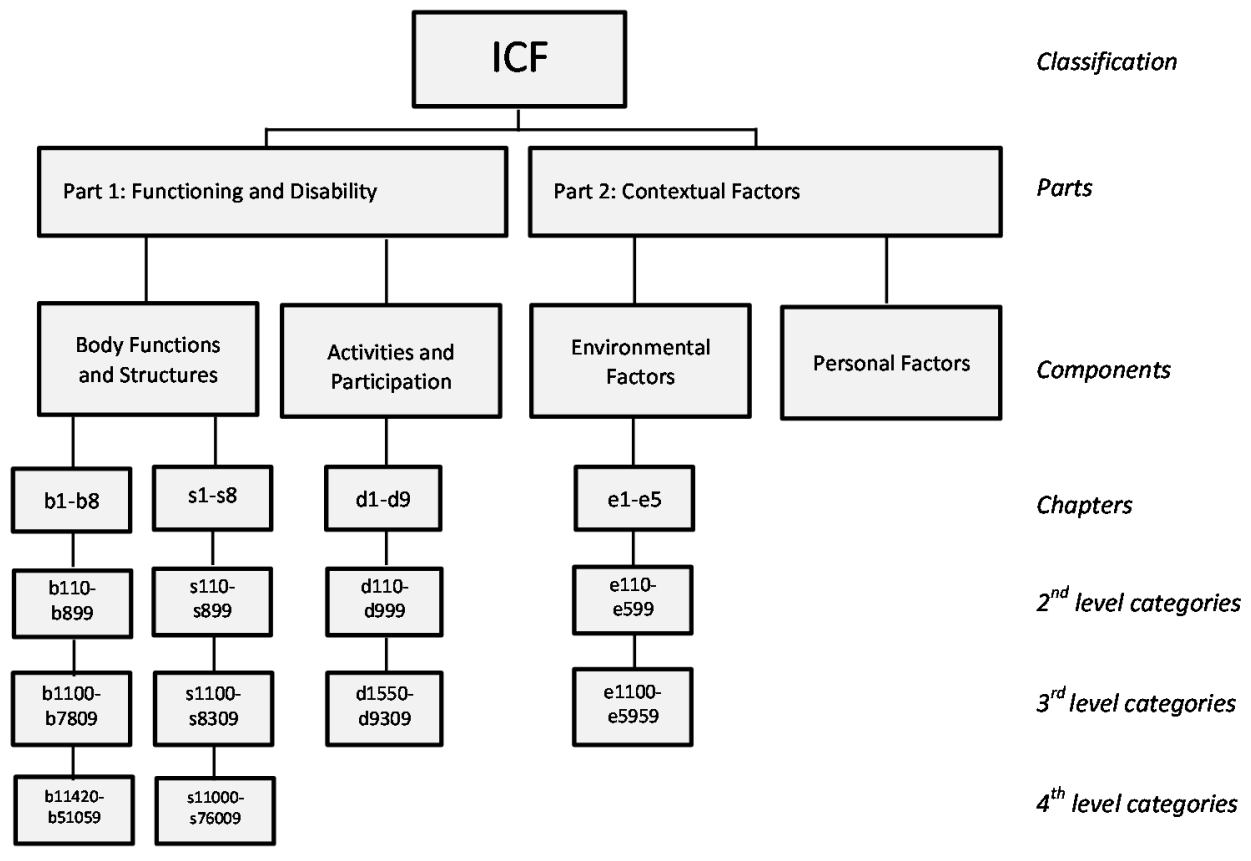

\section{Alphanumeric coding system of the ICF}

The structure of the ICF provides alphanumeric codes and textual definitions that are arranged in a hierarchical fashion, for all ICF components with the exception of Personal Factors (not classified). In the coding, lower levels provide more specific information, while a higher level stands for a broader definition. Below is an illustration of this categorization:

$\begin{array}{lll}\text { Part1: } & \text { Functioning and Disability } & \text { Part } \\ \text { d } & \text { Activities and Participation } & \text { Component } \\ \text { d8 } & \text { Major life areas } & \text { Chapter } \\ \text { d850 } & \text { Remunerative employment } & \text { Second-level category } \\ \text { d8500 } & \text { Self- employment } & \text { Third-level category } \\ \text { d8501 } & \text { Part-time employment } & \text { Third-level category } \\ \text { d8502 } & \text { Full-time employment } & \text { Third-level category }\end{array}$




\section{ICF Qualifiers}

To describe the level of functioning the ICF provides so called qualifiers. The first ICF qualifier is a generic rating scale, which can be used to measure the severity or magnitude of the impairment, capacity limitation, performance problem, or level of environmental barrier/facilitator.

Table 1: International Classification of Functioning, Disability and Health (ICF); general qualifier

\begin{tabular}{lll}
\hline General ICF Qualifier & & \\
\hline $\begin{array}{l}\text { Body functions, body structures, and activities and } \\
\text { participation }\end{array}$ & $\begin{array}{l}\text { Percentage of problem as } \\
\text { provided by WHO }\end{array}$ & $\begin{array}{l}\text { Annotation in the } \\
\text { alpha-numeric code }\end{array}$ \\
\hline 0: no problem (none, absent, negligible, ...) & $0-4 \%$ & $\mathrm{xxx} .0$ \\
1: mild problem (slight, low, . . ) & $5-24 \%$ & $\mathrm{xxx.1}$ \\
2: moderate problem (medium, fair ...) & $25-49 \%$ & $\mathrm{xxx.2}$ \\
3: severe problem (high, extreme, ...) & $50-95 \%$ & $\mathrm{xxx.3}$ \\
4: complete problem (total, ...) & $96-100 \%$ & $\mathrm{xxx.4}$ \\
8: (not specified) & & $\mathrm{xxx.8}$ \\
9: (not applicable) & & $\mathrm{xxx.9}$ \\
\hline
\end{tabular}

Abbreviation: $x x x .=$ proxy for the respective component code $(b=$ body function; $s=$ body structure; $d=$ activities and participation; $\mathrm{e}=$ environmental factor; and the category number

\begin{tabular}{ll}
\hline General ICF Qualifier & \\
\hline Environmental factors (barrier or facilitator) & $\mathrm{xxx.4}$ \\
\hline 4: complete barrier & $\mathrm{xxx.3}$ \\
3: severe barrier & $\mathrm{xxx.2}$ \\
2: moderate barrier & $\mathrm{xxx.1}$ \\
1: mild barrier & $\mathrm{xxx.0}$ \\
0: neither barrier nor facilitator & $\mathrm{xxx} .+1$ \\
+1: mild facilitator & $\mathrm{xxx} .+2$ \\
+2: moderate facilitator & $\mathrm{xxx} .+3$ \\
+3: substantial facilitator & $\mathrm{xxx} .+4$ \\
+4: complete facilitator &
\end{tabular}

Abbreviation: $x x x .=$ proxy for the respective component code $(b=$ body function; $s=$ body structure; $d=$ activities and participation; $\mathrm{e}=$ environmental factor; and the category number

As the ICF qualifiers were developed on an expert consensus bases, they are intended to be used to describe the magnitude of a problem in the sense of a reporting tool, e.g. to describe the functioning profile of a person, the functioning in populations or health condition specific groups. Hence ICF qualifiers were not intended to be used to rate ICF categories in the sense of a measurement instrument. Put on the test, test-retest reliability of ICF qualifiers differ widely from category to category and seam also to be influ- 
enced by the (care) setting in which the single category is evaluated [13-15]. To address the need of how to measure ICF categories in a psychometrical sound and valid way, one possibility is to develop methodological approaches which allow the mapping of outcome measures to the ICF and vice versa. For example with qualitative linking procedures distinct ICF categories can be mapped to calibrated measurement instruments or other standards used to quantify the problem $[16,17]$. To support converting these results, the WHO provides a broad range of percentages assigned to the respective ICF qualifier $[18,19]$. As a further solution, topic-centered sets of ICF categories, e.g. ICF Core Sets, can serve as a basis for the construction of new ICF based measures.

\section{ICF Core Sets}

Using the entire ICF with it's over 1400 categories may not be feasible. One approach to enhance the usability of the ICF and therefore to promote its implementation into practice is to develop, so called ICF Core Sets. There are two versions of the ICF Core Set: comprehensive and brief. The comprehensive Core Set contains as few categories as possible to still be practical but as many as necessary to capture the full spectrum of variables specific to a health condition or health-related event, in a comprehensive and multi-disciplinary assessment. In addition the comprehensive Core Set may provide a pre-selection of categories that can be added to the brief Core Set when needed. A brief Core Set is a sub-set of categories of the comprehensive Core Set. It contains the ICF categories that are essential to describe the typical spectrum of limitations in functioning and environment and is short enough to be practical in clinical studies or trials.

For example: In a multidisciplinary setting such as in hospitals or rehabilitation centers, a variety of health professionals may use the comprehensive Core Set to determine the functioning domains considered as relevant in the assessment process. In a private outpatient clinic, where a single healthcare practitioner is assessing the patient, it may be more convenient to use the brief Core Set, which already provides the minimum number of ICF categories to be assessed, amended with further ICF categories if needed. As a general rule, clinicians and researchers can always add further ICF categories to an ICF Core Set, if they feel that those categories are essential for their purpose and setting.

Since 2001 various Core Sets have been developed under the lead of the ICF Research branch, in collaboration with the World Health Organization Family of International Classifications Team (WHO-FIC), the International Society of Physical and Rehabilitation Medicine (ISPRM), the World Confederation of Physical Therapy (WCPT), the World Federation of Occupational Therapists (WFOT) and Core Set specific project partners. These ICF Core sets are freely accessible at www.icf-research-branch.org [20] 


\section{Vocational Rehabilitation}

\section{Introduction: Vocational rehabilitation in the context of work and work disability}

Work is a central aspect in people's lives and is one of the most powerful social determinants of health, as stated by the WHO [21]. Work is also widely associated with being integrated into society, and economic self-sufficiency [22]. For many people in western culture, the job represents a source for self-confidence, self-worth, social status and is even related to the person's identity. In contrast, losing a job or not being able to resume a job after sick leave is often associated with loss of self-confidence and psychological distress. Unemployment is even associated with an increased mortality risk [23]. When taking the perspective of the society, economic consequences of illness and disease are increasing. In 2008 on average, about 6\% of the working-age population received a disability benefit in countries of the Organisation for Economic Co-operation and Development (OECD). According to the OECD costs for sickness absence and both sickness and disability benefits were equivalent to about $2 \%$ of gross domestic product (GDP), what is equivalent to nearly $30 \%$ of expenditure on old-age pensions [24]. Based on the experiences of the economic downturns in the 1980s and 1990s the unemployment rate in individuals with disabilities is expected to rise. The OECD report "Sickness, Disability and Work: Breaking the Barriers" [25] recommends strategies to its member countries to address this challenge by actively supporting individuals to stay at their workplace or to offer education to facilitate new job opportunities.

While the interest of policy makers in encouraging working ability and return to work of injured or diseased persons is constantly growing. Strategies differ depending on the political and social system and the economy. One key element that is gaining more and more attention during the last decade is vocational rehabilitation (VR)

\section{Definition of vocational rehabilitation}

Many definitions have been proposed for vocational rehabilitation. In 2001, the definition of the OECD just stated that "Vocational rehabilitation includes ability testing, work adjustment measures and training other than ordinary labor market training" [26] where the International Labour Organization (ILO) defined VR by its objectives; "A process which enables disabled persons to secure, retain and advance in suitable employment and thereby furthers their integration or reintegration into society" [27].

However in clinical practice more comprehensive and complete definitions have been proposed, for example Selander stating in 2002 that "Vocational rehabilitation is defined as medical, psychological, social and occupational activities aiming to reestablish, among sick or injured people with previous work history, their working capacity and prerequisites for returning to a job or availability for a job" [28]. Selander emphasizes that vocational rehabilitation describes a process, which starts as early as 
possible after the onset of a disease or injury, initial medical care and rehabilitation. This complex process represents a continuum up to the intended outcome of a final return to work or at the opposite a disability pension and is often characterized by relapses. Then in 2010, an international, multi-professional expert group formulated a new, ICF-based definition for vocational rehabilitation, based on a most comprehensive understanding of VR and the ICF-based conceptual definition of rehabilitation [29]:

"Vocational rehabilitation is a multi-professional evidence-based approach that is provided in different settings, services, and activities to working age individuals with health-related impairments, limitations, or restrictions with work functioning, and whose primary aim is to optimize work participation" [30].

This definition by Escorpizo et.al. reflects the understanding of vocational rehabilitation of the author of this thesis. Since its completion in 2010, it is used as the reference definition of vocational rehabilitation throughout this thesis.

\section{Development of vocational rehabilitation}

In recent years vocational rehabilitation is increasingly acknowledged as a key process to support injured or diseased workers to return to work. Although physician Sir John Collie as early as 1916 discussed barriers for injured workers to resume work [31], and in adverse a negative impact on health of not being employed was recognized by Jahoda [32] during "the great depression" of 1930, structured (medical-oriented) rehabilitation programs have not evolved until the end of world war II, mostly due to the needs of injured soldiers.

The shift of interest in rehabilitation goals from medical restoration to a more comprehensive view of social and work reintegration instead, started in most countries at the beginning of the nineteen-eighties. This paradigm shift was driven by clinicians and researchers in the field of rehabilitation due to growing evidence and awareness that person and body addressed interventions only (interventions addressing body function and structure in the language of the ICF) failed to reintegrate patients into the workforce [33]. Work disability prevention models, as the Sherbrook model for the management of occupational back pain [34] and the conceptual model of work disability by Feuerstein describing the interaction of factors that contribute to the exacerbation and maintenance of work disability [5], were developed. They included not only disease specific evidence and clinical knowledge about rehabilitation, workplace adaptation or education but also aspects of the health care and compensation systems.

On the other hand the rising number of sickness and disability benefit claims in most European countries were alerting policy makers due to the increasing financial burden straining the social security systems. Due to the differences in legislation and 
responsibilities, the development of vocational rehabilitation strategies varied considerably between different countries. In Switzerland, as an example, interventions to reintegrate workers on sick leave are covered by the national disability trust (IV), as a part of the national security system since its formation in 1960 . Until the $5^{\text {th }}$ revision of the IV-legislation in 2007 [35], workers with a disability were not eligibility for vocational rehabilitation interventions or disability pensions until 1year after the causing accident or illness. Since January 2008 early interventions focusing on return-to-work are promoted, based on evidence that the likelihood of returning to work drops according to the time of sickness leave [36]. A strategy of "return-to-work" before disability benefit is widely promoted, acknowledging the importance for the individual as well as the financial gain on sick leave and disability benefits. In the following, this change in legislation facilitated the development of services and early interventions focusing on return-to-work in Switzerland, e.g. case management services and vocational counselling.

The growing conviction and insight in the complexity of disability prevention including vocational rehabilitation, given the available resources, multiple stakeholders and their competing interest, is leading to the understanding that a common framework to guide disability management, with vocational rehabilitation as a key component, is needed.

\section{Overall objective and specific aims of the thesis}

The International Classification of Functioning, Disability and Health (ICF) is a classification to evaluate the functioning of individuals in the context of health. The overall objective of this thesis is to introduce and evaluate the ICF as a reference framework of functioning in the field of vocational rehabilitation and to develop ICF based tools to facilitate the clinical integration of the ICF in vocational rehabilitation. To answer the overall objectives three specific aims will be looked at:

- The first aim is to establish content validity of the ICF as a reference framework of functioning in vocational rehabilitation. (Figure 3: study $a$ and b)

- The second aim is to develop an international standard and methodological approach for creating ICF-based applications in vocational rehabilitation. (Figure 3: study $c$ and d)

- The third aim is to apply ICF based tools in a clinical case example in vocational rehabilitation. (Figure 3: study e) 


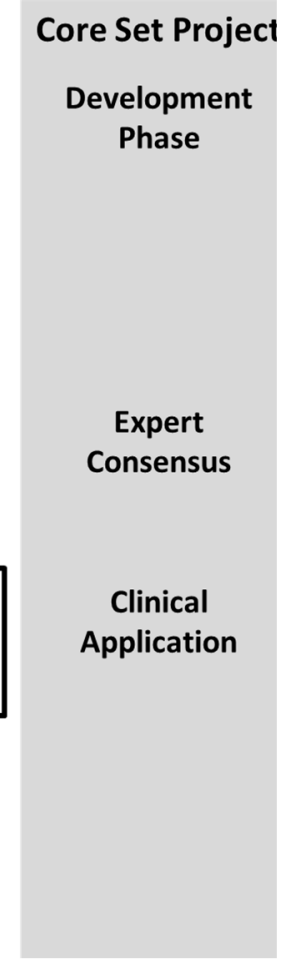

\section{Outline of the Thesis}

To achieve the overall objective, five studies have been conducted:

In Chapter $\mathbf{2}$ we report on study a: Identification of relevant ICF categories in vocational rehabilitation: A cross sectional study evaluating the clinical perspective.

In this study we described the functioning and health of persons undergoing VR, and identified the most common problems around work and in VR using the ICF as the reference framework. In an empirical cross-sectional multicenter study, data were collected using a case record form based on an extended ICF-checklist and sociodemographic information rated by health professionals. The extended ICF-checklist, which was based on the WHO ICF-checklist contained 292 ICF categories. Our study identified relevant categories from all four ICF components that describe functioning domains and which represent the complexity of VR. Such a comprehensive approach in assessing patients in VR may help to understand and customize the process of VR in the clinical setting and to enhance multidisciplinary communication. The results finally were presented to the experts at the ICF Core Set conference for VR (study c) to support an evidence based decision process. 
In Chapter 3 we report on study b: An examination of concepts in vocational rehabilitation that cannot be linked to the ICF: a qualitative analysis of secondary data.

In this study we analyzed secondary data from a systematic review [37], an expert survey [38] and a patient focus group study [39] that have been conducted to develop the ICF Core Set for VR. The overall objective of this study was to explore and examine those vocational rehabilitation-related concepts which could not be linked to distinct ICF codes. Therefore an explorative and qualitative analysis of was performed. 1093 concepts that were classified as not definable were assigned to the corresponding parts of the ICF, 1924 personal factors were linked to a personal factors classification and 441 concepts classified as not covered by the ICF were grouped in six themes. We found that the ICF provides a useful framework to describe most constructs pertaining to vocational rehabilitation. However, a structured way of assessing personal factors specific to vocational rehabilitation is needed and should be explored further. The influence on return-to-work of themes complementary to the ICF such as well-being and quality of life should be further investigated.

In Chapter $\mathbf{4}$ we report on study c: ICF Core Set for vocational rehabilitation: results of an international consensus conference.

In this study we describe the development of the Core Set for vocational rehabilitation based on the International Classification of Functioning, Disability and Health by the World Health Organization. In a two day conference, 23 international experts, chosen by WHO Region and expertise in VR, decided on the ICF categories to be included in the Core Set for VR. The formal decision-making and consensus-based process was based on the evidence from four preparatory studies. The expert opinion and evidence based Core Set could serve as an international standard for what to measure and report concerning functioning of individuals in VR. The Core Set could also provide a common language among clinicians, researchers, insurers, and policymakers in the implementation of successful VR.

In Chapter $\mathbf{5}$ we report on study d: Work Rehabilitation Questionnaire (WORQ): Development and preliminary psychometric evidence of an ICF-based questionnaire for vocational rehabilitation.

In this study we outlined the process for developing an ICF-based questionnaire, the Work Rehabilitation Questionnaire - (WORQ) to assess functioning in vocational rehabilitation and we reported preliminary psychometric evidence. First, ICF categories were selected from the ICF Core Sets for VR using explorative Rasch-analysis and a VR literature review. Questions were worded to assess identified ICF categories based on existing questions from the WHO Disability Assessment Schedule 2.0 (WHODAS 2.0) and the World Health Survey (WHS). WORQ then was translated from English to German. Psychometrics for the German version of WORQ were examined in one VR centre in Switzerland. WORQ appears to be a reliable, ICF-based questionnaire to evaluate functioning in VR. It is easy to administer by health or vocational professionals. The additional information on functioning gained when using WORQ might improve inter- 
disciplinary understanding of the patient's situation and therefore support the integrative planning of the return-to-work process or engagement in gainful employment. The development of WORQ outlined a sensible way to develop ICF based measurement instruments and to collect reliable patient administered data on functioning.

In Chapter 6 we report on study e: Using ICF in physiotherapy in multidisciplinary vocational rehabilitation: A case study of low back pain.

Although the clinical implementation of, the International Classification of Health, Disability and Health (ICF) has shown to be a useful framework to facilitate communication between stakeholders, to help structure rehabilitation plans, and for setting goals and clarifying team roles, its implementation is still challenging. To support the clinical integration of the ICF and ICF based tools, especially in multi-disciplinary teamwork, we use this teaching case as an example of an application of ICF-based tools in a multidisciplinary return to work (RTW) program for patients with non-specific low back pain (NLBP). This case study describes in particular the use of ICF-based tools such as the Rehabilitation Management Sheet (RehabManagement-Sheet) to guide the rehabilitation process, facilitate team-based and physiotherapist goal-setting and documentation in a multidisciplinary RTW program for NLBP. We showed that the use of ICF based tools in multidisciplinary rehabilitation allows for a comprehensive assessment, common goal -setting, and coordinated intervention planning. ICF-based tools like the RehabManagement-Sheet support the physiotherapist's role within the rehabilitation team by enhancing transparency in goal-setting and intervention planning across disciplines.

Chapter $\mathbf{7}$ is a general discussion, in which the main results are presented and critically appraised in the focus of the overall objective.

\section{References}

1. World Health Organization. International Classification of Functioning, Disability and Health. Geneva, Switzerland: World Health Organization; 2001.

2. World Health Organization, 54th World Health Assembly. International Classification of Functioning, Disability and Health (2001). Available from: http://www.who.int/classifications/icf/wha-en.pdf. Accessed 12 Aug 2009.

3. Isernhagen Work Systems. Functional capacity procedure manual. 1st edn ed. Duluth, MN; 1997.

4. Matheson LN, Ogden LD, Violette K, Schultz K. Work hardening: occupational therapy in industrial rehabilitation. Am J Occup Ther. 1985;39(5):314-21.

5. Feuerstein M. A multidisciplinary approach to prevention, evaluation, and management of work disability. J Occup Rehabil 1991;1(1):5-12.

6. Brage S, Donceel P, Falez F, Working Group of the European Union of Medicine in Assurance and Social Security. Development of ICF core set for disability evaluation in social security. Disabil Rehabil 2008;30(18):1392-6.

7. Chamberlain MA, Fialka Moser V, Schuldt Ekholm K, O'Connor RJ, Herceg M, Ekholm J. Vocational rehabilitation: an educational review. J Rehabil Med 2009;41(11):856-69. 
8. Homa DB. Using the International Classification of Functioning, Disability and Health (ICF) in job placement. Work 2007;29(4):277-86.

9. World Health Organization (WHO). How to use ICF: A practical manual for using the International Classification of Functioning, Disability and Health. Exposure draft for comment ed. Geneva, Switzerland: World Health Organization; 2013.

10. Ustun TB, Chatterji S, Bickenbach J, Kostanjsek N, Schneider M. The International Classification of Functioning, Disability and Health: a new tool for understanding disability and health. Disabil Rehabil 2003;25(11-12):565-71.

11. World Health Organization. ICD-10: International Statistical Classification of Diseases and Related Health Problems. 10th revision ed. Geneva, Switzerland; 2007.

12. World Health Organization (WHO). The WHO Family of International Classifications. Available from: http://www.who.int/classifications/en/. Accessed 12 Aug 2013.

13. Okochi J, Utsunomiya S, Takahashi T. Health measurement using the ICF: test-retest reliability study of ICF codes and qualifiers in geriatric care. Health. Qual. Life. Outcomes 2005;3:46.

14. Uhlig T, Lillemo S, Moe RH, Stamm T, Cieza A, Boonen A, et al. Reliability of the ICF Core Set for rheumatoid arthritis. Ann Rheum Dis 2007;66(8):1078-84.

15. Starrost K, Geyh S, Trautwein A, Grunow J, Ceballos-Baumann A, Prosiegel M, et al. Interrater reliability of the extended ICF core set for stroke applied by physical therapists. Phys Ther 2008;88(7):841-51.

16. Cieza A, Geyh S, Chatterji S, Kostanjsek N, Ustun B, Stucki G. ICF linking rules: an update based on lessons learned. J Rehabil Med 2005;37(4):212-8.

17. Cieza A, Brockow T, Ewert T, Amman E, Kollerits B, Chatterji S, et al. Linking health-status measurements to the international classification of functioning, disability and health. J Rehabil Med 2002;34(5):205-10.

18. Stucki G, Kostanjsek N, Ustun B, Cieza A. ICF-based classification and measurement of functioning. Eur J Phys Rehabil Med 2008;44(3):315-28.

19. Grill E, Stucki G. Scales could be developed based on simple clinical ratings of ICF Core Set categories. J Clin Epidemiol 2008;62(9):891-8.

20. ICF Research Branch in cooperation with the WHO Collaborating Centre for the Family of International Classifications in Germany (DIMDI). ICF Core Set Projects. 2012; Available from: http://www.icf-researchbranch.org/. Accessed Oct 11, 2012.

21. World Health Organization (WHO) editor. World Conference on Social Determinants of Health: Rio de Janeiro, Brazil, 19-21 October 2011. Geneva, Switzerland: WHO; 2012.

22. Thomas C, Benzeval M, Stansfeld S. Psychological distress after employment transitions: the role of subjective financial position as a mediator. J Epidemiol Community Health 2007;61(1):48-52.

23. Roelfs DJ, Shor E, Davidson KW, Schwartz JE. Losing life and livelihood: a systematic review and metaanalysis of unemployment and all-cause mortality. Soc Sci Med 2011;72(6):840-54.

24. Organisation for Economic Co-operation and Development Directorate for Employment, Labour and Social Affairs. Sickness, disability and work: Keeping on track in the economic downturn (background paper). May 2009; High-Level Forum, Stockholm, Sweden.

25. OECD. Sickness, Disability and Work: breaking the barriers. Paris, France: OECD Publishing; 2010.

26. OECD. Glossary: Vocational rehabilitation. 2009; Available from: http://stats.oecd.org/glossary/detail.asp?ID=2874. Accessed 12 Dec 2013.

27. International Labour Organization (ILO). Managing disability in the workplace. ILO code of practice. Geneva: International Labour Office; 2002.

28. Selander J, Marnetoft S-, Bergroth A, Ekholm J. Return to work following vocational rehabilitation for neck, back and shoulder problems: risk factors reviewed. Disabil Rehabil 2002;24(14):704-12.

29. Stucki G, Cieza A, Melvin J. The International Classification of Functioning, Disability and Health (ICF): a unifying model for the conceptual description of the rehabilitation strategy. J Rehabil Med 2007;39(4):279-85.

30. Escorpizo R, Reneman MF, Ekholm J, Fritz J, Krupa T, Marnetoft SU, et al. A conceptual definition of vocational rehabilitation based on the ICF: Building a shared global model. J Occup Rehabil 2011;21(2):126-33. 
31. Collie J. Return to Work-Legal and Other Impediments. Br. Med. J. 1916;2(2918):757-9.

32. Jahoda M. Employment and unemployment: A social-psychological analysis. Cambridge, MA: University of Cambridge Press; 1982.

33. International Social Security Association (ISSA). Research Rrogramme: Who returns to work and why? - A Summary. Geneva: ISSA; 2002.

34. Loisel P, Durand P, Abenhaim L, Gosselin L, Simard R, Turcotte J, et al. Management of occupational back pain: the Sherbrooke model. Results of a pilot and feasibility study. Occup Environ Med 1994;51(9):597602.

35. Suva (Swiss accident insurance). Medizinische Mitteilungen Nr.79. Luzern: Suva; 2008.

36. Marnetoft SU, Selander J, Bergroth A, Ekholm J. Factors associated with successful vocational rehabilitation in a Swedish rural area. J Rehabil Med 2001 03;33(2):71-8.

37. Escorpizo R, Finger ME, Glassel A, Gradinger F, Luckenkemper M, Cieza A. A systematic review of functioning in vocational rehabilitation using the international classification of functioning, disability and health. J Occup Rehabil 2011;21(2):134-46.

38. Escorpizo R, Finger ME, Glassel A, Cieza A. An international expert survey on functioning in vocational rehabilitation using the international classification of functioning, disability and health. J Occup Rehabil 2011;21(2):147-55.

39. Glassel A, Finger ME, Cieza A, Treitler C, Coenen M, Escorpizo R. Vocational Rehabilitation From the Client's Perspective Using the International Classification of Functioning, Disability and Health (ICF) as a Reference. J Occup Rehabil 2011;21(2):167-78 



\title{
Chapter 2
}

\section{Identification of Relevant ICF Categories in Vocational Rehabilitation: A Cross Sectional Study Evaluating the Clinical Perspective.}

Article published in J Occup Rehabil (2011) 21:156-166

\author{
Monika E. Finger \\ Andrea Glässel \\ Peter Erhart \\ Felix Gradinger \\ Andreas Klipstein \\ Gilles Rivier \\ Maria Schröer \\ Christian Wenk \\ Hans Peter Gmünder \\ Gerold Stucki \\ Reuben Escorpizo
}




\section{Abstract}

Introduction: Vocational rehabilitation (VR) emphasizes a need for medical support, rehabilitation and biopsychosocial approach to enable individuals to successfully participate in the workforce. Optimal rehabilitation management relies on an in-depth knowledge of the typical spectrum of problems encountered of patients in VR. The International Classification of Functioning, Disability and Health (ICF) is based on a universal conceptual model and provides a holistic view of functioning of the lived experience of people such as those undergoing VR. The objectives of this study are to describe the functioning and health of persons undergoing VR and to identify the most common problems around work and in VR using the ICF as the reference framework.

Methods: An empirical cross-sectional multicenter study was conducted using convenience sampling from March 2009 to March 2010. Data were collected using a Case Record Form rated by health professionals which was based on an extended version of the ICF Checklist containing 292 ICF categories and sociodemographic information.

Results: 152 patients with various health conditions participated. We identified categories from all four ICF components: 24 for body functions, six for body structures, 45 for activities and participation, and 25 for environmental factors.

Conclusions: Our study identified a multitude of ICF categories that describe functioning domains and which represent the complexity of VR. Such a comprehensive approach in assessing patients in VR may help to understand and customize the process of VR in the clinical setting and to enhance multidisciplinary communication.

Keywords: ICF, Cross-sectional study, ICF-checklist, Vocational rehabilitation. 


\section{Introduction}

Vocational rehabilitation (VR) emphasizes a need for medical support, rehabilitation and biopsychosocial approach to enable individuals to successfully participate in the workforce [1]. VR as a process may also, however, aim to integrate those who have not worked before in order to facilitate work participation.

Optimal rehabilitation management relies on an in-depth knowledge of the typical spectrum of problems encountered in persons in VR. Proper knowledge is needed as a basis to specify rehabilitation goals, selection of interventions and evaluation or reevaluation of VR outcomes. To facilitate successful VR outcomes, communication between the different stakeholders along the continuum care of VR is essential $[2,3]$. The wide range of health conditions that may affect work participation also poses a challenge to the understanding of VR because the impact of the various conditions may be different. Conditions which possibly require VR can be acquired (e.g. post-motor vehicular accident) or developmental (e.g. cerebral palsy) and may persist up to adulthood. Typical problems in VR have been identified in a number of studies which mostly describe defined patient groups, rehab settings or specific interventions [4], but there also exist numerous settings or interventions that focus on the common goal of reintegrating people into the workforce, without focusing on a specific health condition. Therefore, a common language and understanding that addresses the complexity of VR as a process of integrating the various players and conditions in which VR is necessary, would be of great value.

There are existing work disability and return to work (RTW) models based on different perspectives such as biomedical, psychosocial, ecological or bio-psychosocial perspectives [5-9]. There is a need for an overarching conceptual model, that is compatible and complementary to other RTW models and that may help integrate these diverse perspectives in RTW $[10,11]$.

The International Classification of Functioning, Disability and Health (ICF) [12] by the World Health Organization (WHO) is based on a universal conceptual model and offers a classification system which allows a comprehensive description of health and health-related states. Drawing upon the scope of the ICF, it would be possible to provide a holistic view of functioning or the lived experience of people such as those undergoing VR. The ICF categories that state the domains of body functions (b), body structures (s), activities and participation (d), environmental factors (e), and personal factors (not coded) could facilitate the description and classification of all relevant aspects of functioning and health in individuals, independent of a specific assessment instrument [13]. As a classification system, the ICF provides alphanumeric codes that are arranged in a hierarchical fashion, hence different levels, for each of the ICF categories or functioning domains. Below is an illustration of this categorization: 


$\begin{array}{lll}\text { ICF component } & \mathrm{d} & \text { activities and participation } \\ \text { Chapter } & \mathrm{d} 8 & \text { Major life areas } \\ \text { Second-level category } & \mathrm{d} 850 & \text { Remunerative employment } \\ \text { Third-level categories } & \mathrm{d} 8500 & \text { Self- employment } \\ & \mathrm{d} 8501 & \text { Part-time employment } \\ & \mathrm{d} 8502 & \text { Full-time employment }\end{array}$

Thus, the ICF would be particularly helpful in the area of clinical evaluation of patients where different instruments are being used and where a standard list of functioning domains would be beneficial to clinician's planning of interventions and the comparison of data for population health statistics [14-16]. The objectives of this study are to describe the functioning and health of patients undergoing VR and to identify the most common problems around work and in VR using the ICF as the reference framework.

\section{Methods}

\section{Study Design}

An empirical cross-sectional multicenter study [17] was conducted from March 2009 to March 2010 as a part of the preliminary studies in the international project "Development of ICF Core Sets for Vocational Rehabilitation" [18]. This study is one of four studies that investigated the important aspects of functioning in VR from different perspectives. Ethics approval was obtained for each of the study centers. The Declaration of Helsinki was employed in the conduct of the study.

\section{Population}

In this study, a convenience sample of 152 patients in VR was gathered from four VR centers in Switzerland and one center in Germany. The following were the inclusion criteria: (1) primary diagnosis (according to the International Classification of Diseases and Health related Disorders ICD-10 [19] that causes functioning problems which required VR. (2) at least 18 years old, (3) can speak, read, and write in German, (4) able to make decision for her- or himself as attested by a health professional, (5) informed of the purpose and reason of the study, and both have been understood, and (6) signed the "patient informed consent form".

Two study centers in Switzerland had a VR setting of work evaluation, ergonomic evaluation, and work-specific physical and cognitive training. In the third center, vocational evaluation and return to work interventions were integrated in an early stage of spinal cord injury rehabilitation. In the fourth center, work related vocational training and supported employment for outpatients were offered. The fifth center located in 
Germany had a VR setting of vocational orientation and vocational training for in- and out-patients. The study centers were chosen to obtain a comprehensive picture of the whole continuum of vocational rehabilitation including the diversity of health conditions and common VR interventions. Health conditions included neurologic conditions such as traumatic brain injuries, stroke and spinal cord injuries, mental diseases like depression or schizophrenia, internal medical diseases such as asthma, or cardiac infarction, and musculoskeletal conditions such as low back pain, fractures of the vertebrae or contusion, distortion, fracture or cut injuries of hands or legs.

\section{Instruments}

Data were collected with a Case Record Form for health professionals (CRF-HP), which was documented and rated by a health professional. Sociodemographic information such as age and sex, main diagnoses, professional and work history, and the current VR intervention were extracted from the medical record. The Extended ICF Checklist [20] was administered during the interview. A pre-test of the feasibility of the CRF-HP was made. The average length of interview in the pretest ranged from 50 to $80 \mathrm{~min}$.

\section{The Extended ICF Checklist}

The basis of the Extended Checklist for VR is the ICF Checklist version 2.1a, developed by the World Health Organization (WHO) [21]. It includes a selection of 125 out of 362 existing second level categories, representing the classifiable ICF components: body function (b), body structure (s), activities and participation (d), and environmental factors (e). To this checklist, more ICF categories have been added that were considered relevant to VR. This extension was first made through a literature search where common assessment instruments in VR were identified and linked to the ICF based on established inking- rules [22]. 31 second level and 75 third and fourth level categories, which were not covered by the ICF Checklist, were added, hence, "extended". As a second step, the checklist was presented to a group of experts in VR and we asked for categories they believed were missing from the checklist. This second step resulted in the integration of all second level categories from environmental factors and all third level categories from chapter e5 Services, systems and policies. Nine more second level categories and 52 third and fourth level categories were added to the checklist. Hence, the Extended ICF Checklist for VR contained 96 categories from body functions (32.9\%), 19 categories from body structures (6.5\%), 120 categories from activities and participation (41.1\%) and 57 environmental factors (19.5\%).

The presence of a problem was denoted for each category of the components body functions, body structures and activities and participation using a visual analogue scale (VAS) of 1-100 (the higher the number, the higher the magnitude of the problem, impairment, limitation, or restriction). The categories of the component environmental 
factors were rated as being a facilitator or a barrier. VAS was also used but this time with positive sign denoting as "facilitator" i.e. rated from 1 to 100, otherwise it was considered "neutral" or a "barrier". In addition, other qualifiers were used-" 8 " was used if the available information was not sufficient to rate that ICF category and " 9 " if the category was not applicable.

The rating of each ICF category was determined by the health professional/interviewer based on his or her interaction with the patient during the interview. This determination was based on the evaluation of the response of the interviewee, observations made by the interviewer during the interview, and consultation of medical records.

\section{Procedure}

The recruitment of the patients was performed by center representatives (CR). The CRs were made aware of the inclusion criteria and were informed about the project. Potential study participants were asked to take part in the study. If patients agreed, their names were forwarded to a study coordinator who then explained the study. Once written informed consent forms were received, a health professional who was trained in administering the study procedures and contents, examined the medical record of the patient and then conducted the interviews. The health professional filled in the CRF-HP. Written material was provided. Plausibility checks were performed by the study coordinator throughout the period of data collection. The data collected were saved in a secure electronic database Microsoft ${ }^{\circledR}$ Access 2007 (Microsoft Corporation, Redmond WA).

\section{Data Analysis}

Descriptive statistics were used to characterize the study population and to examine the frequency of problems recorded in the Extended ICF Checklist. The ICF categories in the components body functions, body structures, and activities \& participation that were rated on the VAS with 5 or more points out of the 100 were arbitrarily regarded as impaired, limited, or restricted. Ratings below 5 were not considered for analyses at this time. In the component environmental factor, barriers or facilitators rated below of 5 points out of 100 (meaning neither a facilitator nor a barrier) were also not included in the analyses. Missing values and response options rated as "not applicable" and "not definable" were not considered in the analyses, while co-morbidities were duly noted. The ICF categories that were problematic in at least 20\% (arbitrary cut-off) of the patients were reported. The results for the study population and sub-population based on health condition groups were examined: neurologic condition, mental condition, internal medical condition, musculoskeletal condition concerning the trunk (MSC_trunk), musculoskeletal condition concerning the extremities (MSC_ext). The results for 
MSC_trunk and MSC_ext were presented separately, due to the distinction made in the literature between the two. Data analyses were performed with SPSS.14.0 for Windows (SPSS Inc., Chicago, IL USA) for the descriptive presentation and to examine relevant second-level categories (aggregated to).

\section{Results}

The sample characteristics of the patients are shown in Table 1. Most of the patients were male (77.6\%). On average, the work experience was 11 years with range of 0-42 years. More than half of the patients were in VR due to a musculoskeletal condition followed by neurologic and mental conditions. Internal medical conditions as main diagnoses consisted $5.3 \%$ of the study sample. Sixteen and half percentage points of the patients had relevant internal medical co-morbidity conditions.

Tables 2, 3, 4, 5 show the ICF categories which were relevant in at least $20 \%$ of the patients. Percentages are shown for the sample and for the condition subgroups. In the component environmental factors, percentage of barriers and facilitators is shown for each category rated in at least $20 \%$ of the patients as either a barrier or as facilitator.

Overall, there were 100 ICF categories that were identified as relevant. Twenty-four categories came from component body function, 6 from the component body structures, 45 from the component activities and participation, and 25 from environmental factors. 


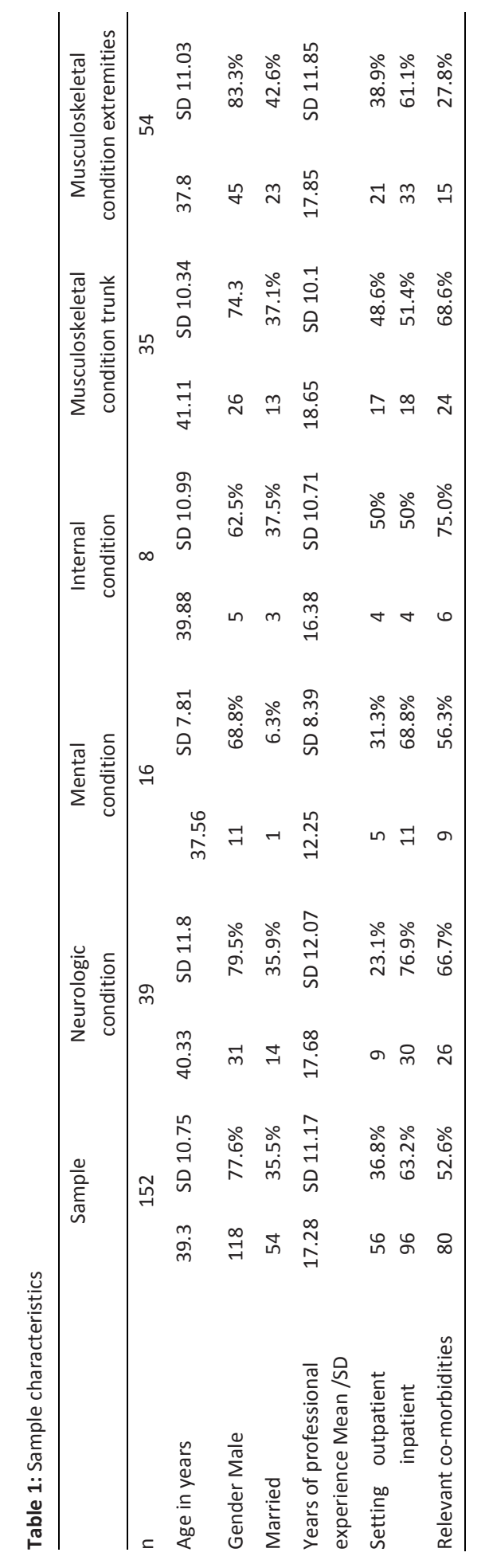




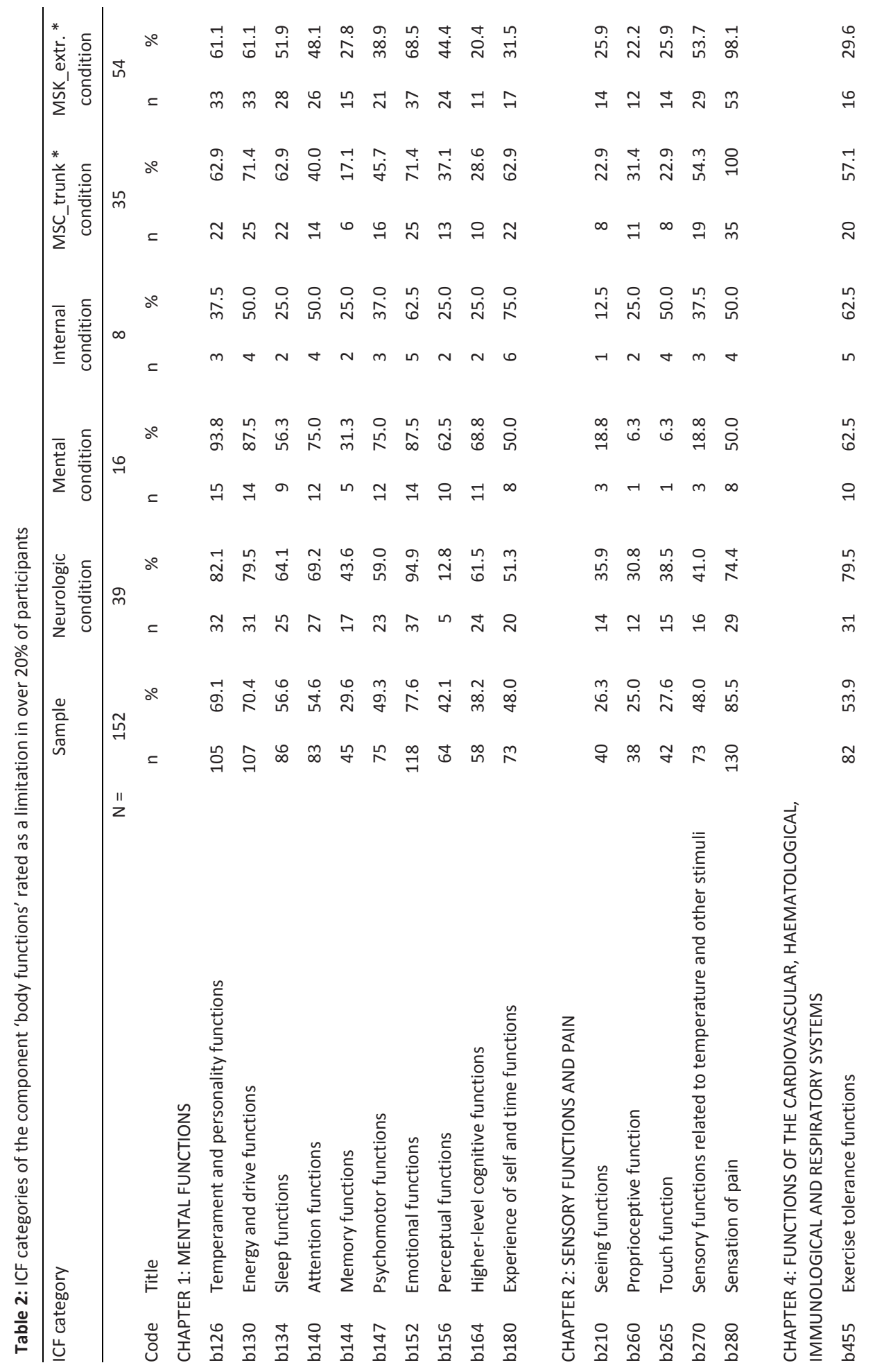




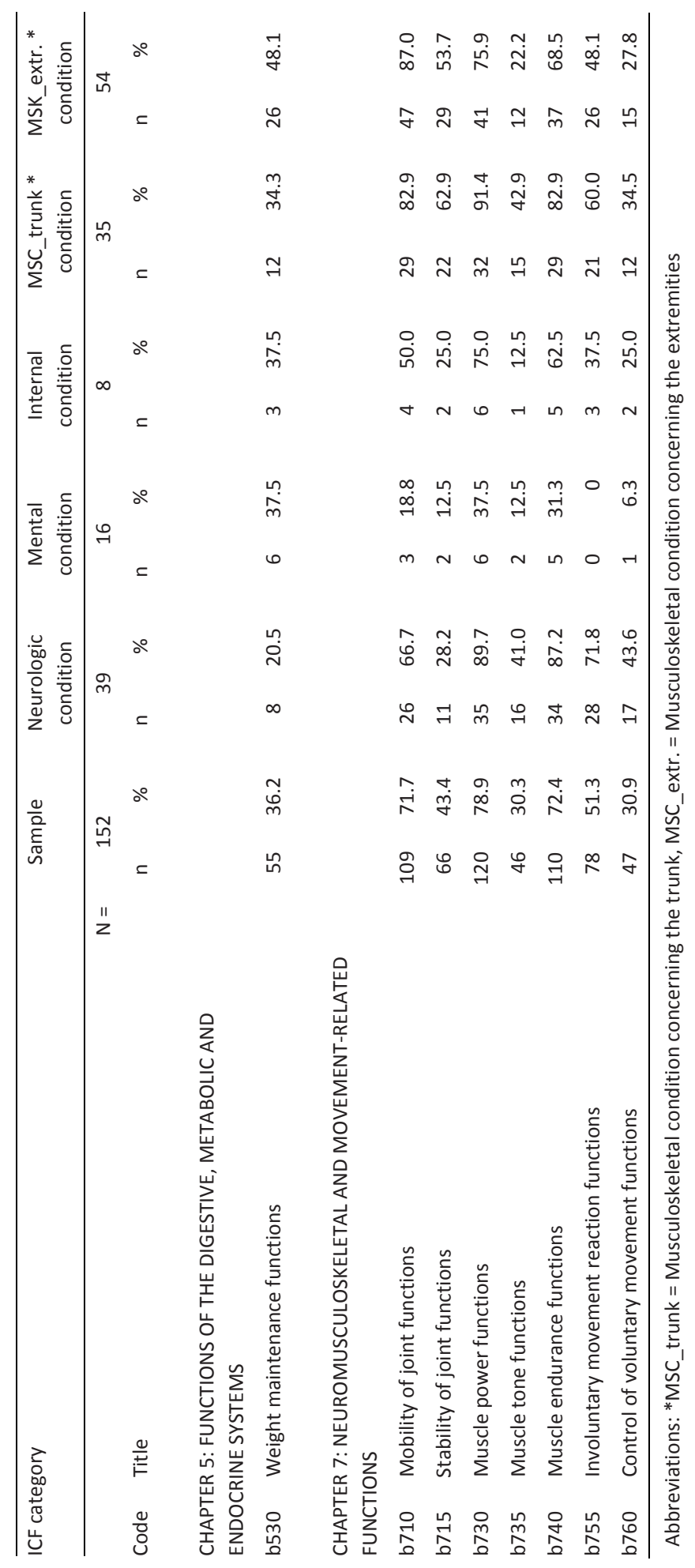



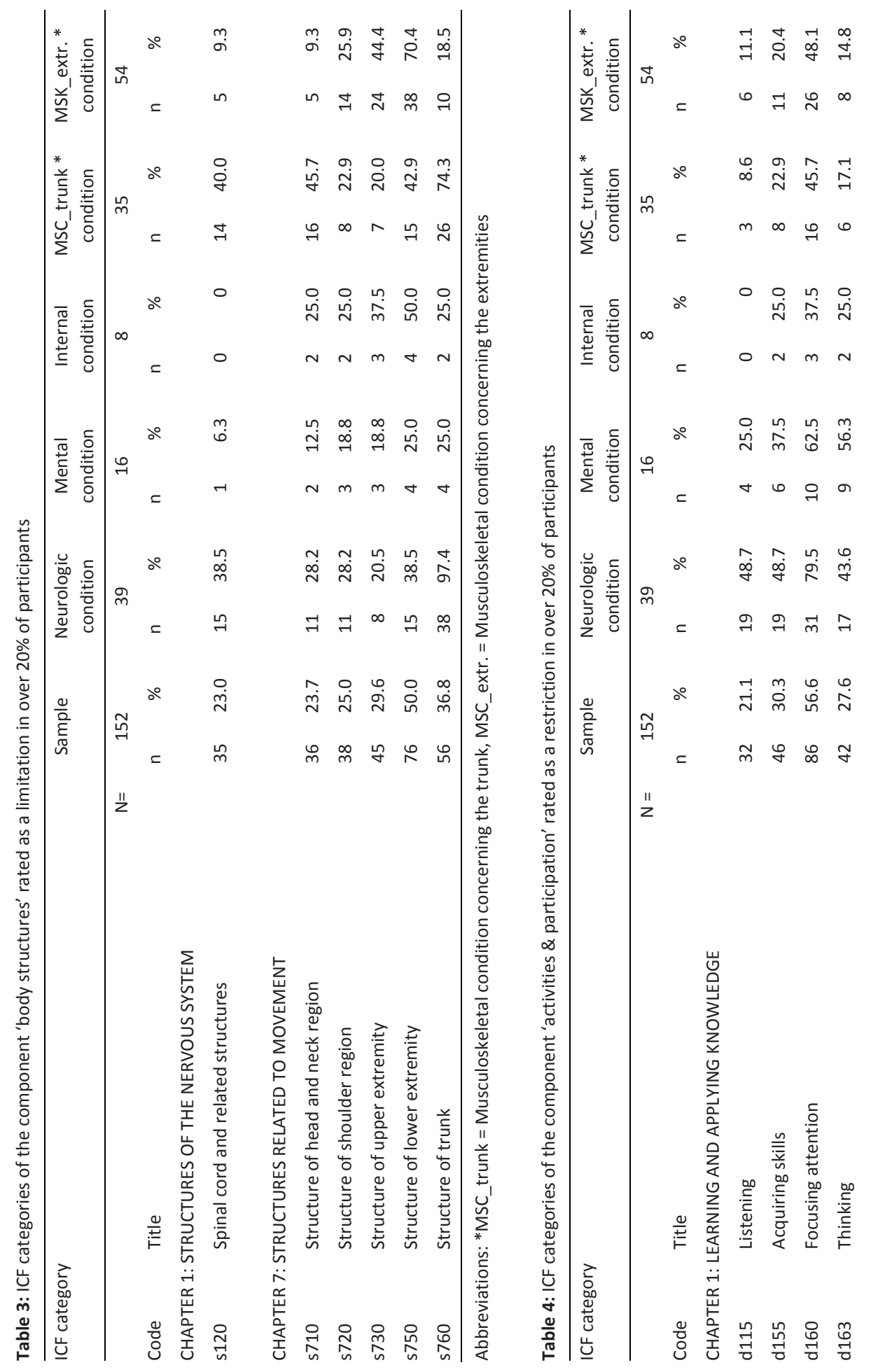


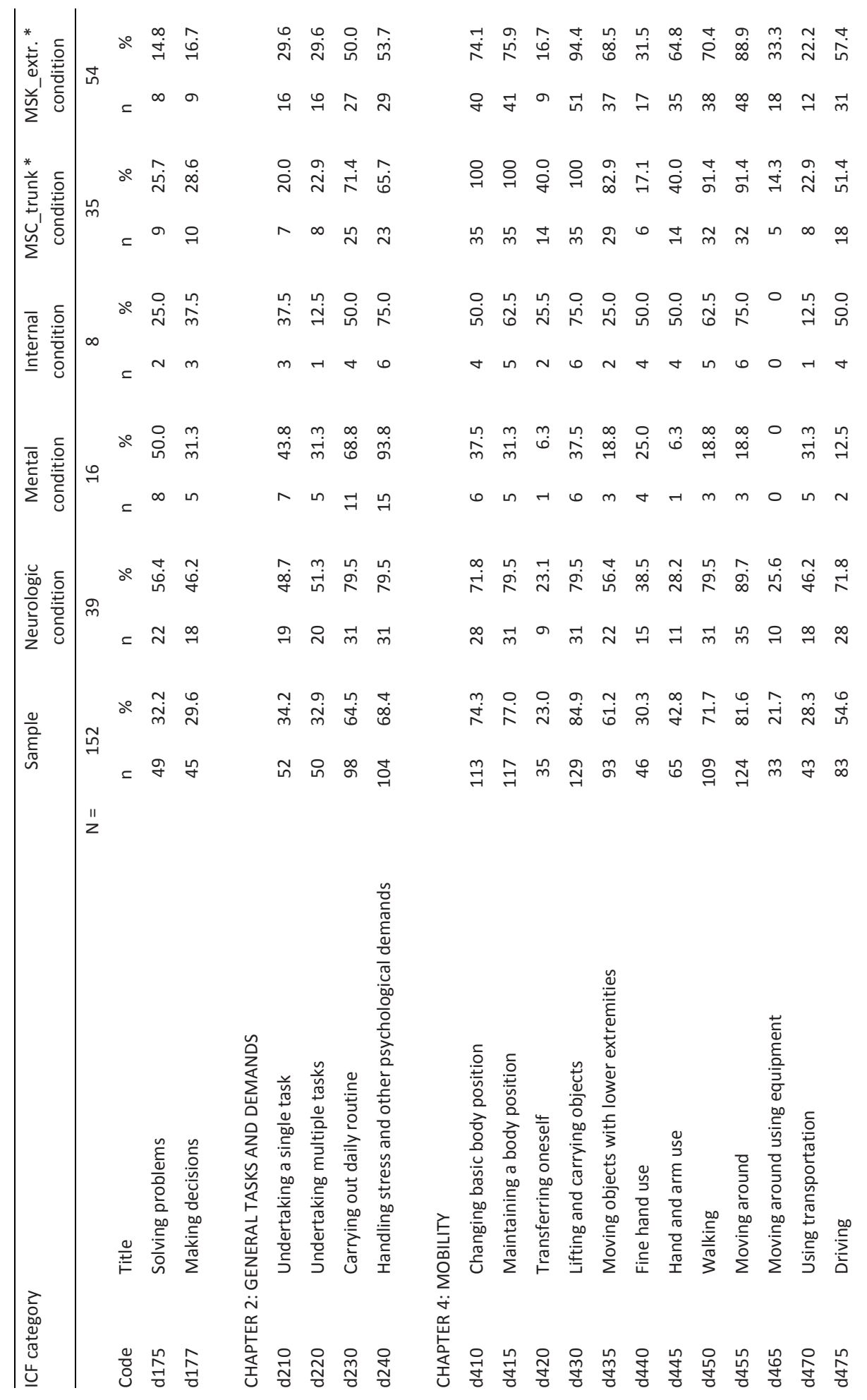




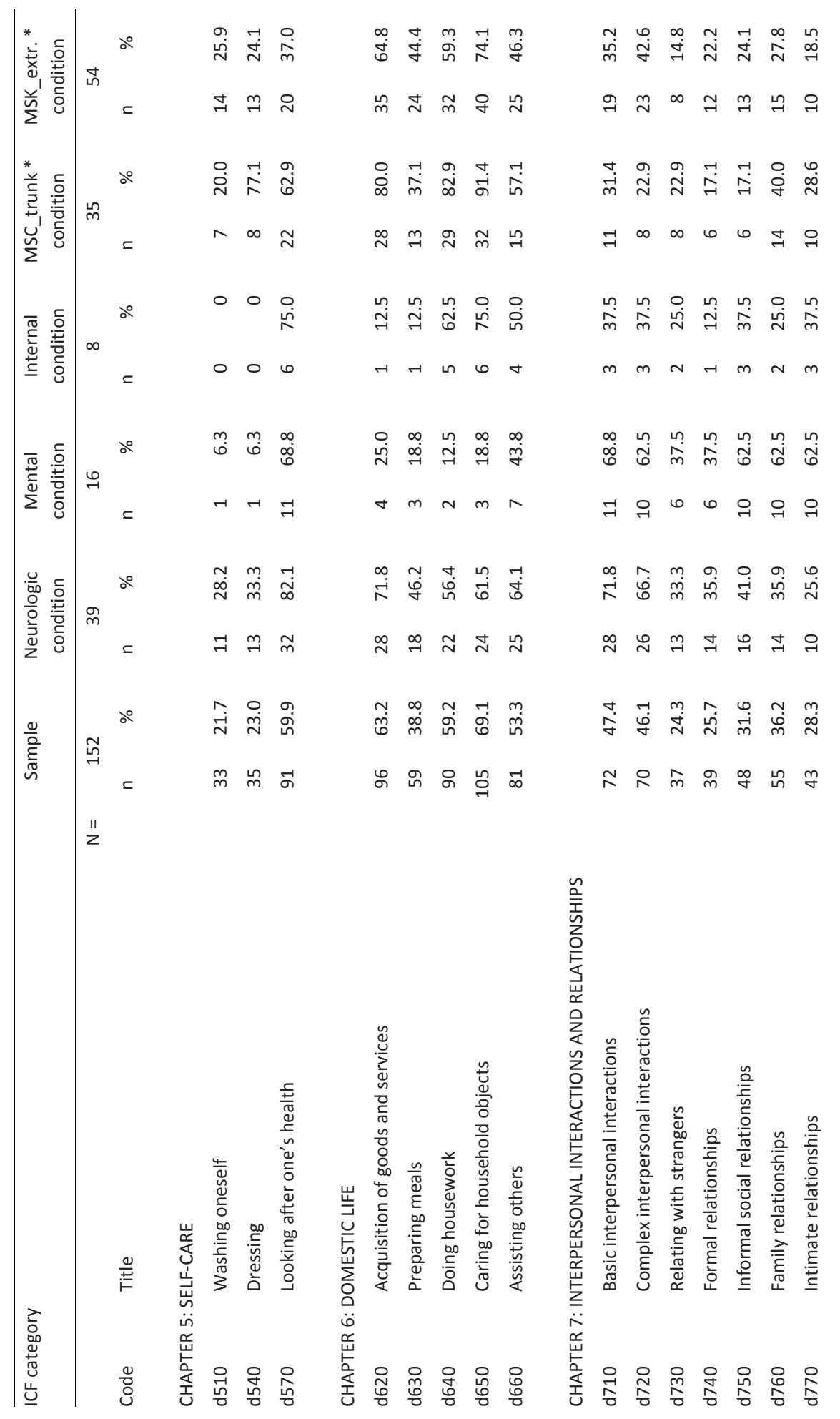




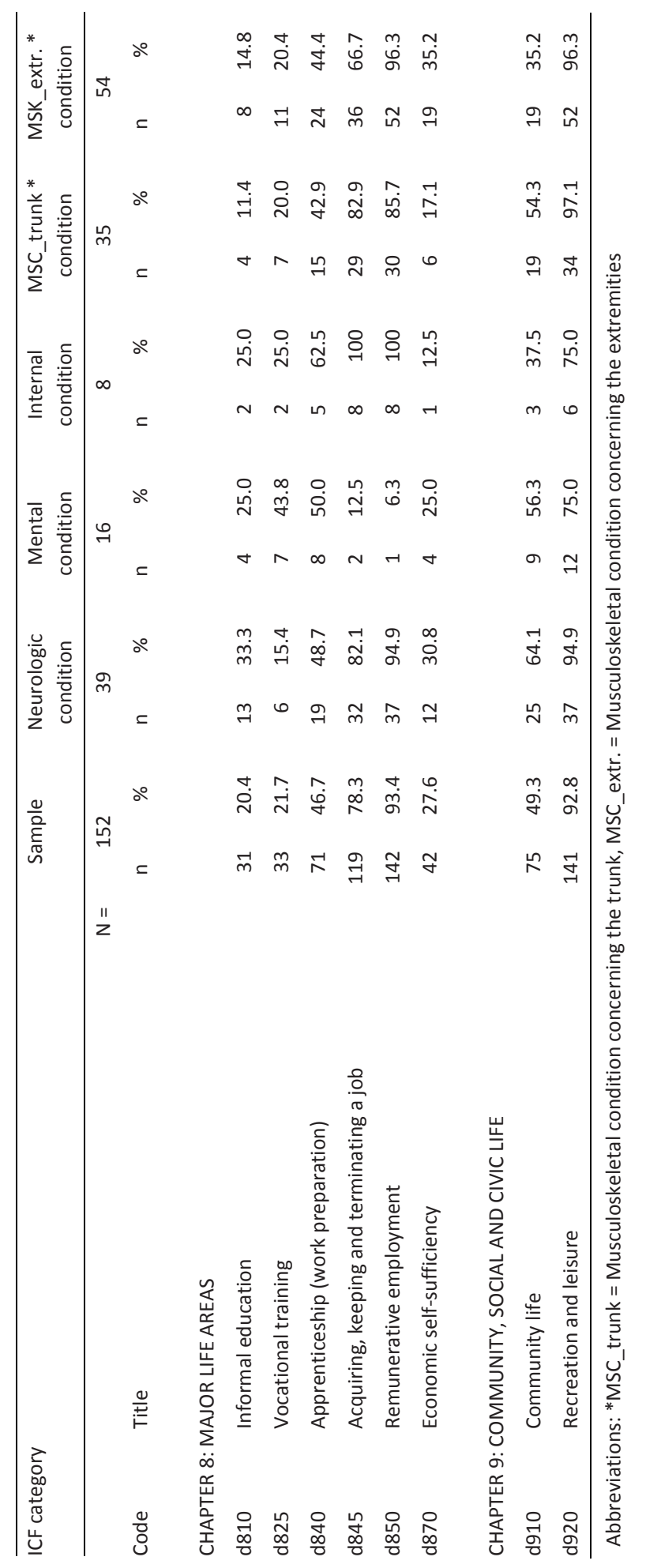




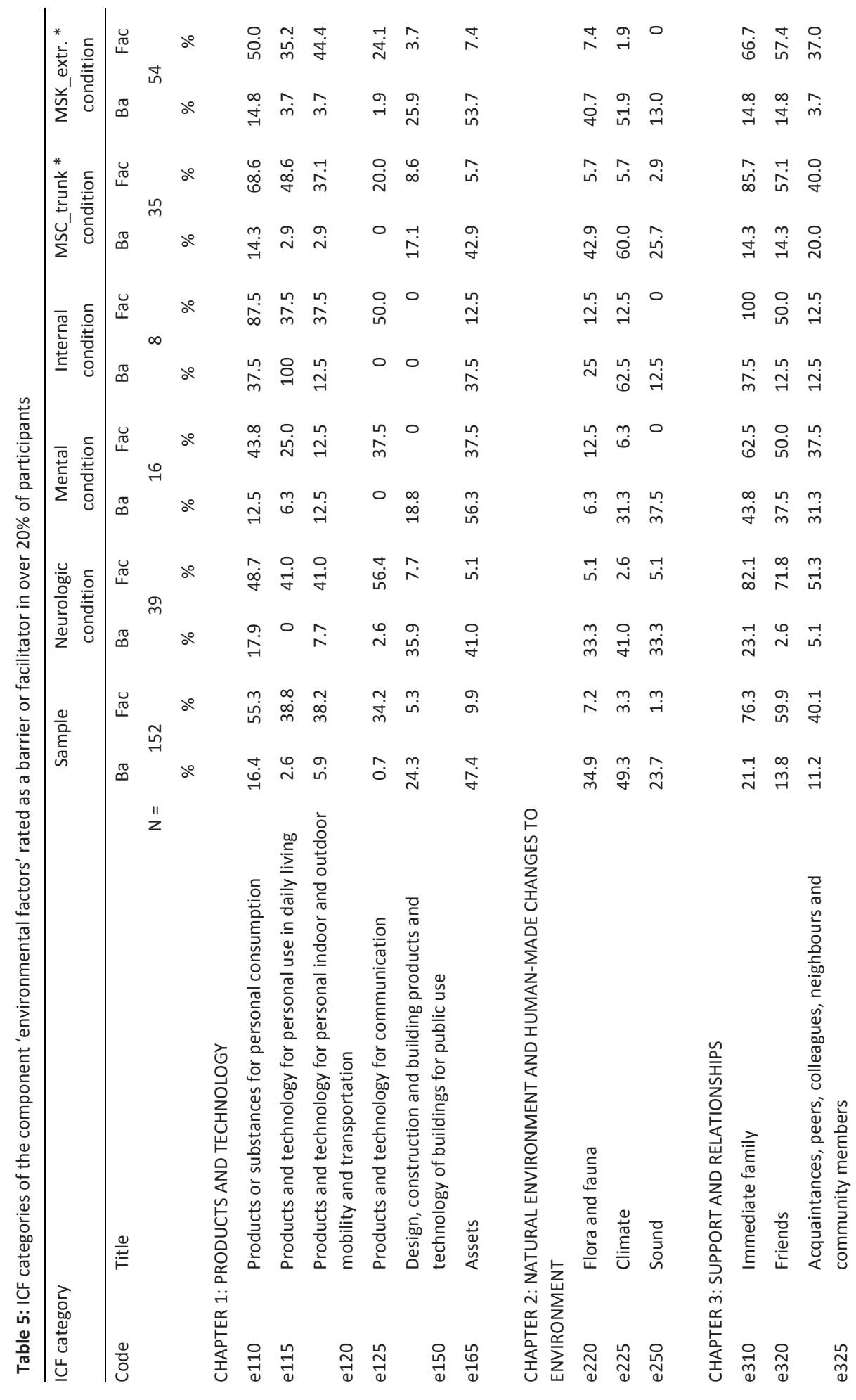




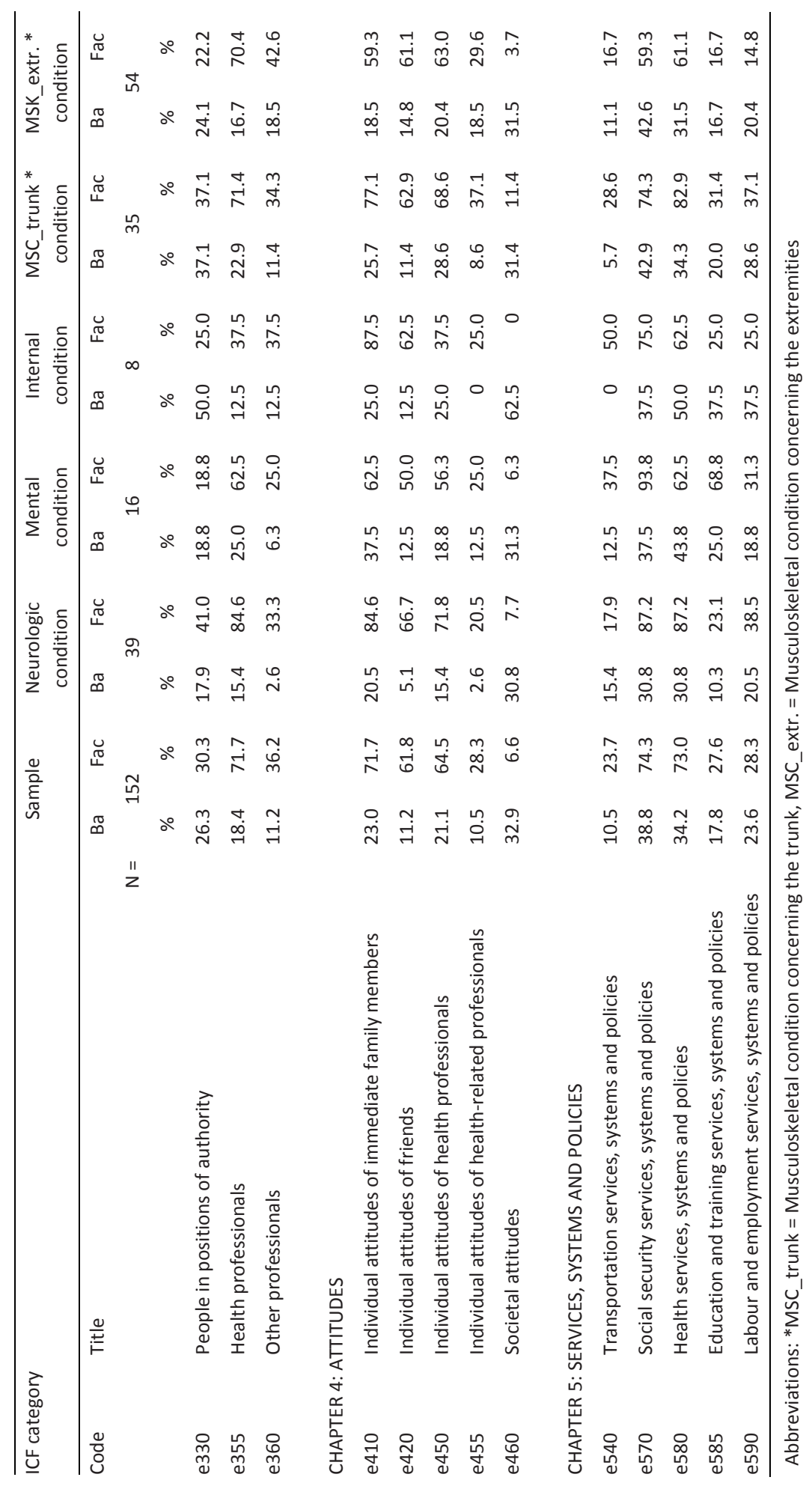




\section{Discussion}

Vocational rehabilitation is a multidisciplinary and complex process and plays a key role in facilitating or improving work participation. The objective of this study was to describe functioning and health of individuals in VR from the clinical perspective using the ICF. The Extended ICF checklist proved to be a useful instrument to comprehensively capture relevant problems in functioning and environmental barriers and facilitators in different VR settings and health conditions. The breadth of functioning domains in VR is reflected in the categories covering body functions, body structures, activities and participation, and environmental factors. The facilitating role of VR combined with the knowledge of these factors that ought to be addressed in VR can be useful in work disability management.

The population in our study consists of patients with different professions and trades and who have received different VR interventions. The diverse study sample was desired with the assumption that the relevant factors describing VR may apply to all forms of VR. We found specificity of some categories to certain diagnostic groups, especially in the component body structures. There were categories that were directly related to a certain diagnostic group (e.g. Spinal cord and related structures (s120) that is mainly related to neurologic conditions such as spinal cord injuries and musculoskeletal-trunk related diseases such as sciatic pain). There were other categories which were relevant to all diagnostic areas in our sample (e.g. Muscle power functions (b730) or Muscle endurance functions (b740). We found that patients undergoing VR experience a certain degree of homogeneity with regard to their limitation in functioning independent of their health condition or the VR setting. This finding is consistent with the findings of Lindner and colleagues and Holtslag and colleagues which showed that in the long term, functional limitations associated with different health conditions become more and more similar [23, 24].

We found the highest prevalence of relevant problems in the component body functions, chapter 1: mental functions. Categories such as b126 Temperament and personality functions and b152 Emotional functions point out the burden of distress created by the situation of health-related work absence [25]. The category b130 Energy and drive functions and b134 Sleep functions highlight that individuals in VR often experience a lot of stress, and prolonged or poor recuperation, while having to deal with an energy consuming situation $[26,27]$. In clinical practice, these factors are often neglected [28]. We also found a high prevalence of Sensation of pain (b280) (85.5\%) in our population. This is consistent with the literature and hence, addressed in intervention planning [4].

Categories from chapter 2: general tasks and demands in the component activities and participation e.g. Carrying out daily routine (d230) and Handling stress (d240) and other psychological demands that we found in our study point out the needs already addressed in chapter 1 of the component body functions, e.g. Emotional functions 
(b152). In chapter 4: Mobility, Changing basic body position (d410) Maintaining a body position (d415), Lifting and carrying objects (d430) and the category Moving around (d455) seem to cover the most important restrictions concerning movement. These findings seem to validate the items assessed by existing outcome measures, for physical capacity evaluation $[29,30]$. Categories from chapter 8: Major life areas provide some insight in a person's work life, as defined in the category d850 Remunerative employment. The results (prevalence of $92.8 \%$ ) for $d 850$ was not totally unexpected as VR has a major focus on remunerative or gainful employment. Also striking is the number of patients who are also restricted in their leisure activities-92.8\% of the patients reported problems in the category $d 920$ Recreation and leisure. Looking at life areas not directly related to work may help to understand the whole range of limitations from a holistic view and to find resources that can be used to facilitate the return to work process with consideration of the non-work factors. This insight strengthens the need to comprehensively evaluate patients in order to decide the appropriate interventions [31].

In terms of environmental factors, relative frequencies for barriers and facilitators have been reported. Obtaining adequate information about the barriers and facilitators to returning to work can be critical, since these factors can often be addressed by providing simple interventions such as adapting the workplace or work scheduling. In such adaptation, the employer or supervisor plays important roles. Modified job duties are reported to be an intermediate step in returning back to work. In some cases, a facilitator can simultaneously be a barrier, e.g. e310 Immediate family or e570 Social security services, systems and policies. For instance, while workers can get physical help from their family, it is also possible that the same family can prevent them, for fear of re-injury, from doing what the worker wants. The social network as represented in chapter e3: Support and relationships could impact VR outcomes positively and negatively [32, 33]. Financial and organizational support during VR appeared to be strong facilitators. The support from social security services and providers (e570 Social security services, systems and policies) and health care services and providers as (e580 Health services, systems and policies), were perceived as facilitators in over $70 \%$ of the patients [34]. In contrast, procedural complexities of the workers' compensation, and health care systems as well as the uncertainty regarding coverage for VR seem to be major barriers [35-38]. To address environmental factors in VR often points to a mediator that can be essential in bringing a worker back to work. For example, appropriate work and supportive workplace-relationships as well as job coaching were identified as encouraging return to work $[32,39,40]$.

The existence of co-morbidity is an important consideration in the understanding of our study population, as $52 \%$ suffered from a relevant co-morbidity such as depression, migraine, heart diseases, asthma or musculoskeletal pain in the back, neck or upper extremities [41]. Co-morbidities seem to exacerbate the main health issues and additionally contribute to its impact. Often, persons in VR experience a lot of minor 
limitations during their working life, which in the end leads to a loss of work ability or decrease in work participation. Co-morbidities not only seem to lower quality of life, they also appear to be a major risk factor for unsuccessful return to work [23, 42].

This cross-sectional study has provided us with broad lists of ICF categories that are relevant to the patients' lived experience and that cover functioning at the individual and societal level. The results of this study could help advance our understanding of factors crucial to successful VR [25]. This study, therefore, provides us with the "what" to look at in the evaluation of individuals in VR from a clinical perspective. An issue remains and that is to determine the use of such set of variables in disability prevention among individuals at risk for work loss due to a health-related issue [43, 44]. Whether or not the ICF categories can provide meaningful information to inform disability prevention strategies is yet to be explored.

When interpreting these results, some issues may be considered. The study results could be biased due to the specific patient selection and convenience sampling employed in our study centers. In current statistics, as shown in the 'Sickness, Disability and Work report 2009' from the Organisation for Economic Co-operation and Development (OECD), approximately one-third of conditions reported were mental and onethird musculoskeletal in nature [45-47]. In our sample, mental conditions represented only $10.5 \%$ of the participants, while the majority of our sample represented musculoskeletal conditions. Therefore, some condition-specific categories might have been missed out. However, the sample we had reflects the "typical" sample of patients in the social systems in Switzerland and Germany $[48,49]$. Stratification of job types was not made; hence, it will be difficult to extend our study findings to determine which ICF categories are more meaningful to one type of job versus another job. Another point for consideration is the ICF as a classification system and taxonomy for health and functioning. It might be prudent to keep in mind the balance of selecting between general definitions of ICF categories (so as to be applicable in various settings and health conditions) and precise definitions (so as to capture the details required by some disciplines). The definition of a single ICF category can be further clarified to define true ICF constructs within that code [50]. Critics have argued that the classification requires further operational definition, if to be useful in practice [11]. Finally, while this study provided a comprehensive list of variables to address VR and functioning, the ICF was not directly linked to concepts like work status, work productivity, work ability, and job type. Therefore, supplementing the ICF with VR-specific indicators, such as work status or job type coupled with contextual and personal factors, will further increase the utility of the ICF in clinical practice.

\section{Conclusions}

The ICF, as an overarching conceptual framework and classification system to describe functioning and disability, has been integrated in work-specific and RTW-relevant litera- 
ture demonstrating compatibility $[32,51,52]$. In this study, we found the ICF to be useful and comprehensive in identifying a set of variables (ICF categories) that describe functioning problems and relevant environmental factors among individuals participating in VR. This set of ICF categories could help in the clinical decision making process of clinicians, and consequently guide appropriate interventions and promote transdisciplinary communication. We encourage clinicians and researchers in VR to further examine the list of variables presented in this study. Further explorative analyses to filter the most significant categories are needed and are being planned in other patient populations and VR settings. Another step we encourage is to explore the operationalization of the ICF categories for the purpose of evaluating functioning of the individuals and measuring the relevant factors beyond the traditional biomedical approach. For clinical documentation, the set of ICF categories could serve as the domains to develop a standard profile of functioning for each patient and to identify the barriers and facilitators within the return to work process. To measure and document outcomes of VR in the practice and in research is required if we want to improve people's lives by increasing their work participation and fulfilling their societal role in general.

\section{Acknowledgments}

The authors would like to thank Wolfgang Segerer for providing technical consultation, data preparation, and assistance during the conduct of the study. Special thanks to Stéphanie Bessard, Olivier Deriaz, Brigitte Egli, Karl Emmenegger, Jacqueline Huber, Jochen Kunert, Markus Roth, Jana Skoblikova and Christine Treitler who made the data collection in the study centers possible. This project was funded by the Swiss Accident Insurance Company (Suva). Conflict of interest None.

\section{References}

1. Selander J. Unemployed sick-leavers and vocational rehabilitation- a person-level study based on a national social insurance material. 1999; PhD thesis, Karolinska Institutet, Department of Rehabilitation Medicine, Stockholm, Sweden.

2. Brunarski D, Shaw L, Doupe L. Moving toward virtual interdisciplinary teams and a multi-stakeholder approach in community- based return-to-work care. Work. 2008;30(3):329-36.

3. Vocational Rehabilitation Task Group-Industrial Injuries Advisory Council, Waddell G, Burton AK, Kendall NA. Vocational rehabilitation-what works, for whom, and when? 1st ed. London: TSO (The Stationery Office); 2008.

4. Buijs PC, Lambeek LC, Koppenrade V, Hooftman WE, Anema JR. Can workers with chronic back pain shift from pain elimination to function restore at work? Qualitative evaluation of an innovative work related multidisciplinary programme. J Back Musculoskelet Rehabil. 2009;22(2):65-73.

5. Schultz IZ, Stowell AW, Feuerstein M, Gatchel RJ. Models of return to work for musculoskeletal disorders. J Occup Rehabil. 2007;17(2):327-52. 
6. Solli HM, da Silva AB, Lie RK, Bruusgaard D. Biomedical model of disease and criteria of distributive justice in disability pension cases. Tidsskr Nor Laegeforen. 2005;125(23):3293-6.

7. Cocchiarella L, Turk MA, Andersson G. Improving the evaluation of permanent impairment. JAMA. 2000;283(4):532-3.

8. Cornelius LR, van der Klink JJ, Groothoff JW, Brouwer S. Prognostic factors of long term disability due to mental disorders: a systematic review. J Occup Rehabil. 2010; 71(12):1689-95.

9. Wilkie R, Cifuentes M, Pransky G. Exploring extensions to working life: job lock and predictors of decreasing work function in older workers. Disabil Rehabil. 2011; 33(19-20):1719-27.

10. Peterson DB. Psychological aspects of functioning, disability, and health. New York: Springer Publishing Company; 2011.

11. Imrie R. Demystifying disability: a review of the International Classification of Functioning, Disability and Health. Sociol Health IIIn. 2004;26(3):287-305.

12. World Health Organization. International classification of functioning, disability, and health: ICF. Geneva, Switzerland., 2010.

13. Ustun B, Chatterji S, Kostanjsek N. Comments from WHO for the Journal of Rehabilitation Medicine Special Supplement on ICF core sets. J Rehabil Med. 2004;44(Suppl):7-8.

14. Tempest S, Mclntyre A. Using the ICF to clarify team roles and demonstrate clinical reasoning in stroke rehabilitation. Disabil Rehabil. 2006;28(10):663-7.

15. Okawa Y, Ueda S, Shuto K. The utilization of ICF in National Legislation and Policies in Japan. WHO-FIC NETWORK MEETING; 16-22 October.

16. Rentsch HP, Bucher P, Dommen Nyffeler I, Wolf C, Hefti H, Fluri E, et al. The implementation of the 'International Classification of Functioning, Disability and Health' (ICF) in daily practice of neurorehabilitation: an interdisciplinary project at the Kantonsspital of Lucerne, Switzerland. Disabil Rehabil. 2003;25(8):411-21.

17. Grimes DA, Schulz KF. An overview of clinical research: the lay of the land. Lancet. 2002;359(9300):57-61.

18. Escorpizo R, Ekholm J, Gmuender HP, Cieza A, Kostanjsek N, Stucki G. Developing a core set to describe functioning in vocational rehabilitation using the International Classification of Functioning, Disability, and Health (ICF). J Occup Rehabil. 2010;20(4):502-11.

19. World Health Organization. ICD-10: International Statistical Classification of Diseases and Related Health Problems. 10th revision ed. Geneva, Switzerland; 2007.

20. World Health Organization. ICF Checklist. 2003; Available from: http://www.who.int/classifications/icf/training/icfchecklist.pdf. 2010.

21. World Health Organization (WHO). ICF Application and Training Tools. Geneva: World Health Organization 2010: Available from: http://www.who.int/classifications/icf/icfapptrain ing/en/index.html. Accessed 06 Dec 2010.

22. Cieza A, Geyh S, Chatterji S, Kostanjsek N, Ustun B, Stucki G. ICF linking rules: an update based on lessons learned. J Rehabil Med. 2005;37(4):212-8.

23. Linder J, Ekholm KS, Jansen G, Lundh G, Ekholm J. Long-term sick leavers with difficulty in resuming work: comparisons between psychiatric-somatic comorbidity and monodiagnosis. Int J Rehabil Res. 2009;32(1):20-35.

24. Holtslag HR, Post MW, van der Werken C, Lindeman E. Return to work after major trauma. Clin Rehabil. 2007;21(4):373-83.

25. Lydell M, Marklund B, Baigi A, Mattsson B, Mansson J. Return or no return-psychosocial factors related to sick leave in persons with musculoskeletal disorders: a prospective cohort study. Disabil Rehabil. 2011;33(13-14):1262-71.

26. San L, Ciudad A, Alvarez E, Bobes J, Gilaberte I. Symptomatic remission and social/vocational functioning in outpatients with schizophrenia: prevalence and associations in a cross-sectional study. Eur Psychiatry. 2007;22(8):490-8.

27. Pawlikowska T, Chalder T, Hirsch SR, Wallace P, Wright DJ, Wessely SC. Population based study of fatigue and psychological distress. BMJ. 1994;308(6931):763-6. 
28. van der Sluis CK, Eisma WH, Groothoff JW, ten Duis HJ. Longterm physical, psychological and social consequences of severe injuries. Injury. 1998;29(4):281-5.

29. Durand MJ, Brassard B, Hong QN, Lemaire J, Loisel P. Responsiveness of the physical work performance evaluation, a functional capacity evaluation, in patients with low back pain. J Occup Rehabil. 2008;18(1):58-67.

30. Soer R, van der Schans CP, Geertzen JH, Groothoff JW, Brouwer S, Dijkstra PU, et al. Normative values for a functional capacity evaluation. Arch Phys Med Rehabil. 2009;90(10):1785-94.

31. Kirsh B, Krupa T, Cockburn L, Gewurtz R. A Canadian model of work integration for persons with mental illnesses. Disabil Rehabil. 2010;32(22):1833-46.

32. Young AE. Return to work following disabling occupational injury-facilitators of employment continuation. Scand J Work Environ Health. 2010;36(6):473-83.

33. Brouwer S, Reneman MF, Bultmann U, van der Klink JJ, Groothoff JW. A prospective study of return to work across health conditions: perceived work attitude, self-efficacy and perceived social support. J Occup Rehabil. 2010;20(1):104-12.

34. Gruber EN, Ivezic-Strkalj S, Agius M, Martic-Biocina S. "Since I have my case manager, I am back to life" case management in Croatia. Psychiatr Danub. 2008;20(1):63-70.

35. MacEachen E, Kosny A, Ferrier S. Unexpected barriers in return to work: lessons learned from injured worker peer support groups. Work. 2007;29(2):155-64.

36. Patel S, Greasley K, Watson PJ. Barriers to rehabilitation and return to work for unemployed chronic pain patients: a qualitative study. Eur J Pain. 2007;11(8):831-40.

37. Eriksson UB, Engstrom LG, Starrin B, Janson S. Falling between two stools; how a weak co-operation between the social security and the unemployment agencies obstructs rehabilitation of unemployed sick-listed persons. Disabil Rehabil. 2008;30(8): 569-76.

38. MacEachen E, Kosny A, Ferrier S, Chambers L. The "toxic dose" of system problems: why some injured workers don't return to work as expected. J Occup Rehabil. 2010;20(3):349-66.

39. Macaden AS, Chandler BJ, Chandler C, Berry A. Sustaining employment after vocational rehabilitation in acquired brain injury. Disabil Rehabil. 2010;32(14):1140-7.

40. Lysaght RM, Larmour-Trode S. An exploration of social support as a factor in the return-to-work process. Work. 2008;30(3):255-66.

41. Glozier N, Hackett ML, Parag V, Anderson CS. Auckland Regional Community Stroke (ARCOS) Study Group. The influence of psychiatric morbidity on return to paid work after stroke in younger adults: the Auckland Regional Community Stroke (ARCOS) Study, 2002 to 2003. Stroke. 2008;39(5):1526-32.

42. Zieger M, Luppa M, Meisel HJ, Gunther L, Winkler D, Toussaint R, et al. The impact of psychiatric comorbidity on the return to work in patients undergoing herniated disc surgery. J Occup Rehabil. 2011;21(1):54-65.

43. Krismer M, van Tulder M, The Low Back Pain Group of the Bone, Joint Health Strategies for Europe Project. Strategies for prevention and management of musculoskeletal conditions Low back pain (nonspecific). Best Pract Res Clin Rheumatol. 2007;21(1):77-91.

44. Shaw WS, van der Windt DA, Main CJ, Loisel P, Linton SJ. "Decade of the Flags" Working Group. Early patient screening and intervention to address individual-level occupational factors ("blue flags") in back disability. J Occup Rehabil. 2009;19(1):64-80.

45. Patten SB, Williams JV, Wang J. Mental disorders in a population sample with musculoskeletal disorders. BMC Musculoskelet Disord. 2006;7:37.

46. Wang J, Adair CE, Patten SB. Mental health and related disability amongworkers: a population-based study.AmJ IndMed. 2006;49(7): 514-22.

47. World Health Organization. The burden of musculoskeletal conditions at the start of the new millenium. 2003; WHO Technical Report Series 919.

48. Fournier-Buchs MF, Gobelet C. Vocational rehabilitation: the swiss model. In: Gobelet C, Franchignoni F, editors. Vocational Rehabilitation. 1st ed. Paris: Springer; 2006. p. 395-403.

49. Schian HM. Vocational Rehabilitation and participation in working life: the Geman model. In: Gobelet C, Franchignoni F, editors. Vocational rehabilitation. 1st ed. Paris: Springer; 2006. p. 309-28. 
50. Maini M. Application problems of the use of the Core set ICF in the rehabilitation area. G Ital Med Lav Ergon. 2008;30(2):178-84.

51. Sandqvist JL, Henriksson CM. Work functioning: a conceptual framework. Work. 2004;23(2):147-57. 52. Wasiak R, Young AE, Roessler RT, McPherson KM, van Poppel MN, Anema JR. Measuring return to work. J Occup Rehabil. 2007; 17(4):766-81. 

Chapter 3

\section{An examination of concepts in vocational rehabilitation that cannot be linked to the ICF using a qualitative analysis of secondary data}

Article under review

Monika E. Finger

Robert A. de Bie

Melissa Selb

Reuben Escorpizo 


\section{Abstract}

Purpose: A systematic review, an expert survey and a patient focus group study have been conducted to develop the ICF core set for vocational rehabilitation project. Information from these studies was linked to the International Classification of Functioning, Disability and Health (ICF). When no appropriate code could be identified an "nd" -not definable, "pf" -personal factors or "nc" -not covered was assigned to the concept. The overall objective of this study was to explore and examine those concepts which could not be linked to distinct ICF codes.

Method: An explorative and qualitative analysis of secondary data was performed on vocational rehabilitation-related concepts which were identified as "nd", "pf" or "nc" from the three studies of the ICF Core Set for vocational rehabilitation project.

Results: 1048 "nd" concepts were matched to the ICF framework, while overarching terms and specific additional categories were developed. 1924 meaningful units were linked to 31 second level categories of a reference personal factor classification. 441 " $n c$ " concepts were grouped and six themes were formulated including the concept of well-being, and attributes related to processes and time.

Conclusions: The ICF model provides a valuable framework for assessing and documenting functioning in vocational rehabilitation. A structured way of assessing personal factors specific to vocational rehabilitation is needed and should be explored further. The influence on return-to-work of themes complementary to the ICF such as well-being and quality of life should be further investigated.

Key words: International classification of functioning, disability and handicap, ICF, vocational rehabilitation. 


\section{Introduction}

In 2001, the International Classification of Functioning, Disability and Health (ICF) [1] was endorsed by the World Health Assembly [2] as the world standard for conceptualizing and classifying functioning and disability [3]. The use of the ICF has spread steadily among health professions and in various health care settings. The value of the ICF to facilitate communication between stakeholders, to help structure rehabilitation plans, for goal setting and clarifying team roles as well as for the documentation of functioning, has also been recognized [4-7]. Subsequently the applicability of the ICF was increasingly evaluated in other health or health related fields, such as education, disability evaluation and vocational rehabilitation [8-12].

As a classification system, the ICF provides alphanumeric codes that are arranged in a hierarchical fashion by way of the components and the ICF categories (figure 1).

Figure 1: The ICF conceptual model and classification system (using "remunerative employment" as an example of the categorization)

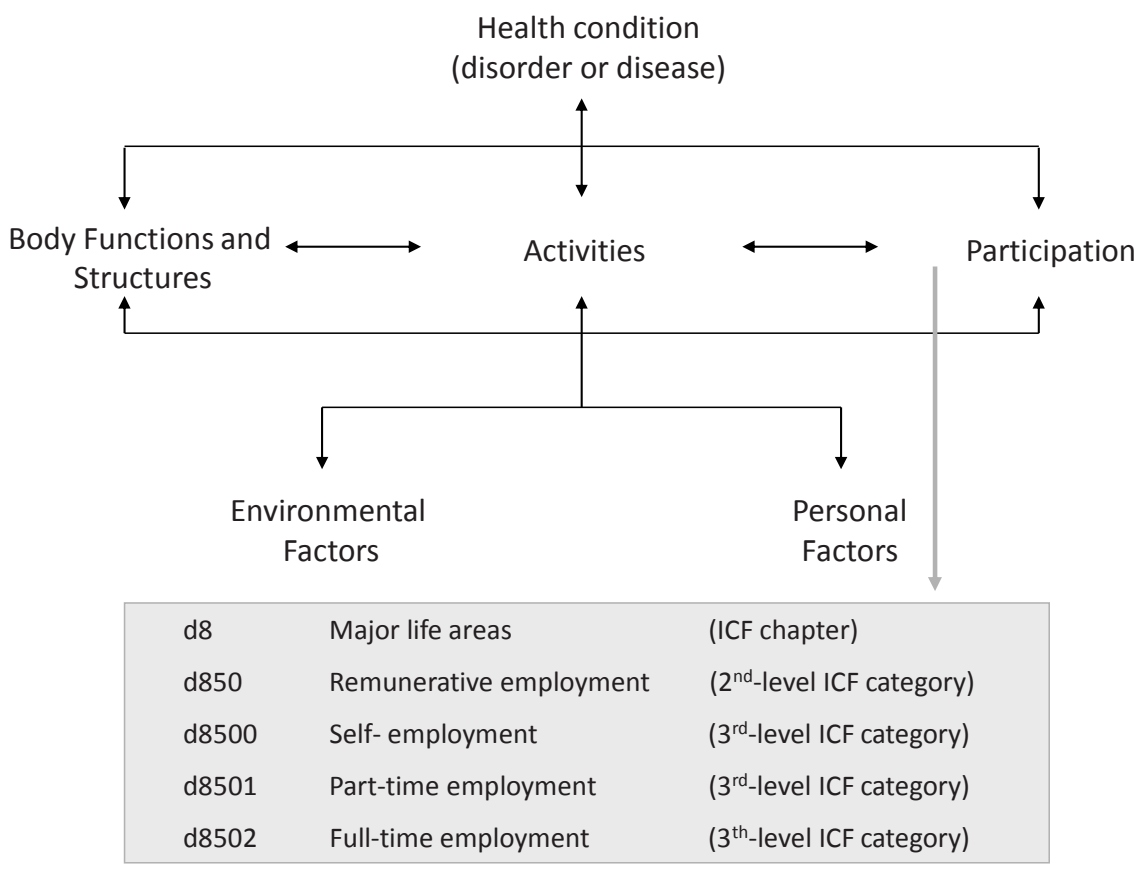

Within the ICF classification, ICF categories are defined with inclusion and exclusion criteria provided (except for body structures). To allow users to also classify uncommon or very specific aspects of functioning, for which no specific ICF category exists, the ICF provides under each chapter of the classification "other specified" or "unspecified" categories indicated with an 8 or 9 respectively at the end of the alpha numeric code. 
This coding scheme allows users to define additional categories for his or her specific purpose.

Although the implementation of the bio-psychosocial model, on which the ICF classification was based, was mostly welcomed in clinical practice, the complexity of the ICF classification, reflected by over 1400 defined categories, proved to be a major challenge with regards to feasibility for use. One approach to enhance the usability of the ICF and therefore to promote its implementation into practice is to develop ICF Core Sets [13]. ICF Core Set have been developed as evidence-based and consensus-based lists of selected ICF categories, to capture the full spectrum of variables relevant to describe the functioning of individuals with a distinct health condition, in a specific health care setting or in a health-related life situation. ICF Core Sets are developed in consensus conferences where international experts decide on ICF categories that were identified to be relevant in four preliminary studies namely a systematic review, an expert survey, a focus group study, and a cross-sectional empirical study. In each study, data obtained are linked to the ICF to look at functioning aspects relevant to the purpose of developing the Core Set. A list of ICF categories is ultimately the product collated from the 4 studies and this list is presented to the experts attending an ICF Core Set consensus conference, at the end of which a Core Set is developed.

\section{Linking data to the ICF}

Linking of data was performed based on the coding guidelines provided in Annex 2 of the ICF [14] and the linking rules formulated by Cieza et. al. [15] which altogether offer detailed guidelines on how to translate health information to the most appropriate or best fitting ICF category. According to these linking rules, first the original text is to be broken down into meaningful units, e.g. "My pain in the hand is increasing, when I am carrying weight." In this patient statement, two different meaningful concepts are identified: "pain in the hand" and "carrying weight". In a second step the two concepts are linked to the most appropriate ICF categories which in this case would be b28014 Pain in upper limb and 14301 Carrying in the hands.

In addition to the rules on how health information is linked to the ICF, in the updated linking rules of Cieza et al. in 2005 [16] three further rules were used; these rules are to be used when dealing with meaningful units that could not be linked to distinct ICF codes. One rule states that: "If the information provided by the meaningful concept is not sufficient for making a decision about the most precise ICF category the meaningful concept is assigned "nd" (not definable). Neither the "other specified" nor the "unspecified" categories are used. An example is the term "activities of daily living" where it is certain that this concept belongs to the ICF component of activities and participation but cannot be assigned to distinct ICF codes because it is simple too vague or too broad. Another rule states that: "If the meaningful concept is not contained in the ICF, but it is clearly a personal factor as defined in the ICF, the meaningful concept will be 
assigned "pf" (personal factor)." Personal factors are defined in the ICF as "the particular background of an individual's life and living, and comprise features of the individual that are not part of a health condition or health states. These factors may include gender, race, age, other health conditions, fitness, lifestyle, habits, upbringing, coping styles, social background, education, profession, past and current experience (past life events and concurrent events), overall behavior pattern and character style, individual psychological assets and other characteristics, all or any of which may play a role in disability at any level" [1]. In the literature the importance of personal factors as predictors for the vocational rehabilitation process [17] and successful return to work [18] are widely acknowledged. Nevertheless the absence of a personal factors classification (lack of personal factors categories) within the scope of the ICF can impede standardization of data collection and comparability of results [19]. A third rule states that: If the meaningful concept is not contained in the ICF and it is clearly not a personal factor, this meaningful concept is assigned "nc" (not covered by ICF)". "Not covered" may contain temporal aspects such as "during the last week", or concepts like "landing on involved leg".

In 2010, the ICF Core Set for vocational rehabilitation was developed and intended for use in vocational rehabilitation or return-to-work settings, covering various health conditions. The ICF Core Set for vocational rehabilitation contained 90 ICF categories representing the components of body functions, activities and participation and environmental factors [20]. Since its finalization the content validity of this Core Set in the context of vocational rehabilitation was confirmed in a couple of studies to date $[21,22]$. However, during the development of the ICF Core Set for vocational rehabilitation we found meaningful concepts concerning aspects around work and employment, as well as personal factors that could not be linked to the ICF classification in an expert survey [23], a systematic review [24], and a patient focus group study [25]. The three studies have been conducted to inform the experts of the ICF consensus conference about aspects relevant for individuals in VR. In those 3 studies, meaningful concepts were assigned to distinct ICF categories and where no appropriate code could be identified an "nd" (not definable), "pf" (personal factors) or "nc" (not covered) was assigned. The ICF codes were reported in the according study papers but the "nd", "pf" and "nc"concepts were not analyzed in depth. Since we consider the information contained in the "nd", "pf" and "nc"-concepts as essential to complete an overview of all aspects relevant to individuals in vocational rehabilitation, we decided to explore those concepts and examine their specific contents. Hence, the overall objective of this study was to examine the concepts which could not be linked to distinct ICF codes collected in the development studies of the ICF Core Sets of vocational rehabilitation project. 


\section{Methods}

This study employed an explorative and qualitative analysis of secondary data obtained from three studies (Table 1) within the ICF Core Set for vocational rehabilitation project. Data consisted of those concepts that could not be linked to a distinct ICF category and which were coded as "nd" = not definable, "pf" = personal factor, and "nc"= not covered. Data analysis was performed qualitatively and descriptively [26].

Table 1: Characteristics of studies where data was obtained for secondary analysis.

\begin{tabular}{|c|c|c|c|c|}
\hline Study & Study design & Perspective & Content / Participants & Findings \\
\hline $\begin{array}{l}\text { A Systematic Review } \\
\text { of Functioning in } \\
\text { Vocational } \\
\text { Rehabilitation using } \\
\text { the ICF. } \\
\text { Escorpizo et al } \\
\text { (2011) [24] }\end{array}$ & $\begin{array}{l}\text { Systematic review } \\
\text { identifying } \\
\text { measures and } \\
\text { outcomes in } \\
\text { vocational } \\
\text { rehabilitation }\end{array}$ & $\begin{array}{l}\text { Published } \\
\text { literature }\end{array}$ & $\begin{array}{l}250 \text { articles containing } \\
648 \text { measures and } \\
\text { outcomes. }\end{array}$ & $\begin{array}{l}10582 \text { identified concepts } \\
\text { linked to } \\
87 \text { different second-level } \\
\text { ICF categories. } \\
1152 \text { concepts were } \\
\text { marked as "nd", "pf" and } \\
\text { "nc". }\end{array}$ \\
\hline $\begin{array}{l}\text { An International } \\
\text { Expert Survey on } \\
\text { Functioning in } \\
\text { Vocational } \\
\text { Rehabilitation using } \\
\text { the ICF. } \\
\text { Escorpizo et al } \\
\text { (2011) [23] }\end{array}$ & $\begin{array}{l}\text { International, } \\
\text { internet-based } \\
\text { expert survey }\end{array}$ & $\begin{array}{l}\text { Experts in } \\
\text { vocational } \\
\text { rehabilitation }\end{array}$ & 151 experts & $\begin{array}{l}4584 \text { identified concepts } \\
\text { linked to } \\
101 \text { different second-level } \\
\text { ICF categories. } \\
899 \text { concepts were marked } \\
\text { as "nd", "pf" and "nc". }\end{array}$ \\
\hline $\begin{array}{l}\text { Vocational } \\
\text { Rehabilitation from } \\
\text { the client's } \\
\text { perspective using ICF } \\
\text { as a reference. } \\
\text { Glässel et al (2011) } \\
\text { [25] }\end{array}$ & $\begin{array}{l}\text { Multi-center } \\
\text { focus group } \\
\text { study. }\end{array}$ & $\begin{array}{l}\text { Clients or } \\
\text { patients } \\
\text { undergoing } \\
\text { vocational } \\
\text { rehabilitation }\end{array}$ & $\begin{array}{l}7 \text { focus groups with a } \\
\text { total of } 26 \text { clients or } \\
\text { patients }\end{array}$ & $\begin{array}{l}4813 \text { identified concepts } \\
\text { linked to } \\
160 \text { different second-level } \\
\text { ICF categories. } \\
1152 \text { Concepts were } \\
\text { marked as "nd", "pf" "nc". }\end{array}$ \\
\hline
\end{tabular}

\section{Process of examination of concepts}

In a first step all concepts were numbered using an alpha numeric code where the first two letters indicated the study type and the following four numbers refer to the numerical order, e.g. SR0001 would indicate the first concept from the systematic review. Then the concepts marked as "nd" in each of the three studies were combined in a single data pool called "nd"-pool. The same was done with the "pf" and "nc"- concepts resulting in a "pf"-pool and an "nc"-pool, respectively (figure 2). 
Figure 2: Course of the study

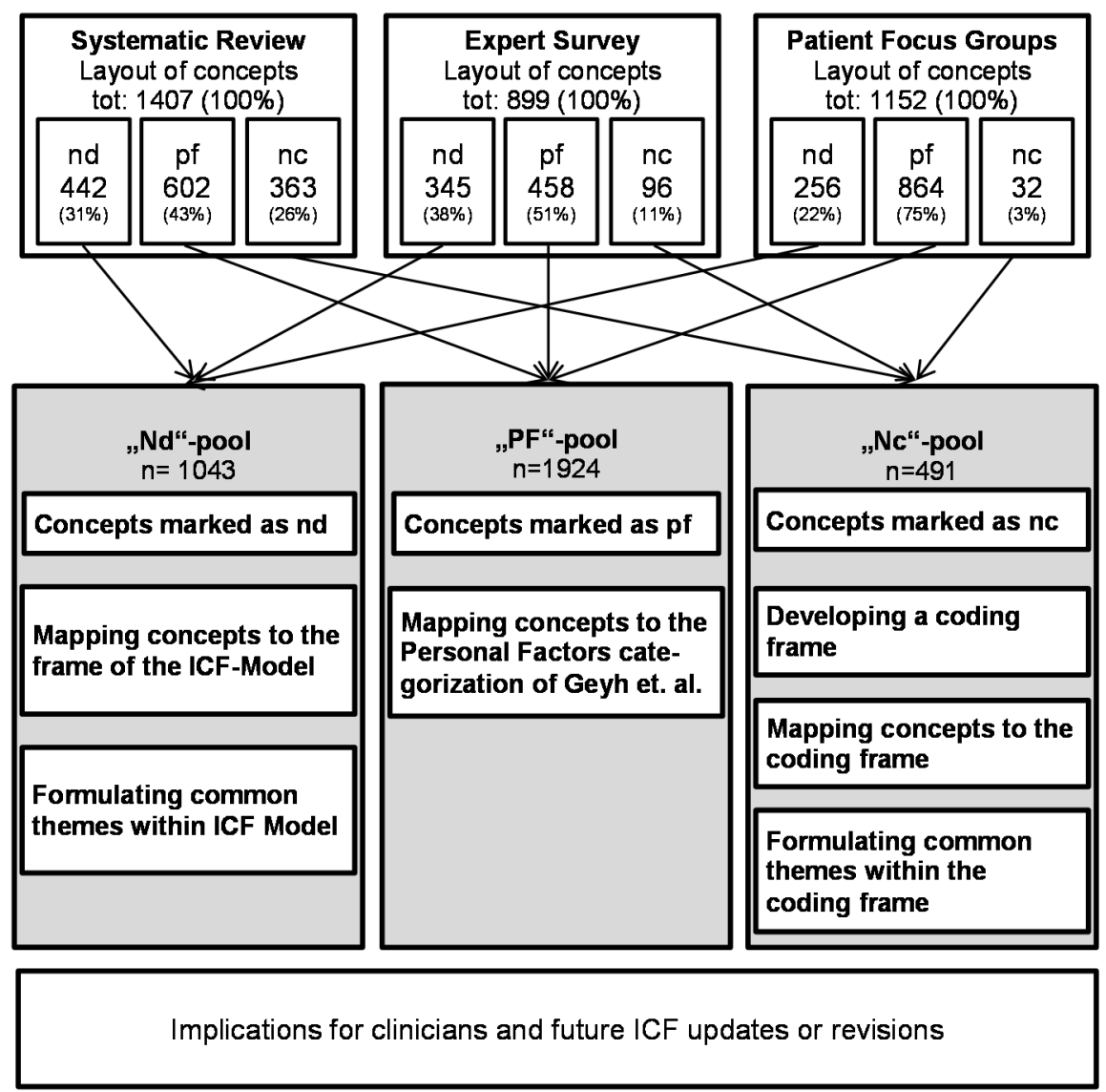

"Nd"-pool: Concepts marked as "nd" are defined as those concepts which can be assigned to the ICF model, but do not contain enough information to be assigned to a specific ICF code. The "nd" concepts can be mapped to overarching parts, components or even chapters of the ICF. On the other hand there may be concepts that are described in such detail that they do not fit into a distinct ICF category. To better understand their relation to the ICF framework, concepts were grouped and summarized according to common themes and these themes were assigned to the ICF model.

"Pf"-pool: The "pf"-concepts were grouped using the personal factor categorization of Geyh et. al. $[27,28]$. This classification was previously successfully used in the context of disability evaluation and in social insurance medicine [29] which we believe would be able to also provide a sensible and comparable framework in the field of vocational rehabilitation. This classification system of Geyh et al. proved to be comprehensive and has sound methodological development [30]. 
"Nc"-pool: To analyze the concepts marked as "nc" qualitative content analysis was used. Qualitative content analysis is a method to systematically describe and analyze the meaning of qualitative data. As suggested by Schreier [26], a coding frame was developed by the first author (MEF) using the "nc's" from the expert survey as a subset of the "nc" data pool. Data were structured, common themes (also called dimensions) and subthemes were generated and defined. While the remaining data from the systematic review and the focus group were added, the frame was constantly verified, revised and expanded if new aspects develop. During the revision and finalization process, the coding frame was discussed with two additional researchers (MS and RE) who were familiar with the ICF framework and the linking procedures and the field of vocational rehabilitation.

\section{Ethics}

The original studies were approved by the Ethics Commission of Aargau, Lucerne, Zurich, and Vallis in Switzerland and Bayern, Germany. Studies were conducted in accordance with the Declaration of Helsinki.

\section{Results}

After data analysis, 49 concepts from the "nc" data pool were redirected to the "nd" data pool leading to 1048 concepts that were finally mapped to the ICF framework. The concepts from the "nc" data pool were assigned to specific activities that could be coded with " 8 " codes, to an "other specified"-category, to "expectations" of individuals and work-related factors assigned to the ICF domain environmental factors. Three major groups of themes could be identified. The first group contains global themes related to the ICF as functioning and disability, which are defined as umbrella terms for the ICF components body functions, body structures and activities and participation. The second group reflects on themes that are too broad to be assigned to one ICF component or category such as symptoms, resources or activities of daily living. Finally, themes are listed that are so specific that they could be transformed into " 8 " code categories (see Table 2). In table 3, nine themes related to the environment based on 375 meaningful units were listed. These themes could be assigned to the chapters 1, 2, 4 and 5 of the environment factor classification of the ICF. Most themes assigned to environmental factors appear to be specifications or supplements to chapters of the environmental factors such as the personal living place in Chapter 1 Products and technology or work related factors that can be assigned to Chapter 5: Services, systems and policies.

1924 meaningful units were linked to 31 second level categories of the personal factor classification of Geyh et al. In addition, table 4 presents an overview of the 
sources of the meaningful units which were linked to distinct personal factor categories; concept examples of the meaningful units are also provided.

A final number of 441 meaningful units in the "nc" pool were analyzed and six main themes were defined that are not covered by the ICF frame (see Table 5). The first theme includes concepts related to well-being. Well-being is a global concept in which human functioning, represented by the ICF, is one component [31]. In contrast, theme two "Attributes related to processes and time" refers to the fact that health information should be assessed and documented with the ICF as applicable to a given moment, or as an indicator of "cross-sectional" information. To employ the ICF to describe a trajectory over time particularly in the context of chronic diseases in vocational rehabilitation, users should identify their own coding style and the time-frame in addition to complement the ICF [14]. 


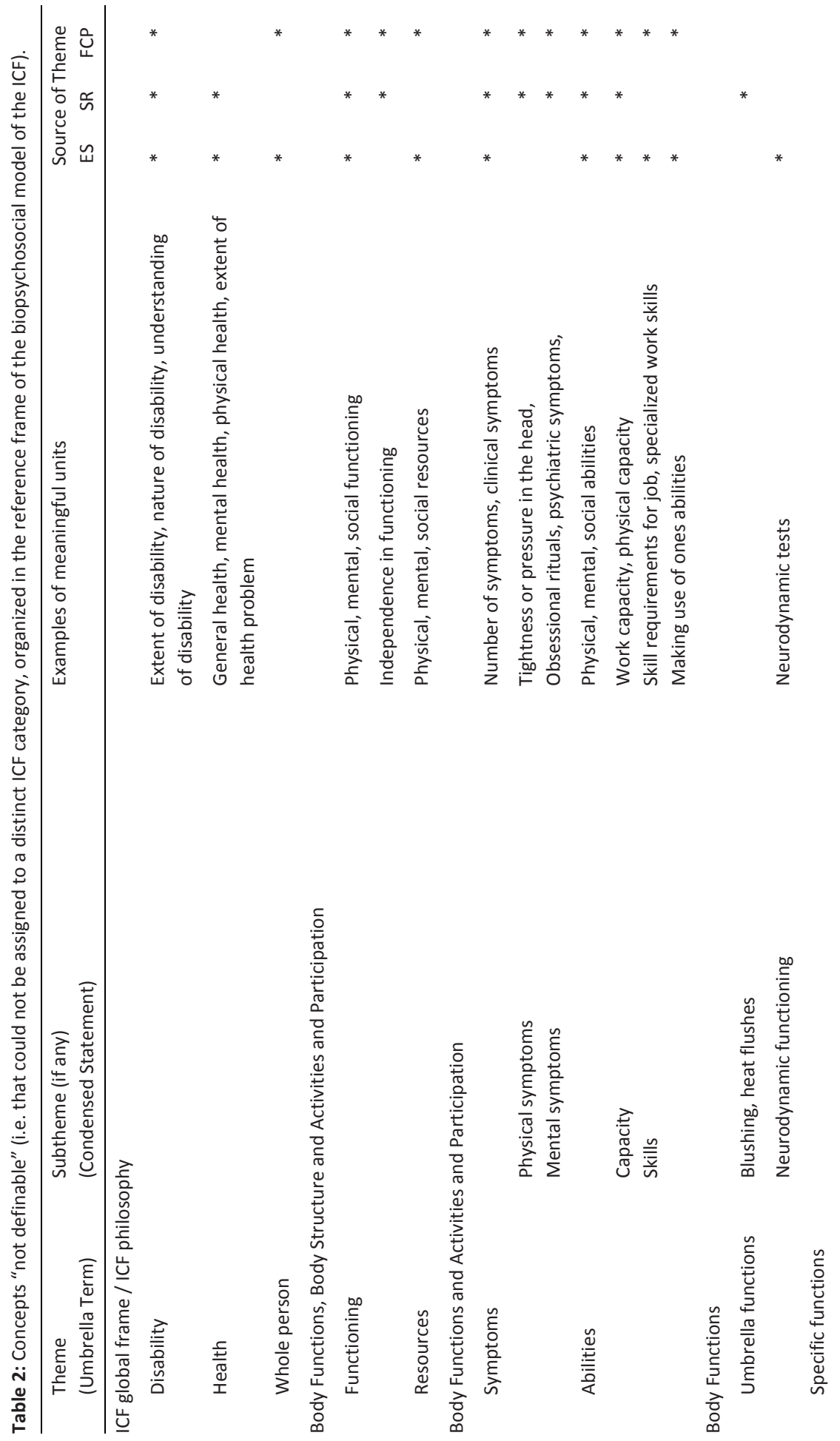




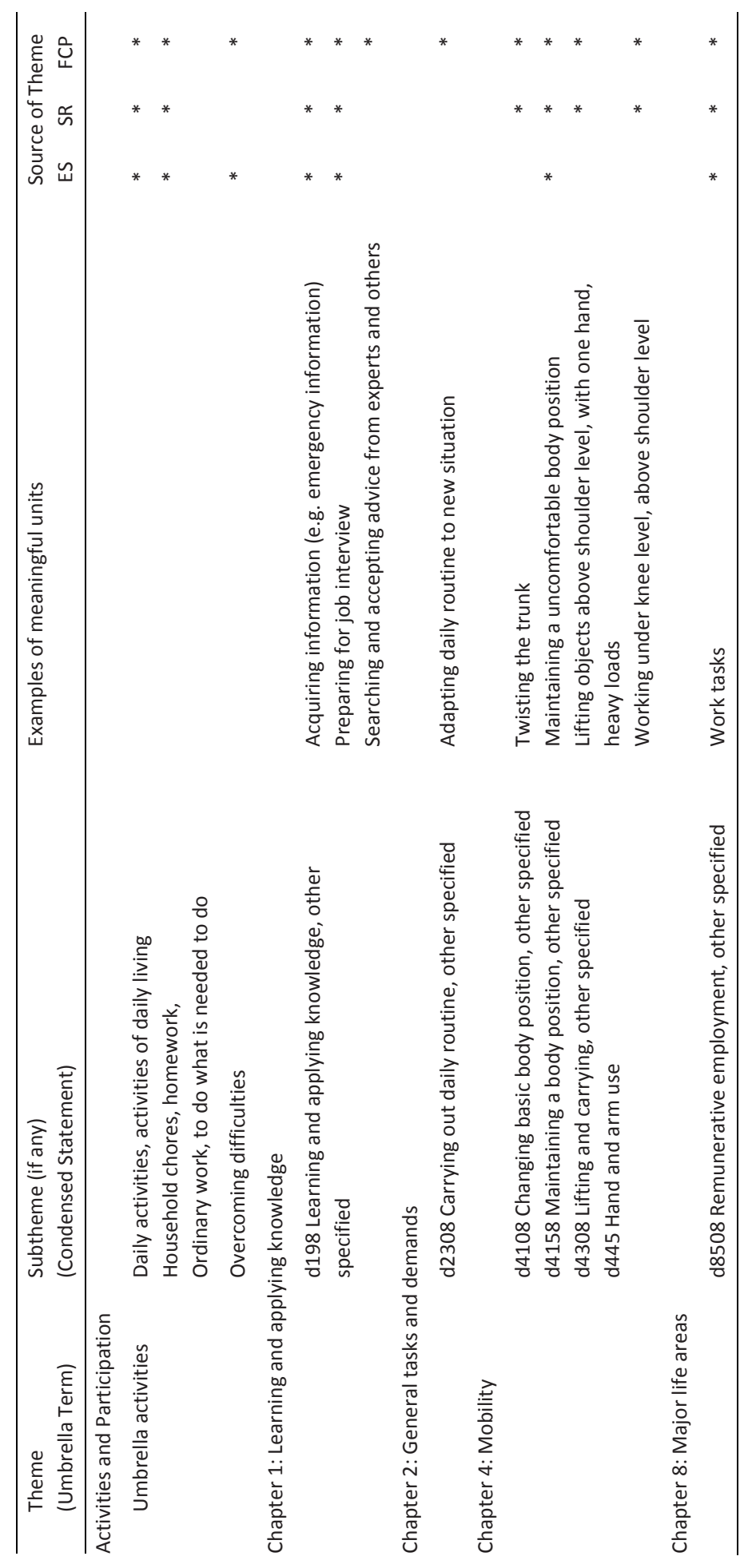




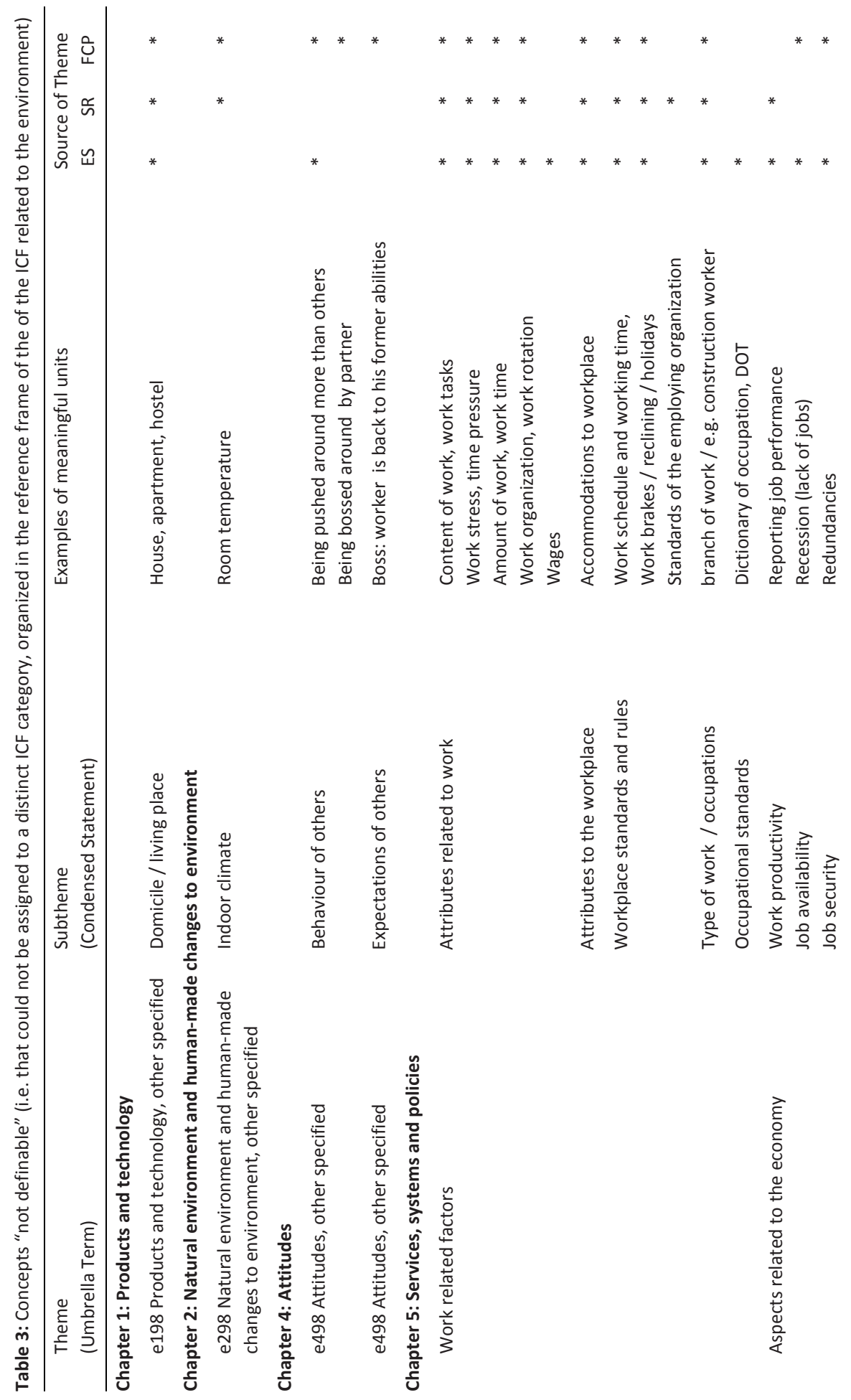




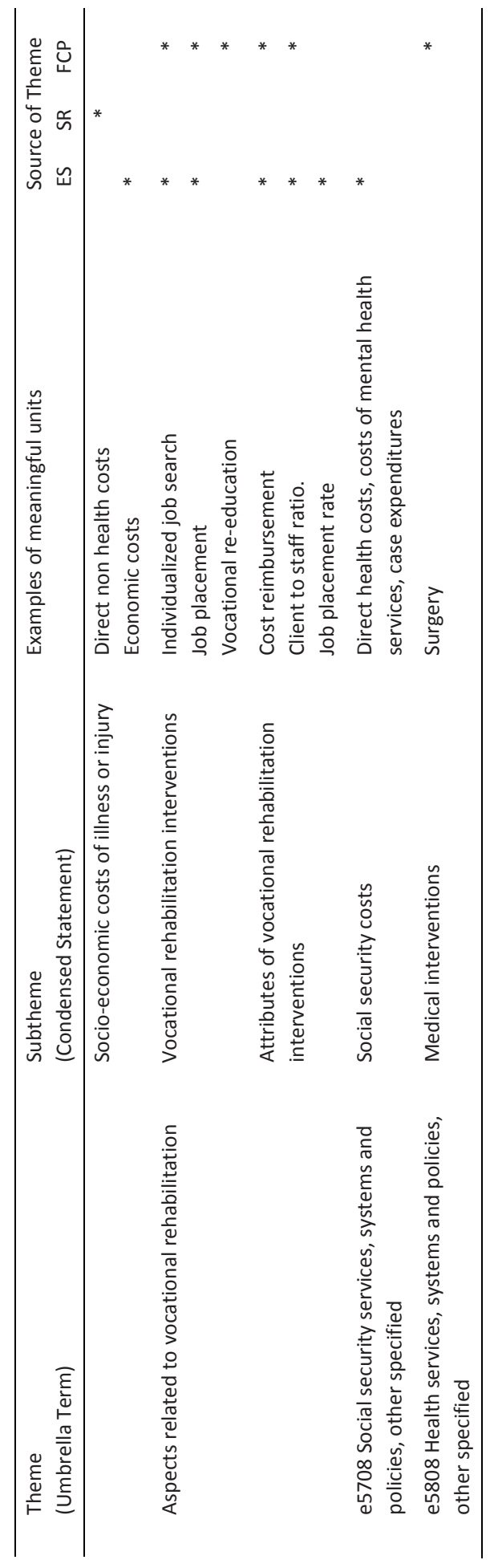




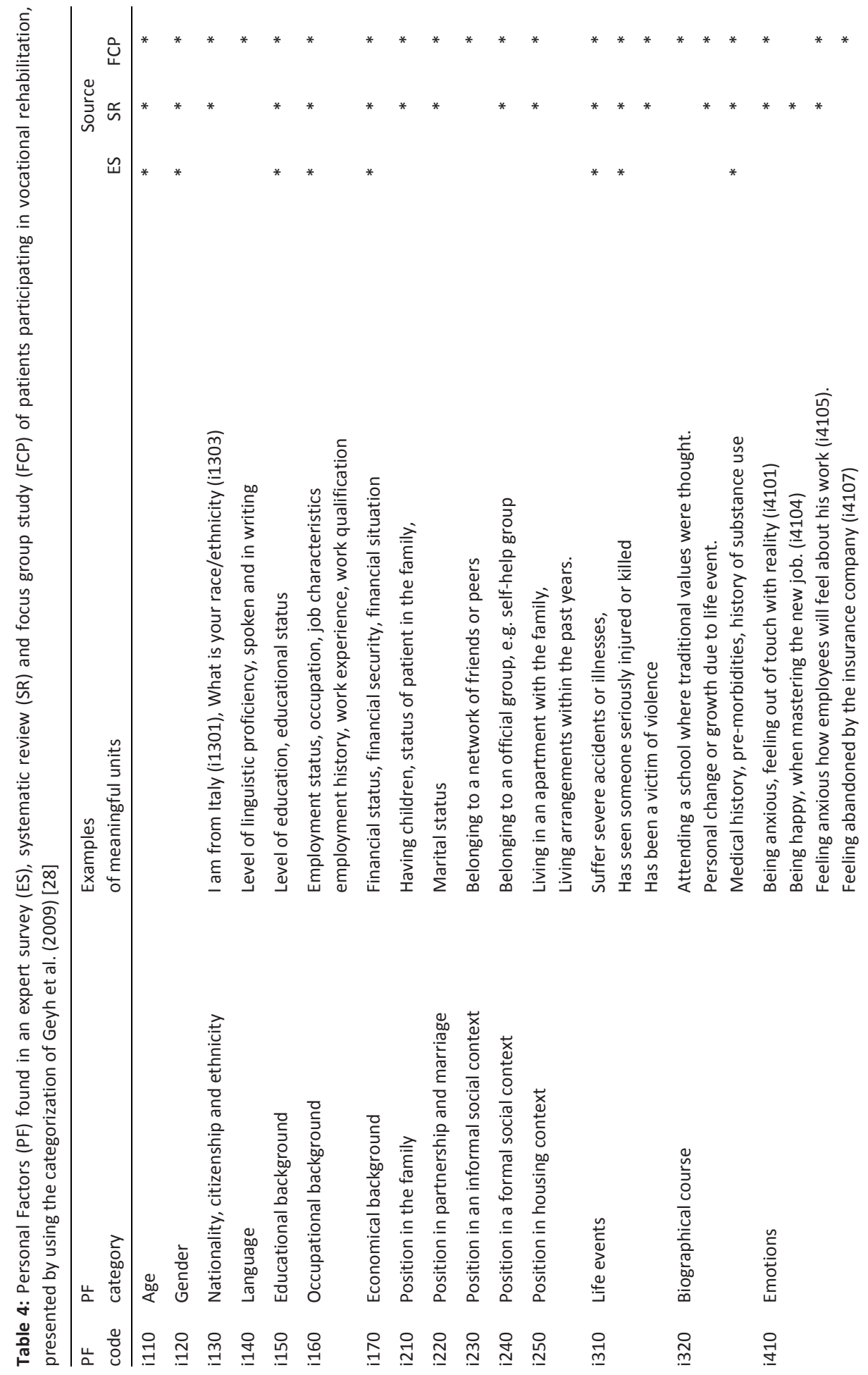




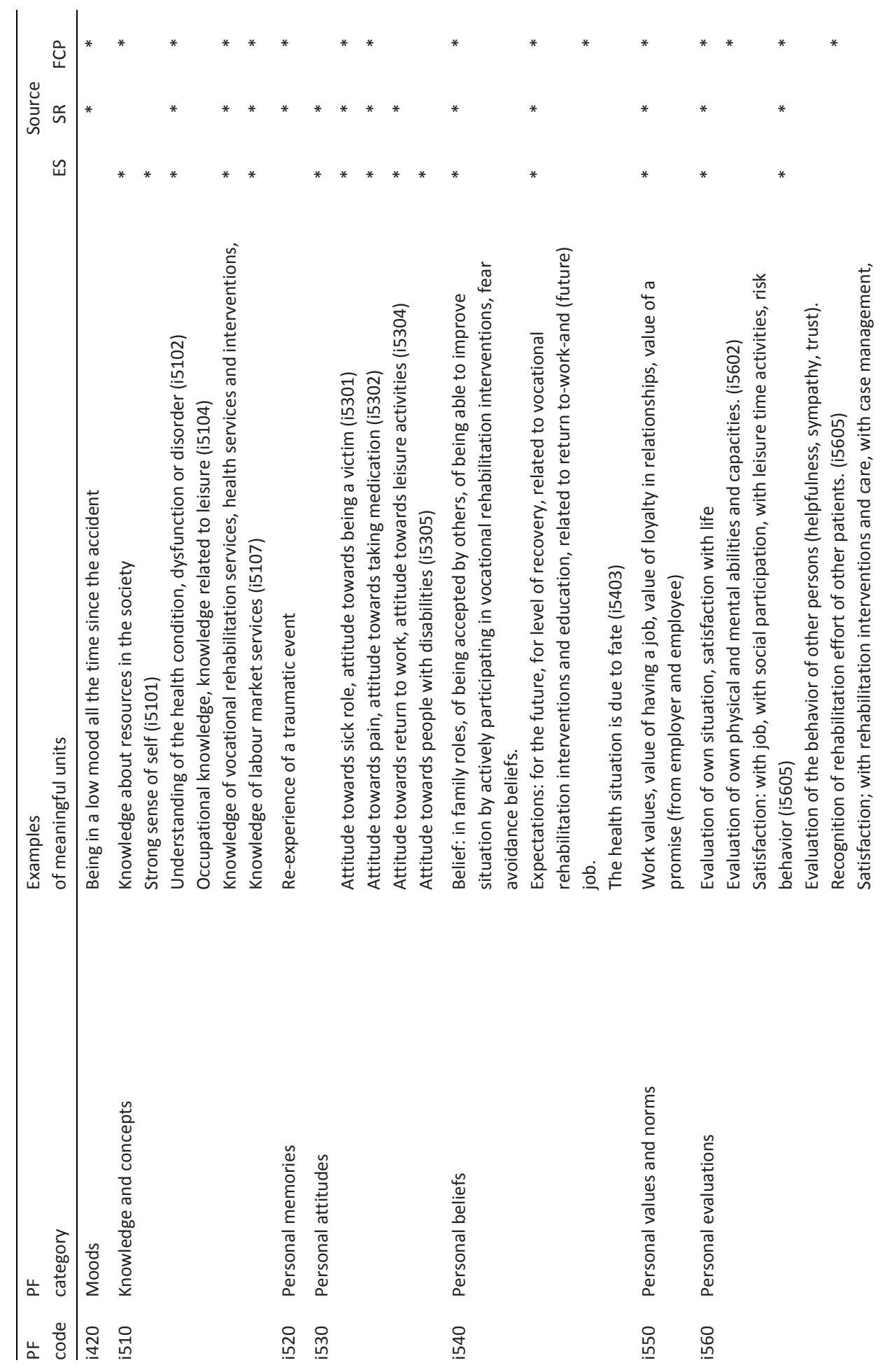




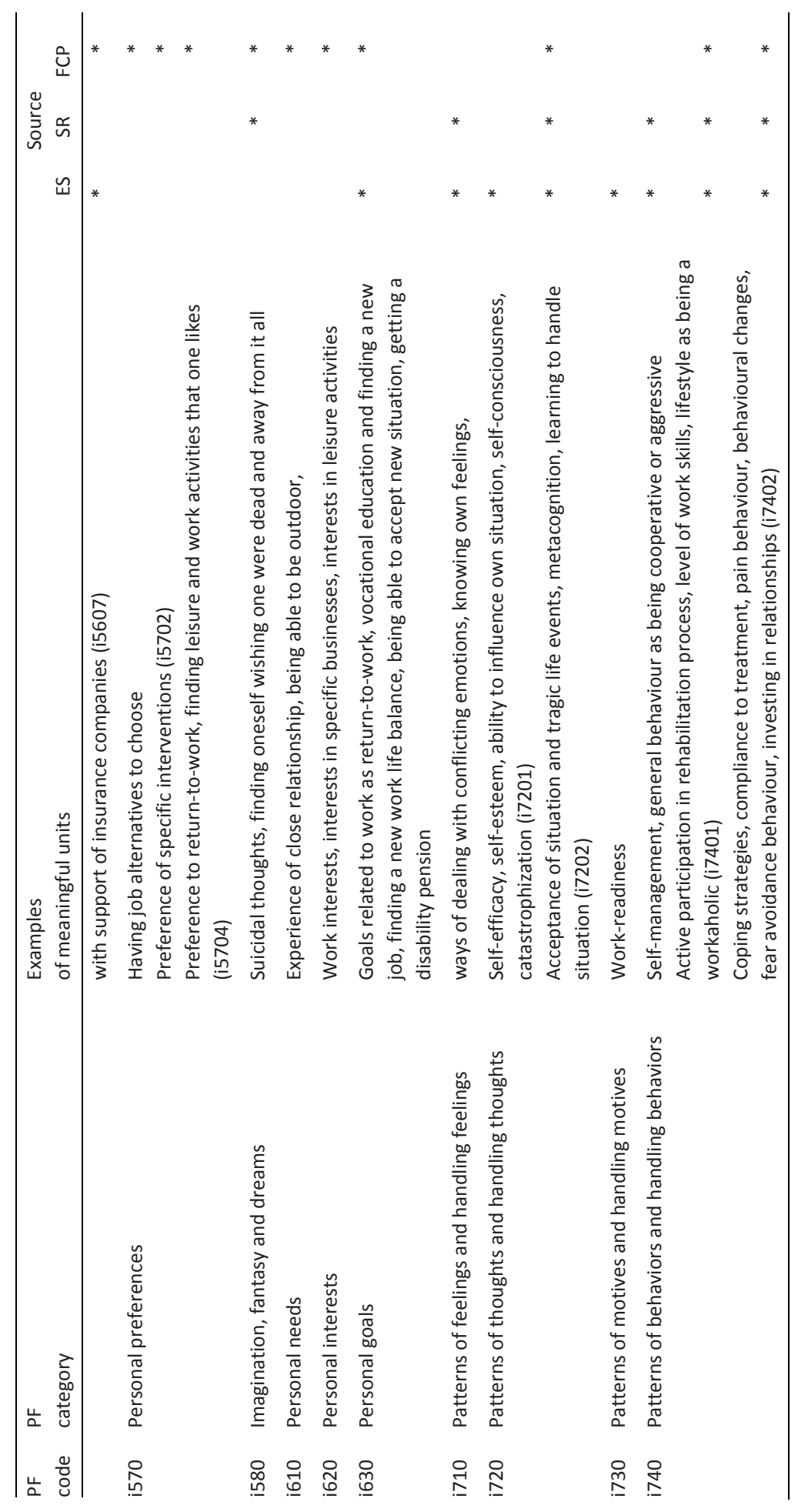




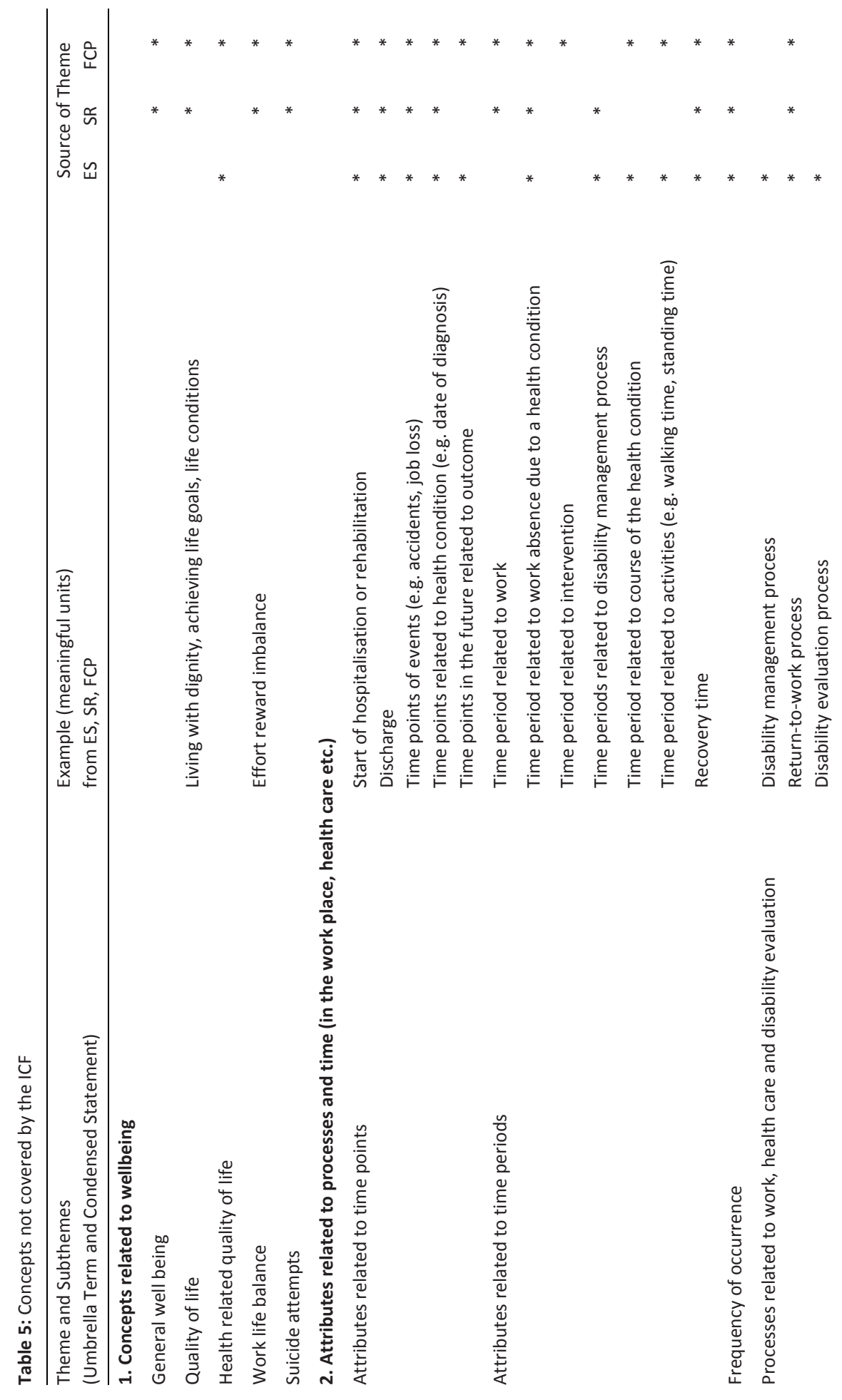




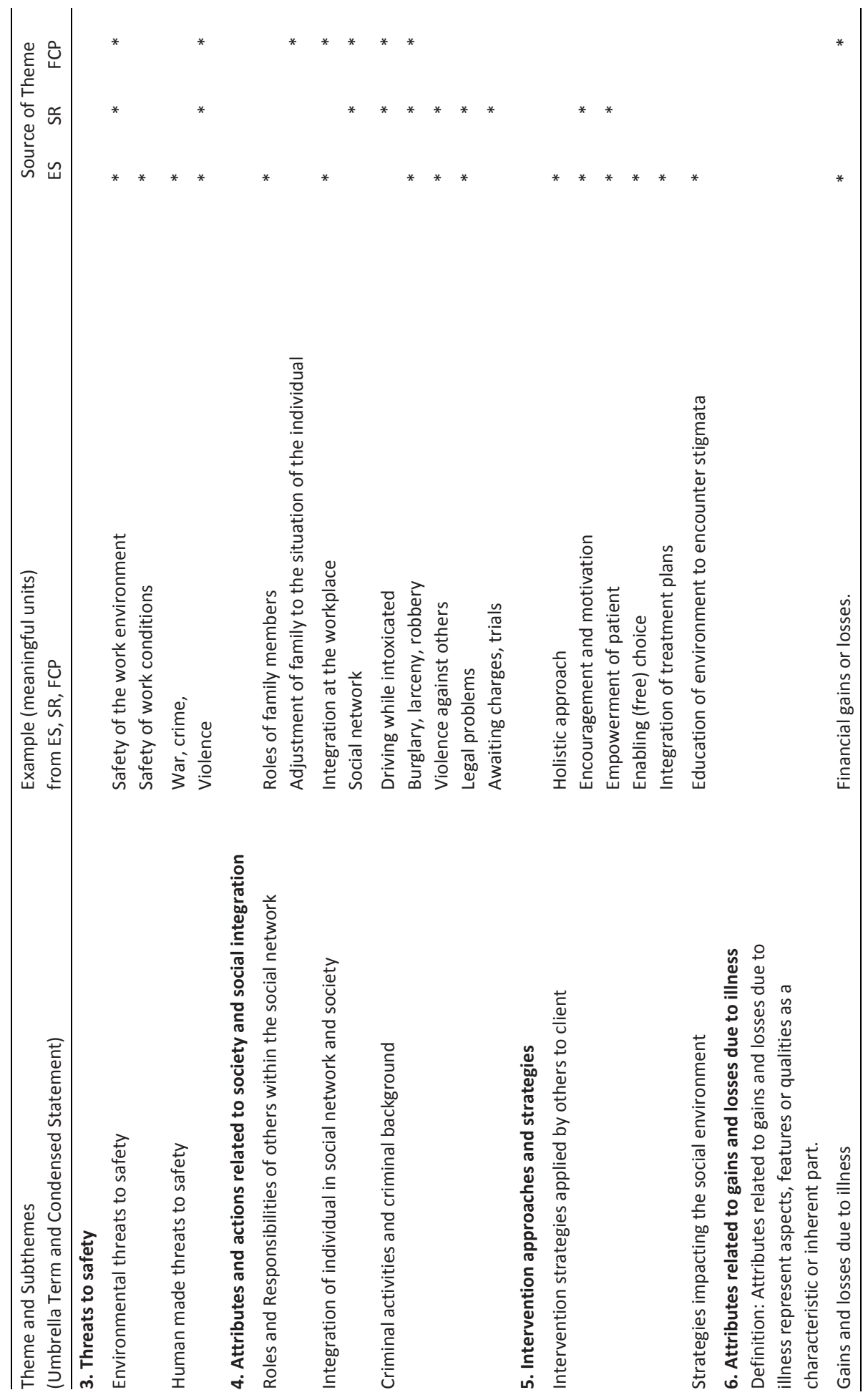




\section{Discussion}

This explorative and qualitative study explored three kinds of meaningful concepts in the context of vocational rehabilitation that could not be linked to distinct ICF categories using secondary data analysis: "nd"-not definable, represents meaningful units where insufficient information exists to make a decision about the most precise ICF category, "pf"- represents personal factors that are included in the ICF-model but not classified in the ICF-classification, and " $n c$ "- not covered, refers to meaningful units that cannot be assigned to any part of the ICF.

Since the development of the ICF Core Set for vocational rehabilitation a valuable standard exists to evaluate and document functioning in the context of vocational rehabilitation $[20,21]$. The results of this study reflect the three perspectives of the original studies; the systematic review reviewed outcomes that have been studied in vocational rehabilitation before, reflecting the research focus [24]. The expert survey evaluated the facts relevant for vocational rehabilitation from the expert perspective [32] and the patient focus group study identified aspects relevant for patients participating in vocational rehabilitation [25]. In our study, we have presented those concepts that were not previously explored and by doing so can help clinicians and researchers to have a complete and comprehensive idea of those aspects relevant to the vocational rehabilitation. The concepts previously un-linked to the ICF have now revealed after further examination complementary and essential aspects of functioning and disability that would be important to assess and document in facilitating return to work for individuals whose participation in work is restricted or hampered.

One finding when analyzing meaningful concepts from the "nd"-not definable-pool, was that experts, questionnaires and patients often use slogans and key terms that are only partially reflected in the ICF terminology. Familiar ICF terms such as functioning or disability can inform discussion on work disability but can at times provide little specification of work-related information. In the ICF functioning and disability are used as umbrella terms for body function, body structure and activities and participation [1,3], allowing a detailed description of capabilities and restrictions. Since the ICF is formulated in a way that is not specific to one profession, frequently used terminology, such as daily activities, or homework are not defined as distinct ICF categories but may be expressed by its more specific underlying (sub-)activities such as d630 Preparing meals, d640 Doing housework, and d650 Caring for household objects for household chores, for example. To improve the conceptualization and understanding of these "language" differences may help clinicians and researchers to reduce misunderstandings when using the ICF.

49 meaningful concepts first identified as " $\mathrm{nc}$ "-not covered because they were not included in any ICF category were reassigned to the global frame of the ICF using the option of the ICF to define new categories using an "8"-code, e.g. d198 Learning and applying knowledge, other specified_acquiring information or 14308 Lifting and carry- 
ing, other specified_lifting objects above shoulder level. Using this " 8 "-code option enables users to formulate ICF-categories specific to a clinical or research need, but on the other hand comparability of results is only given in a group where every stakeholder has agreed on the used definition. In the field of vocational rehabilitation, especially when assessing environmental factors, more detailed and commonly agreed on categories would enhance the precision and comparability of information.

To summarize and evaluate the meaningful units related to "pf"-personal factors the personal factors classification of Geyh et. al $[28,30]$ was used. This classification was based on systematic literature research and was developed using a terminology intended for complementary use along with the ICF classification. Our main reason to use this existing personal factors classification instead of developing a new coding frame was to enhance future comparability with diverse health conditions or settings, as in disability evaluation or work capacity evaluation where the same personal factors classification has been recently used [29]. In this study the classification of Geyh et al. demonstrated to be a valuable frame to group and analyze the meaningful concepts from the "pf"pool in the context of vocational rehabilitation.

Reflecting our data, sociodemographic factors such as educational and occupational background along with life events, medical history and co-morbidities were strongly supported by all three perspectives: experts, research, and patients. This finding validates the importance of educational and professional qualifications and experiences for successful job performance [33]. Co-morbidity on the other hand is not only common for patients in vocational rehabilitation [34] it also depicts a major challenge to treatment and return-to-work [34-36]. Understanding of the health condition, and knowledge about vocational rehabilitation services and labour market services were also found to be relevant by all three sources; this type of information can be provided to the patients and must be taken into account by the respective health professional looking after the care of the worker $[37,38]$. Personal attitudes and beliefs towards sick role and fear avoidance, pain and expectations towards return-to-work were also mentioned by all three sources. Interestingly, the same factors have been found to be major predictors for successful return-to-work $[39,40]$. Meaningful units linked to "personal evaluations" such as satisfaction with life situation, job and social participation were also confirmed by all three perspectives. While satisfaction with job was reported to be a major factor for sustaining work or for a successful return-to-work process [41,42], thought and behavior patterns mostly referred to thinking and handling strategies applied by patients to cope with their situation. As interventions supporting problemsolving abilities are shown to be effective in preventing work disability, evaluation of coping strategies may be a crucial factor in vocational successful rehabilitation programs $[43,44]$. In addition to themes supported by all three sources, personal preferences as having other job alternatives to choose or being able to express preferences for specific interventions was only mentioned by the patients. In the whole scheme of patient-centered care, subjective preferences as well as needs and expectations are 
important factors and are known to improve rehabilitation outcomes [45-47], hence this patient-relevant information must be considered when providing vocational rehabilitation services.

In addition to the ICF Core Set for vocational rehabilitation a pool of additional themes of aspects related to functioning, environmental and personal factors could be established that may help to understand and describe the complexity of functioning of individuals in vocational rehabilitation. A set of meaningful units was found that could not be integrated into the ICF model ("nc's"-not covered). Six themes were identified in relation to the "nc's". The first theme was concepts related to well-being including general well-being and quality of life. In the literature and in clinical practice the wellbeing and quality of life are often used interchangeably [48]. WHO defines well-being though as a term encompassing the total universe of human life domains, including physical, mental and social aspects, that make up what can be called a "good life" [49]. Quality of life on the other hand deals with what people "feel" about their health condition or its consequences. It represents a construct of "subjective well-being" in contrary to the ICF which refers to "objective" description of functioning. The concept of functioning and the concept of quality of life may be therefore be used to complement each other.

The second theme was attributes related to processes and time (in the work place, health care etc.). Attributes related to processes represent aspects, features or qualities as a characteristic or inherent part of the processes; this theme recognizes the developmental and temporal character of vocational rehabilitation and the fact that the ICF was developed to assess and document human functioning in the context of health and not necessarily to describe trajectory over time or during a process. The process of vocational rehabilitation is influenced by many factors. Defining time points, as the start of an intervention, discharge and work resumption and time periods as the duration of sick leave, rehabilitation interventions and the time since injury for example are essential to structure the course of vocational rehabilitation. Users of the ICF are therefore explicitly advised to identify their coding rubric and time frame depending on their need i.e. fit-for-purpose [3].

Theme three refers to threats to safety that may influence how a person behaves with regard to relationships and the environment.

Theme four, attributes and actions related to society and social integration, represents characteristics inherent to society as a whole or features of social integration. Theme four also reflects the role played by others unrelated to the person in question. On the other hand, criminal activities and the criminal background of the person may influence his or her interactions with the environment and also how the environment reacts to the person.

Theme five, intervention approaches and strategies, reflects on the fact that external actors often apply approaches and strategies to benefit the person in vocational rehabilitation. An approach thereby can be seen as a way of dealing with a situation or 
problem against which a strategy represents a plan of action designed to achieve a long-term or overall aim. In contrary to strategies used by the person himself or herself which can be perceived as personal factors, intervention approaches and strategies applied by others reflect the skills and the knowledge of another person applying the intervention.

Theme six, attributes related to gains and losses due to illness, is attributed to the person but not part of his or her biological functioning or activity or participation. The theme implies an attribute related to the process of disability and is therefore due to change.

This study has several limitations. One is that our data are limited to information gained by the three original studies. Since the information comes from diverse sources, only qualitative evaluation of the underlying concepts was possible. Although it could be shown from which source study the single concepts were supported, no quantitative inferences could be made. Identified themes therefore have to be further tested for prognostic and therapeutic value or operationalized in an intervention study or clinical trial. When looking at the patients in the focus group study, while heterogeneity was ensured to the fullest extent possible, the patients represented only a limited number of health conditions and variety of vocational rehabilitation interventions.

To our astonishment only $13 \%$ of the meaningful units linked to "nd", "pf" and "nc" in the three original studies (441 out of a total of 3457), namely the remaining "nc's" could not be linked back to the ICF. To benefit from this knowledge four major points can be taken into consideration: first, work relevant factors can be defined on a level of the specification needed for clinical practice and research in vocational rehabilitation in the frame of the ICF. In a first step, ICF " 8 " code definitions should be developed within a setting or specific vocational rehabilitation program. In the long term, the needs of the clinical practice may inform and influence the future enhancement of the ICF. Second, the importance of personal factors is established knowledge in the scope of vocational rehabilitation $[39,50,51]$. To enhance comparability and completeness personal factors should be addressed in a structured way. In our case the personal factors classification of Geyh et al. proved to be a valuable system and should be examined further perhaps empirically. Third, as recommended by WHO, the ICF can be used when designing rehabilitation and to assess and understand functioning in a comprehensive way. The vocational rehabilitation process itself has to be specified with regards to timing, distribution of task, and involvement of stakeholders such as employers and worker's family and caregivers according to the needs and goals of a particular returnto-work program. Finally, well-being, quality of life and functioning are three different concepts. One needs delineating definitions of well-being, quality of life/health related quality of life to distinguish them from the concept of functioning as represented by the ICF. Depending on the purpose of the data collection, data has to be collected on only one or on all three concepts. 
In conclusion the findings of this study indicate that the ICF model provides a valuable framework for assessing and documenting functioning in vocational rehabilitation. While there are limitations concerning the inability to link some concepts in vocational rehabilitation to the ICF, this study provided a step in exploring and examining those concepts. The findings of this study support the complexity of vocational rehabilitation in practice and in research and provide concepts that are complementary to the existing ICF Core Set for Vocational Rehabilitation; these concepts are essential and are supported by evidence in the literature. We recommend further empirical investigation particularly in the area of intervention trials where the concepts identified in this study can be tested whether or not they determine or influence return-to-work and eventually use those concepts to develop effective vocational rehabilitation programs.

\section{References}

1. World Health Organization. International Classification of Functioning, Disability and Health. Geneva, Switzerland: World Health Organization; 2001.

2. World Health Organization, 54th World Health Assembly. International Classification of Functioning, Disability and Health (2001). Available at: http://www.who.int/classifications/icf/wha-en.pdf. Accessed 08 Dec 2009.

3. World Health Organization (WHO) editor. How to use ICF: A practical manual for using the International Classification of Functioning, Disability and Health. Exposure draft for comment ed. Geneva, Switzerland: World Health Organization; 2013.

4. Glassel A, Rauch A, Selb M, Emmenegger K, Luckenkemper M, Escorpizo R. A case study on the application of International Classification of Functioning, Disability and Health (ICF)-based tools for vocational rehabilitation in spinal cord injury. Work 2012;41(4):465-474.

5. Bickenbach J, Cieza A, Selb M, Emmenegger K, Lückenkemper M, Escorpizo R editors. ICF Core Sets: Manual for Clinical Practice. 1st ed. Göttingen: Hogrefe; 2012.

6. Lohmann S, Decker J, Muller M, Strobl R, Grill E. The ICF forms a useful framework for classifying individual patient goals in post-acute rehabilitation. J Rehabil Med 2011;43(2):151-155.

7. Huber EO, Tobler A, Gloor-Juzi T, Grill E, Gubler-Gut B. The ICF as a way to specify goals and to assess the outcome of physiotherapeutic interventions in the acute hospital. J Rehabil Med 2011 01;43(2):174-177.

8. Hollenweger J. Development of an ICF-based eligibility procedure for education in Switzerland. BMC Public Health 2011;11 Suppl 4:S7-2458-11-S4-S7.

9. Schwegler U, Anner J, Boldt C, Glassel A, Lay V, De Boer WE, et al. Aspects of functioning and environmental factors in medical work capacity evaluations of persons with chronic widespread pain and low back pain can be represented by a combination of applicable ICF Core Sets. BMC Public Health 2012;12:1088-2458-12-1088.

10. Anner J, Schwegler U, Kunz R, Trezzini B, de Boer W. Evaluation of work disability and the international classification of functioning, disability and health: what to expect and what not. BMC Public Health 2012;12:470-2458-12-470.

11. Brage S, Donceel P, Falez F. Development of ICF core set for disability evaluation in social security. Disabil Rehabil 2008;30(18):1392-1396.

12. Cerniauskaite M, Quintas R, Boldt C, Raggi A, Cieza A, Bickenbach JE, et al. Systematic literature review on ICF from 2001 to 2009: its use, implementation and operationalisation. Disabil Rehabil 2011;33(4):281309. 
13. Cieza A, Ewert T, Üstün B, Chatterji S, Kostanjsek N, Stucki G. Development of ICF Core Sets for patients with chronic conditions. J Rehabil Med (Suppl) 2004;36(44):9-11.

14. World Health Organization (WHO). Annex 2: Coding guidelines for ICF. In: WHO, editor. International Classification of Functioning, Disability and Health. Geneva: WHO; 2001. p. 219-233.

15. Cieza A, Brockow T, Ewert T, Amman E, Kollerits B, Chatterji S, et al. Linking health-status measurements to the international classification of functioning, disability and health. J Rehabil Med 2002;34(5):205-210.

16. Cieza A, Geyh S, Chatterji S, Kostanjsek N, Ustun B, Stucki G. ICF linking rules: an update based on lessons learned. J Rehabil Med 2005;37(4):212-218.

17. Chamberlain MA, Fialka Moser V, Schuldt Ekholm K, O'Connor RJ, Herceg M, Ekholm J. Vocational rehabilitation: an educational review. J Rehabil Med 2009;41(11):856-869.

18. Streibelt M, Egner U. A Systematic Review of the Predictors of Return to Work Following Vocational Retraining. Rehabilitation (Stuttg) 11 Dec 2012.[Epub]

19. Weigl M, Cieza A, Cantista P, Reinhardt JD, Stucki G. Determinants of disability in chronic musculoskeletal health conditions: a literature review. Eur J Phys Rehabil Med 2008;44(1):67-79.

20. Finger ME, Escorpizo R, Glassel A, Gmunder HP, Luckenkemper M, Chan C, et al. ICF Core Set for vocational rehabilitation: results of an international consensus conference. Disabil Rehabil 2012;34(5):429438.

21. Saltychev M, Kinnunen A, Laimi K. Vocational rehabilitation evaluation and the International Classification of Functioning, Disability, and Health (ICF). J Occup Rehabil 2013;23(1):106-114.

22. Portmann Bergamaschi R, Escorpizo R, Staubli S, Finger ME. Content validity of the Work Rehabilitation Questionnaire-Self-Report Version WORQ-SELF in a subgroup of spinal cord injury patients. Spinal Cord 2013; 52(3):225-30.

23. Escorpizo R, Finger ME, Glassel A, Cieza A. An international expert survey on functioning in vocational rehabilitation using the international classification of functioning, disability and health. J Occup Rehabil 2011;21(2):147-155.

24. Escorpizo R, Finger ME, Glassel A, Gradinger F, Luckenkemper M, Cieza A. A systematic review of functioning in vocational rehabilitation using the international classification of functioning, disability and health. J Occup Rehabil 2011;21(2):134-146.

25. Glassel A, Finger ME, Cieza A, Treitler C, Coenen M, Escorpizo R. Vocational Rehabilitation From the Client's Perspective Using the International Classification of Functioning, Disability and Health (ICF) as a Reference. J Occup Rehabil 2011;21(2):167-78.

26. Schreier M. Qualitative Content Analysis in Practice. 1st ed. London: Sage Publications Ltd.; 2012.

27. Geyh S, Muller R, Peter C, Bickenbach JE, Post MW, Stucki G, et al. Capturing the psychologic-personal perspective in spinal cord injury. Am J Phys Med Rehabil 2011;90(11 Suppl 2):79-96.

28. Geyh S, Cieza A, Bickenbach J, Stucki G. ICF personal factors. 2009.

29. Schwegler U, Peter C, Trezzini B, Anner J, Geyh S. Toward transparent documentation in medical work capacity evaluations: identifying personal factors in medical reports on Swiss disability claimants with chronic widespread pain. Int J Rehabil Res 2013;36(4):298-307.

30. Geyh S, Peter C, Muller R, Bickenbach JE, Kostanjsek N, Ustun BT, et al. The Personal Factors of the International Classification of Functioning, Disability and Health in the literature - a systematic review and content analysis. Disabil Rehabil 2011;33(13-14):1089-1102.

31. World Health Organization (WHO). Annex 1: Taxonomic and terminological issues. In: WHO, editor. International Classification of Functioning, Disability and Health. 1st ed. Geneva: WHO; 2001. p. 20112018.

32. Escorpizo R, Finger ME, Glässel A, Cieza A. An international expert survey on functioning in vocational rehabilitation using the International Classification of Functioning, Disability and Health. J Occup Rehabil 2011;21(2):147-155.

33. Heerkens Y, Engels J, Kuiper C, Van der Gulden J, Oostendorp R. The use of the ICF to describe work related factors influencing the health of employees. Disabil Rehabil 2004;26(17):1060-1066. 
34. Finger ME, Glassel A, Erhart P, Gradinger F, Klipstein A, Rivier G, et al. Identification of Relevant ICF Categories in Vocational Rehabilitation: A Cross Sectional Study Evaluating the Clinical Perspective. J Occup Rehabil 2011;21(2):156-166.

35. Clay FJ, Newstead SV, McClure RJ. A systematic review of early prognostic factors for return to work following acute orthopaedic trauma. Injury 2010;41(8):787-803.

36. Varekamp I, van Dijk FJ, Kroll LE. Workers with a chronic disease and work disability : Problems and solutions. Bundesgesundheitsblatt Gesundheitsforschung Gesundheitsschutz 2013;56(3):406-414.

37. Flink IK, Boersma K, Linton SJ. Catastrophizing moderates the effect of exposure in vivo for back pain patients with pain-related fear. Eur J Pain 2010;14(8):887-892.

38. Corbiere M, Brouwers E, Lanctot N, van Weeghel J. Employment Specialist Competencies for Supported Employment Programs. J Occup Rehabil 2013 Oct 11.[Epub]

39. Iles RA, Davidson M, Taylor NF. Psychosocial predictors of failure to return to work in non-chronic nonspecific low back pain: a systematic review. Occup Environ Med 2008;65(8):507-517.

40. Nicholas MK, George SZ. Psychologically informed interventions for low back pain: an update for physical therapists. Phys Ther 2011;91(5):765-776.

41. Leyshon R, Shaw L. Using multiple stakeholders to define a successful return to work: a concept mapping approach. Work 2012;41(4):397-408.

42. Laisne F, Lecomte C, Corbiere M. Biopsychosocial predictors of prognosis in musculoskeletal disorders: a systematic review of the literature. Disabil Rehabil 2012;34(5):355-382.

43. van den Hout JH, Vlaeyen JW, Heuts PH, Zijlema JH, Wijnen JA. Secondary prevention of work-related disability in nonspecific low back pain: does problem-solving therapy help? A randomized clinical trial. Clin J Pain 2003;19(2):87-96.

44. Linton SJ, Nordin E. A 5-year follow-up evaluation of the health and economic consequences of an early cognitive behavioral intervention for back pain: a randomized, controlled trial. Spine (Phila Pa 1976) 2006;31(8):853-858.

45. Leplege A, Gzil F, Cammelli M, Lefeve C, Pachoud B, Ville I. Person-centeredness: conceptual and historical perspectives. Disabil Rehabil 2007;29(20-21):1555-1565.

46. Law M, Baptiste S, Mills J. Client-centred practice: what does it mean and does it make a difference? Can J Occup Ther 1995;62(5):250-257.

47. Shaw WS, Main CJ, Johnston V. Addressing occupational factors in the management of low back pain: implications for physical therapist practice. Phys Ther 2011;91(5):777-789.

48. Kahn R, Juster F. Well-Being: Concepts and Measures. Journal of Social Issues 2002;58(4):627-644.

49. World Health Organization (WHO). Annex 8: Future directions for ICF. In: WHO, editor. International Classification of Functioning, Disability and Health. 1st ed. Geneva: WHO; 2001. p. 250-252.

50. Selander J, Marnetoft SU, Asell M. Predictors for successful vocational rehabilitation for clients with back pain problems. Disabil Rehabil 2007;29(3):215-220.

51. Michon HW, van Weeghel J, Kroon H, Schene AH. Person-related predictors of employment outcomes after participation in psychiatric vocational rehabilitation programmes--a systematic review. Soc Psychiatry Psychiatr Epidemiol 2005;40(5):408-416. 



\section{Chapter 4 \\ ICF Core Set for vocational rehabilitation: results of an international consensus conference}

Article published in Disability \& Rehabilitation, 2012; 34(5): 429-438

$\begin{array}{ll}\text { Monika E. Finger } & \text { Julie Fritz } \\ \text { Reuben Escorpizo } & \text { Urban Studer } \\ \text { Andrea Glässel } & \text { Jan Ekholm } \\ \text { Hans Peter Gmünder Nenad Kostanjsek } \\ \text { Miriam Lückenkemper } & \text { Gerold Stucki } \\ \text { Chetwyn Chan } & \text { Alarcos Cieza }\end{array}$




\section{Abstract}

Purpose: Vocational rehabilitation (VR) programs aim to facilitate work participation. However, there is no universal framework to describe the functioning of individuals who participate in VR. The objective of this paper is to report on the Core Set for VR based on the International Classification of Functioning, Disability and Health (ICF) by the World Health Organization (WHO).

Methods: A formal decision-making and consensus-based process was conducted based on the evidence from four preparatory studies. Twenty-three international experts chosen by WHO Region and expertise in VR attended the consensus conference.

Results: Ninety ICF categories were included in the comprehensive Core Set (activities and participation $=40$, environmental factors $=33$, body functions $=17$ ), while the brief Core Set included 13 second level categories (activities and participation $=6$, environmental factors $=4$, body functions $=3$ ).

Conclusions: The expert opinion and evidence-based Core Set could serve as an international standard for what to measure and report concerning functioning of individuals in VR. The Core Set could also provide a common language among clinicians, researchers, insurers, and policymakers in the implementation of successful VR. Further testing and validation studies are encouraged.

Keywords: ICF, ICF Core Set, vocational rehabilitation, employment, classification, return-to-work 


\section{Implications for Rehabilitation}

- Vocational rehabilitation is a multidisciplinary and multi-stakeholder process, which aims to reduce or eliminate the burden of work disability and facilitate work participation.

- The International Classification of Functioning, Disability and Health (ICF) provides a framework to describe and measure the functioning of individuals who are in a vocational rehabilitation program.

- The ICF Core Set for vocational rehabilitation provides us with a list of functioning domains in our effort to examine vocational rehabilitation or return-to-work outcomes and the multiple factors associated with vocational rehabilitation.

- The ICF Core Set for vocational rehabilitation can be used in clinical rehabilitation setting and rehabilitation research, and further steps to ensure the robust measurement, documentation, and reporting of the Core Set in rehabilitation are being planned.

\section{Introduction}

According to the sickness, disability and work report of the Organisation for Economic Co-operation and Development (OECD) in 2009, more than half of OECD countries have seen a substantial growth in disability beneficiary rates in the past decade, with around $6 \%$ of the OECD-wide working-age population collecting disability benefits in 2007 . On average, OECD countries spend $1.2 \%$ of gross domestic product (GDP) on disability benefits alone. This figure can reach from $2 \%$ to $4-5 \%$ when including sickness benefits in some countries which is almost 2.5 times in average as much as what is spent on unemployment benefits, topped by Iceland (5.5 times) and the United Kingdom (4.5 times) and on the other end Canada and Belgium spent $65-72 \%$ on unemployment benefits compared to the amount spent on sickness and disability benefits [1].

Work disability (WD) causes enormous financial burden to the society and stakeholders and impacts the functioning of individuals i.e. restriction in work participation. In addition to the economic impact, being excluded from work is also associated with feeling of self-worthlessness, loss of confidence, depression and a decline in overall social integration [2,3]. Vocational Rehabilitation (VR) as a process in WD management has become a focus in discussions on social security systems, disability insurance, health care provision and employer management [4,5]. VR refers to a multidisciplinary approach that is provided to participants with the aim of optimizing work participation [6].

VR is often a multi-level process with multiple players, and relates the functioning of the individual worker with their work role in the broadest sense [7]. Interventions in VR may include medical, psychological, social and occupational activities that aim to re- 
establish or improve physical, mental or social functions in sick or injured people, i.e. to restore their work capacity as a prerequisite for returning to work or to being available for a job [8]. This definition, however, would not to necessarily exclude those without work history.

Effective rehabilitation within the context of one's vocation or occupation, requires a good co-operation between the different stakeholders with the common goal defining processes and clear communication strategies toward return-to-work $[9,10]$. In clinical setting, there is often a gap between information and communication, concerning goals, procedures and interventions particularly when working in a multidisciplinary process such as VR (e.g. coordination of care between a social worker and an occupational therapist). Moreover, the exchange of information between clinical care providers and the employer also becomes vital in facilitating and sustaining return-to-work [11].

VR players (e.g. health professionals, return-to-work specialists, employers and social insurances, etc.) have different terminologies, frameworks, and approaches, which can make the communication challenging. To understand return-to-work process, in the last decade diverse work disability and work rehabilitation models were developed in different settings [12-15], but a common framework is lacking. Therefore, a "standard" in the area of VR could facilitate comparability of research findings and clinical outcomes $[16,17]$. To achieve a common understanding and shared goals, a comprehensive framework, which can provide a universal language understood by health professionals, researchers, policymakers, workers and employers and patient organizations could improve the VR process [18], and such a framework can be provided by the International Classification of Functioning, Disability and Health (ICF) by the World Health Organization (WHO)[19].

With the approval of the ICF in 2001, we have a universal conceptual framework of domains and classification system to describe the functioning of individuals that can be applied within the context of work participation and VR. As a conceptual model, the ICF recognizes that functioning and disability is a result of the interaction between different components: body functions (b), body structures (s), activities and participation (d), environmental factors (e), and personal factors. However, using the entire ICF with it's over 1400 categories may not be feasible. Hence, an ICF Core Set is needed. An ICF Core Set is a short list of categories or domains of the ICF relevant to a specific health condition or setting [7]. There are two versions of the ICF Core Set: comprehensive and brief. The comprehensive Core Set is a list of ICF categories that includes as few categories as possible to be practical, but as many as necessary to describe the typical spectrum of problems in functioning of patients with a specific condition in a comprehensive and multidisciplinary assessment. The brief ICF Core Set is a list of ICF categories that are essential to describe the typical spectrum of limitations in functioning and the environment of individuals participating in VR, and at the same time short enough to be practical in clinical studies or trials [20]. 
The objective of this paper is to present the developed ICF Core Set for vocational rehabilitation. Our specific aims are: (1) to describe the consensus process and (2) to present the lists of ICF categories for the comprehensive and brief ICF Core Set for vocational rehabilitation.

\section{Methods}

\section{Overview of the process}

The ICF Consensus Conference took place from May 19 to 21, 2010 at the ICF Research Branch in Nottwil, Switzerland. The development of the ICF Core Sets for VR involved a multistage decision-making and consensus process. Evidence from four preparatory studies was introduced at the beginning of the process. The preparatory studies included a systematic review of outcomes used in VR studies [21], a survey of international experts involved in VR [22], a focus group study of individuals (patients) participating in VR, a qualitative study [23], and a cross sectional or empirical study [24]. Details of these studies have been recently published.

The ICF categories that were identified in the four preparatory studies were presented to the consensus participants (experts) as a pool of 752 candidate categories in a document form (Figure 1). In columns 1 to 3 , the ICF code was provided and the title of the code was provided under column 4. The frequency of the ICF categories found in each study (empirical study, expert survey, systematic review and qualitative study) was provided to the experts (columns 5 to 8 of Figure 1). The number of experts in the working group that voted to accept the ICF category in the ICF Core Set for VR was noted in columns 9 to 11 (there were 3 separate working groups, respectively). 
Figure 1: Work document sample for the consensus process.

\begin{tabular}{|c|c|c|c|c|c|c|c|c|}
\hline & & $\begin{array}{l}\text { Empirical } \\
\text { Study }\end{array}$ & $\begin{array}{l}\text { Expert } \\
\text { Survey }\end{array}$ & $\begin{array}{c}\text { Systemati } \\
\text { Review }\end{array}$ & $\begin{array}{l}\text { Sualitative } \\
\text { Study }\end{array}$ & \multicolumn{3}{|c|}{ Working Group (WG) } \\
\hline ICF code & \multirow[t]{2}{*}{ ICF title } & \multirow{2}{*}{$\begin{array}{c}\% \\
n=152\end{array}$} & \multirow{2}{*}{$\begin{array}{c}\% \\
n=142\end{array}$} & \multirow{2}{*}{$\begin{array}{c}\% \\
n=229\end{array}$} & \multirow{2}{*}{$\begin{array}{c}\mathrm{n} \text { of } \\
\text { groups } \\
7\end{array}$} & \multicolumn{3}{|c|}{ Vote A } \\
\hline $\begin{array}{c}2^{\text {nd }} \quad 3^{\text {nd }} \quad 4^{\text {nd }} \\
\text { level level level }\end{array}$ & & & & & & WG 1 & WG 2 & WG 3 \\
\hline b110 & Consciousness function & 3 & & 18 & 5 & & & \\
\hline b114 & Orientation functions & 0 & 2 & 18 & & & & \\
\hline b117 & Intellectual functions & 5 & 25 & 7 & & & & \\
\hline b122 & $\begin{array}{l}\text { Global psychosocial } \\
\text { functions }\end{array}$ & & 12 & & & & & \\
\hline b126 & $\begin{array}{l}\text { Temperament and } \\
\text { personality functions }\end{array}$ & 70 & 51 & 39 & 7 & & & \\
\hline b130 & $\begin{array}{l}\text { Energy and drive } \\
\text { functions }\end{array}$ & 70 & 51 & 42 & 7 & & & \\
\hline
\end{tabular}

Abbreviation: Vote A; the first vote that took place within the three working groups (WG1-3.)

\section{Recruitment of conference participants}

Experts in the field of VR were invited to participate in the consensus. No remuneration or honorarium was paid to the experts who agreed to attend. They were identified based on a systematic review study and an expert survey [21,22]. In summary, the names of the experts came from different sources such as the literature, international and national professional and non-professional organizations, internet search, informal network, editorial board of journals, and referred peers. A Local Advisory Group of the project and an International Steering Committee consisting of representatives from the WHO, the International Labour Organization, the World Confederation for Physical Therapy (WCPT), the World Federation of Occupational Therapists (WFOT), and the International Society of Physical and Rehabilitation Medicine (ISPRM) were also consulted for experts in the field of VR. The selection of experts was based on the WHO region of residence, professional background (see Table 1), and area of expertise (e.g. musculoskeletal condition, education, etc.). As in previous Core Set developments $[20,25-28]$, all WHO regions will need to be represented and partnership with international organizations will also need to be forged [7] 


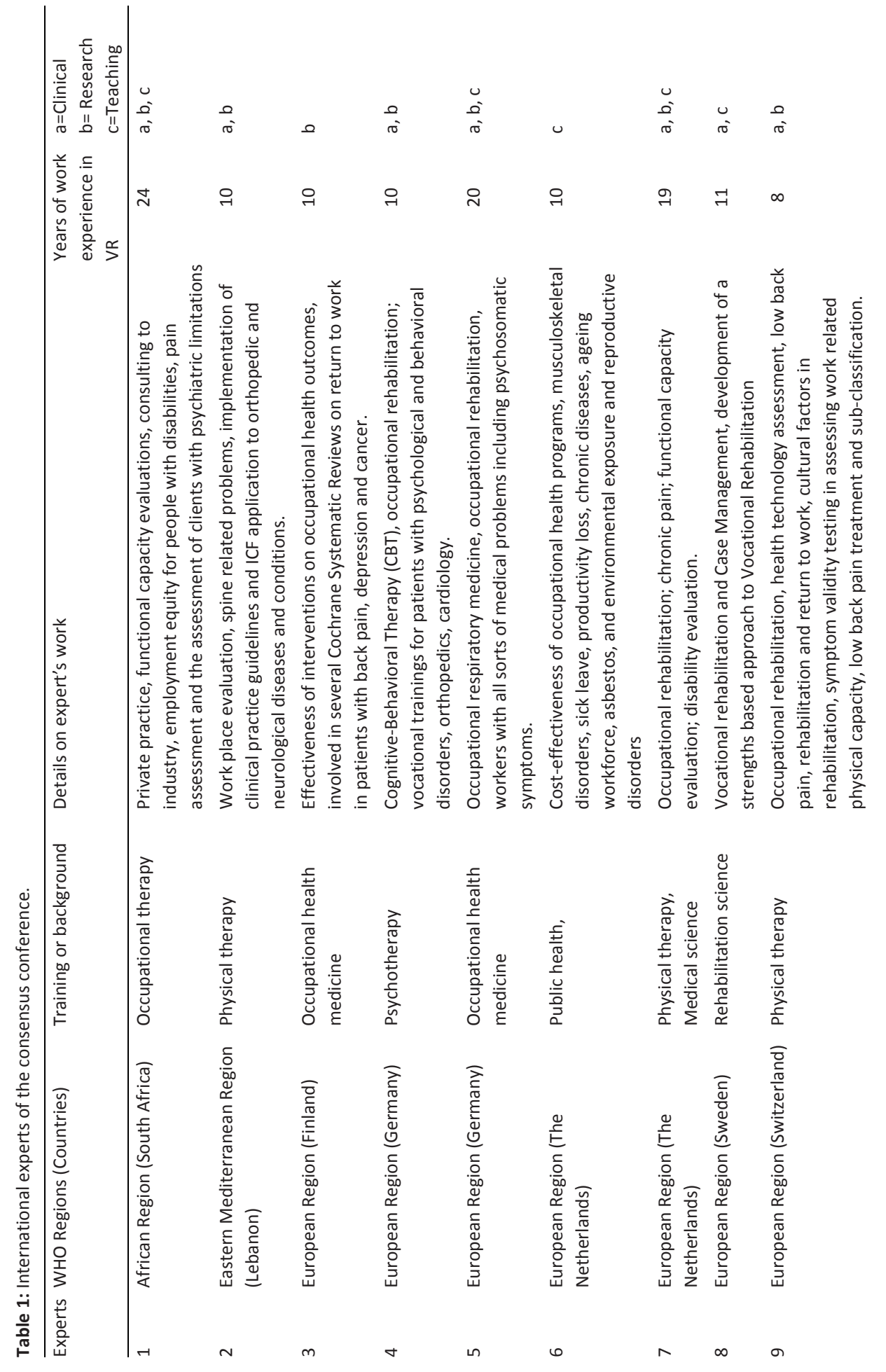




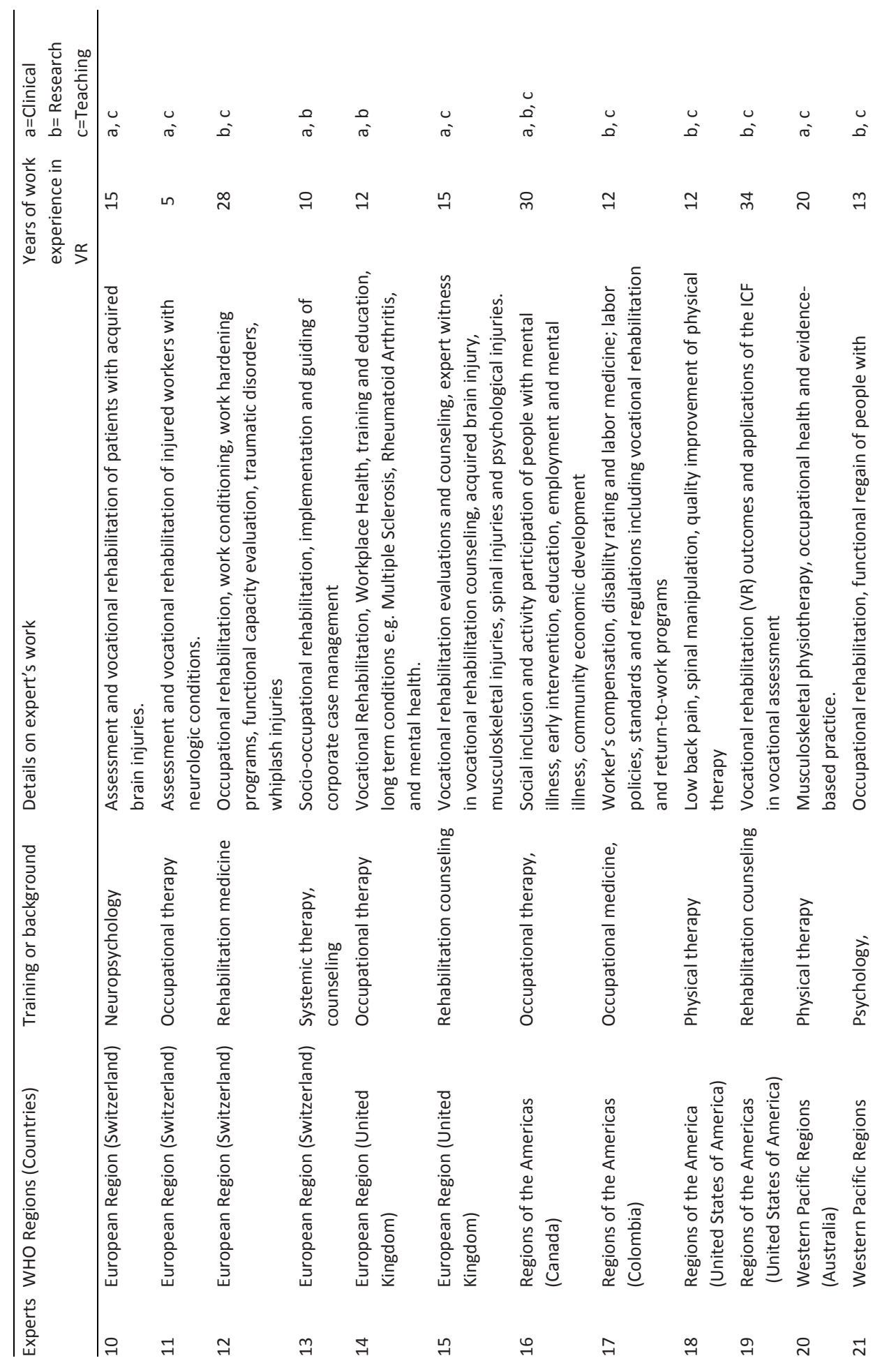




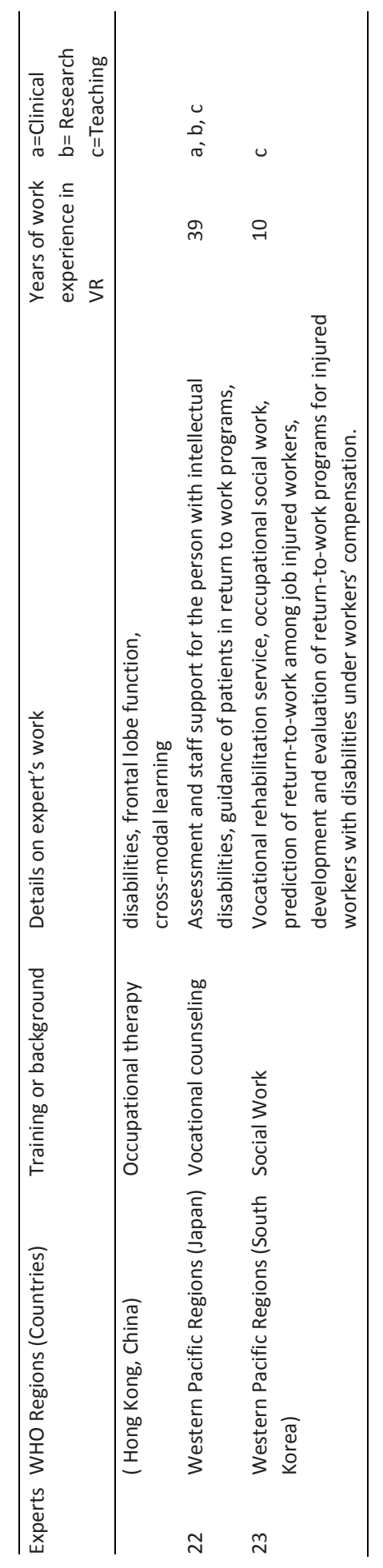




\section{Consensus process}

At the beginning of the conference, expert participants were provided with information on the ICF, procedural steps of the consensus, and were oriented to their role as participants. Afterwards, the results of the four preparatory studies were presented and printed copies of which were also given to them. An initial voting took place where experts voted individually and ranked which of 752 candidate ICF categories they felt to be important in VR. Multiple working group (WG) sessions with plenary sessions in between were held over two days, which were opportunities for the experts to openly discuss arguments in favour of or against an ICF category. The whole process was moderated and facilitated by a member of the ICF Research Branch (AC). Figure 2 illustrates the consensus process for the comprehensive ICF Core Set for VR.

For the working group sessions, experts were divided in three groups. In WG session 1, the experts discussed and voted on including or excluding the ICF categories presented on the 2 nd level (vote A). Those categories that were accepted with over $75 \%$ of the vote in all three WGs were included immediately in the comprehensive Core Set. Categories that were excluded were those that were voted by only $40 \%$ or less in all WGs. Categories which got $40-75 \%$ vote were reviewed in the plenary session 1 where the experts presented their arguments in favour of including or excluding the category. Experts reconvened for the WG session 2, where the experts voted on the remaining categories (i.e. those with $40-75 \%$ vote from WG1). Accepted categories with over $75 \%$ vote for inclusion in all three WGs were immediately included and categories with only $40 \%$ or less vote for inclusion in all WGs were excluded. The remaining categories (i.e. those with $40-75 \%$ vote for inclusion) were discussed and then voted again during plenary session 2 where now categories with over $50 \%$ votes were included. At this stage all categories for the comprehensive ICF Core Set at the 2 nd level were included. 
Figure 2: Voting process: Comprehensive ICF Core Set for vocational rehabilitation.

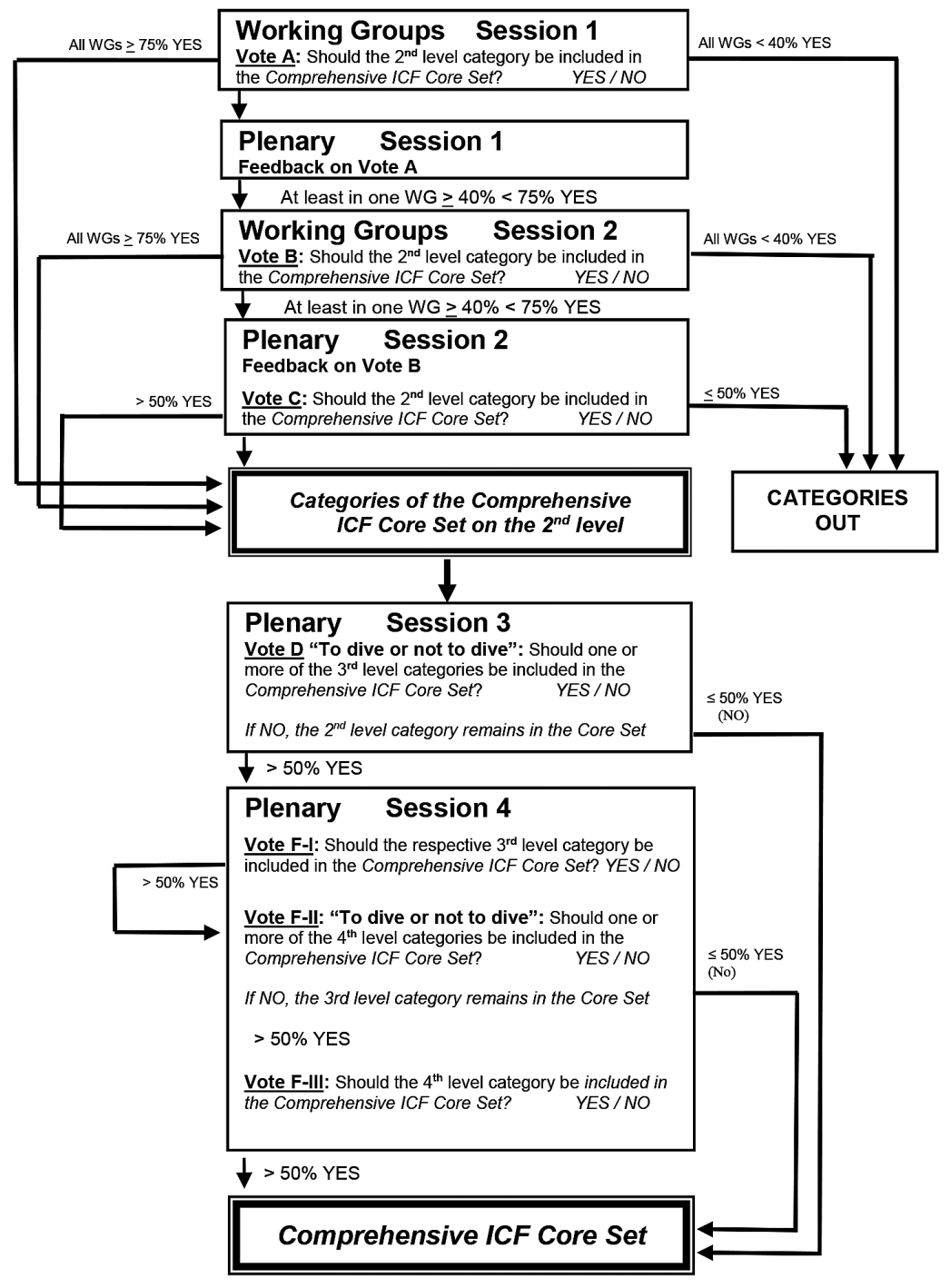

In plenary sessions 3 and 4 , the experts had to decide whether or not they preferred to stay at the second level (e.g. b280 Sensation of pain) of the classification, or instead go more specific and include third- (e.g. b2801 Pain in body part) or fourth-level (e.g. b28010 Pain in head and neck) categories. This process was called "diving". At the end of this stage, the first milestone, the comprehensive Core Set, was developed.

In the second part of the consensus process, the experts had to decide on the brief ICF Core Set for VR using a ranking procedure (figure 3). 
Figure 3: Voting process: Ranking exercise for the brief ICF Core Set for vocational rehabilitation.

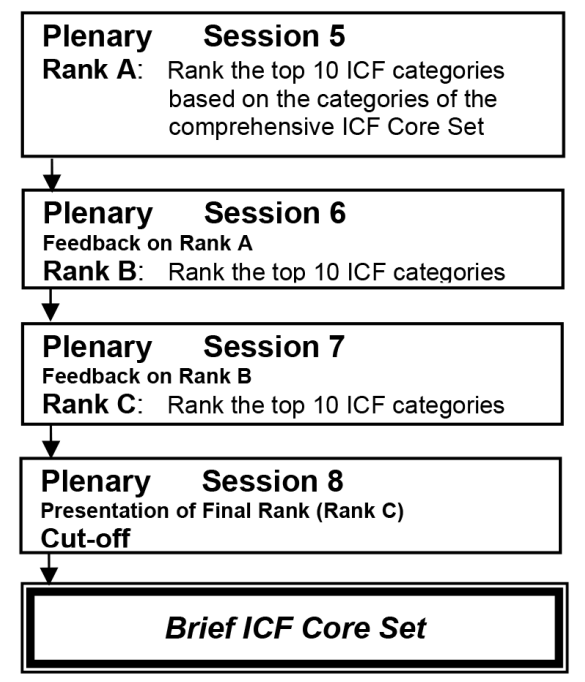

Three ranking rounds were conducted, each followed by feedback and discussion. The task of the experts was to rank the 10 most relevant ICF categories out of the comprehensive version of the Core Set for VR (which was developed earlier) for each ICF component. In the final vote, a cut-off number (number of ICF categories included) for each ICF component was defined by the experts by consensus (e.g. top 5 categories of body function, top 10 categories of environmental factors, etc.).

\section{Results}

Twenty-three experts were chosen from the expert pool using different sources to ensure widest possible distribution in terms of the selection criteria (WHO region, background, and expertise). The distribution and description of the experts was consistent with the pool in the expert survey. For instance, relatively more experts were therapists and were from developed regions or countries (Table 1).

Based on the list of 752 candidate categories on the second, third, and fourth level of the classification from the four preparatory studies, the experts decided on the comprehensive and brief ICF Core Set for VR. From the 752 categories, 251 were body functions, 130 were body structures, 244 were from activities and participation, and 127 were environmental factors. 


\section{Comprehensive ICF Core Set for vocational rehabilitation.}

The number of categories in the comprehensive ICF Core Set totaled 90. Tables 2-4 show the ICF categories that were included in the comprehensive ICF Core Set. All categories in the comprehensive Core Set belong to the second level of the ICF except for e1101 Drugs, which is a third-level category. No fourth-level categories were included. The component activities and participation contained 40 categories (44\% of all categories included in the comprehensive Core Set), 33 (25\%) for environmental factors, and 17 (19\%) for body functions. No category was included from body structures.

Table 2: Comprehensive Core Set on activities and participation $(\mathrm{N}=40)$.

\begin{tabular}{|c|c|}
\hline ICF Code & Title \\
\hline d155 & Acquiring skills \\
\hline d160 & Focusing attention \\
\hline d163 & Thinking \\
\hline d166 & Reading \\
\hline d170 & Writing \\
\hline d172 & Calculating \\
\hline d175 & Solving problems \\
\hline d177 & Making decisions \\
\hline $\mathrm{d} 210$ & Undertaking a single task \\
\hline $\mathrm{d} 220$ & Undertaking multiple tasks \\
\hline d230 & Carrying out daily routine \\
\hline d240 & Handling stress and other psychological demands \\
\hline d310 & Communicating with - receiving - spoken messages \\
\hline d315 & Communicating with - receiving - nonverbal messages \\
\hline d350 & Conversation \\
\hline d360 & Using communication devices and techniques \\
\hline d410 & Changing basic body position \\
\hline $\mathrm{d} 415$ & Maintaining a body position \\
\hline $\mathrm{d} 430$ & Lifting and carrying objects \\
\hline d440 & Fine hand use \\
\hline d445 & Hand and arm use \\
\hline d450 & Walking \\
\hline d455 & Moving around \\
\hline d465 & Moving around using equipment \\
\hline $\mathrm{d} 470$ & Using transportation \\
\hline $\mathrm{d} 475$ & Driving \\
\hline d530 & Toileting \\
\hline d540 & Dressing \\
\hline d570 & Looking after one's health \\
\hline
\end{tabular}




\begin{tabular}{ll}
\hline ICF Code & Title \\
\hline d710 & Basic interpersonal interactions \\
d720 & Complex interpersonal interactions \\
d740 & Formal relationships \\
d820 & School education \\
d825 & Vocational training \\
d830 & Higher education \\
d840 & Apprenticeship (work preparation) \\
d845 & Acquiring, keeping and terminating a job \\
d850 & Remunerative employment \\
d855 & Non-remunerative employment \\
d870 & Economic self-sufficiency \\
\hline
\end{tabular}

Table 3: Comprehensive Core Set on environmental Factors $(N=33)$.

\begin{tabular}{|c|c|}
\hline ICF Code & Title \\
\hline e1101 & Drugs \\
\hline e115 & Products and technology for personal use in daily living \\
\hline e120 & Products and technology for personal indoor and outdoor mobility and transportation \\
\hline e125 & Products and technology for communication \\
\hline e130 & Products and technology for education \\
\hline e135 & Products and technology for employment \\
\hline e150 & Design, construction and building products and technology of buildings for public use \\
\hline e155 & Design, construction and building products and technology of buildings for private use \\
\hline e225 & Climate \\
\hline e240 & Light \\
\hline e250 & Sound \\
\hline e260 & Air quality \\
\hline e310 & Immediate family \\
\hline e320 & Friends \\
\hline e325 & Acquaintances, peers, colleagues, neighbours and community members \\
\hline e330 & People in positions of authority \\
\hline e340 & Personal care providers and personal assistants \\
\hline e355 & Health professionals \\
\hline e360 & Other professionals \\
\hline e430 & Individual attitudes of people in positions of authority \\
\hline e450 & Individual attitudes of health professionals \\
\hline e460 & Societal attitudes \\
\hline e465 & Social norms, practices and ideologies \\
\hline e525 & Housing services, systems and policies \\
\hline e535 & Communication services, systems and policies \\
\hline
\end{tabular}




\begin{tabular}{ll}
\hline ICF Code & Title \\
\hline e540 & Transportation services, systems and policies \\
e550 & Legal services, systems and policies \\
e555 & Associations and organizational services, systems and policies \\
e565 & Economic services, systems and policies \\
e570 & Social security services, systems and policies \\
e580 & Health services, systems and policies \\
e585 & Education and training services, systems and policies \\
e590 & Labour and employment services, systems and policies \\
\hline
\end{tabular}

Table 4: Comprehensive Core Set on body functions ( $N=17)$.

\begin{tabular}{ll}
\hline ICF Code & Title \\
\hline b117 & Intellectual functions \\
b126 & Temperament and personality functions \\
b130 & Energy and drive functions \\
b134 & Sleep functions \\
b140 & Attention functions \\
b144 & Memory functions \\
b152 & Emotional functions \\
b160 & Thought functions \\
b164 & Higher-level cognitive functions \\
b210 & Seeing functions \\
b230 & Hearing functions \\
b235 & Vestibular functions \\
b280 & Sensation of pain \\
b455 & Exercise tolerance functions \\
b730 & Muscle power functions \\
b740 & Muscle endurance functions \\
b810 & Protective functions of the skin \\
\hline
\end{tabular}

\section{Brief ICF Core Set for vocational rehabilitation}

The brief ICF Core Set included 13 second-level categories. Table 5 shows the categories that were selected for the brief ICF Core Set. There were 6 categories (59\%) from activities and participation, 4 (27\%) from environmental factors, and 3 (14\%) from body functions. 


\section{Discussion}

VR is an essential element in WD management because it could facilitate early and sustained return-to-work, or could enable people to participate in work. At the same time, VR is a complex process that involves multiple players and factors. We turn to the ICF as a conceptual framework and classification system by the WHO to address this complexity. Using the ICF to develop a Core Set of variables that are important in VR, we embarked on a formal consensus process that integrates evidence from preparatory studies. At the end of an international consensus conference, the ICF Core Set for vocational rehabilitation was developed: 90 ICF categories for the comprehensive version and 13 ICF categories for the brief version.

There are two reasons why the ICF could be useful in describing the functioning of individuals who are in a VR program. First, work or occupation being the main object of $V R$, is multifaceted. It involves not only the work itself but extends to family, community, policy, and governance [29]. The ICF is a comprehensive framework that captures functioning domains from the individual level (e.g. muscle strength, mobility) to the society level (e.g. systems and policy, community, social support). Second reason is that people with health conditions or disabilities that hinders their work participation is a reality that confronts both developed and developing countries [30-32]. The ICF was intended by the WHO to be applied across cultures or regions and hence, the "language" is universal.

In developing ICF Core Sets for VR we used similar methodology as the other Core Set development projects $[7,20]$. The challenge in VR is that it involves a variety of health conditions in a variety of settings. Hence, unlike other condition specific Core Sets, the Core Set for VR would have to be as generic as possible to be applicable in different health conditions and settings. At the same time, the Core Set for VR would also need to be as specific as possible to ensure that the true and relevant functioning domains in VR are considered.

The comprehensive version of the Core Set reflects the breadth of VR as a process and a field of practice and research. There were more categories relevant to activities and participation and environmental factors which stress the importance of these areas in facilitating successful VR outcomes and together with body functions categories, the Core Set addresses the domains of functioning in a comprehensive and holistic manner, which is consistent with how the ICF has been interfaced with "work functioning [33]".

Activities and participation categories in the Core Set capture a wide variety of domains that include the traditional work domains (e.g. d850 Remunerative employment) and non-traditional work domains (e.g. self-care like toileting and dressing [5]). Some categories apply to jobs with mental-type of demands (e.g. attention, calculation) and other categories could apply to physically demanding jobs (e.g. Lifting, Moving around). It goes without saying that some jobs do require both mental and physical skills. The environmental factors, be it physical or support from people, could facilitate 
return-to-work [34,35]. Hence, the Core Set includes factors from products and technology, to people who can support the worker and also factors relating to the "environment" at the policy and systems level. Indeed, the environment can influence work at different levels [29]. There was no body structure category selected because any part of the body can be affected, which would require referral to VR service. Hence, a Core Set for body structures may not be necessary. While body structures is a functioning domain according to the ICF, a disease classification such as the International Classification of Diseases [36] which is already used anyway, could also provide information on what body structure is involved. Further, the experts suggested that the order of ICF components as presented in the Core Set be ordered with activities and participation first, followed by environmental factors, and then body functions, which might be indicative of the strength of the ICF in activities and participation domains and environmental factors within the context of VR.

In the brief ICF Core Set, the main goal of the experts was, to define a standard that can be used as the minimum dataset to be collected in patient evaluation or in clinical studies. When a minimum dataset in VR is available, this could help in performing comparison across settings which would eventually enhance standardization of reporting evidence (e.g. treatment outcomes). During the discussion on the brief version, concerns were raised on how to capture important information within the component environmental factors. The categories in chapter e5 Services, systems and policies are attractive because of umbrella services that are provided within the VR context such as e580 Health services, systems and policies and e590 Labour and employment services, systems and policies. In activities and participation, three categories were selected to describe work situation: acquiring, keeping and terminating a job (d845), Remunerative employment (d850) and even Non-remunerative employment (d855) showing on one hand work as the object in VR and on the other hand, non-paid employment such as volunteer roles.

The ICF considers contextual factors which include environmental factors and personal factors. However, in the current version of the ICF, personal factors is not classified and coded amidst its major role in terms of predicting return-to-work, in allocating resources, or in examining modifiable factors relevant to VR $[37,38]$. Aspects relevant to VR such as job satisfaction, expectation of recovery and return to work, fear of reinjury and social status are likely to be personal factors [39].

The selection of ICF Categories for the comprehensive and brief version of the Core Set for VR could serve as a "tool" that is able to cover all important and relevant aspects of VR possible without losing the practicability of the ICF in clinical or research setting. Another part of the consensus was to ensure that the ICF categories selected would have no huge overlap. For example, the concepts of support (e3) and attitude (e4) from the component Environmental Factors were intensively discussed as both sets of domain have similar theme of factors. For example, Support from people in positions of authority (e330) is assigned a different ICF code versus Attitudes of people in 
positions of authority (e430). To avoid what seems to be a redundancy, discussions have dealt on whether or not a category would better capture to some degree the other category and made the decision based on that. Additional discussion was made around specific ICF categories in the comprehensive version such as b134 Sleep functions and b810 Protective functions of the skin. Sleep or the impairment thereof has been reported to be relevant in the context of work performance and participation [4042]. The experts argued that a great proportion of patients in VR experience lack of energy due to lack of sleep. The other category on Skin functions (b810) was argued for inclusion in the Core Set because patients with skin-related condition (e.g. burn) are also commonly referred to VR [43-45].

The experts decided to stay on the second-level category in order to keep a broader perspective rather than being too specific and possibly loosing information. For example, it might be beneficial to stay at the second-level category of b280 Sensation of pain and not the 3rd-level category 62800 Generalized pain because as such will miss b2801 Pain in body part which would be captured anyway when b280 is selected. The third-level category Drugs (e1101) was an exception because the experts felt that the other domains under $e 110$ (e.g. food) is not a necessary domain in VR.

The 6th World Health Assembly in 2007 stated in their document "Workers' health: global plan of action", "[to] encourage and develop strategies to ensure reintegration of sick and injured workers into the mainstream of society [46]". Given the multifactorial nature of VR, the coordination between players or actors in the workplace, healthcare, vocational retraining programs and workers' compensation system and the individual worker remains to be a challenge [47]. Several authors addressed this challenge by developing work rehabilitation and disability models to depict the return-towork process $[12-14,48]$. Most are specific to a health condition or a setting and an overall agreed framework. However, links to specific needs and requirements is still missing. The ICF could offer one solution in bringing about a standard reference framework and language in VR. In addition, the ICF Core Sets for VR represent functioning domains that are relevant to VR participants and would help bridge the gap in collecting and documenting information and planning appropriate intervention in a comparable way [49-51].

In the development of the ICF Core Set for VR, a few things need to be considered. There is no common definition of VR at the conceptual level while there might be $a$ common understanding of the purpose of VR. Based on the need to agree on a common definition of VR, experts aimed to agree to a conceptual definition post-consensus conference [6]. The Core Set should be applicable to VR regardless of setting or health condition [52]. Admittedly, however, some categories were included in the comprehensive Core Set which are only valid for a particular diagnostic area or intervention. For example, the category $d 430$ Lifting and carrying objects, may be relevant to certain jobs [53] or the category $d 530$ Toileting, may hold a specific importance to health conditions 
such as spinal cord injury [54]. In this sense though, the Core Set has a generic appeal with broad coverage and purpose.

Another issue concerns the sample of experts. As seen in Table 1, most experts were from developed countries. This might, however, reflect the distribution of VR infrastructure in reality based on the fact that VR can be a health service depending on the national social and health systems. This distribution of experts was similar to the pool of experts from the worldwide expert survey which was also conducted as part of the Core Set development [22]. Another limitation is the potential bias regarding patient selection and convenience sampling employed in the study centers in Switzerland and Germany $[23,24]$ but can be addressed with testing and validation studies later.

The comprehensive ICF Core Set for VR was developed integrating the experiences and needs of different professional perspectives. The domains of the Core Set could guide patient-centered goal setting process in multidisciplinary settings, where resources and problems could be identified and profession-specific treatment goals could be identified. To fulfill the requirements of a VR program, the identified categories can then be assigned to specific areas of expertise for evaluation and treatment, and for clinical-decision making $[18,55]$. The categories of the brief ICF Core Set can be used as a minimum set of domains to report in trials or intervention studies. It can also be used in independent clinical practice setting which would help clinicians compare results and weigh the evidence based on the specific health care setting where they practice and the type of patients they treat.

The Core Set is the first step in answering the question "what to measure". Examining the level of impairment or restriction in a category will have to be addressed further in the next step. A challenge is that the current way of quantifying a category may prove to be not sensitive enough to detect clinical changes [56]. Another challenge in the use of the ICF Core Set particularly in the clinical setting is the broad definition provided such as e580 Health services, systems and policies or e590 Labour and employment services, systems and policies. Operationalization of these categories is needed if it were to be used as a practical tool or instrument [57].

In the future, validation studies will be helpful in determining if there are subsets of the Core Set that could be more meaningful given a certain setting and to investigate the Core Set's applicability across a range of health conditions and culture. External validity of the VR Core Sets i.e. whether or not it is applicable to different countries or health care settings, will have to be examined further. The use of Core Sets could also be explored in terms of work performance and work productivity determinants or predictors in the context of VR. It will also be beneficial to involve employers and patient organizations as we advance the ICF Core Set for VR. 


\section{Conclusions}

A formal consensus process integrating evidence and expert opinion contributed to the development of the ICF Core Set for VR. The Core Set reflects the multidisciplinary, multistakeholder, and complex characteristics of VR. This development is a first step towards an internationally accepted and standardized framework when collecting and reporting variables or measures in the field and practice of VR.

\section{Acknowledgements}

We are most grateful for the contributions from the following experts who attended the consensus conference: Alex Burdorf, Tania Buys, Chetwytn Chan, Julie Fritz, Jain Holmes, Debra B. Homa, Stefan Koch, Jan Kool, Terry Krupa, Sven-Uno Marnetoft, Claude Maroun, Dennis Nowak, Rahel Oertli, Soo-Kyung Park, Robin Pickard, Michiel Reneman, Julietta Rodriguez Guzman, Eva Schonstein, Stefan Staubli, Frank Staudenmann, Urban Studer, Yoshiko Suzuki, and Jos Verbeek. Special thanks to collaborating organizations in the International Steering Committee and their representatives: World Health Organization, Classification, Terminology and Standards (WHO CTS), International Labour Organization (ILO), World Confederation for Physical Therapy (WCPT), World Federation of Occupational Therapists (WFOT), and the International Society of Physical and Rehabilitation Medicine (ISPRM). We would also like to thank the moderator Alarcos Cieza, the coordinator of the ICF Research branch Melissa Selb, the working group assistants Nandini Devi, Nicole Emmenegger, Fary Khan, and Felix Gradinger who also helped in the writing of the protocol in the plenary sessions. Special thanks to Jerome Bickenbach, Heinrich Gall, Christian Geyh, Cornelia Oberhauser, Urban Schwegler, Wolfgang Segerer, Katharina Strasky, and Niklas Wiegand for their invaluable support during the conference.

\section{Declaration of interest:}

This project was funded by the Swiss Accident Insurance Company (SUVA) in Switzerland. 


\section{References}

1. Organisation for Economic Co-operation and Development Directorate for Employment, Labour and Social Affairs. Sickness, disability and work: Keeping on track in the economic downturn (background paper). ; May 2009. High-Level Forum, Stockholm, Sweden.

2. Warr P. Psychological aspects of employment and unemployment. Psychol Med 1982;12:7-11.

3. Audhoe SS, Hoving JL, Sluiter JK, Frings-Dresen MH. Vocational interventions for unemployed: Effects on work participation and mental distress. A systematic review. J Occup Rehabil 2010;20:1-13.

4. Verordnung über die Invalidenversicherung (IV), Artikel I (28.September 2007).

5. Kirsh B, Krupa T, Cockburn L, Gewurtz R. A canadian model of work integration for persons with mental illnesses. Disabil Rehabil 2010;32:1833-46.

6. Escorpizo R, Reneman MF, Ekholm J, Fritz J, Krupa T, Marnetoft SU, Maroun CE, Guzman JR, Suzuki Y, Stucki G, Chan CC. A conceptual definition of vocational rehabilitation based on the ICF: Building a shared global model. J Occup Rehabil 2011;21:126-33.

7. Escorpizo R, Ekholm J, Gmuender HP, Cieza A, Kostanjsek N, Stucki G. Developing a core set to describe functioning in vocational rehabilitation using the international classification of functioning, disability, and health (ICF). J Occup Rehabil 2010;20:502-11.

8. Selander J. Unemployed sick-leavers and vocational rehabilitation - a person-level study based on a national social insurance material. [dissertation]. Karolinska Institutet, Department of Rehabilitation Medicine, Stockholm, Sweden; 1999.

9. Brunarski D, Shaw L, Doupe L. Moving toward virtual interdisciplinary teams and a multi-stakeholder approach in community-based return-to-work care. Work 2008;30:329-36.

10. Vocational Rehabilitation Task Group - Industrial Injuries Advisory Council, Waddell G, Burton AK, Kendall NA. Vocational rehabilitation - what works, for whom, and when? 1st ed. London: TSO (The Stationery Office); 2008.

11. Leyshon RT, Shaw LE. Using the ICF as a conceptual framework to guide ergonomic intervention in occupational rehabilitation. Work 2008;31:47-61.

12. Feuerstein M. A multidisciplinary approach to prevention, evaluation, and management of work disability. J Occup Rehabil 1991;1:5-12.

13. Loisel P, Durand P, Abenhaim L, Gosselin L, Simard R, Turcotte J, Esdaile JM. Management of occupational back pain: The sherbrooke model. Results of a pilot and feasibility study. Occup Environ Med 1994;51:597-602.

14. Franche RL, Krause N. Readiness for return to work following injury or illness: Conceptualizing the interpersonal impact of health care, workplace, and insurance factors. J Occup Rehabil 2002;12:233-56.

15. Schultz IZ, Crook J, Meloche GR, Berkowitz J, Milner R, Zuberbier OA, Meloche W. Psychosocial factors predictive of occupational low back disability: Towards development of a return-to-work model. Pain 2004;107:77-85.

16. Stephens B, Gross DP. The influence of a continuum of care model on the rehabilitation of compensation claimants with soft tissue disorders. Spine (Phila Pa 1976) 2007;32:2898-904.

17. Chamberlain MA, Fialka Moser V, Schuldt Ekholm K, O'Connor RJ, Herceg M, Ekholm J. Vocational rehabilitation: An educational review. J Rehabil Med 2009;41:856-69.

18. Tempest S, Mclntyre A. Using the ICF to clarify team roles and demonstrate clinical reasoning in stroke rehabilitation. Disabil Rehabil 2006;28:663-7.

19. World Health Organization. International classification of functioning, disability, and health: ICF. Geneva, Switzerland 2001

20. Cieza A, Ewert T, Üstün B, Chatterji S, Kostanjsek N, Stucki G. Development of ICF core sets for patients with chronic conditions. J Rehabil Med (Suppl) 2004;36:9-11.

21. Escorpizo R, Finger ME, Glassel A, Gradinger F, Luckenkemper M, Cieza A. A systematic review of functioning in vocational rehabilitation using the International Classification of Functioning, Disability and Health. J Occup Rehabil 2011;21:134-46. 
22. Escorpizo R, Finger ME, Glassel A, Cieza A. An international expert survey on functioning in vocational rehabilitation using the International Classification of Functioning, Disability and Health. J Occup Rehabil 2011;21:147-55.

23. Glassel A, Finger ME, Cieza A, Treitler C, Coenen M, Escorpizo R. Vocational rehabilitation from the client's perspective using the International Classification of Functioning, Disability and Health (ICF) as a reference. J Occup Rehabil 2011;21:167-78.

24. Finger ME, Glassel A, Erhart P, Gradinger F, Klipstein A, Rivier G, Schroer M, Wenk C, Gmunder HP, Stucki $G$, Escorpizo R. Identification of relevant ICF categories in vocational rehabilitation: A cross sectional study evaluating the clinical perspective. J Occup Rehabil 2011;21:156-66.

25. Cieza A, Kirchberger I, Biering-Sorensen F, Baumberger M, Charlifue S, Post MW, Campbell R, Kovindha A, Ring $\mathrm{H}$, Sinnott A, Kostanjsek N, Stucki G. ICF core sets for individuals with spinal cord injury in the longterm context. Spinal Cord 2010;48:305-12.

26. ICF Core Sets [Internet]; ICF Research Branch: WHO-FIC Collaboration Centre in Germany. Available from: http://www.icf-research-branch.org/icf-core-sets-projects.html . Accessed 25 June 2011.

27. Kesselring J, Coenen M, Cieza A, Thompson A, Kostanjsek N, Stucki G. Developing the ICF core sets for multiple sclerosis to specify functioning. Mult Scler 2008;14:252-4.

28. Biering-Sorensen F, Scheuringer M, Baumberger M, Charlifue SW, Post MW, Montero F, Kostanjsek N, Stucki G. Developing core sets for persons with spinal cord injuries based on the international classification of functioning, disability and health as a way to specify functioning. Spinal Cord 2006 ;44:541-6.

29. Lipscomb HJ, Loomis D, McDonald MA, Argue RA, Wing S. A conceptual model of work and health disparities in the united states. Int J Health Serv 2006;36:25-50.

30. Gartrell A. 'A frog in a well': The exclusion of disabled people from work in Cambodia. Disabil Soc 2010;25:289-301.

31. Opini BM. A review of the participation of disabled persons in the labour fource: The Kenyan context. Disabil Soc 2010;25:271-87.

32. Stubbs J, Deaner G. When considering vocational rehabilitation: Describing and comparing the Swedish and American systems and professions. Work 2005;24:239-49.

33. Sandqvist JL, Henriksson CM. Work functioning: A conceptual framework. Work 2004;23:147-57.

34. Young AE. Return to work following disabling occupational injury - facilitators of employment continuation. Scand J Work Environ Health 2010;36:473-83.

35. Brouwer S, Reneman MF, Bultmann U, van der Klink JJ, Groothoff JW. A prospective study of return to work across health conditions: Perceived work attitude, self-efficacy and perceived social support. J Occup Rehabil 2010;20:104-12.

36. International Classification of Diseases (ICD-10) [Internet] Geneva.: World Health Organization. Available from: http://www.who.int/classifications/icd/en/. Accessed 12 June 2011.

37. Oyeflaten I, Hysing M, Eriksen HR. Prognostic factors associated with return to work following multidisciplinary vocational rehabilitation. J Rehabil Med 2008;40:548-54.

38. Mannion AF, Junge A, Taimela S, Muntener M, Lorenzo K, Dvorak J. Active therapy for chronic low back pain: Part 3. factors influencing self-rated disability and its change following therapy. Spine 2001;26:9209.

39. Lydell M, Marklund B, Baigi A, Mattsson B, Mansson J. Return or no return - psychosocial factors related to sick leave in persons with musculoskeletal disorders: A prospective cohort study. Disabil Rehabil 2010;33:1262-71.

40. Bolge SC, Joish VN, Balkrishnan R, Kannan H, Drake CL. Burden of chronic sleep maintenance insomnia characterized by nighttime awakenings among anxiety and depression sufferers: Results of a national survey. Prim Care Companion J Clin Psychiatry 2010;12:PCC.09m00824.

41. Dorrian J, Baulk SD, Dawson D. Work hours, workload, sleep and fatigue in Australian rail industry employees. Appl Ergon 2010;42:202-9.

42. Slesina W, Rennert D, Patzelt C. Prediction models on return to work of rehabilitants following vocational training programme participation. Rehabilitation (Stuttg) 2010;49:237-47. 
43. Dyster-Aas J, Kildal M, Willebrand M. Return to work and health-related quality of life after burn injury. J Rehabil Med 2007;39:49-55.

44. Oster C, Kildal M, Ekselius L. Return to work after burn injury: Burn-injured individuals' perception of barriers and facilitators. J Burn Care Res 2010;31:540-50.

45. Quinn T, Wasiak J, Cleland H. An examination of factors that affect return to work following burns: A systematic review of the literature. Burns;36:1021-6.

46. World Health Organization. Workers' health: Global plan of action. 2007; Report nr 60th World Assembly. WHA60.26.

47. MacEachen E, Kosny A, Ferrier S, Chambers L. The "toxic dose" of system problems: Why some injured workers don't return to work as expected. J Occup Rehabil 2010;20:349-66.

48. Loisel P, Durand P, Abenhaim L, Gosselin L, Simard R, Turcotte J, Esdaile JM. Management of occupational back pain: The sherbrooke model. results of a pilot and feasibility study. Occup Environ Med 1994;51:597-602.

49. Schultz IZ, Stowell AW, Feuerstein M, Gatchel RJ. Models of return to work for musculoskeletal disorders. J Occup Rehabil 2007;17:327-52.

50. Escorpizo R, Davis K, Stumbo T. Mapping of a standard documentation template to the ICF core sets for arthritis and low back pain. Physiother Res Int 2010;15:222-31.

51. Rauch A, Cieza A, Stucki G. How to apply the international classification of functioning, disability and health (ICF) for rehabilitation management in clinical practice. Eur J Phys Rehabil Med 2008;44:329-42.

52. Escorpizo R, Stucki G, Cieza A, Davis K, Stumbo T, Riddle DL. Creating an interface between the international classification of functioning, disability and health and physical therapist practice. Phys Ther 2010; 90:1053-63.

53. McIntyre A, Tempest S. Two steps forward, one step back? A commentary on the disease-specific core sets of the International Classification of Functioning, Disability and Health (ICF). Disabil Rehabil 2007;29:1475-9.

54. Frings-Dresen MH, Sluiter JK. Development of a job-specific FCE protocol: The work demands of hospital nurses as an example. J Occup Rehabil 2003;13:233-48.

55. Lidal IB, Huynh TK, Biering-Sorensen F. Return to work following spinal cord injury: A review. Disabil Rehabil 2007;29:1341-75.

56. Atkinson HL, Nixon-Cave K. A tool for clinical reasoning and reflection using the international classification of functioning, disability and health (ICF) framework and patient management model. Phys Ther 2011;91:416-30.

57. Okawa Y, Ueda S, Shuto K, Mizoguchi T. Development of criteria for the qualifiers of activity and participation in the International Classification of Functioning, Disability and Health based on the accumulated data of population surveys. Int J Rehabil Res 2008;31:97-103.

58. Cieza A, Hilfiker R, Boonen A, Chatterji S, Kostanjsek N, Ustun BT, Stucki G. Items from patient-oriented instruments can be integrated into interval scales to operationalize categories of the international classification of functioning, disability and health. J Clin Epidemiol 2009; 62:912-21. 



\section{Chapter 5}

\section{Work Rehabilitation Questionnaire (WORQ): Development and Preliminary}

Psychometric Evidence of an ICF-Based Questionnaire for Vocational Rehabilitation

Article published in J Occup Rehabil DOI 10.1007/s10926-013-9485-2. 27.Nov.2013 [Epub ahead of print].

Monika E. Finger Reuben Escorpizo Cristina Bostan Robert A. De Bie 


\section{Abstract}

Purpose: The International Classification of Functioning, Disability and Health (ICF) has proven to be a valuable framework for vocational rehabilitation (VR). No reliable and valid ICF-based instruments to capture work functioning is known, hence, the aims of this study were: (1) to outline the process for developing an ICF-based questionnaire, the Work Rehabilitation Questionnaire (WORQ) to assess functioning in VR and (2) to report preliminary psychometric evidence.

Methods: ICF categories were selected from the ICF Core Sets for VR using explorative Rasch-analysis and VR literature review. Questions were worded to assess identified ICF categories. WORQ was translated from English to German. Psychometrics for the German version of WORQ was examined in one VR center in Switzerland.

Results: 44 ICF categories were selected which resulted in 36 questions related to functioning. The psychometric evaluation of WORQ showed high test-retest reliability (Spearman correlation 0.79) $(n=53)$ and good internal consistency (Cronbach's Alpha 0.88) ( $n=74$ ) WORQ showed moderate correlation with Beck Depression Inventory II (Spearman correlation 0.511) and low correlation (Spearman correlation -0.353) with SF-36.

Conclusions: WORQ appears to be a reliable, ICF-based questionnaire to evaluate functioning in VR, easy to administer by health or vocational professionals. The additional information gained when using WORQ would contribute to improving interdisciplinary understanding of the patient's situation and therefore support the integrative planning of the return-to-work process or engagement in gainful employment. However, further studies are needed to further examine its use in clinical practice and research, when validated in other patient populations and settings.

Keywords: Vocational rehabilitation, Return-to-work, WORQ, ICF, Classification, Psychometrics 


\section{Introduction}

The main goal of vocational rehabilitation (VR), is to enable workers, to keep their jobs or to return to gainful employment after an accident, injury or onset of an unfavorable health condition [1]. VR, including return-to-work strategies, is an important element in disability management as stated in the International Labour Organization's code of practice on managing disability in the workplace [2]. For most individuals employment ensures adequate economic resources for covering financial needs and full participation in the society. In addition, it provides the basis for the individual's social status, social role and is often crucial to self-confidence and identity [3]. In contrary, being unemployed often leads to the inability to meet financial obligations, causing a negative impact on organizing daily activities and social participation. Depressive symptoms and anxiety, along with adopting unhealthy lifestyle, problems in family- and socialrelationships, and increase in suicide rate may be associated with being off work $[4,5]$.

A comprehensive bio-psychosocial framework to truly understand the complex and non-linear relationship between work, health, and health-related states could be of great benefit. As shown in previous studies, the International Classification of Functioning, Disability and Health (ICF), from the World Health Organization (WHO) is a model that we can use to disentangle the issues that confront the work-health relationship by providing a common framework for describing functioning domains (body functions and body structures, activities and participation) and contextual factors (e.g. environmental factors) $[6,7]$. In VR, the ICF could support interdisciplinary communication between health professionals and facilitate dialogue with service payers and employers.

ICF Core Sets are lists of ICF categories that describe the most relevant aspects of functioning in a disease or a specific setting [8]. The ICF Core Set for VR was developed in 2010 and consists of 90 and 13 ICF categories for its comprehensive and brief version, respectively [9]. The brief Core Set for VR represents a subset of categories of the comprehensive ICF Core Set for VR that contains the essential categories that should be assessed in VR. One challenge with ICF Core Sets is the lack of guideline or measurement instrument by which the ICF categories can be assessed resulting in non-uniform implementation of the ICF, making comparison across VR settings and interdisciplinary communication difficult.

Amidst the complexity and multifactorial aspects of VR, an instrument based on the biopsychosocial model of the ICF would be helpful in the implementation of the ICF in VR. After reviewing the instruments currently used in VR none was found that was designed to capture functioning domains relevant in VR given the diverse health conditions and return-to-work settings.

To address the need for an instrument to measure work functioning in individuals participating in VR while satisfying utility in various settings, a generic instrument called "Work Rehabilitation Questionnaire" (WORQ) was developed. WORQ is based on the ICF Core Set for VR which can be administered by health or work professionals and case 
managers. The objectives of this paper are: (1) to outline the process of developing an ICF-based questionnaire (WORQ) to assess functioning in VR; and (2) to report preliminary psychometric evidence.

\section{Methods}

The development of the first version of WORQ consisted of two parts with different phases in each part of the development (see Table 1).The questionnaire was first developed in English.

Table 1: Development process of the first version of WORQ

PART I: Development of WORQ

Phase 1: Selecting ICF categories for WORQ

1. Starting point: brief ICF Core Set for VR

2. Categories added by statistical (Rasch) analysis

3. Categories added by clinical considerations

Phase 2: Phrasing questions for the selected ICF categories

Phase 3: Cross cultural adaptation of WORQ from English to German

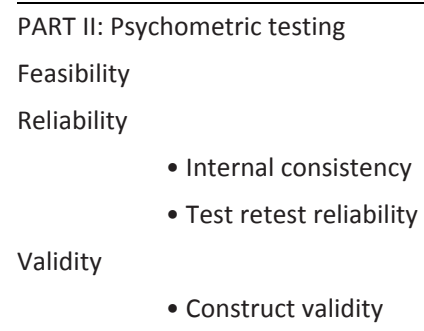

\section{Part I: Development of the Questionnaire}

\section{First Phase}

This phase includes the identification of ICF categories that are to be represented in WORQ and started with the 13 categories from the brief ICF Core Set for VR. Additional ICF categories under Body Functions and Activities and Participation, from the comprehensive ICF Core Set for VR were included using a pre-defined selection process through an explorative Rasch analysis using RUMM 2030 [10] on the whole comprehensive ICF Core Set for VR, with data from 152 participants from a previous study [11]. Based on the Rasch model, analyzing data gives a range of details for checking whether or not tested variables are measuring the same construct, e.g. functioning in the context of work. This is referred to as the item fit between the data and the model. Anoth- 
er condition of the Rasch model is local dependency in which items in a test should not be related to each other. The cut off for the model fit was set at 0.05 Bonferroni and the cut off for the local dependency at $0.3[12,13]$. Categories from the comprehensive version of the Core Set that fit the Rasch model and showed no local dependency with other categories were considered as additional categories. If categories from activities and participation showed local dependency with a category from Body Functions, the Activities and Participation category was selected and added as a category. This decision of choosing Activities and Participation over Body Functions categories is based on a consensus of experts' study which gave higher weight to Activities and Participation within the context of work disability [9]. If two categories showed local dependency, item fit showed no preference for one category and a meaningful clinical decision based on evidence from the literature could not be made, both categories were added for further testing. Additional categories that did not fit the model were also selected for further testing, if they were judged to be important to evaluate work functioning in VR based on the literature or were part of the generic set. The generic set is a statistically developed list of seven ICF categories that depicts the core of functioning of persons with any health condition and in any setting [14].

\section{Second Phase}

The WORQ was intended to be patient-reported in two forms: intervieweradministered and self-reported. WORQ as presented in this study is the former. Therefore, the questions have to be easy to understand for the interviewer and patient alike and to be applicable in any setting of VR. In its first section the WORQ contains 17 questions to the individuals work background and sociodemographics, including questions to evaluate the three environmental factors identified by the brief ICF Core Set for VR. For the main section of the WORQ, evaluating the work functioning of individuals in VR, a stem question was developed: "Overall in the past week, to what extent did you have problems with ...". A recall period of 1 week was chosen to ensure that the patient was able to experience the intended construct to be assessed by the questionnaire but keeping the ability to measure change in a rehabilitation program lasting on average 46 weeks [15].

The phrasing and wording of questions corresponding to the ICF categories were done using multiple sources: the WHO Disability Assessment Schedule 2.0 (WHODAS 2.0) [16] and the World Health Survey (WHS) [17]. If no appropriate question from those questionnaires was found that adequately capture the intended concept, the developers consulted the ICF handbook for the technical definition of the ICF category [6]. Questions from measurement instruments identified in a systematic review [18], which have been linked to the ICF were also considered.

For the response options to each question, a visual-analogue scale from 0 to 100 (VAS-100) was established with anchor points of 0 (no problem) and 100 (complete problem) [19]. 
After the wording of the items was completed, the items were cognitively tested among expert clinicians and non-clinicians. Understandability of questions was addressed by asking "Did you have any difficulties understanding these questions? If YES please write down which question/s." For suitability of response options the question was: "Did the response options make sense to you? Please comment", and for feasibility and appropriateness of length of the entire questionnaire, the participants were asked to choose one of the following options: "too long", "a little long" "a good length", "a little short", and "too short".

\section{Third Phase}

This phase included cross-cultural adaptation. The first English version of the WORQ was translated to German as the initial psychometric testing was to be performed in a German-speaking VR center in Switzerland. To ensure quality, the cross-cultural adaptation was performed according to the recommendations of Beaton [20]. Two bilingual translators with German as their native language conducted a forward-translation from English language to German language; the two worked independently of each other. The first translator was aware of the WORQ concept being measured and has a background in physiotherapy. The second was not aware of the WORQ concept and has a background in psychology and communications. The translated versions were compared and analyzed until there was a consensus regarding the final translation. During the process, a third bilingual person who was aware of the WORQ concept, but was not involved in the development of WORQ was involved. Three German-speaking nonclinicians tested the German version and based on their input, a first German version of WORQ was developed. This first version was back-translated to English independently by two bilingual translators. The first translator was a native English speaker who was aware of the concept of the WORQ. The second translator was a German native speaker who was a certified English translator; she was not aware of the concept of the WORQ. Both people who did the back-translation did not participate in the previous development phases. The results of the back translation were evaluated and discussed in a group consisting of the four translators, one developer of the questionnaire and a research psychologist who is experienced in the translation of measurement instruments. Discrepancies in the wording of the WORQ were identified, discussed and resolved in a group consensus.

\section{Part II: Psychometric Testing}

The psychometric testing was performed on the German version of WORQ. The study was conducted in a German speaking VR center in Switzerland. Data collection took place from November 2011 to August 2012. A convenience sample of patients between 18 and 65 years old participating in a VR intervention program was recruited. The patients had to be proficient in German (both oral and written) to be able to fill a patient 
case report form (CRF-P) and to take part in an interview conducted by a health- or work professional. The patient had to sign an informed consent form. The study was approved by the responsible Ethics Commission and was conducted in compliance with the Declaration of Helsinki.

First, the professional responsible handed the CRF-P to the patients. The professionals were four occupational therapists, three vocational counselors and two work reintegration specialists. After the patients completed the CRFP, the responsible professional administered the WORQ in an interview format; professionals conducted 5-9 interviews each. Within 14 days, WORQ was administered the second time to evaluate test-retest reliability. To examine test-retest reliability, a score was calculated for each participant by summing the scores from the 36 equally weighted questions of the main section of the WORQ (body function and activities and participation) divided by the total number of questions. The second interview was conducted by another health professional, a physiotherapist, who was not aware of the results from the first interview. Test for feasibility and interpretability of administering WORQ was also conducted. Both the professionals and patients who participated in the study answered 4 questions about comprehensiveness, understandability of questions, the response option and the length of the WORQ. Health and work professionals were also asked to value the information obtained from using the WORQ. Using a think-aloud methodology (cognitive interview) [21], patients were asked to think about their ratings and to formulate in words, what the rating meant to them.

\section{Instruments}

The WORQ consists of two sections. Section one contains 17 sociodemographic and work-related items, while section two contains 36 questions to evaluate functioning related to work. The CRF-P contained sociodemographics and work-specific information, information concerning their health, functioning, and pain and other questionnaires: EuroQol- 5D-single index (EQ-5D) [22], the Medical Outcome Study Short Form 36 (SF-36) [23], Beck's Depression Inventory_ II (BDI_ II) [24], and the World Health Organization Quality of Life Questionnaires (WHOQoL) [25]. The EQ-5D, is a standardized measure of health status developed by the EuroQol Group in order to provide a simple, generic measure of health for clinical and economic appraisal. Applicable to a wide range of health conditions and treatments, it provides a simple descriptive profile and a single index value for health status that can be used in the clinical and economic evaluation of health care as well as in population health surveys [22]. The SF-36 is the most widely-used general health-status instrument in VR and is suitable for subjects aged 14 years and older [23]. BDI_-II is one of the most widely used instruments for detecting depression. The BDI_-II consists of 21 items to assess the severity of depression in clinical and normal patients. Each item is a list of four statements arranged in increasing severity about a particular symptom of depression [24]. WHOQoL has been 
developed to measure quality of life in a variety of cultural settings and therefore allows comparison of results from different populations and countries [25].

\section{Statistical Analysis}

Descriptive statistics was performed to describe the sample. Test-retest reliability was calculated using Spearman or Pearson correlation depending on the distribution of the data. Correlations measure the strength and direction of the relationship between two variables. Values for the coefficient $r$ can range from 0 (no correlation) to -1 or 1 (perfect negative or perfect positive correlation); a value above 0.7 is considered highly positive [26]. Normality was tested based on histogram analysis and KolmogorovSmirnov and Shapiro-Wilk test [27]. Internal consistency of the WORQ was examined using Cronbach's alpha, which is a general coefficient of homogeneity between items. Values for the coefficient a can range from 0 (no internal consistency) to 1 (perfect internal consistency), where a value above 0.8 is considered acceptable [28].

Face and content validity was examined in interviews with patients and interviewers by asking them to comment on the comprehensiveness of the WORQ-specific and in relation to VR. In order to analyze criterion-related validity, the association between the WORQ score and EQ-5D, SF-36, BDI_II and WHOQoL scores was calculated using Spearman correlation due to the non-normal distribution of the data. The data was analyzed using SPSS Inc. PASW Statistics for Windows [29]. The level of significance was set at alpha level of 0.05. Imputation for missing data for Cronbach's Alpha was done with RStudio [30].

\section{Results}

\section{Part I: Development of the Instrument}

\section{First Phase}

A total of 44 ICF categories (15 categories from Body Functions, 25 categories from Activities and Participation and 4 categories from Environmental Factors) were included for operationalization i.e. phrasing, in a three stage process (see Table 2). Table 3 presents the items of WORQ, the ICF category measured, the mechanism by which it was included, and how the item was phrased. Two ICF categories were added based on evidence from the literature and were also operationalized: b730 Muscle power functions and $d 430$ Lifting and carrying objects [31]. 
Table 2: Process of adding ICF categories from the comprehensive ICF Core Set VR to the brief ICF Core Set for WORQ

Phase 1:

Selecting ICF categories for WORQ

Total: 44 ICF categories

1. Starting point:

Brief ICF Core Set for Vocational Rehabilitation

13 ICF categories from:

6 Activities and Participation

4 Environmental Factors

3 Body Functions

2. Categories added by statistical (Rasch)analysis

28 ICF categories from:

17 Activities and Participation

11 Body Functions

3. Categories added by clinical considerations

3 ICF categories from:

2 Activities and Participation

1 Body Functions 


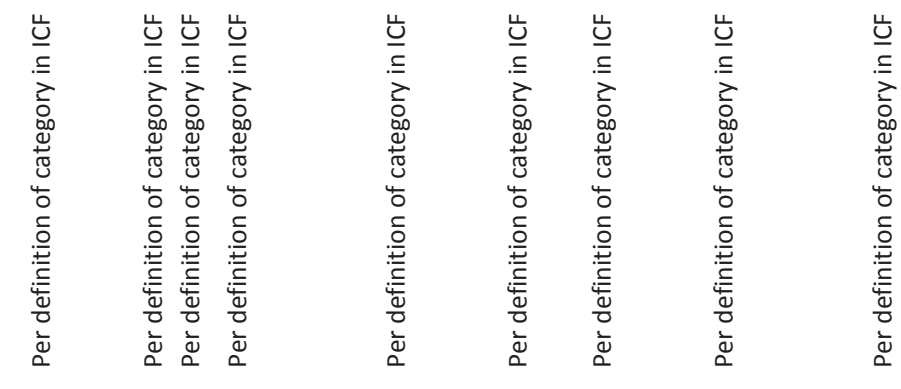

훙

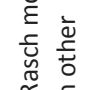

索

节

ํㅡㄹ

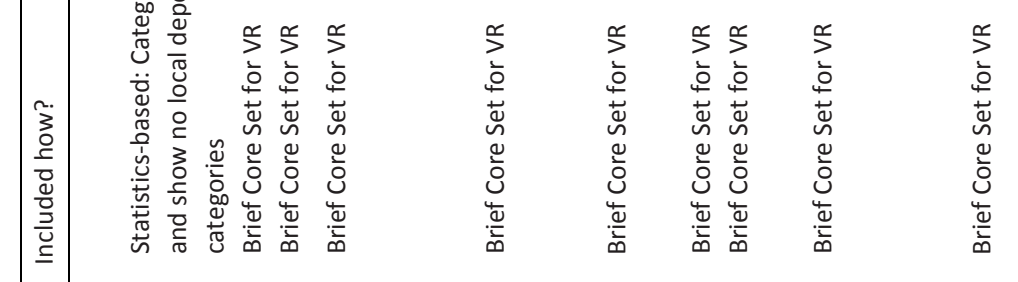

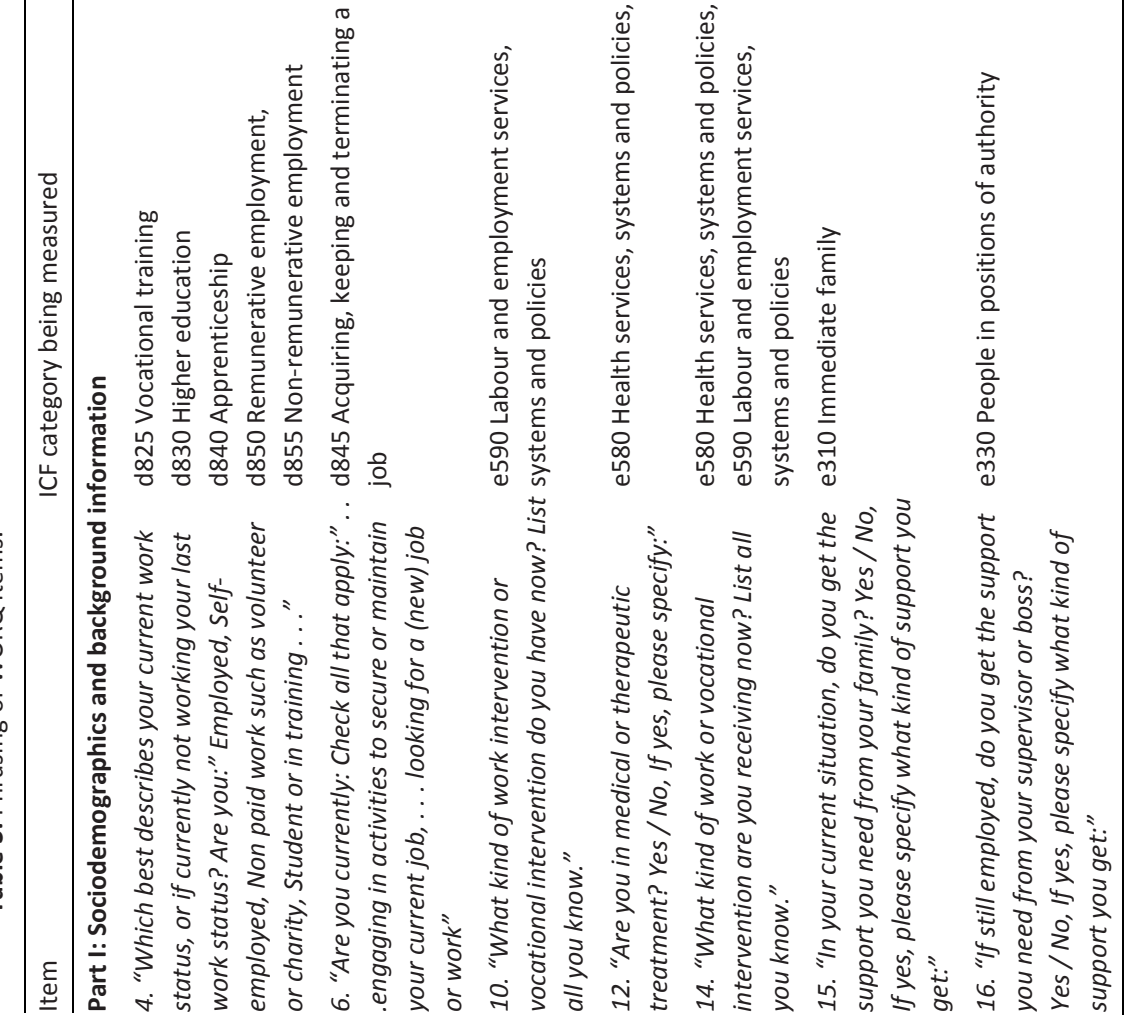




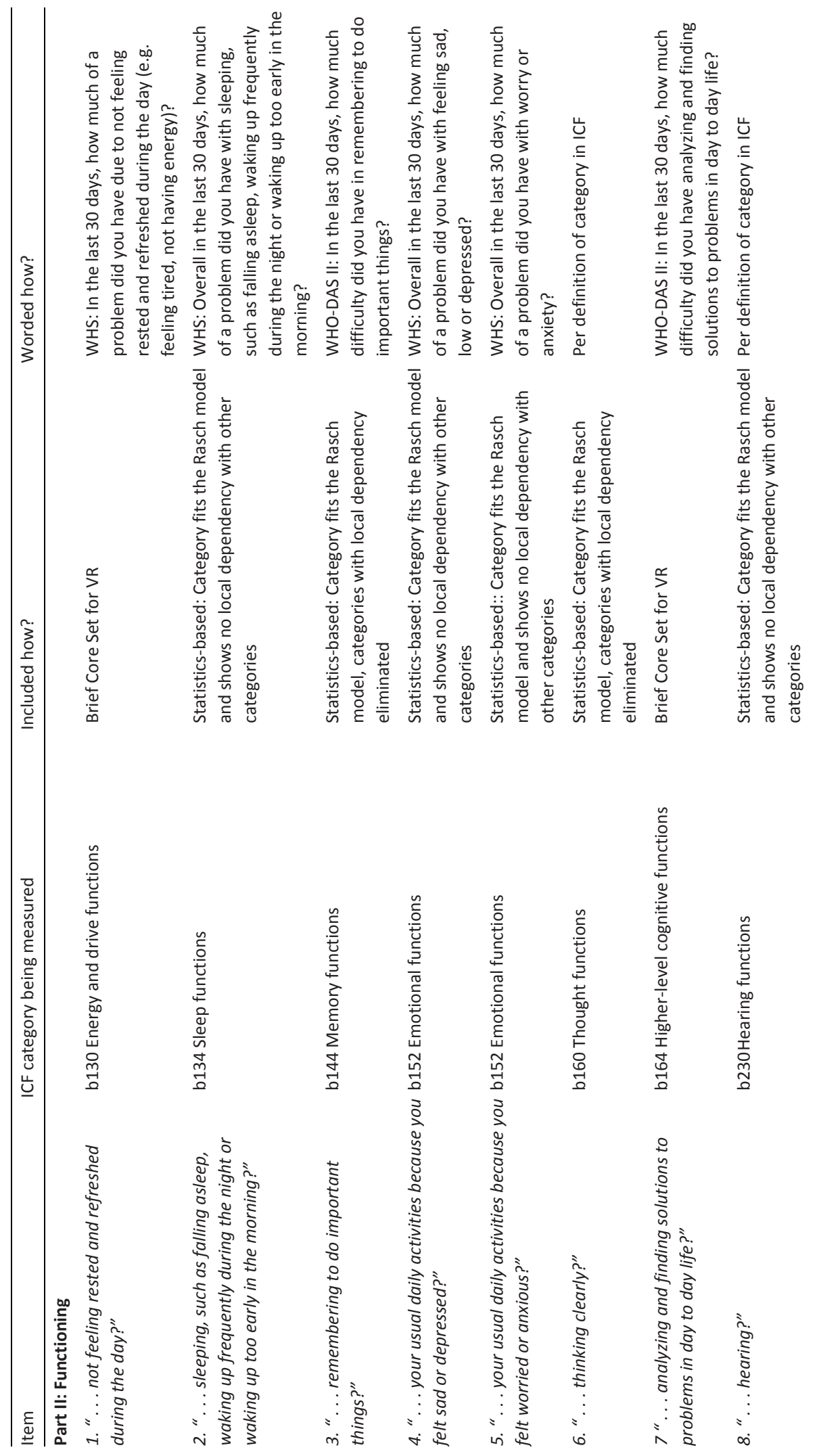




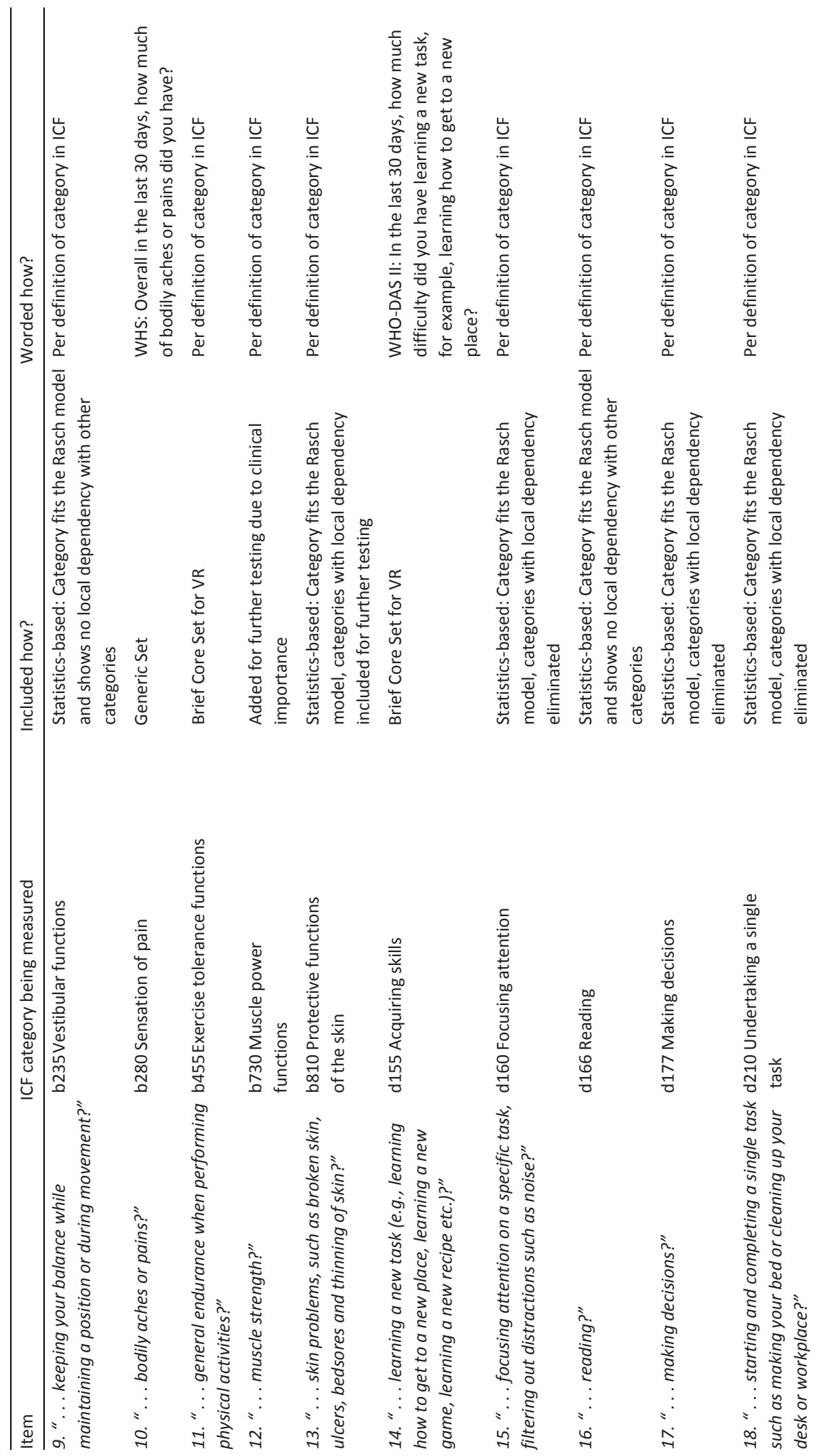




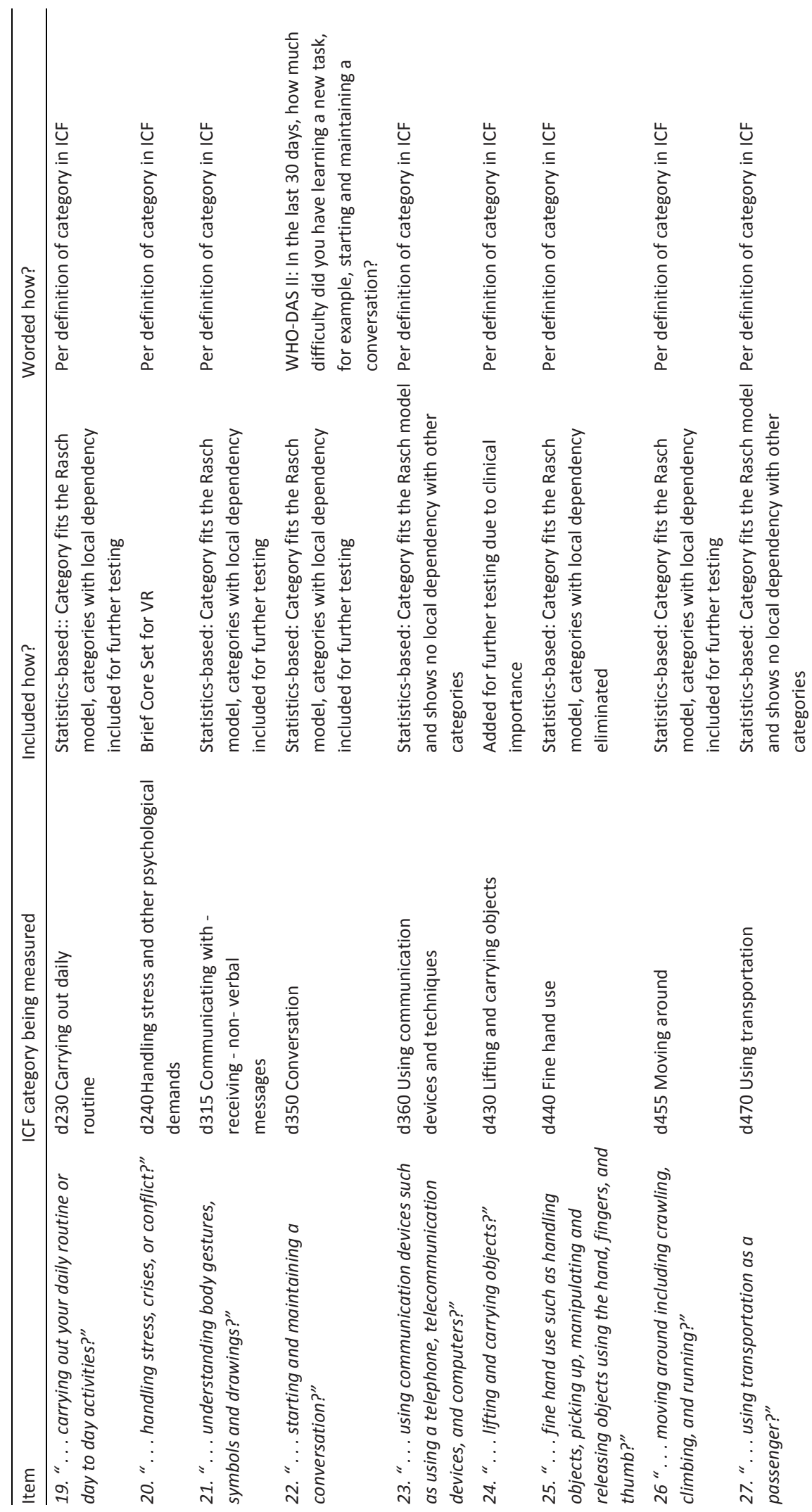




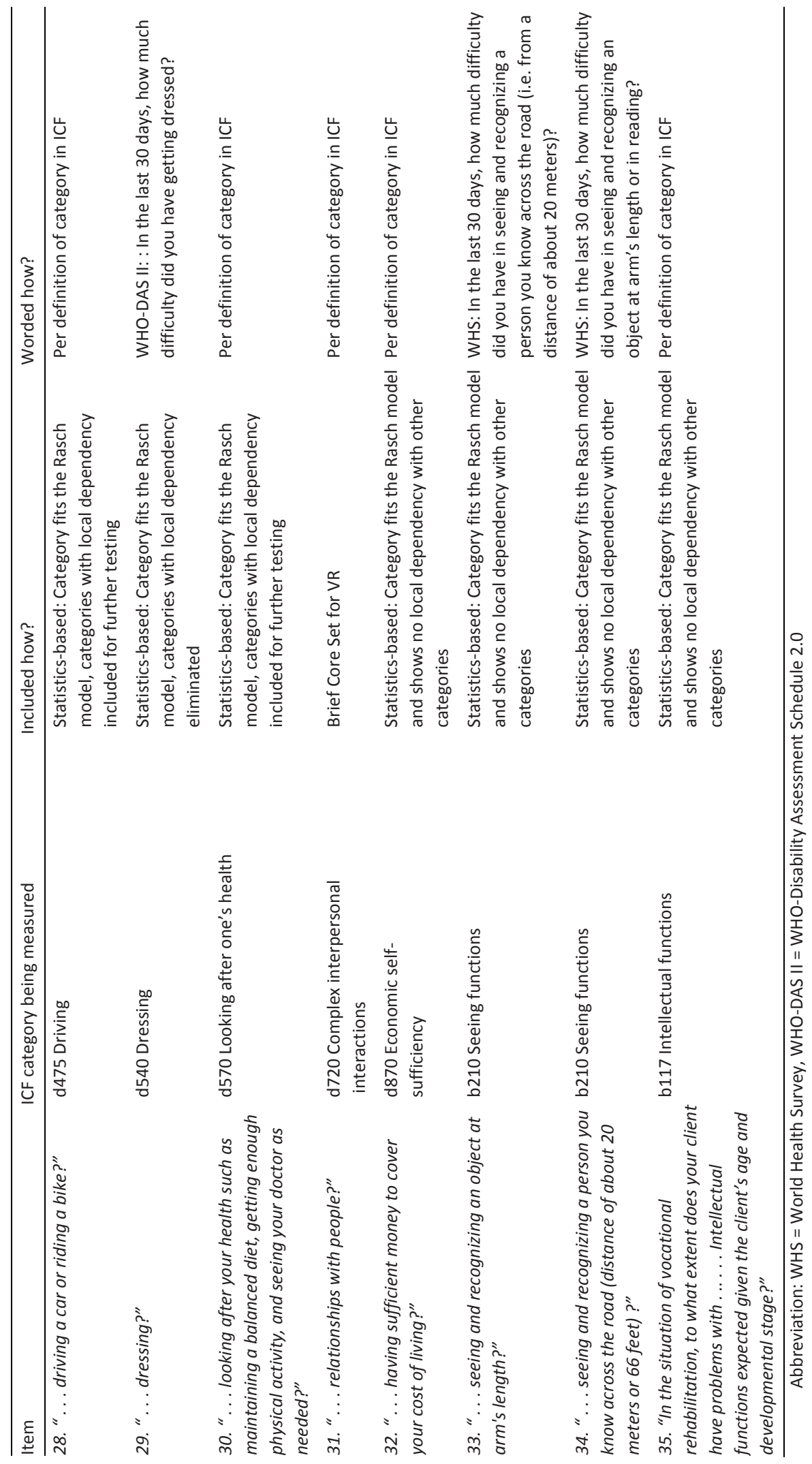




\section{Second Phase}

WORQ questionnaire was divided into two sections. Section one contains 17 sociodemographic and work-related questions regarding the four environmental categories from the brief ICF Core Set namely e310 Immediate family, e330 People in positions of authority, e580 Health services, systems and policies and e590 Labour and employment services, systems and policies were included in this part. The six categories from activities and participation that describe vocational education or work situations namely d825 Vocational training, d830 Higher education, d840 Apprenticeship (work preparation), d845 Acquiring, keeping and terminating a job, d850 Remunerative employment, and $d 855$ Non-remunerative employment were also included in section one.

In the main section of WORQ, 36 questions were phrased representing 34 categories. Two questions ( 35 and 36) of the WORQ, which evaluate the ICF categories b117 Intellectual functions and b126 Temperament and personality functions, respectively, were instead to be rated by the interviewer due to the challenge in rating them as patient-reported.

WORQ was cognitively tested by three health professionals and two non-clinicians, addressing understandability of questions, suitability of response options and appropriateness of length. Based on their responses, changes were made in the introduction of the second section of WORQ from " . . I w would like you to think about the last week, taking both good and bad days into account" to " . . I would like you to think about the past week, considering both your good and bad days". Modifications of the wording for questions 4, 5 and 9 were also made. In question 4, " . . how much problems did you have feeling sad or depressed" was modified to " . . how much problems did you have with your usual daily activities because you felt sad or depressed". In question 5 , ". . . how much problems did you have with feeling worried or anxious" was modified to " . . how much problems did you have with your usual daily activities because you felt worried or anxious". In question 9, " . . how much problems did you have with your balance" was modified to " . . how much problems did you have with keeping your balance while maintaining a position or during movement". Length and response options were assessed to be adequate and good.

\section{Third Phase}

WORQ, developed in English, was translated to German and a first version of the questionnaire in both German and English was obtained.

\section{Part II: Psychometric Testing}

Description of the Sample: A total of 74 subjects took part in the first interview, 52 subjects in the second, where the second interviews were performed 14.33 days (SD \pm 1.57) after the first (see Table 4). In this second interview questions 35 and 36 on intellectual functions and temperament functions, respectively were not administered since 
the interviewer reported lack of comfort in rating the patient's problems in those aspects only after their first encounter. Hence, only 34 items were used for test-retest calculation of the main section of WORQ that evaluates work functioning. Spearman correlation for test-retest values of WORQ scores was made because the data was not normally distributed. The test-retest agreement was 0.789 . The internal consistency of WORQ ( $n=74$ ) showed a Cronbach's alpha of 0.883 for the full 36 items and a Cronbach's alpha of 0.887 when item 35 and 36 were deleted.

Time needed to administer the first WORQ interview was $25.57 \mathrm{~min}$ (SD \pm 11.55 ). The nine professionals and 25 patients were asked to comment on the usability of WORQ. Understandability of the wording was rated as "no difficulty" by 8 out of 9 ( 89 $\%)$ professionals and 23 out of 25 (92\%) patients, two patients argued the questions were at times too generic e.g. concerning having problems with strength or lifting ability. One work reintegration specialist argued that having to repeat the stem question of "Overall in the past week, to what extent did you have problems with . . . . ." when reading out the questions to the patient was laborious and cumbersome. The response option of the VAS was rated as "good" by 6 professionals (67 \%) and 21 (84 \%) patients. The length of the questionnaire and the time needed to administer was rated as "good" by all patients but being too long by two vocational counselors and one work reintegration specialist (33\%). Three professionals (33\%) found it difficult and challenging how to rate the patient's problem with questions 35 and 36.

Table 4: Characteristics of respondents

\begin{tabular}{lll}
\hline Characteristics & $\begin{array}{l}\text { first interview } \\
\mathrm{n}=74(\%)\end{array}$ & $\begin{array}{l}\text { second interview } \\
\mathrm{n}=52\end{array}$ \\
\hline Age, mean (SD), years & $37.68(12.7 \mathrm{SD})$ & $36.75(12.4 \mathrm{SD})$ \\
Male & $62(83.8)$ & $45(86.5)$ \\
More than high school education & $43(58.1)$ & $32(61.5)$ \\
Work experience, median (IQR), years & $16.0(5-28)$ & $17.0(5-27)$ \\
Married & $28(37.8)$ & $19(36.5)$ \\
VR type & & \\
$\quad$ Work-related physical training/intervention & $46(62.2)$ & $33(63.5)$ \\
$\quad$ Work-related cognitive training/intervention & $54(73.0)$ & $38(73.1)$ \\
Return to work to the same employer & $29(39.2)$ & $19(36.5)$ \\
Looking for/change to a new profession & $16(21.6)$ & \\
Type of disorders & & $24(46.2)$ \\
$\quad$ Neurological & $34(45.9)$ & $24(46.2)$ \\
$\quad$ Musculoskeletal & $33(44.6)$ & $4(7.7)$ \\
Internal/psychiatric & $9(9.5)$ & $11(21.2)$ \\
Number of comorbidities (SCQ) & & $18(34.6)$ \\
0 comorbidity & $16(21.6)$ & $23(44.2)$ \\
1 comorbidity & $26(35.1)$ & $8(4.0-21.25)$ \\
$\geq 2$ comorbidities & $32(43.2)$ & $10.0(4.0-22.25)$ \\
Duration of sickness absence, median (IQR), month & &
\end{tabular}


Looking at face validity, professionals rated WORQ to be comprehensive concerning functioning in VR but WORQ seemed to miss additional contextual factors such as work place descriptions or personal factors such as coping strategies. Patients in general appreciated the breadth of coverage of WORQ (face validity), as they felt that the questionnaire allowed them to reflect upon their daily problems in functioning that hinder them to successfully return to work. Through WORQ, the patients felt as it seemed that they were able to express and convey their physical problems as well as their psychosocial issues and needs. Three patients (12\%) mentioned that they missed an item related to "walking", although question 26 asks for " . . . to what extent did you have problems with moving around including crawling, climbing, and running?".

Spearman correlation was used to assess construct validity for WORQ score, compared to EuroQol-single index, BDI_II, SF-36 and WHOQoL BREF (Table 5).

\begin{tabular}{ll} 
Table 5: Construct validity of WORQ $(\mathrm{n}=74)$ \\
\hline Standard Questionnaires & WORQ Sum Score \\
& $\mathrm{N}=74$ \\
\hline EuroQoL (VAS current health) & $-.419^{* *}$ \\
Becks Depression Inventory II & $.511^{* *}$ \\
SF-36 & $-.353^{* *}$ \\
General Health & .164 \\
Physical Functioning & -.215 \\
Physical Role & $-.298^{* *}$ \\
Emotional Role & $-.513^{* *}$ \\
Social Functioning & .115 \\
Pain & $.294^{*}$ \\
Vitality & .049 \\
Mental Functioning & $-.358^{* *}$ \\
Anticipated Health in one year & .151 \\
WHOQoL 5 item & $-.439^{* *}$
\end{tabular}

With a moderate Spearman correlation coefficient of (0.511), BDI_ II showed the strongest association with WORQ. The SF-36 showed the lowest association of -0.353 with WORQ, with the SF-36 subscale "Emotional role" showing a moderate negative association with a coefficient of -0.513 at best and the vitality subscale and social functioning showing no association at all (Table 5).

Content validity for the context of VR is assumed due to the fact that the items in the questionnaire were derived from the ICF Core Set for VR. The Core Set was rigorously developed using input from patients, clinicians, experts, and the literature to assess and describe the relevant factors concerning functioning in VR independent of the health condition or VR setting. 


\section{Discussion}

Based on the ICF Core Sets for VR, an interviewer-administered questionnaire, the WORQ, was developed to assess functioning in VR and to guide the VR and return-towork process. WORQ was developed using mixed methodology including sophisticated statistical approach and qualitative content assessment. Initial psychometric evidence for the German version of WORQ on reliability, validity, and feasibility and interpretability using our sample has been demonstrated and reported in this seminal paper.

Vocational rehabilitation is a complex and multi-faceted and multi-stakeholder process and as such will need a framework that is integrative, comprehensive, and biopsychosocial like the ICF. We have not found a measurement instrument that captures functioning per ICF in a VR setting, hence, we felt that we can address this gap by developing a new instrument called the WORQ. We used the ICF Core Set for VR as a basis for the development of the questionnaire. The questionnaire would address the challenge of clinician users either being unable to operationalize the ICF in VR or having no standard way of operationalization resulting in lack of comparability across programs. The WORQ would allow assessing functioning of individuals in VR independent of health condition, throughout the whole continuum of the return-to-work process in a straightforward way using simple questions and a well-tested rating scale, a visual analogue scale from 0 to 100 .

The attempt to develop ICF Core Set based instruments was first made in the Inflammatory Bowel Disease Index [32] in which the 19 categories of the brief ICF Core Set for Inflammatory Bowel Diseases were transformed to questions to evaluate disability. A 5-point numeric rating scale was chosen to evaluate disability in this chronic condition. A health index in patients with ankylosing spondylitis [33] is currently developed in which an item pool covering the categories of the ICF Core Set was generated. Items were internationally tested and final items were selected in several following steps using expert opinion and statistical testing (Rasch analysis). Similar with the WORQ, in both attempts the respective ICF Core Set was used as a starting point, providing external validity. In contrast to the indexes of inflammatory bowel disease and ankylosing spondylitis, WORQ reflects a health situation with not only one but also a variety of health conditions, and because of this, the developers of WORQ felt that the categories of the brief ICF Core Set for VR alone could not contain enough information to evaluate functioning in a clinically meaningful way in VR. Therefore, we started with the brief ICF Core Set VR but then complemented the questionnaire with additional categories from the comprehensive ICF Core Set VR in a multi-step process.

Although, Cronbach's Alpha of WORQ showed with 0.883 a good scale reliability, partially due to the 36 scale items included, not all items showed sufficient good average correlation between items, e.g. one item, question 32 " . . having sufficient money to cover your cost of living?" was even inversely correlated with an inter-item correlation of -0.132 , suggesting that functioning in VR, as measured by the WORQ consists of 
more than one underlying concept. At the current stage of development, WORQ can be used to collect relevant background information concerning work situation and sociodemographic data in section one. In the main section, WORQ provides information concerning the functioning of individuals in VR in a systematic way. This information can be used to evaluate abilities and problems of the individual and may also serve as a basis for intervention and management planning within the context of return-to-work and sustaining return-to-work. In addition, WORQ scores can be compared for the same individual and can be used to monitor the patient's work-related functioning over time. Based on our preliminary results, it is possible that the WORQ score may not have a definitive relationship with the overall level of functioning nor can it be used to compare and draw concrete conclusion on the level of functioning from one person to another. With further testing, it is possible that there may be distinct and internally consistent subscales that allow for an in-depth interpretation based on subscale scores, addressing specific groups or levels of functioning domains.

For our next step, we plan to further evaluate the underlying factors of the WORQ as well as its sensitivity and responsiveness to change and its predictive value on return to work in different patient groups like those with musculoskeletal and neurologic health conditions which are burdensome conditions in terms of cost and impact on an individual's functioning.

Test-retest reliability with a Spearman correlation coefficient of 0.789 was promising, especially when taking into consideration that the first test was administered by 9 different professionals and the re-test was done only by one rater who was not part of first testing group.

The excluded questions assessing intellectual- and temperament functions have to be carefully reviewed, since in the tested form they showed to be impractical at least during the first encounter which might later affect the utility of the WORQ. These findings are similar to the results of Karidi et al., who stated that "this may be due to the nature of the item, in that it implies the assessor's access to the patient's emotions rather than observation of outward behavior" [34, 35]. Nevertheless, due to the clinical importance, most comprehensive evaluation procedures in VR include complex standardized tests to evaluate general intelligence and temperament or personality of the client [36]. Therefore, the challenge in the future version of the WORQ is to find sound proxy questions that would allow to identify functioning problems related to intellect and personality.

What was interesting was that contrary to our expectation on criterion validity, the correlation coefficient between WORQ and general health assessed by SF-36 was fairly low $(-0.353)$. Where quality of life assessed by WHOQOL $(-0.439)$ and EuroQoL-current health $(-0.419)$ was moderate. These findings appear to acknowledge that the perception of general health and quality of life, as measured by SF-36, EuroQoL and WHOQOL represent concepts that are only partially related to work functioning and therefore should be evaluated independently [37]. We also need to consider that perception of 
general health and quality of life could have mediating effects on work functioning. The highest correlation coefficient was found between WORQ and the BDI II (0.548) indicating that mental and psychological functioning play a major role in self-perceived functioning in VR in our sample, although we are not able to empirically test whether or not any of the variables in our study played a mediating, modifying, or confounding role. This is particularly interesting, since none of the patients in the study population reported psychiatric conditions as primary health condition, but more than $75 \%$ of clients in our sample reported at least one comorbidity and indicated to experience periods of being depressed or anxious concerning their future-a finding that is consistent with the literature [38]. Furthermore, it was shown that depressive symptoms are also negatively related to health-related quality of life [39].

To achieve good content validity of WORQ, we carefully followed defined inclusion and exclusion criteria when selecting ICF categories from the comprehensive ICF Core Set VR which we have used as a reference standard of what domains to look in VR concerning functioning. Good face validity was also supported by the responses from the participants when asked how much can they relate to the items. Therefore we conclude that WORQ, is a valid instrument to evaluate and document functioning of patients in VR (in our sample), independent of their health condition, phase of rehabilitation or type of VR setting.

In practice, WORQ provides an easy way for clinicians to evaluate patients in VR according to the ICF language and classification. The questionnaire can be considered a generic instrument to gain a comprehensive profile of the self-perceived functional abilities and problems of patients. A matter that was appreciated by patients is that they felt that the WORQ gave them the perspective of their health and functioning with its complexity being examined from the different dimensions of health by the interviewers. The patients were also provided with the opportunity for their concerns to be considered and conveyed to the health professional.

The visual analogue scale (VAS) (0-100) is a well-known way to rate the amount of diverse problems [40]. Nevertheless, WORQ represents a generic measure of functioning in VR, in which the rating of the individual questions depend on the momentary perception of the patient's problems and his or her interpretation of the impact those problems have on their current life situation [4, 5]. This perceived health and its consequences are reported to be important factors, when examining barriers to return-towork [41]. In addition the perception of problems is also related to the requirement of the actual life setting of the patient and has to be taken into account when interpreting and evaluating the scores of the WORQ.

Our study had limitations. In the development process, only categories from the comprehensive ICF Core Set for VR were considered for WORQ and therefore other relevant categories may have been missed. However since the ICF Core Set for VR has been developed with input from multiple stakeholders such as patients, clinicians, experts, and researchers, the Core Set with the comprehensive version could be consid- 
ered as an inclusive standard for items relevant to describe functioning in VR. As the inclusion process for ICF categories was rather generous, some questions might be redundant and therefore could be excluded after further testing a modified version of WORQ. We also need further studies with a larger sample size (about 250-300) to evaluate unidimensionality in order to see if we can calculate a total score or subscores used for comparison between persons [42, 43]. In addition weighting of items while theoretically plausible cannot be supported by our data at this point and would need further investigation with a fit-for-purpose study design. Another consideration for further development of WORQ is to create a self-reported version of WORQ since the professionals, particularly the work reintegration specialists raised the issue of time needed to complete the interview. One advantage of self-reporting is that patient would be able to complete the questionnaire while waiting to be seen by a VR specialist, or the questionnaire can be mailed days before the appointment with the specialist. There was an uncertainty from the administering work professionals regarding asking questions on emotional or psychological problems or pain, but something that occupational therapists appreciated as being helpful. This difference may be due to the fact, that the therapists are better trained to address those problems in the context of their intervention and their training. Recognizing the possible negative impact of perceived disability on participation in return to work programs would support the development of strategies to address these factors within the rehabilitation process [44].

A further limitation is that the psychometrics established in this study refer only to the German version of the WORQ. This study employed convenience sampling of patients from a single VR center which were included in the psychometric testing. Hence, we caution the interpretation and generalization of our results to the rest of the populations or other samples undergoing VR. To ensure the applicability of the WORQ in other clinical settings or in patient groups, with diverse health conditions, further studies exploring reliability, validity (including other cross-cultural validation) and sensitivity to change in different settings and with other existing measurement instruments or tools that are routinely used in VR, are needed.

In conclusion, WORQ appears to be a valid, reliable and feasible questionnaire that is easy to administer by health or VR professionals to evaluate work functioning in VR that is based on the ICF. The additional information gained when using the WORQ would contribute to improving interdisciplinary understanding of the patient's situation and therefore support the integrative planning of the return-to- work process or engagement in gainful employment. However, further studies are needed to further examine its use in clinical practice and research, or in other patient populations and settings. 


\section{Acknowledgments}

The authors would like to thank Melissa Selb and Annette Frischmann for their help with the cross-cultural adaptation and Wolfgang Segerer for providing technical consultation, data preparation, and assistance during the conduct of the study. Special thanks to Franco Lanfranchi, Frank Staudenmann, Dora Büschlen, Marianne Moor, Richard Leuenberger, Stefan Staubli and Jonas Peterhans, who made the data collection in the study center Rehaklinik Bellikon, Switzerland possible. We would also like to thank Prof. Alarcos Cieza for her guidance and inspiration.

This project was funded by the Swiss Accident Insurance Company (Suva) and the Swiss Paraplegic Research. WORQ can be freely accessed through www.myworq.org.

\section{References}

1. Escorpizo R, Reneman MF, Ekholm J, Fritz J, Krupa T, Marnetoft SU, et al. A conceptual definition of vocational rehabilitation based on the ICF: building a shared global model. J Occup Rehabil. 2011;21(2):126-33.

2. International Labour Organization (ILO). Managing disability in the workplace. ILO code of practice. 2002;15.04.3.

3. Vocational Rehabilitation Task Group-Industrial Injuries Advisory Council, Waddell G, Burton AK, Kendall NA. Vocational rehabilitation-what works, for whom, and when?. 1st ed. London: TSO (The Stationery Office); 2008.

4. Milner A, Page A, LaMontagne AD. Long-term unemployment and suicide: a systematic review and metaanalysis. PLoS ONE. 2013;8(1):e51333.

5. Rosenthal L, Carroll-Scott A, Earnshaw VA, Santilli A, Ickovics JR. The importance of full-time work for urban adults' mental and physical health. Soc Sci Med. 2012;75(9):1692-6.

6. World Health Organization. International Classification of Functioning, Disability and Health. Geneva: World Health Organization; 2001.

7. Saltychev M, Kinnunen A, Laimi K. Vocational rehabilitation evaluation and the International Classification of Functioning, Disability, and Health (ICF). J Occup Rehabil. 2013;23(1):106-14.

8. Escorpizo R, Ekholm J, Gmuender HP, Cieza A, Kostanjsek N, Stucki G. Developing a Core Set to describe functioning in vocational rehabilitation using the International Classification of Functioning, Disability, and Health (ICF). J Occup Rehabil. 2010;20(4):502-11.

9. Finger ME, Escorpizo R, Glassel A, Gmunder HP, Luckenkemper M, Chan C, et al. ICF Core Set for vocational rehabilitation: results of an international consensus conference. Disabil Rehabil. 2012;34(5):42938.

10. Andrich D, Lyne A, Sheridan B, Luo G. RUMM2030. Perth: RUMM Laboratory; 2010.

11. Finger ME, Glassel A, Erhart P, Gradinger F, Klipstein A, Rivier G, et al. Identification of relevant ICF categories in vocational rehabilitation: a cross sectional study evaluating the clinical perspective. J Occup Rehabil. 2011;21(2):156-66.

12. Mills RJ, Young CA, Pallant JF, Tennant A. Development of a patient reported outcome scale for fatigue in multiple sclerosis: the Neurological Fatigue Index (NFI-MS) health. Qual Life Outcomes. 2010;12(8):22.

13. Pallant JF, Tennant A. An introduction to the Rasch measurement model: an example using the Hospital Anxiety and Depression Scale (HADS). Br J Clin Psychol. 2007;46(1):1-18.

14. Bickenbach J, Cieza A, Selb M, Emmenegger K, Lückenkemper M, Escorpizo R, editors. ICF Core Sets: manual for clinical practice. 1st ed. Göttingen: Hogrefe; 2012. 
15. Stull DE, Leidy NK, Parasuraman B, Chassany O. Optimal recall periods for patient-reported outcomes: challenges and potential solutions. Curr Med Res Opin. 2009;25(4):929-42.

16. Ustün TB, Kostanjsek N, Chatterji S, Rehm J, editors. Measuring health and disability-manual for WHO Disability Assessment Schedule (WHODAS 2.0). Geneva: World Health Organization; 2010.

17. World Health Organization (WHO). World Health Survey 2002; Individual Questionnaire. 2012; http://www.who.int/healthinfo/ survey/whslongindividuala.pdf. Accessed 12 Jan 2012.

18. Escorpizo R, Finger ME, Glassel A, Gradinger F, Luckenkemper M, Cieza A. A systematic review of functioning in vocational rehabilitation using the International Classification of Functioning, Disability and Health. J Occup Rehabil. 2011;21(2):134-46.

19. Wewers ME, Lowe NK. A critical review of visual analogue scales in the measurement of clinical phenomena. Res Nurs Health. 1990;13(4):227-36.

20. Beaton DE, Bombardier C, Guillemin F, Ferraz MB. Guidelines for the process of cross-cultural adaptation of self-report measures. Spine (Phila Pa. 1976). 2000;25(24):3186-91.

21. Johnstone CJ, Bottsford-Miller NA, Thompson SJ. Using the think aloud method (cognitive labs) to evaulate test design for students with disabilities and English language learners (Technical Report 44). 2006; Available from: http://education.umn. Edu/NCEO/OnlinePubs/ Tech44/. 29 Sep 2013.

22. The EuroQolGroup. EuroQol: a newfacility for the measurement of health-related quality of life. Health Policy. 1990;16(3):199-208.

23. Ware JE. SF-36 Health Survey. Manual and interpretation guide. New England Medical Center, Boston: The Health Institute; 1997.

24. Kuhner C, Burger C, Keller F, Hautzinger M. Reliability and validity of the Revised Beck Depression Inventory (BDI-II). Results from German samples. Nervenarzt. 2007;78(6):651-6.

25. Skevington SM, Lotfy M, O'Connell KA, WHOQOL Group. The World Health Organization's WHOQOL-BREF quality of life assessment: psychometric properties and results of the international field trial. A report from the WHOQOL group. Qual Life Res. 2004;13(2):299-310.

26. Hinkle D, Wiersma W, Jurs S, editors. Applied statistics for the behavioral sciences. 5th ed. Boston: Houghton Mifflin; 2003.

27. Field A. Discovering statistics using SPSS. 3rd ed. London: SAGE Publications; 2009.

28. George D, Mallery P. SPSS for Windows step by step: a simple guide and reference. 11.0 update. 4th ed. Boston: Allyn and Bacon; 2003.

29. SPSS Inc. PASW statistics for windows. Chicago: SPSS Inc.; 2009.

30. RStudio. RStudio: Integrated development environment for R v0.96. 2012. Boston, USA: Available from http://www.rstudio. org/. Accessed August 30, 2012.

31. Soer R, van der Schans CP, Geertzen JH, Groothoff JW, Brouwer S, Dijkstra PU, et al. Normative values for a functional capacity evaluation. Arch Phys Med Rehabil. 2009;90(10):1785-94.

32. Peyrin-Biroulet L, Cieza A, Sandborn WJ, Coenen M, Chowers Y, Hibi T, et al. Development of the first disability index for inflammatory bowel disease based on the International Classification of Functioning, Disability and Health. Gut. 2012;61(2):241-7.

33. Kiltz U, van der Heijde D, Cieza A, Boonen A, Stucki G, Ustun B, et al. Developing and validating an index for measuring health in patients with ankylosing spondylitis. Rheumatology (Oxford). 2011;50(5):894-8.

34. Karidi MV, Papakonstantinou K, Stefanis N, Zografou M, Karamouzi G, Skaltsi P, et al. Occupational abilities and performance scale-reliability-validity assessment factor analysis. Soc Psychiatry Psychiatr Epidemiol. 2005;40(5):417-24.

35. Lee G. Vocational rehabilitation for people with disabilities. In: Stone J, Blouin M, editors. International Encyclopedia of Rehabilitation. 2013. http://cirrie.buffalo.edu/encyclopedia/en/article/ 128/; Accessed 14 May 2013.

36. Chan F, Reid C, Kaskel L, Roldan G, Rahimi MM. Vocational assessment and evaluation of people with disabilities. Phys Med Rehabil Clinics N Am. 1997;8(2):311-25.

37. Cieza A, Bickenbach J, Chatterji S. The ICF as a conceptual platform to specify and discuss health and health-related concepts. Gesundheitswesen. 2008;70(10):e47-56. 
38. Linder J, Ekholm KS, Jansen GB, Lundh G, Ekholm J. Long-term sick leavers with difficulty in resuming work: comparisons between psychiatric-somatic comorbidity and monodiagnosis. Int J Rehabil Res. 2009;32(1):20-35.

39. Ferdiana A, Post MWM, Finger ME, Bültmann U, Escorpizo R. Assessment of health-related quality of life of clients in vocational rehabilitation: association with depressive symptoms and type of services. Eur J Phys Rehabil Med. 2013 Dec 5. [Epub].

40. Nicklin J, Cramp F, Kirwan J, Greenwood R, Urban M, Hewlett S. Measuring fatigue in rheumatoid arthritis: a cross-sectional study to evaluate the Bristol Rheumatoid Arthritis Fatigue Multi-Dimensional questionnaire, visual analog scales, and numerical rating scales. Arthritis Care Res (Hoboken). 2010;62(11):1559-68.

41. Lotters F, Carlier B, Bakker B, Borgers N, Schuring M, Burdorf A. The Influence of Perceived Health on Labour Participation Among Long Term Unemployed. J Occup Rehabil. 2013;23(2):300-8.

42. Linacre JM. Sample size and item calibration [or person measure] stability. 2013. www.rasch.org/rmt/rmt74m.htm. Accessed 15 May 2013.

43. Mundform DJ, Shaw DG, Ke TL. Minimum sample size recommendations for conducting factor analysis. Int J Test. 2005;5:159-68.

44. Marois E, Durand MJ. Does participation in interdisciplinary work rehabilitation programme influence return to work obstacles and predictive factors? Disabil Rehabil. 2009;31(12):994-1007. 


\section{Chapter 6}

\section{Using ICF in physiotherapy in multidisciplinary vocational rehabilitation: A case study of low back pain}

Article published in PRI- Physiotherapy Research International: DOI: 10.1002/pri.1587. 13. Feb. 2014 [Epub ahead of print].

Monika E. Finger

Melissa Selb

Robert A. de Bie

Reuben Escorpizo 


\section{Abstract}

Objectives: Multidisciplinary teamwork is increasingly recognized as a critical factor of success in vocational rehabilitation. Although its clinical implementation is still challenging, the International Classification of Health, Disability and Health (ICF) has shown to be a useful framework to facilitate communication between stakeholders, to help structure rehabilitation plans, and for setting goals and clarifying team roles. With this in mind, the objective of this teaching case study is to illustrate an application of ICFbased tools in a multidisciplinary return to work (RTW) program for patients with nonspecific low back pain (NLBP) from the perspective of the physiotherapist. Participant: 42-year-old kindergarten teacher, who was on sick leave for 10 weeks due to nonspecific low back pain (NLBP).

Methods: This case study describes the use of ICF-based tools such as the Rehabilitation Management Sheet (RehabManagement-Sheet) to guide the rehabilitation process, facilitate team-based and physiotherapist goal-setting and documentation in a multidisciplinary RTW program for NLBP.

Results: Utilizing ICF tools, long- and short-term goals were defined, improvements in the patient's impairments, activity limitations, and participation restrictions were documented and action steps were formulated.

Conclusion: The use of ICF based tools in multidisciplinary rehabilitation allows for a comprehensive assessment, common goal -setting, and coordinated intervention planning. ICF-based tools like the RehabManagement-Sheet support the physiotherapist's role within the rehabilitation team by enhancing transparency in goal- setting and intervention planning across disciplines.

Keywords: ICF Core Set, International Classification of Functioning Disability and Health, low back pain, vocational rehabilitation 


\section{Introduction}

As stated in the literature physiotherapists are essential members of a multidisciplinary team in vocational rehabilitation (VR) [1]. Specifically the contribution of physiotherapists in improving a patient's physical functions and abilities are instrumental in measuring VR outcomes. [2,3].Essential to the success of any multidisciplinary VR or returnto-work (RTW) program is the effective exchange of information among the healthcare professionals together with the patient and other stakeholders (e.g. employer, social insurances) involved in the process [4,5]. Current findings suggest that interprofessional collaboration in a multidisciplinary team is needed to enable the team members to work in concert with clients with chronic disabilities in achieving solution focused goals for returning to work and improving functioning. Fundamental for a successful team are clear processes facilitating the team members to nurture consensus, to build up professional synergies and to support a learning culture $[5,6]$

To understand RTW process, in the last decade diverse work disability and work rehabilitation models were developed or suggested for different settings, targeting various health conditions [7-10], but a common standard is lacking. A "standard" in the area of VR could facilitate comparability of research findings and clinical outcomes $[11,12]$

The International Classification of Functioning, Disability and Health (ICF) [13] is a comprehensive and internationally accepted framework to reach a common understanding of health and health related states including human functioning and disability among health professionals, patients and other stakeholders [14,15]. In the context of the ICF, functioning is understood as an umbrella term encompassing all body functions, activities and participation; similarly, disability serves as an umbrella term for impairments, activity limitations or participation restrictions. The ICF also lists environmental factors that interact with all these constructs.

As a classification system the ICF has two parts; part I: functioning and disability including body functions and -structures and activities and participation and part II: contextual factors including environmental factors and personal factors. With exception of personal factors, all ICF components are arranged in a hierarchical fashion, using alphanumeric codes and textual definitions, where the coding unit of the ICF is called an ICF category. The ICF also provides a so called generic 5-point ICF qualifier scale to rate the severity of the problem an individual experiences in a distinct category. The values range from no problem (0) to complete problem (4) in functioning with intermediate levels of mild (1), moderate (2) and severe problem (3) [13].

In addition to facilitating the sharing of information, the ICF has most recently shown to also be useful in structuring rehabilitation plans, clarifying team roles and setting rehabilitation goals [16-21]. As a universal language, the ICF can be applied in multidisciplinary RTW programs that provide VR services for patients with a variety of health conditions, including low back pain (LBP) $[22,23]$, one of the most leading causes 
of global burden of diseases [24] and a health condition that has a significant impact on a person's work ability [25-27].

For sub-acute or chronic LBP, intensive interdisciplinary bio-psychosocial rehabilitation programs (including physical exercises, cognitive behavioral therapy and workplace interventions) are recommended as most promising approach to reduce disability in patients who do not improve with self-care options and medication $[2,28,29]$

The overall objective of this teaching case study is to illustrate an application of the ICF and ICF-based tools in the rehabilitation management process of a multidisciplinary RTW program for patients with non-specific low back pain (NLBP) from the perspective of the physiotherapist. The specific aims are 1) to demonstrate how the ICF can be used within a multidisciplinary team to improve communication between health professionals, patients and employers, 2) to show how ICF-based tools are used to facilitate profession specific goal-setting of physiotherapists as well as joint goal-setting in the multidisciplinary team and 3 ) to structure multidisciplinary documentation.

\section{ICF-based rehabilitation tools}

Among a diverse array of ICF-based tools available, ICF Core Sets gradually infuse clinical practice. ICF Core Sets i.e. shortlists of ICF categories that are relevant to specific health conditions or health-related settings [30,31], were developed to enable a more practical application of the ICF in clinical practice. There are three types of ICF Core Sets: the Generic, brief and comprehensive ICF Core Sets. The Generic Set consists of seven categories from the ICF components of body functions and activities and participation which have been statistically determined to be generally applicable across health conditions and healthcare contexts. The comprehensive ICF Core Set is an extensive list of ICF categories that reflect the spectrum of typical problems that a patient with a health condition or in a specific healthcare context may experience. The brief ICF Core Set, a selection from the comprehensive ICF Core Set, contains those categories that capture the essence of a person's experience of functioning and disability [18]. For this case study, the combination of the Generic Set and the brief ICF Core Sets for LBP and for $V R$ was employed [30,32], as this combination reflects the minimum of functioning domains (categories) that should be looked at when considering the context of vocational rehabilitation (RTW program) and the underlying health condition (low back pain). 
Table 1: Check List: Combination of the ICF Generic Set, the brief ICF Core Sets for LBP and for VR

\begin{tabular}{|c|c|c|c|c|}
\hline ICF code & ICF category title & $\begin{array}{l}\text { ICF Core } \\
\text { Set for LBP }\end{array}$ & $\begin{array}{l}\text { ICF Core } \\
\text { Set for VR }\end{array}$ & $\begin{array}{c}\text { ICF } \\
\text { Generic Set }\end{array}$ \\
\hline \multicolumn{5}{|c|}{ Body Functions } \\
\hline b130 & Energy and drive functions & $\sqrt{ }$ & $\sqrt{ }$ & $\sqrt{ }$ \\
\hline b134 & Sleep functions & 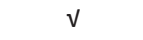 & & \\
\hline b152 & Emotional functions & 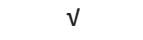 & & $v$ \\
\hline b164 & Higher level cognitive functions & & $\checkmark$ & \\
\hline b280 & Sensation of pain & 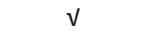 & & 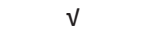 \\
\hline b455 & Exercise tolerance functions & V & $\sqrt{ }$ & \\
\hline b710 & Mobility of joint functions & V & & \\
\hline b715 & Stability of joint functions & 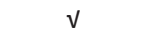 & & \\
\hline b730 & Muscle power functions & $\checkmark$ & & \\
\hline b735 & Muscle tone functions & $\sqrt{ }$ & & \\
\hline b740 & Muscle endurance functions & V & & \\
\hline \multicolumn{5}{|c|}{ Body Structures } \\
\hline s120 & Spinal cord and related structures & 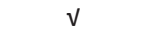 & & \\
\hline s760 & Structure of trunk & 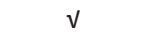 & & \\
\hline s770 & Additional musculoskeletal structures related to movement & 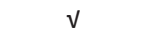 & & \\
\hline \multicolumn{5}{|c|}{ Activities and Participation } \\
\hline d155 & Acquiring skills & & V & \\
\hline $\mathrm{d} 230$ & Carrying out daily routine & & & V \\
\hline $\mathrm{d} 240$ & Handling stress and other psychological demands & $\sqrt{ }$ & $\sqrt{ }$ & \\
\hline $\mathrm{d} 410$ & Changing basic body position & $\sqrt{ }$ & & \\
\hline d415 & Maintaining a body position & $\checkmark$ & & \\
\hline d430 & Lifting and carrying objects & $\mathrm{V}$ & & \\
\hline d450 & Walking & $\checkmark$ & & $\checkmark$ \\
\hline d455 & Moving around & & & $\checkmark$ \\
\hline d530 & Toileting & $\sqrt{ }$ & & \\
\hline d540 & Dressing & V & & \\
\hline $\mathrm{d} 640$ & Doing housework & $\sqrt{ }$ & & \\
\hline d720 & Complex interpersonal interactions & & 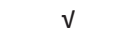 & \\
\hline $\mathrm{d} 760$ & Family relationships & 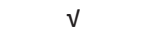 & & \\
\hline d845 & Acquiring, keeping and terminating a job & 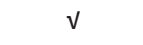 & 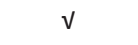 & \\
\hline d850 & Remunerative employment & V & $\checkmark$ & $\checkmark$ \\
\hline d859 & Work and employment, other specified and unspecified & $\sqrt{ }$ & & \\
\hline d855 & Non remunerative employment & & $\checkmark$ & \\
\hline \multicolumn{5}{|c|}{ Environmental Factors } \\
\hline e110 & Products or substances for personal consumption & 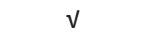 & & \\
\hline e135 & Products and technology for employment & $\sqrt{ }$ & & \\
\hline e155 & $\begin{array}{l}\text { Design, construction and building products and technology of } \\
\text { buildings for private use }\end{array}$ & V & & \\
\hline e310 & Immediate family & $v$ & V & \\
\hline e330 & People in positions of authority & & $v$ & \\
\hline
\end{tabular}




\begin{tabular}{|c|c|c|c|c|}
\hline ICF code & ICF category title & $\begin{array}{c}\text { ICF Core } \\
\text { Set for LBP }\end{array}$ & $\begin{array}{l}\text { ICF Core } \\
\text { Set for VR }\end{array}$ & $\begin{array}{c}\text { ICF } \\
\text { Generic Set }\end{array}$ \\
\hline e355 & Health professionals & $\mathrm{V}$ & & \\
\hline e410 & Individual attitudes of immediate family members & $\sqrt{ }$ & & \\
\hline e450 & Individual attitudes of health professionals & $\mathrm{V}$ & & \\
\hline e550 & Legal services, systems and policies & $\sqrt{ }$ & & \\
\hline e570 & Social security services, systems and policies & $\sqrt{ }$ & & \\
\hline e580 & Health services, systems and policies & $\mathrm{V}$ & $\mathrm{V}$ & \\
\hline e590 & Labour and employment services, systems and policies & & $\mathrm{V}$ & \\
\hline
\end{tabular}

This combined set serves as a checklist for identifying the level of the patient's functioning. The checklist encourages team members to look at all relevant aspects of functioning of a particular patient (see Table 1). To facilitate assessment efficiency and avoid redundancy among team members, specific ICF categories on the checklist are assigned to specific team members that reflect the functioning domains most commonly addressed within the respective professional discipline. Note, however, that there may be categories that are addressed by more than one team member, since distinct categories may reflect a range of problems that have to be targeted by multiple interventions or approaches. E.g. sleep problems (b134 Sleep functions) may be due to not finding a proper sleeping position, addressed by the PT, as well as due to unfavorable sleeping behavior, addressed by a psychologist. Sleeping problems may even be treated with sleeping medication by the rehabilitation physician.

To capture the disability experience of the patients in a standardized way, the Work Rehabilitation Questionnaire (WORQ) was used. WORQ is an interviewer administered questionnaire that was developed based on the ICF Core Set for vocational rehabilitation to create a comprehensive profile of functioning as experienced by the patient. It contains 40 questions covering body functions and activities relevant to individuals in vocational rehabilitation [33,34].

The RehabManagement-Sheet, is used as the main multidisciplinary documentation and process guiding tool (see Table 2 ) $[35,36]$. The individual professional assessments concerning the ICF categories that are considered as problematic and requiring intervention to achieve the rehabilitation goal, by the patient and the rehabilitation team are collected and included in the RehabManagement-Sheet. Inserted categories are used, to create an individualized profile of functioning as rated by ICF qualifiers. The RehabManagement-Sheet not only summarizes the patient's long-term and short-term goals, but also assures that the intervention targets specific ICF categories. The health professionals responsible for conducting the intervention are also indicated, and the results of the first and pre-discharge assessments are shown. The latter reflects the extent of a problem a patient has in a particular ICF category before (first value) and after intervention (final value). At the beginning of the program a goal value is defined, in order to determine if the program goal is achieved or not (Table 2). 


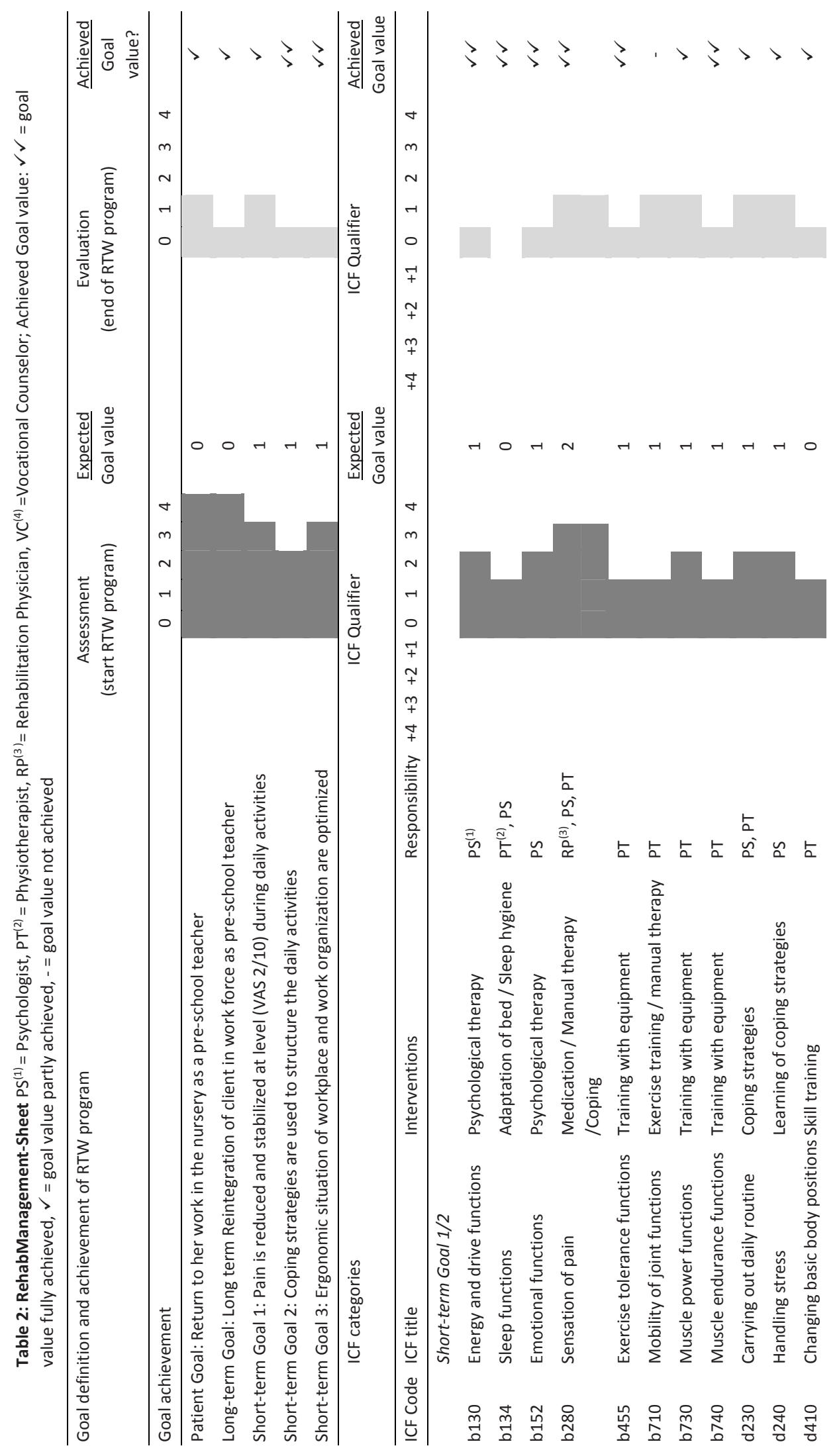




\section{>3 $3 \cdot 33>333>33$}
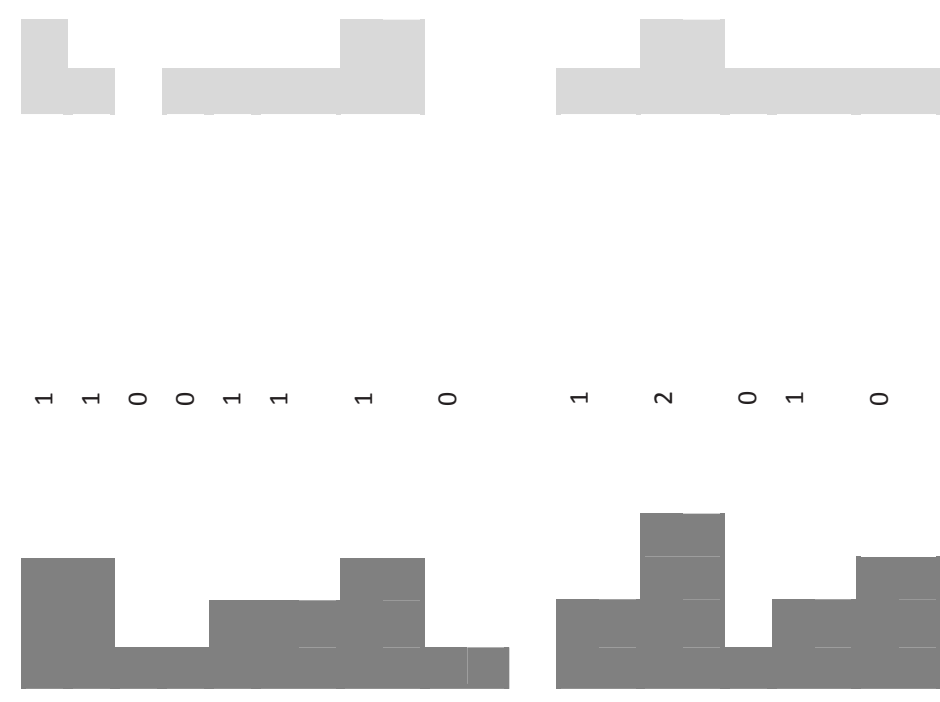

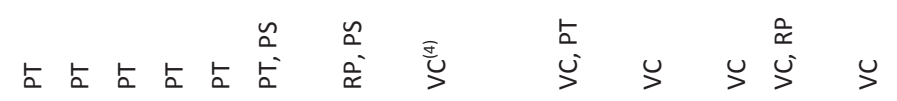

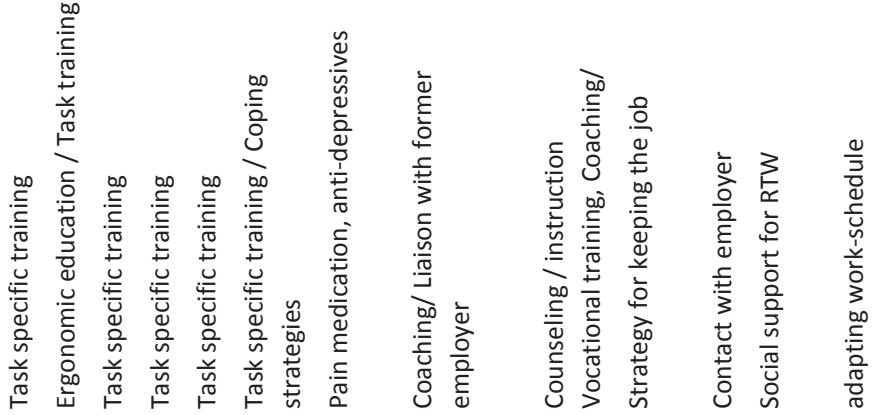

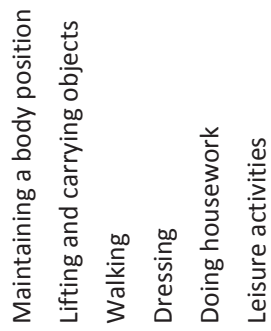

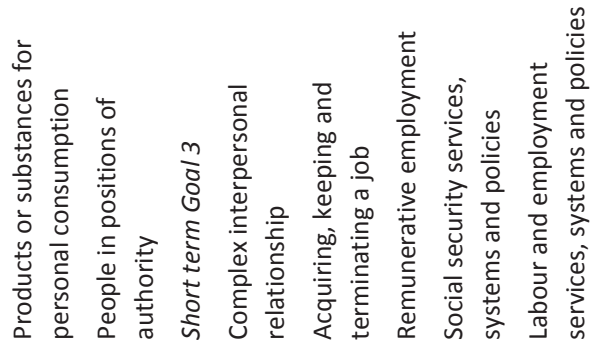

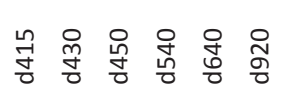

용

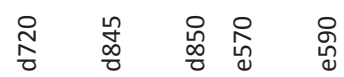




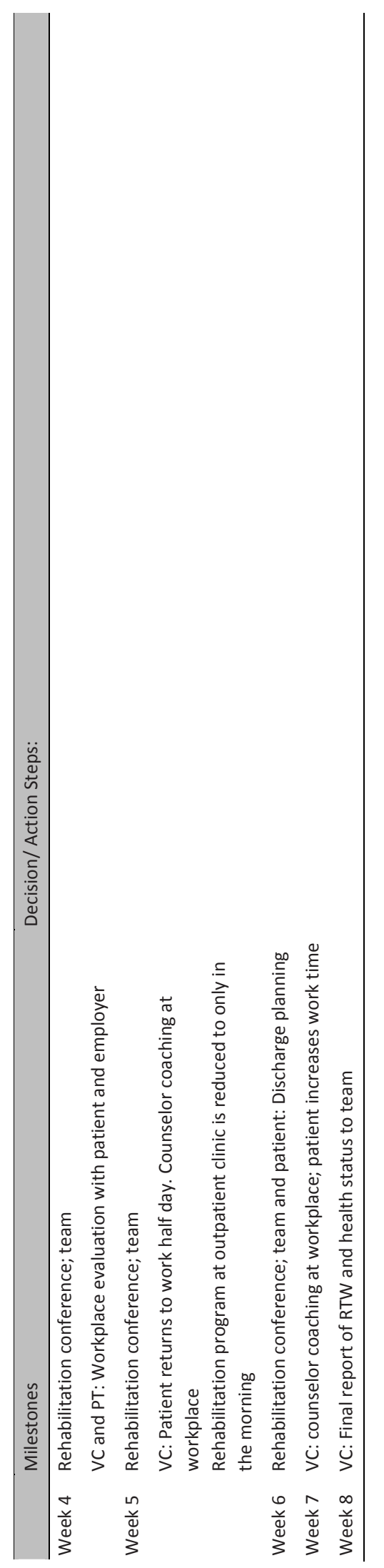




\section{Case History}

This hypothetical case study is based on clinical experience, and was constructed solely to demonstrate the use of the ICF in a multidisciplinary setting. Victoria Meier is a $42-$ year-old kindergarten teacher, who applied for sick leave ten weeks ago due to low back problems. Her main concern was a "burning and stabbing" pain in her back. She had been experiencing fatigue and pressure in her lower back for more than 10 years. However, during the last five months not only had Victoria's pain intensified, the quality of her pain had changed. This coincided with starting a new job providing daycare to toddlers. Her pain was characterized by a constant feeling of ever-increasing pressure when standing, a burning sensation when bending forward for a short period of time and stabbing pain in the lower back when lifting objects over $5 \mathrm{~kg}$. During the visit with her physician at which time Victoria received the referral to the RTW program, she rated her pain as $9 / 10$ at worst, $1 / 10$ at best on a numeric rating scale (NRS). Aggravating activities included sitting or kneeling on the floor, lifting children onto the diaperchanging table, carrying children from one room to another as well as other non-work related activities such as walking her dog longer than 45 minutes or vacuuming her apartment. She also reported episodes of stabbing pain followed by spasm of the lumbar muscles that last up to several hours and prevented her from bending forward. Because no satisfactory alleviation of pain and recovery of function occurred even after taking anti-inflammatory medication and doing prescribed exercises, her physician referred her to a multidisciplinary RTW program for people with NLBP.

\section{Setting and RTW-Program}

The RTW program within a multidisciplinary outpatient clinic is designed for patients, who are on sick leave for at least 6 weeks up to 6 months due to NLBP. The main objectives of the clinical rehabilitation program are: (1) return to work; (2) increase activity levels; and (3) reduce pain intensity. During the 6 weeks patients undergo 5 days a week for 6 hours physical training interventions, including general endurance training and strengthening complemented with work specific task training, a cognitivebehavioral -based pain self-management program in a group twice a week with individual psychological support to improve coping strategies [37]. Return to work planning includes workplace interventions, ergonomic adaptations or work organization. If the patient is employed, the employer as well the insurance company is involved in the work reintegration planning, leading often to graded employment and ergonomic adaptations in the starting phase. Otherwise job application skills are trained and job seeking is assisted. The multidisciplinary rehabilitation team consists of a rehabilitation physician, a physiotherapist, a psychologist and a vocational counselor.

In the RTW program an electronic information system is used, which allows all team members to access the patient's medical and therapy documentation. Team 
members use the RehabManagement-Sheet as the main information instrument to guide the rehabilitation process and to monitor the patient's overall progress in the program.

\section{Assessment and goal-setting}

Based on the medical information provided by the referring physician, a specific assessment plan was developed for Victoria. At admission day, she met individually with a rehabilitation physician (RP), a physiotherapist (PT), a psychologist (PS) and a vocational counselor (VC), for a comprehensive assessment during which each team member employed discipline-specific clinical tests and measures taking into account the assigned ICF categories from the checklist [36]. If considered relevant based on the assessment of the patient's functioning, additional ICF categories can be added to checklist and consequently to the RehabManagement-Sheet. For example, d920 Recreation and leisure was considered relevant for completing Victoria's functioning profile, thus d920 was included in the RehabManagement-Sheet.

For sake of simplicity we will concentrate on the PT activities. The physiotherapist decided to initiate the assessment by asking Victoria to answer the WORQ in order to gain an overall picture of Victoria's disability experience. The results of the WORQ and its discussion showed not only a decline in functioning due to reduced mobility and pain but also due to exhaustion and to worries and anxiety. To gain a better understanding of the impact of Victoria's beliefs and worries, the PT decided to let Victoria fill out the Tampa Scale for Kinesiophobia $[38,39]$ that was developed as a measure of fear of movement or (re)injury. It scored 40, revealing high level of kinesiophobia. In the following clinical examination the PT focused on identifying and analyzing the most relevant activity limitations using information from his initial interview, WORQ and the checklist. In maintaining (d410) and changing body positions (d415), the PT assessed standing and bending forward. In lifting and carrying objects (d430) the PT looked at lifting objects from the floor onto a table. These two activities reflected her most impaired work tasks. In addition, in the category doing housework (d640) the PT examined vacuuming the floor, since Victoria named this activity as one of her biggest concerns. In addition to the categories listed on the checklist, Victoria also named her inability to do any sports activity as a big concern, what would be covered by the ICF category $\mathrm{d} 920$ Recreation and leisure.

Initial pain in a standing position was 2/10 located at the center of the lumbar spine region. Victoria's active range of motion (AROM) in the thoracic and lumbar spine while bending forward revealed that flexion was severely limited, mostly due to pain and fear of muscular spasm. Carrying and lifting was examined using lifting tests from a functional capacity evaluation battery set [40]. The PT further assessed tactile perception, muscle power, passive range of motion (PROM), and tenderness, first to assure Victoria that no potential harmful sign was missed and second to get a deeper understanding of 
the interconnection between Victoria's activities and participation and functioning problems.

The first multidisciplinary rehabilitation team case-meeting was used to integrate the findings of the PT as well as those of the other rehabilitation team members and Victoria's needs, to set individualized rehabilitation goals and to develop a customized rehabilitation plan for Victoria. Using a beamer, the RehabManagement-Sheet was visualized to provide a shared overview of facts and to document the findings. In a first step each team member presented her or his findings using the checklist and possible additional ICF categories as guideline. Each of the ICF categories was rated by the responsible team member using an ICF qualifier to describe the severity of the problem. For example the PT presented lifting an object from the ground, (classified in the ICF activity $\mathbf{1 4 3 0}$ Lifting and carrying objects), as a severe work problem, indicated by a qualifier of 3. The PT based his rating on Victoria's judgment captured on the WORQ and on test findings of the functional capacity evaluation. In addition to the categories listed in the checklist, the PT advocated adding $d 920$ Recreation and leisure for completing the functioning profile, since Victoria mourned that she felt unable do any sport, because of her back. The relevance of an ICF category and its ratings were discussed within the team, including possible assessment results from other professionals. Categories that the team agreed on being a problem and requiring intervention to achieve return-to-work, where then electronically inserted into the RehabManagement-Sheet (Table 2).

In the end the RehabManagement-Sheet provided a visualization of Victoria's detailed functioning status at a glance. To gain a common level of understanding, priorities and relationships could be evaluated, as a basis to guide the goal-setting process. Victoria and the team defined one long-term goal concerning return-to-work and three short-term goals on the body function and activity levels as mediators to be reached within the next six weeks. These goals were in accordance to the objectives of the program and reflecting Victoria's situation. (Table 2)

Then the team allocated the ICF categories included in the RehabManagementSheet to the most appropriate, long-term or the short-term goals. In addition, the team and Victoria agreed on the interventions that would target the specific goals and responsibilities. The timeframe and milestones e.g. rehabilitation case-conferences, weekly team meetings, evaluation at the workplace and reintegration to work were discussed and entered in the RehabManagement-Sheet. See the Milestones section of Table 2.

When looking at the PT, he took the main responsibility for supporting Victoria to master the physical demands relevant to her job. One aspect was to improve her endurance (b455 Exercise tolerance functions) by integrating her to a Nordic Walking group, what also supported Victoria's wish to walk her dog (d920 Leisure activities). The physical training included also practical task training, as simulated lifting of toddlers up from the ground or down from a climbing frame including education for proper body 
ergonomics as well as guidance for Victoria to incorporate pain management strategies and (re)gain confidence in her body.

In addition the use of the RehabManagement-Sheet made intervention areas, as targeted by different professionals transparent and compelled them to coordinate their interventions. E.g. the physiotherapist integrated pain self-management strategies that Victoria had learned in the cognitive behavioral program in his training.

\section{Rehabilitation process and multidisciplinary communication}

The RehabManagement-Sheet not only served as the main instrument for compiling relevant information in the language of an universal classification the team level, it provided an overview of Victoria's goals and her achievements expressed in the changes of the functioning profile that was also the driving source for discussion during the team meetings and the rehabilitation case-conferences. The categories of the functioning profile were re-rated every week by the assigned health professional and agreed on in the team meeting where Victoria's progress in achieving her goals as well as the obstacles to goal-achievement since the last meeting/ case-conference were documented and discussed. Modifications to the rehabilitation program were decided on and documented in the Milestone section of the RehabManagement-Sheet. If new topics came up, new goals and milestones were defined.

During the rehabilitation case-meeting at week 6 (discharge), comparisons between the ratings from the first and last rehabilitation case-meeting (week 1 vs. week 6) based on the same assessments aimed to see whether the long-term and short-term goals were reached. Discrepancies were analyzed together with Victoria and findings were incorporated in her discharge plan. Recommendations for maintaining the achieved functioning level (or improving upon) were formulated. The further support of Victoria for the work integration process by the vocational counsellor was planned until the beginning of full time work.

\section{Discussion}

Successful multidisciplinary team-work, crucial for employing effective and efficient multidisciplinary interventions and rehabilitation programs, is characterized by openness with mutual respect of roles, increased cross-boundary cooperation and effective communication [16]. In this teaching case we illustrated how the ICF can support communication between health professionals, the patient and the employer by providing a common framework for understanding the patient's functioning and its impact on daily life, including work life. The ICF-driven weekly team meetings and rehabilitation caseconferences allowed the health professionals involved to be informed about the patient's progress and status of the rehabilitation process, with the RehabManagement- 
Sheet as a guiding document, in an open and transparent manner, that in turn lead to a better understanding of the other disciplines' perspective. In addition this case study demonstrated how ICF-based tools, as ICF Core Set based checklists, the RehabManagement-Sheet or WORQ are used to facilitate shared goal-setting and coordinated intervention planning and to structure multidisciplinary documentation $[19,36]$.

The RehabManagement-Sheet confirmed its utility as an effective tool to formulate meaningful, sensible and reachable long-term and short-term goals based on the different components of the ICF. Indicating on the RehabManagement-Sheet which health professional is responsible for tackling specific patient problems lead to the identification of overlapping intervention areas. This promoted coordination of activities and fostered multidisciplinary synergies e.g. integrating pain management skills from the cognitive-behavioral program into task training and daily routine.

Weekly reevaluation of the key problems and the short-term goals during the team meeting motivated the health professionals to reflect their therapeutic strategies, thus facilitating ongoing clinical reasoning. With regards to documentation and monitoring of patient progress, a functioning profile of the patient was established at admission and at discharge and documented in the RehabManagement-Sheet. The functioning profile displays an overall expert rating of the patient's functioning using ICF qualifiers based on clinical data i.e. findings of the discipline-specific clinical tests, clinical examinations and questionnaires. However, to some extent the rating is sometimes wrought with reliability and precision concerns, especially in the context of research [41]. Thus, to reinforce the utility of ICF qualifier ratings, established standard measures or tests are indispensable, e.g. a numeric rating scale for pain or a functional evaluation test to assess lifting capacities.

There are challenges when applying the ICF in a multidisciplinary context such as in this case study. The use of ICF-based documentation tools mentioned in this paper to guide and document rehabilitation processes are still in its infancy and needs to be further developed. However, the development of electronic ICF-based documentation tools for use in multidisciplinary clinical settings is making headway [42-44]. Another challenge around integrating ICF-based documentation tools in practice is the time, human and financial resources required for training all the staff and for adopting the ICF in the patient management system. Implementation of an electronic documentation system may reduce the time expended for administration and documentation thus increasing the attractiveness of ICF-based management and documentation tools [17].

This case study has some limitations. This case description focused on the use of ICF-based tools from the PT perspective, thus limiting the vantage point with regard to the use of clinical assessments and interventions of other health professionals in the multidisciplinary process. Assessments and interventions of PTs were also abbreviated solely for the purpose of illustrating the possible use of ICF-based tools i.e. checklist, WORQ and the RehabManagement-Sheet. 
Of further consideration is the selection of the appropriate checklist. In this case we used a merged list based on the ICF Core Set for chronic low back pain, vocational rehabilitation and the Generic Set as the minimum number of categories to be considered when describing a person with NLBP in a RTW setting. A checklist with another combination of ICF categories may be appropriate for another health population in a RTW setting, and ICF categories can also be added if necessary to optimally capture a person's functioning.

\section{Implication to Physiotherapy Practice}

This teaching case study exemplified how the ICF and ICF- based tools can be used in a multidisciplinary rehabilitation program to promote effective communication between physiotherapists and other health professionals, patient and other stakeholders. ICFbased tools like the RehabManagement-Sheet support the physiotherapist's role within a multidisciplinary team in that these tools enhance transparency in goal- setting and intervention planning across disciplines. This possibly encourages interprofessional collaboration, use of synergies and therefore rehabilitation outcome. Nevertheless, further research and implementation efforts are needed to optimize clinical utility and feasibility, especially in exploring the great potential of electronic medium. Amidst the challenges, using the ICF-based tools presented in this paper paves a promising path for implementing the ICF in physiotherapy practice within multidisciplinary rehabilitation.

\section{References}

1. Family Health Teams. Guide to Interdisciplinary Team Roles and Responsibilities. 2005; Available from: http://www.health.gov.on.ca/en/pro/programs/fht/docs/fht_inter_team.pdf. Accessed 12 Aug 2013.

2. Vocational Rehabilitation Task Group - Industrial Injuries Advisory Council, Waddell G, Burton AK, Kendall NA. Vocational rehabilitation - what works, for whom, and when? 1st ed. London: TSO (The Stationery Office); 2008.

3. Brunarski D, Shaw L, Doupe L. Moving toward virtual interdisciplinary teams and a multi-stakeholder approach in community-based return-to-work care. Work 2008;30(3):329-36.

4. O'Daniel M, Rosenstein A. Professional Communication and Team Collaboration. In: Hughes R, editor. Patient Quality and Safety. An evidence based handbook for Nurses. 1st ed. Rockville, MD, US: Agency for Healthcare Research and Quality; 2008. p. 1-14.

5. Shaw L, Walker R, Hogue A. The art and science of teamwork: Enacting a transdisciplinary approach in work rehabilitation. Work 2008;30(3):297-306.

6. D'Amour D, Ferrada-Videla M, San Martin Rodriguez L, Beaulieu MD. The conceptual basis for interprofessional collaboration: core concepts and theoretical frameworks. J Interprof Care 2005;19 Suppl 1:11631.

7. Feuerstein M. A Multidisciplinary Approach to the Prevention, Evaluation, and Management of Work Disability. J Occup Rehabil 1991;1(1):5-12. 
8. Loisel P, Durand P, Abenhaim L, Gosselin L, Simard R, Turcotte J, et al. Management of occupational back pain: the Sherbrooke model. Results of a pilot and feasibility study. Occup Environ Med 1994;51(9):597602.

9. Franche RL, Krause N. Readiness for return to work following injury or illness: conceptualizing the interpersonal impact of health care, workplace, and insurance factors. J Occup Rehabil 2002;12(4):233-56.

10. Desiron HA, Donceel P, de Rijk A, Van Hoof E. A Conceptual-Practice Model for Occupational Therapy to Facilitate Return to Work in Breast Cancer Patients. J Occup Rehabil 2013;23(4):516-26.

11. Stephens B, Gross DP. The influence of a continuum of care model on the rehabilitation of compensation claimants with soft tissue disorders. Spine (Phila Pa. 1976) 2007;32(25):2898-904.

12. Chamberlain MA, Fialka Moser V, Schuldt Ekholm K, O'Connor RJ, Herceg M, Ekholm J. Vocational rehabilitation: an educational review. J Rehabil Med 2009;41(11):856-69.

13. World Health Organization. International Classification of Functioning, Disability and Health. Geneva, Switzerland: World Health Organization; 2001.

14. Leyshon RT, Shaw LE. Using the ICF as a conceptual framework to guide ergonomic intervention in occupational rehabilitation. Work 2008;31(1):47-61.

15. Escorpizo R, Reneman MF, Ekholm J, Fritz J, Krupa T, Marnetoft SU, et al. A Conceptual Definition of Vocational Rehabilitation Based on the ICF: Building a Shared Global Model. J Occup Rehabil 2011;21(2):126-33.

16. Motor Neurone Disease Association editor. Multidisciplinary working: a best practice guide - provided by the Motor Neurone Disease Association. 1st ed. Northampton: Motor Neurone Disease Association; 2011.

17. Glassel A, Rauch A, Selb M, Emmenegger K, Luckenkemper M, Escorpizo R. A case study on the application of International Classification of Functioning, Disability and Health (ICF)-based tools for vocational rehabilitation in spinal cord injury. Work 2012;41(4):465-74.

18. Bickenbach J, Cieza A, Selb M, Emmenegger K, Lückenkemper M, Escorpizo R editors. ICF Core Sets: Manual for Clinical Practice. 1st ed. Göttingen: Hogrefe; 2012.

19. Lohmann S, Decker J, Muller M, Strobl R, Grill E. The ICF forms a useful framework for classifying individual patient goals in post-acute rehabilitation. J Rehabil Med 2011;43(2):151-5.

20. Huber EO, Tobler A, Gloor-Juzi T, Grill E, Gubler-Gut B. The ICF as a way to specify goals and to assess the outcome of physiotherapeutic interventions in the acute hospital. J Rehabil Med 2011;43(2):174-7.

21. Tempest S, McIntyre A. Using the ICF to clarify team roles and demonstrate clinical reasoning in stroke rehabilitation. Disabil Rehabi. 2006;28(10):663-7.

22. Guzman J, Esmail R, Karjalainen K, Malmivaara A, Irvin E, Bombardier C. Multidisciplinary bio-psychosocial rehabilitation for chronic low back pain. Cochrane Database Syst Rev 2002;(1):CD000963.

23. Henchoz Y, de Goumoens $P$, So AK, Paillex R. Functional multidisciplinary rehabilitation versus outpatient physiotherapy for non-specific low back pain: randomized controlled trial. Swiss Med Wkly 2010;140:w13133.

24. Dagenais S, Caro J, Haldeman S. A systematic review of low back pain cost of illness studies in the United States and internationally. Spine J 2008;8(1):8-20.

25. Hoy D, Bain C, Williams G, March L, Brooks P, Blyth F, et al. A systematic review of the global prevalence of low back pain. Arthritis Rheum 2012;64(6):2028-37.

26. Gerfin A. Rückenreport Schweiz 2011: Die Erhebung zur Rückengesundheit von Herrn und Frau Schweizer. Zürich: Rheumaliga Schweiz; 2011.

27. Schiller J, Lucas J, Ward B, Peregoy J. Summary health statistics for U.S. adults: National Health Interview Survey, 2010. Vital Health Stat 10 (252): National Center for Health Statistics. 2012.

28. Chou R, Qaseem A, Snow V, Casey D, Cross JT,Jr, Shekelle P, et al. Diagnosis and treatment of low back pain: a joint clinical practice guideline from the American College of Physicians and the American Pain Society. Ann Intern Med 2007;147(7):478-91.

29. Lin CW, Haas M, Maher CG, Machado LA, van Tulder MW. Cost-effectiveness of guideline-endorsed treatments for low back pain: a systematic review. Eur Spine J 2011;20(7):1024-38. 
30. Finger ME, Escorpizo R, Glassel A, Gmunder HP, Luckenkemper M, Chan C, et al. ICF Core Set for vocational rehabilitation: results of an international consensus conference. Disabil Rehabil 2012;34(5):429-38.

31. Cieza A, Ewert T, Üstün B, Chatterji S, Kostanjsek N, Stucki G. Development of ICF Core Sets for patients with chronic conditions. J Rehabil Med (Suppl) 2004;36(44):9-11.

32. Cieza A, Stucki G, Weigl M, Disler P, Jäckel W, S, et al. ICF Core Sets for low back pain. J Rehabil Med (Suppl) 2004;36(44):69-74.

33. Escorpizo R, Finger ME, Reneman MF. Integration and Application of the International Classification of Functioning, Disability and Health (ICF) in Return-to-Work. In: Schultz IZ, Gatchel R, editors. Handbook of Return to Work: Springer; 2013.

34. Finger M, Escorpizo R. The Work Rehabilitation Questionnaire - WORQ. 2013; Available from: http://www.myworq.org/. Accessed 1 Apr 2014.

35. Rauch A, Escorpizo R, Riddle DL, Eriks-Hoogland I, Stucki G, Cieza A. Using a case report of a patient with spinal cord injury to illustrate the application of the International Classification of Functioning, Disability and Health during multidisciplinary patient management. Phys Ther 2010;90(7):1039-52.

36. Rauch A, Cieza A, Stucki G. How to apply the International Classification of Functioning, Disability and Health (ICF) for rehabilitation management in clinical practice. Eur J Phys Rehabil Med 2008;44(3):32942.

37. Nicholas MK, Asghari A, Blyth FM, Wood BM, Murray R, McCabe R, et al. Self-management intervention for chronic pain in older adults: a randomised controlled trial. Pain 2013;154(6):824-35.

38. Kori,S.H. Miller,R.P. Todd,D.D. Kinesiophobia: a new view of chronic pain behaviour. Pain Management 1990(3):35-43.

39. Goubert L, Crombez G, Van Damme S, Vlaeyen JW, Bijttebier P, Roelofs J. Confirmatory factor analysis of the Tampa Scale for Kinesiophobia: invariant two-factor model across low back pain patients and fibromyalgia patients. Clin J Pain 2004;20(2):103-10.

40. Reneman MF, Dijkstra PU, Westmaas M, Göeken LNH. Test-retest reliability of lifting and carrying in a 2day functional capacity evaluation. J Occup Rehabil 2002;12:269-75.

41. Uhlig T, Lillemo S, Moe RH, Stamm T, Cieza A, Boonen A, et al. Reliability of the ICF Core Set for rheumatoid arthritis. Ann Rheum Dis 2007;66(8):1078-84.

42. Verhoef J, Toussaint PJ, Putter H, Zwetsloot-Schonk JH, Vliet Vlieland TP. The impact of introducing an ICF-based rehabilitation tool on staff satisfaction with multidisciplinary team care in rheumatology: an exploratory study. Clin Rehabi. 2008;22(1):23-37.

43. Verhoef J, Toussaint PJ, Zwetsloot-Schonk JH, Breedveld FC, Putter H, Vliet Vlieland TP. Effectiveness of the introduction of an International Classification of Functioning, Disability and Health-based rehabilitation tool in multidisciplinary team care in patients with rheumatoid arthritis. Arthritis Rheum 2007;57(2):240-8.

44. Spreyermann R, Luthi H, Michel F, Baumberger ME, Wirz M, Mader M. Long-term follow-up of patients with spinal cord injury with a new ICF-based tool. Spinal Cord 2011;49(2):230-5. 

Chapter 7

General Discussion 


\section{Introduction}

Vocational rehabilitation is increasingly acknowledged by policy-makers, payers, health professionals and researchers as a key process in disability management to return injured or ill workers to work as soon as possible [1,2]. Evidence is growing that successful vocational rehabilitation programs involve multidisciplinary approaches, early intervention and case management throughout the entire return-to-work process [3-6]. Another crucial element in successful vocational rehabilitation is effective communication between all stakeholders, independent of the worker's health condition, practice settings or the stage of the rehabilitation process [7]. Vocational rehabilitation interventions commonly target aspects of physical and mental functioning, vocational education or retraining and workplace accommodation $[2,8]$. Given the variability of requirements found throughout the vocational rehabilitation process, including the number of interfaces between clients, settings and stakeholders as well as the different interests and perspectives of all the involved, appropriate information, communication and coordination become a challenge [9].

Even when looking at multidisciplinary vocational intervention, a common understanding of the patients' needs, problems and abilities, an agreement on the intervention goals and a clear goal-centered allocation of responsibilities for all team members is crucial for successful goal achievement $[10,11]$. Far too often health professionals present only their own discipline-oriented perspective in interdisciplinary team meetings and patient status reporting and use discipline- specific terminology. This can lead to constrained interprofessional collaboration, and in turn hamper synergies and the coordination of joint efforts that could support the patient in reaching his or her rehabilitation goals. To counter this, a common language in the team and a joint understanding of the patient's problems and goals could improve an effective exchange of information and appropriate allocation of responsibilities and resources, thus enhancing the patient's achievement of rehabilitation goals.

Another field of vocational rehabilitation, where a common framework would help to acquire an overview over the existing and emerging knowledge is research. And since in recent years the body of evidence, on e.g. risk factors for work disability [1214], the appraisal of rehabilitation strategies and distinct interventions to improve the return-to-work outcome, has grown continuously, there exists a challenge to keep track of these new developments.

The International Classification of Functioning, Disability and Health (ICF) provides a framework and common language for organizing and documenting information on functioning and disability and its influencing factors (WHO 2001) [15]. As a common language and tool to structure function related information the use of the ICF would be beneficial for vocational rehabilitation practice and research $[16,17]$.

This thesis reports on the research that introduces and evaluate the use of the ICF as a reference framework for functioning in the field of vocational rehabilitation and on 
the development of ICF based tools to facilitate the integration of the ICF into clinical practice of vocational rehabilitation [18-23]. The main findings addressing the specific aims introduced in the general introduction (chapter 1 ) are discussed below.

\section{Main Results}

\section{Content validity of the ICF as a reference framework of functioning in vocational rehabilitation.}

In a cross-sectional study (chapter 2) [18], the functioning of 152 individuals in five different vocational rehabilitation settings was evaluated. For this purpose an extended ICF checklist, based on the ICF checklist of the WHO [24] amended with ICF categories specifically identified by a literature search and expert advice was used to capture relevant functioning aspect in vocational rehabilitation. A visual-analogue scale from 0-100 was used to rate the extent of a problem a patient had in a particular ICF category [25]. The ICF checklist contains categories from all functioning components of the ICF: body functions, body structures, activities and participation and environmental factors. Personal factors such as sociodemographics and work-related factors were also collected. In this study 100 out of 152 second-level ICF categories were identified to be relevant for at least $20 \%$ of the participants. Data was collected by reviewing medical records and conducting patient interviews. At the end of the interview, patients were asked if they felt if other relevant aspects of their functioning were missing from the interview. No further aspects of functioning were mentioned as relevant. However, 6 persons (4\%) reported additional aspects of the environment that impacted on their functioning. These were mostly related to work such as specific job demands $(n=3)$ or lack of work breaks $(n=2)$ [26]. Based on the results of this study we concluded that the ICF framework, as reflected by the ICF checklist, showed good face and content validity in evaluating functioning in vocational rehabilitation.

One criticism of the ICF is its lack of direct applicability and granularity in relation to some features of vocational rehabilitation, which leads to thinking by some health professionals and researchers that the ICF does not adequately cover all the necessary aspects of vocational rehabilitation that need to be assessed. Hence, a secondary data analysis (chapter 3$)[19,20]$ using data from three studies carried out as part of the entire project was conducted in order to look at those concepts that were unable to be linked to a distinct ICF category, hence coded as "nd", "pf" and "nc". It was shown that $87.2 \%$ of these concepts were covered by the biopsychosocial model of the ICF. $31.6 \%$ belonged to the domains of functioning or the environment. It seems that these concepts were considered either too broad or too precise to be linked to distinct ICF categories in the previous studies. $55.6 \%$ of the concepts were related to personal factors. Only $12.8 \%$ of concepts were "nc" not covered by the biopsychosocial model of the 
ICF. Most of these "nc" concepts belonged to two themes i.e. "well-being" that includes quality of life [27] and "attributes related to processes and time"[28]

\section{Development of an international standard and methodological approach for applications based on the ICF in vocational rehabilitation.}

While the ICF with its 1424 plus categories was intended to represent all major aspects of functioning in the context of health, this comprehensiveness might pose a challenge to feasibility of use $[29,30]$. To enhance the usability of the ICF in the context of vocational rehabilitation, an extraction of the ICF in the form of the ICF Core Set for vocational rehabilitation was developed (chapter 4) [20]. The comprehensive Core Set contains 90 ICF categories and 13 categories make up the brief Core Set. The categories included reflect the components of activities and participation (40 categories in the comprehensive Core Set / 6 categories in the brief Core Set), environmental factors (33/4 categories) and body functions (17/3 categories). While the ICF Core Set for vocational rehabilitation was developed to serve as an international standard when evaluating individuals in vocational rehabilitation, irrespective of the initial health condition, setting or stage of rehabilitation, still some aspects of functioning may not be as relevant for certain patient groups as for others. For instance, when evaluating the functioning of persons with musculoskeletal problems in the context of vocational rehabilitation, the focus will be different than when evaluating people with visual impairment or people with a spinal cord injury [31-33]. On the other hand the comprehensive approach of the ICF Core Set may help clinicians to document all relevant functioning problems, even those caused by comorbidities or ageing [34]. Comorbidities were common in our sample of individuals in vocational rehabilitation, e.g. $52 \%$ as noted in our cross-sectional study [18] and $78 \%$ in the sample where we tested the psychometric properties of the WORQ [22]. This finding of comorbidities is consistent with the literature. Comorbidities such as cardiovascular diseases or mental problems are identified as determinants of return-to-work [35,36], and may therefore play a crucial role for goal setting and intervention planning.

In clinical practice or research agreeing on the relevant aspects that should be considered in the field $[37,38]$ is an essential first step towards transparency and developing common strategies to improve sustained return-to-work. With the development of the ICF Core Set for vocational rehabilitation the gateway to an ICF-based international reference standard to assess and document work functioning in the context of vocational rehabilitation has to open. This standard has now to be put to the test in different populations, settings and throughout the whole vocational rehabilitation process [34].

The development of the ICF Core Set for vocational rehabilitation is a first attempt towards the integration of the ICF in clinical practice. However, it is not without challenge. The categories of the ICF essentially indicate what to assess when evaluating 
functioning [39]. In employing the "WHO ICF qualifiers" one might be able to assess the magnitude of the problem in functioning. However, the lack of reliability and sensitivity pose a difficulty in interpreting change $[40,41]$ in the context of intervention. This gap led to the development of the first version of the Work Rehabilitation Questionnaire (WORQ) (chapter 5) [22]. WORQ items are entirely based on the ICF Core Set for vocational rehabilitation. It covers all categories of the brief Core Set complemented with categories from the comprehensive Core Set which were selected based on an explorative Rasch-analysis. Moreover, evidence from the literature was also considered in the selection of further additional items. WORQ contains 18 sociodemographic and workrelated questions in part 1 and 36 questions evaluating functioning in part 2 . The second part contained questions targeting physical, mental and social functioning.

The WORQ was tested in a sample $(n=74)$ of musculoskeletal and neurological patients participating in vocational rehabilitation in a rehabilitation center in Switzerland. Preliminary psychometrics are encouraging. Test-retest reliability evaluated with a Spearman correlation (0.789) and internal consistency showed a Cronbach's alpha of 0.883 [42-44]. The WORQ may be used to document a functioning profile of individuals in vocational rehabilitation and as an outcome measure on an individual basis. It may not be appropriate to compare sum scores across groups of individuals, at this point in time.

Looking at usability, the WORQ was mostly appreciated by the patients as they felt that the questionnaire allowed them to reflect upon their daily problems in functioning and express the full range of problems they considered as barriers for a successful return to work. Although the information gained through WORQ was valued by the professionals, the time of 25 minutes (on average) needed to administer WORQ by clinician interviewers was reported to be a major obstacle to integrating WORQ in daily practice. The first interviewer administered version of WORQ can be seen as an example of how to approach the design of ICF-based instruments that evaluate functioning in vocational rehabilitation.

\section{Clinical application of ICF based tools in vocational rehabilitation.}

Although the biopsychosocial model of the ICF is increasingly considered when describing functioning and disability in the context of rehabilitation medicine $[39,45,46]$, the effective integration of the ICF as a classification system into clinical practice may be cumbersome and untested $[47,48]$. The ICF, being a classification system, does not per se model the "process" of functioning and disability. It is intended to describe functioning by compiling functioning profiles on distinct points in time and may be repeated when needed. However, in the ICF book it is explicitly stated that the ICF can be used [28], to describe a process of functional change by providing a timely description of functioning that can be included in any process capturing functioning or disability. 
To encourage the integration of the ICF and ICF based tools in structuring rehabilitation programs, management processes or interventions, we illustrated one case on how the ICF [15], ICF Core Sets [49], WORQ [22] and an "ICF based Management Sheet" [10,50] could be used to structure a vocational rehabilitation program for nonspecific low back pain (chapter 6)[23].

Based on the fact that the ICF is increasingly used as the model in rehabilitation management or when developing rehabilitation processes or interventions, these programs are often referred to as "ICF based programs or interventions" or as using an "ICF approach"[51-53], indicating that functioning is monitored over time by using the ICF classification or the ICF conceptual model. Therefore, the author of this thesis proposes that the terminology "ICF model" or "ICF classification" is used when referring to the theoretical framework of the ICF. In addition the terms "ICF based rehabilitation" or "ICF based approach" should be used when referring to a clinical application or the description of a process of functioning or disability using the ICF as a framework.

\section{Reflections and limitations}

In this section, we will discuss the issues of the study design that could have influenced the results of our study.

\section{Cross sectional study}

The cross sectional study [18] was designed to identify and to quantify the problems in functioning of participants in vocational rehabilitation. We used the ICF checklist of the WHO but since we felt that the original checklist would not cover all the needs of participants in vocational rehabilitation, we decided to extend the original checklist with aspects relevant to functioning identified in the literature. In a further step we included additional aspects judged as relevant by vocational rehabilitation specialists from different professions such as physiotherapists, occupational therapists, vocational counselors and work reintegration specialists. Although we tried to be as inclusive as possible, we could have missed some relevant aspects of functioning in our extended checklist. On the other hand none of the participants reported further functioning problems that were missed at the end of the interview. This fact is a reassurance that we have comprehensively captured the indicators of functioning within a vocational rehabilitation context. Our study sample might be underpowered. Regardless of the fact that we included five different study centers, mental conditions and internal medical conditions like coronary heart diseases and cancer, were underrepresented [54]. Although the group of participants with a primary mental disorder was small in our study population, over $25 \%$ of the participants with other primary diagnosis reported mental problems as comorbidity. Therefore, we assume that all functioning categories relevant to describe 
work functioning in individuals with mental disorders were identified. The group of participants with internal medical conditions as a primary diagnosis on the other hand was just $5 \%$. As only categories relevant to at least $20 \%$ of the total sample were reported, functioning and environmental factor categories only relevant to individuals with internal medical conditions may be missed. It would be interesting if our findings could be confirmed in a population with solely made up or persons with only a mental disorder or how the functioning pattern would look in populations with diverse internal conditions.

\section{Secondary data analysis of concepts that could not be linked to the ICF Concepts: "nd" not definable, "pf" personal factors or "nc" not covered}

After grouping and analyzing all 3458 concepts that could not be linked to a distinct ICF category, to our surprise over $87 \%$ were covered by the biopsychosocial model of the ICF. $56 \%$ of the concepts belonged to personal factors, which are a component of the ICF that has yet to be classified. Using the newly developed personal factors classification of Geyh et al. $[55,56]$ employed together with the ICF classification, was expedient in the context of vocational rehabilitation. This approach provided us with a wellstructured synopsis of sociodemographic and biographical data, feelings, attitudes and beliefs. The category patterns of behaviors and handling behaviors in addition referred to (work-related) skills, coping strategies and life style. Most of the factors were confirmed in the vocational rehabilitation literature [14, 57-59], but no review or study provided such a comprehensive overview. The use of an existing classification allowed us further to compare our results to findings in specific health conditions, such as spinal cord injury [60] or in medical work capacity evaluations [61]. One aspect of the classification of Geyh et al. in vocational rehabilitation that we considered as challenging is the very broad definition of the specification level for learned abilities and skills. Learned abilities and skills are considered as crucial factors in return-to-work. In conclusion, a personal factors classification would improve systematic and comparable data collection in vocational rehabilitation. The classification of Geyh et al. proved to be beneficial in our study and its use in vocational rehabilitation should be further evaluated.

One main theme that emerged out of the $13 \%$ of concepts "nc" not covered by the ICF was "attributes related to processes and time". This theme refers to the periods, time points or aspects related to change over time e.g. start of vocational rehabilitation program, and time needed to recover. It has to be noticed that the ICF can provide functioning profiles, but is not designed to depict a time course. Time related attributes are needed when modeling the "process" of functioning and disability. To monitor a return-to-work process or program, distinct time points such as the start of an intervention or discharge as well as time periods as return-to-work time or time of sick leave, are needed as confirmed by the experts, in the literature and by patients themselves [62-65]. 
Another relevant theme not covered by the ICF is well-being. It is important to clarify that the concept of well-being is not equivalent to the concept of functioning. In the ICF "well-being" is defined to be a general term encompassing the total universe of human life domains, including physical, mental and social aspects that make up what can be called a "good life" [66]. Another frequently used definition of "well-being" is the one espoused by the Organization for Economic Co-operation and Development (OECD) "Subjective well-being reflects the notion that how people experience a set of circumstances is as important as the circumstances themselves and that people are the best judges of how their own lives are going " [67]. This definition is closely linked to the concept of quality of life; for which also various definitions have been proposed [6871].

From the perspective of WHO, described in Annex 1 of the ICF, well-being encompasses all human life domains. Health domains including physical, mental and social aspects and health-related domains such as education, employment or the environment are seen as a subset of domains that make up the total universe of human life. In this context, the concept of functioning and disability is seen as "objective well-being referring to objective and externalized signs of the individual". In contrast to "functioning, disability and health" (ICF), the concept of "quality of life" deals with subjective [72] and internalized signs or with what people "feel" about their health condition or its consequences and can therefore be seen as a construct of "subjective well-being".

Depending on the aim, functioning or quality of life should be assessed independently and may complement each other [73].

\section{Consensus conference}

When reviewing the development process for the ICF Core Set for vocational rehabilitation several points could have impacted the result. First, the ICF Core Set was developed in an expert consensus process. The experts identified the most relevant categories from a preselected list of 752 ICF categories. Despite this extensive list, we could have missed presenting a category that is relevant to a particular expert. To minimize this risk, we asked the experts after deciding on the comprehensive Core Set to review its content as a whole and if needed, to propose potentially missing ICF categories. However no additional categories were proposed.

As the ICF Core Set was developed to become an international standard in vocational rehabilitation, the experts had to considerate the whole process of vocational rehabilitation and represent the needs of the clinical and research settings, multiple disciplines and providers of vocational rehabilitation in all the six WHO regions. The consensus conference was carefully moderated and guided in every step of the iterative process. However, the selection of the experts, the expert's personal experience and their fluency in the English language may have influenced the selection of categories. 
Another critical point of an expert panel approach is the lack of patient representation. To integrate the patient perspective into the decision process, the experts were constantly asked to also consider the data from the patient focus group study. Despite the effort to consider the patient perspective in the ICF Core Set, the final version of the comprehensive ICF Core Set for vocational rehabilitation, does not include any ICF categories related to chapter 9: Recreation and Leisure, although the category d920 Recreation and Leisure was mentioned as important in all 7 focus groups [74].

The fact that Recreation and Leisure activities were ignored in the final Core Set contradicts evidence from the literature emphasizing the importance to keep a healthy balance between work and recreation as a basis for sustained work productivity $[75,76]$. As often seen in patients, the extra effort spent within a vocational rehabilitation program and later in the workplace as result of their functional problems, may lead to depletion of their physical and psychological resources $[77,78]$. Without appropriate recovery from such strenuous efforts made during vocational rehabilitation interventions or work, increasing exhaustion may lead to delayed return-to-work or even renewed sick leave [59]. An additional aspect of work life balance is stressed by the OECD: "The ability to combine work, family commitments and personal life is also important for society as a whole, as it ensures that people have sufficient time to socialize and participate in the life of the community" [67].

To ensure that the ICF Core Set for vocational rehabilitation covers the patients' needs as well as those of clinicians and researchers, the 90 categories have to be tested in various settings and patient groups perhaps in parallel with other determinants of work such as recreation and leisure and non-remunerative work.

\section{The Work Rehabilitation Questionnaire - WORQ}

When reflecting on the development process of the Work Rehabilitation Questionnaire (WORQ) a-priori requirements had to be met. The first one was that WORQ should be able to assess work functioning irrespective of the health condition, the setting or the stage of vocational rehabilitation. This requirement implies that the questionnaire could be administered by any professional engaged in the vocational process. Therefore the questions as well as the rating scale had to be easy to understand. This decision also implies that WORQ employs a generic rating scale that provided an overview of the aspects most relevant to the functioning of individuals in vocational rehabilitation. When selecting the ICF categories on which WORQ was based, it was clear that our questionnaire would have to be multidimensional.

Data collection for the usability evaluation and psychometric testing was difficult, partially due to time constraints of the health professionals who administered the WORQ and partially due to the eligibility and availability of patients. Despite a two month extension of the recruitment period we were only able to include 74 patients for the first interview, thus preventing us to test for unidimensionality of subscales which 
would require a sample size bigger than $74[79,80]$. At the current stage of the development, the WORQ can be recommended to assess functioning profiles of the patient and to compare them over time. We have limited evidence at this time to be able to robustly compare between patients or patient groups; this is a research agenda that will be pursued in the near future to further support the psychometrics of the WORQ.

As a consequence of the usability testing, where the professionals stated the benefit of a patient administered version of the WORQ, we developed the WORQ-Self which was recently validated in the context of spinal cord injury [81].

\section{Implementation of ICF and ICF based Instruments in clinical practice}

The use and possible implementation of the ICF into clinical practice has been described by several authors reflecting on the topics of clinical decision making $[11,82]$ including the assessment of functioning [10], joint multidisciplinary goal setting $[16,83,84]$, structuring the rehabilitation process $[85,86]$ and planning of interventions $[47,87]$. We illustrated in a teaching case how a multidisciplinary vocational rehabilitation program could benefit by integrating the ICF and ICF based tools into the rehabilitation process. In clinical practice this example can be adapted to restructure current rehabilitation interventions or to develop new approaches in vocational rehabilitation or only to define a common integrative standard on what to assess based on the ICF. The main challenge remains that every facility or health care professional willing to integrate the ICF needs to learn and understand a relatively new (and often unfamiliar) model in the form of the ICF to be able to integrate and utilize the ICF in clinical practice and research.

\section{Implication for further practice}

Vocational rehabilitation is described as a continuous process which starts as early as shortly after the onset of a disease or injury, up to the intended outcome of sustained return-to-work. Depending on the complexity and the duration of this process the patient is confronted with a vast number of stakeholders, settings and interests $[10,88]$ that provide or require information concerning the patient's health state or functioning.

Our findings indicate that the ICF provides a valid framework to evaluate functioning in vocational rehabilitation. Furthermore, with the ICF Core Set for vocational rehabilitation a selection of the most relevant ICF categories could be provided that defines what should be considered when describing and documenting the functioning of a patient in vocational rehabilitation.

The ICF Core Set for vocational rehabilitation could be considered as a resource for guidelines development, in which the ICF categories that are most relevant to assess 
and describe functioning in vocational rehabilitation are listed. For this purpose we recommend that all 13 categories of the brief Core Set [21] along with the additional 7 categories of the Generic ICF Set [89] are assessed for all patients in order to establish a common data basis for a comparison across patients, health conditions and vocational rehabilitation settings. The comprehensive ICF Core Set on the other hand can be seen as a comprehensive pool of ICF categories that can guide clinicians to select the categories needed to describe the functioning of their specific selection of patients beyond what is already provided by the brief Core Set. Ultimately, the responsibility for choosing the adequate ICF categories and the respective assessment measurements remains with the clinician, the multidisciplinary team or the organization as a whole. To successfully implement the ICF as a reference for clinical practice, the professionals need at least a basic knowledge of the ICF model and an understanding of the multidirectional interactions of its components in the description of functioning and disability as well as knowledge concerning the structure of the ICF.

The endorsement of the ICF in 2001 by the World Health Assembly paved the way for increased awareness of researchers and clinicians of the shift of focus from a purely biomedical perspective to that of an integrative functioning perspective [90]. This paradigm shift led to an increased integration of the ICF in the education of health professionals [91]. Additionally, ICF training workshops have been developed all over the world. However, workshops and courses are time consuming and costly. The development of training material to learn about the ICF and its possible clinical applications such as the ICF eLearning tool [92], and a series of case studies provided online by the ICF Research Branch [93] may provide an inexpensive and feasible way to educate users about the ICF.

To support patients and professionals who are not familiar or only partially familiar with the ICF, WORQ-Self is now available. The WORQ is worded in "layman" terms so that is understandable for patients and stakeholders involved in the vocational rehabilitation process. The WORQ assesses self-perceived strengths and problems in functioning and can be administered in an interviewer or patient administered version and is freely available at www.myworq.org. The assessment of self-perceived functioning is increasingly supported by evidence to reliably predict sustained return-to-work and to improve the predictive value of clinical assessment [94], e.g. functional capacity evaluation [95]. WORQ was designed to provide an overview of physical, mental, cognitive and social aspects as well as sociodemographics and work related information that influences the return-to-work process. It can be used to determine specific assessment, goals and interventions and it can be used to document functioning of one patient over time. 


\section{Implications for future research}

Implications for future research of this thesis have emerged addressing the update of the ICF, the testing of the ICF Core Set for vocational rehabilitation and the further development of the WORQ on the one hand and the use of ICF and ICF based tools in the scope of clinical research on the other.

The ICF undergoes regular updates through a update proposal process designated by the WHO $[96,97]$. When looking at the content validation study (chapter 3 ) and the findings with respect to functioning and environmental factors in vocational rehabilitation, a possible update proposal may emphasized an increase in the specificity of the environmental factor component to allow for documentation of facilitators and barriers in a more meaningful way. Another point of ICF debate is represented by the component of personal factors. Personal factors are defined in the ICF as "the particular background of an individual's life and living and comprise features of the individual that are not part of a health condition or health state". Growing research has been done in recent years identifying psychosocial risk factors such as recovery expectation and fear avoidance beliefs [59] as important determinants for the return-to-work process [98]. Hence there is a need for personal factors to be assessed carefully. In the meantime, the use of the personal factor classification of Geyh et al. $[56,57]$ in our study may encourage WHO in their endeavour to classify personal factors within the scope of the ICF. An official classification of personal factors would improve the comparability of clinical results and support a standardized assessment of personal factors considerably, providing a positive impact on how vocational rehabilitation is conducted.

A further challenge for future research will be to establish links between the ICF concept of functioning with quality-of-life concepts and the measurement of subjective well-being. Therefore, deeper insights into the complex interactions between functioning and quality of life are needed. As there is still no agreement on the definition of quality of life [99], determinants to clearly distinguish between both the concept of functioning and the concept of quality of life have to be identified. Moreover, implications for use of both concepts in the context of vocational rehabilitation needs to be clarified.

Although the ICF Core Set for vocational rehabilitation is found to be the most comprehensive tool to capture functioning in patients participating in vocational rehabilitation [35] it still has to be tested in varying health condition groups and across care settings. Future studies could explore whether health condition specific or setting specific patterns of functioning exist within the context of vocational rehabilitation.

The WORQ was first designed as an interviewer administered version with the aim to assess and document functioning in the context of vocational rehabilitation for individual patients. A self-administered version of the WORQ (i.e. WORQ-Self) was also developed. Currently the translation of the first version of the WORQ-Self, including the testing of psychometrics, is planned in French, Italian, Chinese, and Finnish. As a next 
step, an investigation into the dimensionality of WORQ-Self is planned that will examine whether uni-dimensional subscales could be identified. This would allow the application of the WORQ-Self-Future-Version to compare the functioning of individuals and patient groups. The development of the WORQ and WORQ-Self may serve as an example of how further ICF based instruments could be developed.

Since we found the ICF to be a valid framework for vocational rehabilitation its use can be recommended to structure evaluative and interventions studies in return-towork. When determining study outcomes, components of functioning should be considered (body function, body structure, activity and participation) and relevant environmental and personal factors are to be documented. Collecting data in all ICF components may enhance future understanding of their complex interaction.

\section{Final conclusions}

This thesis demonstrates that the ICF provides a valid framework to describe and document functioning in the context of vocational rehabilitation and that ICF based standards such as the ICF Core Set for vocational rehabilitation and ICF based tools like the WORQ have the potential to improve rehabilitation management and clinical practice within the context of vocational rehabilitation.

Since the start of the ICF Core Set project for vocational rehabilitation, the knowledge about the ICF amongst health and vocational professionals has increased and the agreement to set the focus of vocational rehabilitation on work participation as endpoint has been enhanced. We believe that further evidence on the benefits with respect to the time required for documentation, quality of care, and transparency of multidisciplinary communication will continue to increase the uptake of the ICF in clinical practice. In addition, evolving technical support systems like ICF based electronic documentation systems will not only facilitate the successful implementation of the ICF in vocational rehabilitation programs, it would encourage health and vocational professionals, providers of health services and other stakeholders to use the ICF.

\section{References}

1. International Labour Organization (ILO).Managing disability in the workplace. ILO code of practice. Geneva: International Labour Office; 2002.

2. Vocational Rehabilitation Task Group - Industrial Injuries Advisory Council, Waddell G, Burton AK, Kendall NA. Vocational rehabilitation - what works, for whom, and when? 1st ed. London: TSO (The Stationery Office); 2008.

3. Brunarski D, Shaw L, Doupe L. Moving toward virtual interdisciplinary teams and a multi-stakeholder approach in community-based return-to-work care. Work 2008;30(3):329-36.

4. Hoefsmit N, Houkes I, Nijhuis FJ. Intervention characteristics that facilitate return to work after sickness absence: a systematic literature review. J Occup Rehabil 2012;22(4):462-77. 
5. Marnetoft SU, Selander J, Bergroth A, Ekholm J. Factors associated with successful vocational rehabilitation in a Swedish rural area. J Rehabil Med 2001 03;33(2):71-8.

6. Ewers M, Schaeffer D. Case Management in Theorie und Praxis. 2nd ed. Bern: Huber Verlag; 2005.

7. O'Daniel M, Rosenstein A. Professional Communication and Team Collaboration. In: Hughes R, editor. Patient Quality and Safety. An evidence based handbook for Nurses. 1st ed. Rockville, MD, US: Agency for Healthcare Research and Quality; 2008. p. 1-14.

8. Franche RL, Cullen K, Clarke J, MacEachen E, Frank J, Sinclair S, et al. Workplace-based Return-to-Work Interventions: A Systematic Review of the Quantitative and Qualitative Literature (Summary). J Occup Rehabil. 2005;15(4):607-31.

9. Leyshon R, Shaw L. Using multiple stakeholders to define a successful return to work: a concept mapping approach. Work 2012;41(4):397-408.

10. Glassel A, Rauch A, Selb M, Emmenegger K, Luckenkemper M, Escorpizo R. A case study on the application of International Classification of Functioning, Disability and Health (ICF)-based tools for vocational rehabilitation in spinal cord injury. Work 2012;41(4):465-74.

11. Lohmann S, Decker J, Muller M, Strobl R, Grill E. The ICF forms a useful framework for classifying individual patient goals in post-acute rehabilitation. J Rehabil Med 2011;43(2):151-5.

12. Oyeflaten I, Lie SA, Ihlebaek CM, Eriksen HR. Prognostic Factors for Return to Work, Sickness Benefits, and Transitions Between These States: A 4-year Follow-up After Work-Related Rehabilitation. J Occup Rehabil 2013 Aug 9.[Epub ahead of print].

13. Virtanen $P$, Janlert $U$, Hammarstrom A. Health status and health behaviour as predictors of the occurrence of unemployment and prolonged unemployment. Public Health 2013;127(1):46-52.

14. Streibelt M, Egner U. A Systematic Review of the Predictors of Return to Work Following Vocational Retraining. Rehabilitation (Stuttg) 2013;52(2):111-8.

15. World Health Organization. International Classification of Functioning, Disability and Health. Geneva, Switzerland: World Health Organization; 2001.

16. Huber EO, Tobler A, Gloor-Juzi T, Grill E, Gubler-Gut B. The ICF as a way to specify goals and to assess the outcome of physiotherapeutic interventions in the acute hospital. J Rehabil Med 2011;43(2):174-7.

17. Tempest S, McIntyre A. Using the ICF to clarify team roles and demonstrate clinical reasoning in stroke rehabilitation. Disabil Rehabil 2006;28(10):663-7.

18. Finger ME, Glassel A, Erhart P, Gradinger F, Klipstein A, Rivier G, et al. Identification of Relevant ICF Categories in Vocational Rehabilitation: A Cross Sectional Study Evaluating the Clinical Perspective. J Occup Rehabil 2011;21(2):156-66.

19. Finger M, De Bie R, Selb M, Escorpizo R. An examination of concepts in vocational rehabilitation that cannot be linked to the ICF using a qualitative analysis of secondary data. [under review].

20. Finger ME, Escorpizo R, Glassel A, Gmunder HP, Luckenkemper M, Chan C, et al. ICF Core Set for vocational rehabilitation: results of an international consensus conference. Disabil Rehabil 2012;34(5):429-38.

21. Finger M, Escorpizo R. The Work Rehabilitation Questionnaire - WORQ. 2013; Available from: http://www.myworq.org/. Accessed 2013 Dec, 13.

22. Finger M, Escorpizo R, Bostan C, De Bie R. Work Rehabilitation Questionnaire (WORQ): Development and preliminary psychometric evidence of an ICF-based questionnaire for vocational rehabilitation. J. Occup. Rehabil. 2013 Nov 27. [Epub ahead of print].

23. Finger $M$, Selb M, Escorpizo R. Using ICF in physiotherapy in multidisciplinary vocational rehabilitation: $A$ case study of low back pain. 2014 Feb 13. DOI: 10.1002/pri.1587 [Epub ahead of print].

24. World Health Organization. ICF Checklist. 2003; Available from: http://www.who.int/classifications/icf/training/icfchecklist.pdf. Accessed 2013 Dec 10.

25. Wewers ME, Lowe NK. A critical review of visual analogue scales in the measurement of clinical phenomena. Res Nurs Health $1990 ; 13(4): 227-36$.

26. Homa DB. Using the International Classification of Functioning, Disability and Health (ICF) in job placement. Work 2007;29(4):277-86. 
27. OECD. Definition of Quality of Life. Glossary of Environment Statistics, Studies in Methods, Series F, No. 67, United Nations, New York, 1997. 2005; Available from: http://stats.oecd.org/glossary/detail.asp?ID=2218. Accessed 2013 Aug 3.

28. World Health Organization (WHO). Annex 2: Coding guidelines for ICF. In: WHO, editor. Internationanl Classification of Functioning, Disability and Health. Geneva: WHO; 2001. p. 219-233.

29. World Health Organization (WHO) editor. How to use ICF: A practical manual for using the International Classification of Functioning, Disability and Health. Exposure draft for comment ed. Geneva, Switzerland: World Health Organization; 2013.

30. Cieza A, Ewert T, Üstün B, Chatterji S, Kostanjsek N, Stucki G. Development of ICF Core Sets for patients with chronic conditions. J Rehabil Med (Suppl) 2004;36(44):9-11.

31. Franche RL, Pole JD, Hogg-Johnson S, Vidmar M, Breslin C. The impact of work-related musculoskeletal disorders on workers' caregiving activities. Am J Ind Med 2006;49(9):780-90.

32. Smith PM, Black O, Keegel T, Collie A. Are the Predictors of Work Absence Following a Work-Related Injury Similar for Musculoskeletal and Mental Health Claims? J Occup Rehabil 2014;24(1):79-88.

33. Kivioja AH, Myllynen PJ, Rokkanen PU. Is the treatment of the most severe multiply injured patients worth the effort? A follow-up examination 5 to 20 years after severe multiple injury. J Trauma 1990;30(4):480-3.

34. Saltychev M, Kinnunen A, Laimi K. Vocational rehabilitation evaluation and the International Classification of Functioning, Disability, and Health (ICF). J. Occup. Rehabil. 2013;23(1):106-14.

35. Holtslag HR, Post MW, van der Werken C, Lindeman E. Return to work after major trauma. Clin Rehabil 2007;21(4):373-83.

36. Varekamp I, van Dijk FJ, Kroll LE. Workers with a chronic disease and work disability : Problems and solutions. Bundesgesundheitsblatt Gesundheitsforschung Gesundheitsschutz. 2013;56(3):406-14.

37. Fekete C, Boldt C, Post M, Eriks-Hoogland I, Cieza A, Stucki G. How to measure what matters: development and application of guiding principles to select measurement instruments in an epidemiologic study on functioning. Am J Phys Med Rehabil 2011;90 (11 Suppl 2):S29-38.

38. Post MWM, Brinkhof MWG, von Elm E, Boldt C, Brach M, Muff C, et al. Swiss Spinal Cord Injury Cohort Study (SwiSCI): Design of an ICF-based cohort study. Am J Phys Med Rehab. 2011;90(11 Suppl 2):5-16.

39. Stucki G, Cieza A, Ewert T, Kostanjsek N, Chatterji S, Ustun TB. Application of the International Classification of Functioning, Disability and Health (ICF) in clinical practice. Disabil Rehabil 2002;20;24(5):281-2.

40. Okochi J, Utsunomiya S, Takahashi T. Health measurement using the ICF: test-retest reliability study of ICF codes and qualifiers in geriatric care. Health Qual Life Outcomes 2005;29;3:46.

41. Jette AM, Norweg A, Haley SM. Achieving meaningful measurements of ICF concepts. Disabil Rehabil 2008;30(12-13):963-9.

42. Hinkle D, Wiersma W, Jurs S editors. Applied statistics for the behavioral sciences. 5th ed ed. Boston, Mass.,[etc]: Houghton Mifflin; 2003.

43. Field A.Discovering Statistics Using SPSS. 3rd ed. London, Thousand Oaks, New Delhi, Singapore: SAGE publications Ltd; 2009.

44. George D, Mallery P. SPSS for Windows step by step: A simple guide and reference. 11.0 update. 4th ed. Boston, MA: Allyn and Bacon; 2003.

45. Stucki G, Ewert T, Cieza A. Value and application of the ICF in rehabilitation medicine. Disabil Rehabil 2003;3-17;25(11-12):628-34.

46. Jette AM. Toward a common language for function, disability, and health. Phys Ther 2006;86(5):726-34.

47. Escorpizo R, Stucki G, Cieza A, Davis K, Stumbo T, Riddle DL. Creating an interface between the International Classification of Functioning, Disability and Health and physical therapist practice. Phys Ther 2010;90(7):1053-63.

48. Bagraith KS, Strong J. The International Classification of Functioning, Disability and Health (ICF) can be used to describe multidisciplinary clinical assessments of people with chronic musculoskeletal conditions. Clin Rheumatol 2013;32(3):383-9. 
49. ICF Research Branch in cooperation with the WHO Collaborating Centre for the Family of International Classifications in Germany (DIMDI). ICF Core Set Projects. 2012; Available from: http://www.icf-researchbranch.org/. Accessed 2012 Oct 11.

50. Rauch A, Cieza A, Stucki G. How to apply the International Classification of Functioning, Disability and Health (ICF) for rehabilitation management in clinical practice. Eur J Phys Rehabil Med 2008;44(3):32942.

51. Rentsch HP, Bucher P, Dommen Nyffeler I, Wolf C, Hefti H, Fluri E, et al. The implementation of the 'International Classification of Functioning, Disability and Health' (ICF) in daily practice of neurorehabilitation: an interdisciplinary project at the Kantonsspital of Lucerne, Switzerland. Disabil Rehabil 2003;22;25(8):411-21.

52. Leyshon RT, Shaw LE. Using the ICF as a conceptual framework to guide ergonomic intervention in occupational rehabilitation. Work 2008;31(1):47-61.

53. Gagné JP, Jennings MB, Southhall K. The ICF: A Classification System and Conceptual Framework Ideal for Audiological Rehabilitation. Perspectives on Aural Rehabilitation and Its Instrumentation.2009;16(1):814.

54. Bundesamt für Sozialversicherungen (BSV). Statistiken zur sozialen Sicherheit. IV-Statistik 2012. Schweizer Eidgenossenschaft, Bern. 2012. Available from: http://www.bfs.admin.ch/bfs/portal/de/index/news/publikationen.html?publicationID=5204. Accessed 2013 Dec 11.

55. Geyh S, Cieza A, Bickenbach J, Stucki G. ICF personal factors. Swiss Paraplegic Research: 2009.

56. Geyh S, Peter C, Muller R, Bickenbach JE, Kostanjsek N, Ustun BT, et al. The Personal Factors of the International Classification of Functioning, Disability and Health in the literature - a systematic review and content analysis. Disabil Rehabil 2011;33(13-14):1089-102.

57. Lydell M, Marklund B, Baigi A, Mattsson B, Mansson J. Return or no return - psychosocial factors related to sick leave in persons with musculoskeletal disorders: a prospective cohort study. Disabil Rehabil 2011;33(8):661-6.

58. Iles RA, Davidson M, Taylor NF. Psychosocial predictors of failure to return to work in non-chronic nonspecific low back pain: a systematic review. Occup Environ Med 2008;65(8):507-17.

59. Berecki-Gisolf J, Clay FJ, Collie A, McClure RJ. Predictors of sustained return to work after work-related injury or disease: insights from workers' compensation claims records. J Occup Rehabil 2012;22(3):28391.

60. Geyh S, Muller R, Peter C, Bickenbach JE, Post MW, Stucki G, et al. Capturing the psychologic-personal perspective in spinal cord injury. Am J Phys Med Rehabil 2011;90(11 Suppl 2):S79-96.

61. Schwegler U, Peter C, Trezzini B, Anner J, Geyh S. Toward transparent documentation in medical work capacity evaluations: identifying personal factors in medical reports on Swiss disability claimants with chronic widespread pain. Int J Rehabil Res 2013;36(4):298-307.

62. Wasiak R, Young AE, Roessler RT, McPherson KM, van Poppel MN, Anema JR. Measuring return to work. J Occup Rehabi. 2007;17(4):766-81.

63. Young AE, Roessler RT, Wasiak R, McPherson KM, van Poppel MN, Anema JR. A developmental conceptualization of return to work. J Occup Rehabil 2005;15(4):557-68.

64. Dunstan DA, Covic T, Tyson GA. What leads to the expectation to return to work? Insights from a Theory of Planned Behavior (TPB) model of future work outcomes. Work 2013;46(1):25-37.

65. de Buck PD, de Bock GH, van Dijk F, van den Hout WB, Vandenbroucke JP, Vliet Vlieland TP. Sick leave as a predictor of job loss in patients with chronic arthritis. Int Arch Occup Environ Health 2006;80(2):160-70.

66. World Health Organization (WHO). Annex 1: Taxonomic and terminological issues. In: WHO, editor. International Classification of Functioning, Disability and Health. Geneva: WHO; 2001. p. 2011-2018.

67. OECD. How's Life? Measuring well-being. OECD Publishing 2011. http://dx.doi.org/10.1787/9789264121164-en. Accessed 2013 Aug 3.

68. Cummins RA. Moving from the quality of life concept to a theory. J Intellect Disabil Res 2005;49(Pt 10):699-706.

69. Ventegodt S, Merrick J, Andersen NJ. Measurement of quality of life II. From the philosophy of life to science. Scientific World Journal 2003;3:962-71. 
70. Allison PJ, Locker D, Feine JS. Quality of life: a dynamic construct. Soc Sci Med 1997;45(2):221-30.

71. Felce D, Perry J. Quality of life: its definition and measurement. Res Dev Disabi. 1995;16(1):51-74.

72. Ferdiana A, Post MWM, Finger ME, Bültmann U, Escorpizo R. Assessment of health-related quality of life of clients in vocational rehabilitation: association with depressive symptoms and type of services. European journal of physical and rehabilitation medicine. 2013 Dec 5. [Epub ahead of print].

73. Joseph RP, Royse KE, Benitez TJ, Pekmezi DW. Physical activity and quality of life among university students: exploring self-efficacy, self-esteem, and affect as potential mediators. Qual LifeRes 2014;23(2):659-67.

74. Glassel A, Finger ME, Cieza A, Treitler C, Coenen M, Escorpizo R. Vocational Rehabilitation From the Client's Perspective Using the International Classification of Functioning, Disability and Health (ICF) as a Reference. J Occup Rehabil 2011;21(2):167-78.

75. Wiese BS. Work-Life-Balance. In: Moser K, editor. Wirtschaftspsychologie Heidelberg: Springer Berlin Heidelberg; 2007. p. 245-263.

76. Lewis S, Gambles R, Rapoport R. The constraints of a 'work-life balance' approach: an international perspective. The International Journal of Human Resource Management 2007;18(3):360-73.

77. Joosen M, Frings-Dresen M, Sluiter J. Process and Outcome Evaluation of Vocational Rehabilitation Interventions in Patients with Prolonged Fatigue Complaints. Int J Behav Med 2010; 18(2): 160-171.

78. Radbruch L, Sonntag B, Elsner F, Loick G, Schmeisser N, Kiencke P, et al. Deficits in the treatment of chronic pain (I). Z. Arztl. Fortbild. Qualitatssich. 2000 ;94(5):373-8.

79. Linacre J. Sample Size and Item Calibration Stability. Fasch Measurement Transactions 1994;7:328.

80. Linacre JM. Sample Size and Item Calibration [or Person Measure] Stability. Available from: www.rasch.org/rmt/rmt74m.htm. Accessed 2013 Aug 12.

81. Portmann Bergamaschi R, Escorpizo R, Staubli S, Finger ME. Content validity of the Work Rehabilitation Questionnaire-Self-Report Version WORQ-SELF in a subgroup of spinal cord injury patients. Spinal Cord 2013; Nov 19. [Epub ahead of print].

82. Kellett D, Mpofu E, Madden R. Reflective action assessment with a prospective clinical problem solving tool in the context of rehabilitation medicine: an illustrative case study. Disabil Rehabil 2013;35(13):1048-54.

83. Marois $E$, Durand MJ. Does participation in interdisciplinary work rehabilitation programme influence return to work obstacles and predictive factors? Disabil Rehabil 2009;31(12):994-1007.

84. Grill E, Huber EO, Gloor-Juzi T, Stucki G. Intervention goals determine physical therapists' workload in the acute care setting. Phys Ther 2010;90(10):1468-78.

85. Rauch A, Escorpizo R, Riddle DL, Eriks-Hoogland I, Stucki G, Cieza A. Using a Case Report of a Patient With Spinal Cord Injury to Illustrate the Application of the International Classification of Functioning, Disability and Health During Multidisciplinary Patient Management. Phys Ther 2010; 90(7):1039-52.

86. Jacob T. The implementation of the ICF among Israeli rehabilitation centers - The case of physical therapy. Physiother Theory Pract 2013; 29 (7):536-546.

87. Desiron HA, Donceel P, de Rijk A, Van Hoof E. A Conceptual-Practice Model for Occupational Therapy to Facilitate Return to Work in Breast Cancer Patients. J Occup Rehabil 2013; 23(4):516-26.

88. Franche RL, Baril R, Shaw W, Nicholas M, Loisel P. Workplace-based return-to-work interventions: optimizing the role of stakeholders in implementation and research. J Occup Rehabil 2005;15(4):525-42.

89. Bickenbach J, Cieza A, Selb M, Emmenegger K, Lückenkemper M, Escorpizo R editors. ICF Core Sets: Manual for Clinical Practice. 1st ed. Göttingen: Hogrefe; 2012.

90. Engel GL. The need for a new medical model: a challenge for biomedicine. Science 1977 8;196(4286):12936.

91. Cerniauskaite M, Quintas R, Boldt C, Raggi A, Cieza A, Bickenbach JE, et al. Systematic literature review on ICF from 2001 to 2009: its use, implementation and operationalisation. Disabil Rehabil 2011;33(4):281309.

92. WHO. ICF E-Learning Tool. 2013; Available from: http://icf.ideaday.de/en/index.html. Accessed 2013 Dec 15. 
93. ICF Research Branch. Case Studies: An illustration using the ICF in rehab practice. 2013; Available from: http://www.icf-research-branch.org/component/content/article/120-quicklinks/external-links/377-casestudies-website. Accessed 2013 Dec 15.

94. Post M, Krol B, Groothoff JW. Self-rated health as a predictor of return to work among employees on long-term sickness absence. Disabil Rehabil 2006;15;28(5):289-97.

95. Kuijer PP, Gouttebarge V, Wind H, van Duivenbooden C, Sluiter JK, Frings-Dresen MH. Prognostic value of self-reported work ability and performance-based lifting tests for sustainable return to work among construction workers. Scand J Work Environ Health 2012;38(6):600-3.

96. Cuenot M. Report on the review process of the ICF update proposals. Poster C509 presented at the WHO Family of International Classifications Network Annual Meeting in Beijing, China, 12-18 October 2013. Available from: http://apps.who.int/classifications/whofic2013c500.pdf. Accessed 2013 Dec 16.

97. World Health Organization (WHO). ICF Update Platform.WHO; Geneva, Switzerland. 2013; Available from: https://extranet.who.int/icfrevision/nr/loginICF.aspx. Accessed 2013 Dec 16.

98. Gatchel RJ. Musculoskeletal disorders: primary and secondary interventions. J Electromyogr Kinesiol 2004;14(1):161-70.

99. Smith KW, Avis NE, Assmann SF. Distinguishing between quality of life and health status in quality of life research: a meta-analysis. Qual Life Res 1999;8(5):447-59. 

Addendum 



\section{English Summary}

Work is a central aspect in people's lives and is one of the most powerful social determinants of health, as stated by the WHO. Work is also widely associated with being integrated into society and economic self-sufficiency. For many people in western culture, their job also represents a source for self-confidence, self-worth, social status and is even related to the person's identity. From the perspective of society, economic consequences of illness and disease and the costs of disability benefits are increasing. According to the OECD (Organisation for Economic Co-operation and Development), in 2008 the total cost of sickness absence and both sickness and disability benefits were on average equivalent to about $2 \%$ of gross domestic product (GDP). While these facts lead policy makers and health care providers to increasingly encourage workers to stay at work or to return to work as early as possible after enduring an injury or sickness, strategies on how to achieve this differ depending on the respective political and social system and the economy. One key element of disability management and policy that is gaining more and more attention in the last decade is vocational rehabilitation. The increasing interest in vocational rehabilitation and the return-to-work process has led to the development of a wide range of interventions and vocational rehabilitation programs. Nevertheless, few common standards for identifying, evaluating and monitoring work-related abilities and problems are used. This lack of a common understanding of functioning not only hampers the exchange of information within a setting, but also hinders an efficient communication between different stakeholders, e.g. clinicians, payers, employers and politicians.

The International Classification of Functioning, Disability and Health (ICF), endorsed by the World Health Assembly in May 2001 provides a reference framework for conceptualizing, describing and documenting human functioning in the context of health in a standardized way. Therefore it is expected that the ICF could provide a common language and foundation to define standards in vocational rehabilitation, too.

The overall objective of this thesis is to introduce and evaluate the ICF as a reference framework of functioning in the field of vocational rehabilitation, and to develop ICF-based tools to facilitate the clinical integration of the ICF in vocational rehabilitation. To answer the overall objectives three specific aims will be looked at: (1) to establish content validity of the ICF as a reference framework of functioning in vocational rehabilitation, (2) to develop an international standard and methodological approach for creating ICF-based applications in vocational rehabilitation, and (3) to apply ICF based tools in a clinical case example in vocational rehabilitation.

The objective of the study described in Chapter $\mathbf{2}$ was to describe functioning and health of individuals in vocational rehabilitation from the clinical perspective using the ICF. In a cross-sectional multicentre study data were collected and rated by health pro- 
fessionals using a case record form based on an extended ICF-checklist that contained 292 ICF categories. The population $(n=152)$ in this study consisted of patients with different professions or trades and who have received different vocational rehabilitation interventions. Eighty-nine patients were in vocational rehabilitation due to musculoskeletal conditions, 39 due to neurologic conditions and 24 due to internal medicine or mental problems. 100 categories from all four ICF components were identified to be relevant for the functioning of at least $20 \%$ of the patients. The ICF was found to be useful and comprehensive in identifying a set of variables (ICF categories) that describe functioning problems and relevant environmental factors among individuals participating in vocational rehabilitation.

To complement the information gained in the cross-sectional study we conducted a secondary data analysis of concepts that could not be linked to the ICF (Chapter 3). These data were derived from a systematic review, an expert survey and a patient focus group study that were conducted to develop the ICF Core Set for vocational rehabilitation. The overall objective of this study was to explore and examine those vocational rehabilitation-related concepts which could not be linked to distinct ICF codes. An explorative and qualitative analysis of the data was performed. From 3458 concepts identified, 1093 were assigned to the corresponding parts of the ICF, 1924 were linked to a personal factors classification and 441 concepts were identified as not covered by the ICF framework. These 441 concepts were then grouped into 6 themes that included concepts such as well-being and quality of life, which could be further investigated in the future. In conclusion, the ICF can be considered a valid and comprehensive framework to describe and document functioning in vocational rehabilitation, and that can be complemented with specific work models or classifications as needed.

In Chapter 4 the development of the ICF Core Sets for vocational rehabilitation is described. An international conference that followed a formal decision-making and consensus-based process based on the evidence from four preparatory studies -a systematic literature review, an expert survey, a cross-sectional study (Chapter 2), and a patient focus group study was held. Twenty-three experts from all six WHO regions who have an expertise in vocational rehabilitation attended the consensus conference, during which they finalized the comprehensive and the brief ICF Core Sets for vocational rehabilitation. They included 90 ICF categories in the comprehensive ICF Core Set (activities and participation $=40$, environmental factors $=33$, body functions $=17$ ), while the brief ICF Core Set included 13 second level categories (activities and participation $=6$, environmental factors $=4$, body functions $=3$ ). This expert opinion and evidence-based ICF Core Set could serve as an international standard for what to measure and report concerning functioning of individuals engaged in vocational rehabilitation. The ICF Core Set could also provide a common language among clinicians, researchers, insurers, and policymakers in the implementation of successful vocational rehabilitation programs and interventions. 
Although with the development of the ICF Core Set for vocational rehabilitation a standard on what to look at was defined, no reliable and valid ICF-based instruments for measuring work functioning was identified. Hence the aims of the study described in Chapter 5 were: (1) to outline the process for developing an ICF-based questionnaire, the Work Rehabilitation Questionnaire (WORQ) to assess functioning in vocational rehabilitation and (2) to report preliminary psychometric evidence. Starting from the 13 categories of the brief ICF Core Set for vocational rehabilitation, 31 additional categories from the comprehensive ICF Core Set were selected, using an explorative Raschanalysis and evidence from the vocational rehabilitation literature review. Questions were worded to assess the identified ICF categories based on existing questions from the WHO Disability Assessment Schedule 2.0 (WHODAS 2.0) and the World Health Survey (WHS). WORQ was then translated from English to German, as the psychometric testing took part in a Vocational Rehabilitation Centre in the German-speaking part of Switzerland. The psychometric evaluation of WORQ showed high test-retest reliability (Spearman correlation 0.79) $(n=53)$ and good internal consistency (Cronbach's Alpha 0.88) ( $n=74)$. WORQ showed moderate correlation with Beck Depression Inventory II (Spearman correlation 0.511) and low correlation (Spearman correlation -0.353) with SF-36. This first version of WORQ appears to be a reliable ICF-based questionnaire to evaluate functioning in vocational rehabilitation. WORQ is easy to administer by health and vocational professionals alike. The additional information gained when using WORQ would contribute to improving interdisciplinary understanding of the patient's situation and therefore support the integrative planning of the return-to-work process or engagement in gainful employment. However, additional studies are needed to gain insight into the dimensionality of WORQ as well as its prognostic value concerning return-to-work. Even though the first version of WORQ proved to be a useful instrument in the tested setting, further examination of its use in multiple clinical settings and health conditions as well as in research is also warranted. In conclusion, the ICF Core Set for vocational rehabilitation offers an international standard for the evaluation and documentation of functioning in vocational rehabilitation. With the first version of WORQ a user-friendly ICF-based instrument to measure work functioning is now available.

The objective of the teaching case described in Chapter 6 was to illustrate an application of ICF-based tools in a multidisciplinary return-to-work (RTW) program for patients with non-specific low back pain (NLBP). Multidisciplinary teamwork is increasingly recognized as a critical factor for success in vocational rehabilitation. This case demonstrates how the integration of the ICF can enhance communication between stakeholders, help structure rehabilitation plans and foster common goal-setting. It may also be used in clarifying team roles by enhancing transparency in goal- setting and intervention planning across disciplines. In addition, this teaching case could demonstrate possibilities of how ICF-based tools such as the RehabManagement-Sheet and 
WORQ can help guiding a rehabilitation process, encourage a comprehensive assessment and facilitate team-based and profession-based goal-setting and documentation.

In Chapter 7, the general discussion, the main findings and methodological reflections are described. Implications for clinical practice and research arising from the studies presented in this thesis are discussed and recommendations for further research are provided.

In conclusion, the ICF proved to be a valid framework to describe functioning in vocational rehabilitation. With the ICF Core Set for vocational rehabilitation an international ICF- based standard could be defined and with WORQ an instrument that assesses self-reported functioning in patients participating in vocational rehabilitation. The next steps toward the implementation of the ICF and ICF-based tools in clinical practice and research should encompass:

- The education of health professionals i.e. integrating the ICF into curricula for the basic professional training of health professionals.

- The introduction of health professionals to the basics of the ICF by using available resources such as the freely accessible ICF e-Learning tool.

- The integration of the ICF in electronic health records and documentation tools.

- Active participation in the ICF update-process.

- Efforts to disentangle the concepts of functioning (ICF) and well-being in vocational rehabilitation.

- The further development of ICF-based instruments that are self-explanatory and comfortable to use. 


\section{Deutsche Zusammenfassung}

Arbeit ist ein zentraler Aspekt im Leben von Menschen und ist zudem gemäss WHO eine der wichtigsten sozialen Determinanten von Gesundheit. Soziale Integration und wirtschaftliche Unabhängigkeit basieren vielfach auf einer erfolgreichen Berufstätigkeit. Die Arbeit stellt bei vielen Menschen in der westlichen Gesellschaft eine nicht zu unterschätzende Grundlage für Selbstbewusstsein, Selbstwertgefühl und sozialen Status dar und wird darüber hinaus oftmals mit der Identität der Person assoziiert. Aus Sicht der Gesellschaft sind die wirtschaftlichen Folgen von Unfällen und Krankheit, sowie die Kosten für medizinische Behandlungen und Invalidenrenten erheblich. Nach Angaben der OECD (Organisation für wirtschaftliche Zusammenarbeit und Entwicklung), betrugen im Jahr 2008 die Gesamtkosten von Arbeitsausfällen und Kranken-und Invaliditätsleistungen im Durchschnitt etwa $2 \%$ des Bruttoinlandsprodukts (BIP).

Während Kostendruck und Erkenntnisse aus Medizin und Wissenschaft zunehmend sowohl politische Entscheidungsträger wie auch Gesundheitsfachleute dazu bewegen, Arbeitnehmer zu ermutigen bei der Arbeit zu bleiben oder so früh wie möglich nach einer Verletzung oder Krankheit, an den Arbeitsplatz zurückzukehren, unterscheiden sich die jeweiligen Strategien, in Abhängigkeit der politischen- und sozialen Systeme und der wirtschaftlichen Situation, erheblich. Ein Schlüsselelement des DisabilityManagements (dt. Arbeits-, Berufsunfähigkeits-, oder auch BehinderungsManagement), welches in den letzten zehn Jahren zunehmend mehr Aufmerksamkeit gewonnen hat, ist die berufliche Rehabilitation. Dieses Interesse am gesamten „ReturnTo-Work" Prozess, beginnend bei der Erkrankung oder dem Unfall bis zur Rückkehr an den Arbeitsplatz, hat zur Entwicklung einer breiten Palette von Interventionen und Programmen im Rahmen der beruflichen Rehabilitation geführt. Gemeinsame Standards für die Erfassung, Beurteilung und Dokumentation von Funktionsfähigkeit und Behinderungen existieren jedoch nicht. Dieser Mangel an einem gemeinsamen Verständnis, behindert nicht nur den Austausch von Informationen innerhalb eines Rehabilitationssettings, sondern auch eine effiziente Kommunikation zwischen den verschiedenen Akteuren, z. B. Gesundheitsfachleuten, Kostenträgern, Arbeitgebern und Politikern.

Die Internationale Klassifikation der Funktionsfähigkeit, Behinderung und Gesundheit (ICF), die von der Weltgesundheitsorganisation (WHO) im Mai 2001 verabschiedet wurde, bietet einen standardisierten Bezugsrahmen für die Konzeption, Beschreibung und Dokumentation der Funktionsfähigkeit von Menschen im Kontext einer gesundheitlichen Problematik. Es ist zu erwarten, dass die ICF auch im Kontext der beruflichen Rehabilitation als gemeinsame Sprache und Rahmenklassifikation zum definieren von Standards dienen kann. 
Das übergeordnete Ziel dieser Thesis ist, die ICF als Bezugsrahmen, im Bereich der beruflichen Rehabilitation einzuführen und zu evaluieren und ICF-basierte Instrumente zu entwickeln, um die Integration der ICF in die Praxis der beruflichen Rehabilitation zu erleichtern. Zur Beantwortung des übergeordneten Ziels wurden drei spezifische Ziele definiert:

(1) Evaluieren und etablieren der Inhaltsvalidität der ICF als Bezugsrahmen für die Erfassung der Funktionsfähigkeit von Personen in der beruflichen Rehabilitation, (2) definieren eines internationalen Standards zur Erfassung der Funktionsfähigkeit und zum entwickeln eines methodischen Ansatzes für die Erstellung von ICF-basierte Instrumenten in der beruflichen Rehabilitation, und (3) aufzeigen von klinischen Anwendung von ICF-basierten Instrumenten im Rahmen eines Fallbeispiels in der beruflichen Rehabilitation.

Das Ziel der in Kapitel 2 beschrieben Studie war es, die Funktionsfähigkeit und die Behinderung von Menschen in der beruflichen Rehabilitation aus der Sicht von Gesundheitsfachpersonen mit Hilfe der ICF zu beschreiben. In einer multizentrischen Querschnittsstudie wurden anhand einer ICF- Checkliste, mittels der Analyse von Krankenakten und Patienteninterviews, Daten zur Funktionsfähigkeit von Personen in der beruflichen Rehabilitation erhoben und bewertet. Die erweiterte ICF-Checkliste enthielt 292 ICF-Kategorien. Die Studienteilnehmer $(n=152)$ hatten einen vielfältigen beruflichen Hintergrund und absolvierten fallspezifisch unterschiedliche Rehabilitationsmassnahmen. Neunundachtzig Patienten nahmen aufgrund einer Erkrankung des Bewegungsapparats an den beruflichen Rehabilitationsmassnahmen teil, 39 aufgrund neurologischer Erkrankungen und 24 wegen internistischen oder psychischen Problemen. Insgesamt wurden 100 ICF Kategorien identifiziert, welche für mindestens 20\% der Patienten relevant waren. Diese Kategorien stammten aus allen Bereichen der ICF; Körperfunktion und -Struktur, Aktivität und Partizipation und Umweltfaktoren. Die ICF erwies sich als nützliche und umfassende Klassifikation zur Identifizierung von Variablen (ICF Kategorien), für die Erfassung und Beschreibung von Problemen der Funktionsfähigkeit und von relevanten Umweltfaktoren, bei Personen in der beruflichen Rehabilitation.

Um die Informationen aus der Querschnittsstudie zu ergänzen, führten wir, in der Folge die in Kapitel 3 beschriebenen Studie durch, eine Sekundäranalyse von Konzepten, die nicht mit spezifischen Kategorien der ICF verknüpft (gelinkt) werden konnten. Diese Daten entstammten einer systematischen Review, einem Expertensurvey, und einer Patienten Fokusgruppenstudie, welche im Rahmen der Entwicklung des ICF -CoreSets für die berufliche Rehabilitation, durchgeführt wurden. Das übergeordnete Ziel dieser Konzeptanalyse war es diejenigen Konzepte in der beruflichen Rehabilitation zu analysieren und zu gruppieren, welche nicht zu einem spezifischen ICF -Codes gelinkt werden konnten. Eine explorative und qualitative Analyse der Daten wurde durchgeführt. Von den 3458 identifizierten Konzepten, wurden 1093 den entsprechenden Teilen der ICF zugeordnet. 1924 Konzepte wurden als persönliche Faktoren klassifiziert 
und 441 Konzepte wurden als ausserhalb des bio-psychosozialen Modells der ICF stehend klassifiziert. Diese 441 Konzepte wurden zu 6 Themen zusammengefasst. „Wohlbefinden und Lebensqualität" gehörten zu diesen Themen und sollten in ihrer Interaktion mit Funktionsfähigkeit und Behinderung in Zukunft weiter untersucht werden. Abschliessend kann gesagt werden, dass die ICF eine valide und umfassende Rahmenklassifikation darstellt, um Funktionsfähigkeit und Umweltfaktoren im Rahmen der beruflichen Rehabilitation zu erfassen und zu dokumentieren. Die ICF kann dabei bei Bedarf durch spezifische arbeitsorientierte Klassifikationen und Modelle ergänzt werden.

In Kapitel 4 wurde die Entwicklung des ICF Core Sets für die berufliche Rehabilitation im Rahmen einer internationalen Konsensuskonferenz beschrieben. Dreiundzwanzig Experten aus allen sechs WHO-Regionen und mit vielfältigen Fachkenntnissen im Gebiet der beruflichen Rehabilitation nahmen teil. Sie entschieden in einem formalen Entscheidungs- und Konsensus-Findungsprozess, welche ICF Kategorien ins Core Set eingeschlossen werden sollten. Ihre Entscheidungen basierten sie auf ihre Erfahrung und die Evidenz aus vier vorbereitenden Studien - einer systematischen Literaturreview, einem Expertensurvey, einer Querschnittsstudie (Kapitel 2) und einer Patienten Fokusgruppenstudie. Das Umfassende ICF Core Set für die berufliche Rehabilitation umfasst 90 ICF-Kategorien; Aktivitäten und Partizipation = 40 Kategorien, Umweltfaktoren = 33 Kategorien, Körperfunktionen = 17 Kategorien. Das Kurze ICF Core Set für die berufliche Rehabilitation enthält 13 ICF Kategorien; Aktivitäten und Partizipation = 6, Umweltfaktoren $=4$, Körperfunktionen $=3$. Dieses auf Expertenkonsensus und Evidenz basierende ICF Core Set für die berufliche Rehabilitation kann als internationaler Standard aufzeigen, welche Aspekte der Funktionsfähigkeit bei Personen in der beruflichen Rehabilitation gemessen und rapportiert werden sollten. Das ICF Core Set kann zudem als gemeinsame Sprache für Gesundheitsfachleute, Forscher, Versicherer und die Politiker dienen und dadurch zu einer erfolgreichen Gestaltung und Durchführung von Programmen und Maßnahmen der beruflichen Rehabilitation beitragen.

Obwohl mit der Entwicklung der ICF -Core-Sets für die berufliche Rehabilitation ein Standard geschaffen wurde, welcher aufzeigt, welche Aspekte der Funktionsfähigkeit gemessen und dokumentiert werden sollen, wurde kein reliables, valides und ICFbasiertes Instrument zum Messen der Funktionsfähigkeit gefunden. Daher ergaben sich für die in Kapitel 5 beschriebene Studie folgende Ziele: (1) Den Entwicklungsprozess für einen ICF-basierten Fragebogen zur Erfassung der Funktionsfähigkeit im Rahmen der beruflichen Rehabilitation zu beschreiben. Dieser Fragebogen - der Work Rehabilitation Questionnaire (WORQ) - sollte unabhängig von der jeweiligen medizinischen Diagnose und vom Rehabilitationssetting einsetzbar sein. (2) Erste Psychometrische Daten erheben und die Nützlichkeit des WORQ in der Klinik evaluieren.

Grundlage für die Entwicklung des WORQ bildeten die Kategorien des Kurzen ICF Core Sets für die berufliche Rehabilitation. Ergänzend zu diesen, wurden mit Hilfe einer explorativen Raschanalyse und basierend auf einer Literaturreview 31 weitere Katego- 
rien aus dem Umfassenden ICF Core Set ausgewählt. Um die ausgewählten ICF Kategorien zu erfassen, wurden in Analogie zu bestehenden Fragen aus dem WHO Disability Schedule 2.0 (WHODAS 2.0) und dem World Health Survey (WHS) Fragen formuliert. Der WORQ wurde dann von Englisch auf Deutsch übersetzt, da die psychometrische Testung in einem Zentrum für berufliche Rehabilitation im deutschsprachigen Teil der Schweiz stattfand.

Die psychometrischen Auswertungen des WORQ zeigten eine hohe Test-RetestReliabilität (Spearman Korrelation 0,79$)(n=53)$ und eine gute interne Konsistenz (Cronbach's Alpha 0,88) ( $n=74)$. WORQ zeigte eine moderate Korrelation mit dem Beck Depression Inventory II (Spearman Korrelation 0,511) und eine geringe Korrelation (Spearman Korrelation -0,353) mit dem SF-36. Diese erste Version des WORQ stellt ein zuverlässiges Instrument zur Erfassung eines ICF basierten Funktionsprofils, für Personen in der beruflichen Rehabilitation, dar. WORQ ist für Gesundheitsfachleute einfach zu erheben. Die zusätzlichen Informationen, welche bei der Anwendung des WORQ gewonnen werden, können zur Verbesserung der interdisziplinären Kommunikation und zur erweiterten Erfassung der Situation des Patienten beitragen und eine strukturierte Planung des Return-To-Work-Prozesses unterstützen. Es sind allerdings weitere Studien erforderlich, um Einblick in die Dimensionalität des WORQ zu erhalten, sowie seine prognostischen Aussagekraft für eine erfolgreiche Rückkehr an den Arbeitsplatz zu erforschen. Auch wenn die erste Version des WORQ sich als ein nützliches Instrument zur Erfassung der Funktionsfähigkeit im getesteten Setting erwiesen hat, ist eine weitere Prüfung in unterschiedlichen klinischen Settings und bei unterschiedlichen Krankheits- und Verletzungsbildern angezeigt. Schlussfolgernd kann gesagt werden, dass mit dem ICF Core Set für die berufliche Rehabilitation ein internationaler Standard zur Erfassung und Dokumentation der Funktionsfähigkeit in der Beruflichen Rehabilitation geschaffen wurde. Mit der ersten Version des WORQ ist jetzt ein benutzerfreundliches, ICF-basiertes Instrument zur Messung der Funktionsfähigkeit verfügbar.

In Kapitel 6 wurde eine klinische Fallstudie über eine Anwendung von ICF-basierten Instrumenten in einem multidisziplinären Return-To-Work-Programm, für Patienten mit unspezifischen Rückenschmerzen (NLBP) beschrieben. Multidisziplinäre Teamarbeit wird zunehmend als kritischer Faktor für die Rehabilitation von chronischen Rückenschmerzproblemen aber auch für einen Erfolg in der beruflichen Rehabilitation anerkannt. Dieser Fall zeigt auf, wie die Integration der ICF die Kommunikation zwischen den verschiedenen Gesundheitsfachpersonen, der Patientin und weiteren Akteuren, durch transparente Zielsetzung und die gemeinsame Erstellung von ICF basierten Rehabilitationsplänen fördern kann. Der Einsatz von ICF basierten Instrumenten kann zu einer Klärung von Zuständigkeiten und Teamrollen beitragen und die Steuerung, sowie die Dokumentation des Rehabilitationsprozesses können strukturiert und vereinfacht werden.

In Kapitel 8 werden die hauptsächlichen Resultate und methodologische Überlegungen besprochen. Implikationen für die klinische Praxis und Forschung, die sich aus 
den Untersuchungen in dieser Arbeit ergeben werden diskutiert und Empfehlungen für künftige Forschungsprojekte gemacht.

Insgesamt erwies sich die ICF als valide Rahmenklassifikation zur Erfassung und Dokumentation der Funktionsfähigkeit von Personen in der beruflichen Rehabilitation. Mit dem ICF-Core-Set für die berufliche Rehabilitation konnte ein internationaler Standard definiert werden und mit dem WORQ wurde ein Instrument geschaffen, welches die Funktionsfähigkeit aus Sicht des Patienten in der beruflichen Rehabilitation erfasst.

Weiterführende Schritte in der Einführung und Anwendung der ICF und von ICFbasierten Instrumenten in der klinischen Praxis und Forschung sollten folgende Punkte in Betracht ziehen:

- Ausbilden von Gesundheitsfachpersonen wie z.B. der Integration der ICF in Lehrpläne und Curricula der Grundausbildung und der Weiterbildung.

- Einführen von Gesundheitsfachpersonen in die Grundlagen der ICF durch das Bekanntmachen von vorhandene kostenlosen Weiterbildungsressourcen wie z.B. dem ICF e-Lerning Tool und dem ICF Manual.

- Integrieren der ICF in elektronische Dokumentationssysteme und Patientenakten.

- Aktives teilnehmen am ICF-Update-Prozess.

- Evaluieren der komplexen Verstrickungen von Funktionsfähigkeit, Lebensqualität und „Well-Being“ im Kontext der beruflichen Rehabilitation.

- (Weiter)Entwickeln von ICF-basierten, benutzerfreundlichen und psychometrisch validen Instrumenten. 


\section{Acknowledgements}

Writing this dissertation has been one of the greatest challenges I have ever had to face. During the last years and especially in the last months and weeks it became obvious that without the support, patience and guidance of my supervisors, colleagues, friends and my mother this thesis would never have been completed.

First of all, I would like to thank my supervisor, Prof. Dr. Rob de Bie. We met the first time in 1997 during a three-day workshop in Egolzwil, Switzerland, where he taught 16 Swiss Bobath Instructors "Experimental epidemiology and literature analysis". This was an exciting new experience for all of us. For me, it was the first time that I was confronted with the fact that a physiotherapist could develop an academic career, be an Assistant Professor at university and conduct his own research. In 2003, when we met for a second time, Rob was one of the leaders of the first Master's program for physiotherapists conducted in Switzerland, in which I had been a student. When we saw each other again for the third time in 2009, I had just started working in an ICF project at Swiss Paraplegic Research (SPR) in Nottwil, Switzerland. Rob had been invited to Nottwil by Prof. Gerold Stucki, the head of SPR, and I had the chance to present my project to him. Rob concluded that this could be an exciting PhD project and that he would support me as a supervisor. As my supervisor Rob supported me with open arms, followed the progress of my project and provided important guidance with constructive suggestions and his positive attitude. I would also like to thank Rob for enabling me to visit his department at Maastricht University three times to finalize and fine-tune this thesis. Here I would also like to warmly thank Dr. Carolien Bastiaenen. Her questions and comments helped me to substantially structure my thoughts and to take on new perspectives.

My deepest thanks go to my two co-supervisors, Prof. Alarcos Cieza and Prof. Reuben Escorpizo. Thank you, Alarcos, for helping me take my first steps in research during my Masters studies and for supporting me in developing the first outline of my PhD project. I never believed that I could succeed. But I learned from you that "there exist no problems, only challenges". This quote became some sort of a motto for me. Reuben, thank you deeply for all the support and inspiration you provided me the whole time. Your scientific and clinical knowledge, your positive attitude and your belief that I am able to achieve my goals inspired me to complete this thesis. Sometimes when you challenged me with new projects, writing book chapters or presentations I had doubt about my ability to master these tasks, but with your support I was not only able to completed these tasks, I was able to grow and develop on a scientific level as well as personally. Thank you for maintaining close contact and continuing your support for me although you found new challenges across the ocean. 
I owe my deepest gratitude also to my colleague Melissa Selb, ICF Research Branch Coordinator at SPR. You supported me not only with correcting my English and valuable feed-back on my papers. I learned a lot from you about the ICF, its further developments and social networking. But even more important was your daily personal support. Thank you. I also like to thank Dr. Andrea Glässel. You were an invaluable colleague during my first projects at SPR and you are a dear friend. Thank you also to my colleagues Christina Bostan, Carolina Ballert and Wolfgang Segerer. You always had an open ear, a good advice and a helpful hand, when needed. And thank you to all my other colleagues, who provided me with ideas, feedback or just a feeling of support during conversations in the aisle, coffee breaks or in meetings.

In addition I would like to express many thanks to Prof. Gerold Stucki, the Director of Swiss Paraplegic Research and Ms. Mirjam Brach, the Administrative Manager of SPR for enabling and supporting me in my work. Without their encouragement this thesis would never have happened.

I would also like to acknowledge the support of the former Medical Director of the Rehaklinik Bellikon and current Director of the Swiss Paraplegic Center Dr. Hans Peter Gmünder. Without his foresight and enthusiasm the ICF Core Set for vocational rehabilitation project would never have started. He not only contacted the ICF Research Branch and SPR to develop this project, he also convinced Suva, the Swiss accident insurance, to finance it. I am grateful that he encouraged me to take a big step from clinic to the adventure of research. On this note, I would also like to warmly thank my former colleagues from Bellikon, especially Stefan Staubli and Klaus Schmitt, who made bridging the gap between clinic and practice easy for me. I would also like to acknowledge the former head of the physiotherapy department, Paul Saurer, who sadly already left us. He encouraged me from my first working day on to accept professional challenges and to finally enter the Master's program. I have enjoyed working in the Rehaklinik Bellikon as a physiotherapist and as a researcher. And I am thankful for all the support and encouragement I experienced over 21 years. Thank you Werner Strebel, without meeting you, I would not be the person I am today.

I greatly acknowledge also the support of the Suva, who founded the ICF Core Set development for vocational rehabilitation project in a first grant, and also supported the development of the WORQ with a second grant. Suva's financial investment was indispensable for the completion of this thesis.

I would also like to thank the members of the reading committee of my PhD thesis and the corona for their time and interest in my work: Prof. dr. Mrs. A. Boonen, Prof. dr. IJ. Kant, Prof. dr. F. Nijhuis, Dr. J. Kool and Prof. dr. M.F. Reneman.

Many thanks also to Conny De Zwart, secretary and good soul of the Department of Epidemiology. She helped indescribably with all organizational tasks.

I absolutely cannot do without expressing my deepest thanks to my friends Daniela Stier and Susanne Duffner, who never gave up on me and forced me not to forget my life outside of my work. 
Finally I would very much like to thank my mother Erna. Her emotional support and ongoing optimism provided me with the sound background that I needed to accomplish this work. She and my father Hans encouraged me all my life to learn and to take on new challenges. Thank you.

So many people have been involved in this $\mathrm{PhD}$ project, supported it in many ways or expressed their empathy. I might have forgotten to acknowledge somebody here. In this case, thank you very much. 


\section{About the author}

Monika E. Finger was born on June 6, 1965 in Biel, Switzerland. She attended the Seeland College in Biel where she obtained her senior high school diploma in 1984 (Matura Typ C). Then she studied Physical Therapy at the Physiotherapy School at the University Hospital Insel in Berne. After her graduation in 1988 she started working as a physiotherapist at the department of internal medicine at the University Hospital Insel where she discovered her interest in neurologic physical therapy and stroke rehabilitation.

After a sabbatical in 1990, during which Monika travelled though Australia and New Zealand, she started working in the Rehaklinik Bellikon. In 1991 she became a group leader, responsible for a neurologic and an orthopedic ward. At the same time, Monika began a course of study in Management and a training toward becoming a Bobath Instructor, which she finished in 2000. In addition to these educational achievements Monika attended continuing education courses in Rehabilitation Training, Manual Therapy, Proprioceptive Neuromuscular Facilitation (IPNF2), Facio-Oral Tract Therapy, Movement Analysis and Motor-Learning. Since 2000 she has been conducting continuing education courses for Physiotherapists, Occupational Therapists and Nurses in Switzerland and Germany. In 2002 Monika became the leader of the supervisor group for health professionals in the Neurologic Department of the Rehaklinik Bellikon, where she was involved in developing educational concepts, and conducting courses and bedside teaching.

In 2005 Monika was awarded a Master's degree in Physiotherapy Science from the University of Maastricht, a collaborative program between the University Hospital of Zürich (Switzerland) and the University of Maastricht (The Netherlands). The subject of her Master thesis was the Identification of intervention categories for physiotherapy, based on the International Classification of Functioning, Disability and Health (ICF): a Delphi exercise. From 2006-2007 she further refined her teaching skills by completing a course of study for trainers in the workplace, acquiring a national degree (eidg. Dipl. Betriebsausbildnerin). Since 2006 Monika has been engaged in a working group of the Swiss Physiotherapy Association to develop a national concept for continuing education, in which she has been able to apply her extensive experience as trainer and developer of continuing education courses. At this point in time, Monika's scientific efforts focused on the development of internal clinical guidelines and the integration of evidence- based therapy in the daily work of the neurologic therapists and nurses in Bellikon.

In 2008 a cooperation between the Rehaklinik Bellikon and the Swiss Paraplegic Research offered Monika an opportunity to work part-time in the ICF Core Set for vocational rehabilitation development project. In 2009 she initiated her PhD studies with the support of Prof. Rob de Bie from the department of Epidemiology, Faculty of Health 
Sciences and Medicine at Maastricht University as her supervisor. In 2011 she received a grant from the Suva Fund to develop the WORQ, after which she stopped working in the Rehaklinik Bellikon and expanded her position at the Swiss Paraplegic Research. It is at Swiss Paraplegic Research where Monika has been part of the training team conducting ICF Workshops organized by the ICF Research Branch in Nottwil.

After finishing her PhD, her work focus will be on a combination of further advancing and testing the WORQ instrument, the evaluation of functioning patterns in the context of vocational rehabilitation and the influence of the environment on functioning, teaching and patient care.

\section{Memberships}

Physioswiss Schweizer Physiotherapie Verband

FK-NMS Fachkommission Neuromotorik und Sensorik, Physioswiss

IGPTR-N Interessengemeinschaft Physiotherapie Rehabilitation - Neurologie

SAR Schweizerische Arbeitsgemeinschaft für Rehabilitation

IBITA Swiss Bobath InstruktorInnen Schweiz

IBITA International Bobath Instructors Training Association 


\section{Publications}

\section{Peer reviewed publications}

Finger ME, Selb M, Escorpizo R. Using ICF in physiotherapy in multidisciplinary vocational rehabilitation: A case study of low back pain. P R I 2014: DOI: 10.1002/pri.1587. Epub.

Finger ME, Escorpizo R, Bostan C, De Bie R. Work Rehabilitation Questionnaire (WORQ): Development and preliminary psychometric evidence of an ICF-based questionnaire for vocational rehabilitation. J Occup Rehabil 2013 Nov 27. [Epup].

Finger ME, Escorpizo R, Glassel A, Gmunder HP, Luckenkemper M, Chan C, et al. ICF Core Set for vocational rehabilitation: results of an international consensus conference. Disabil Rehabil 2012;34(5):429-38.

Escorpizo R, Finger ME, Glassel A, Gradinger F, Luckenkemper M, Cieza A. A systematic review of functioning in vocational rehabilitation using the international classification of functioning, disability and health. J Occup Rehabil 2011;21(2):134-46.

Escorpizo R, Finger ME, Glassel A, Cieza A. An international expert survey on functioning in vocational rehabilitation using the international classification of functioning, disability and health. J Occup Rehabil 2011;21(2):147-55.

Finger ME, Glassel A, Erhart P, Gradinger F, Klipstein A, Rivier G, et al. Identification of Relevant ICF Categories in Vocational Rehabilitation: A Cross Sectional Study Evaluating the Clinical Perspective. J Occup Rehabil 2011;21(2):156-66.

Glassel A, Finger ME, Cieza A, Treitler C, Coenen M, Escorpizo R. Vocational Rehabilitation From the Client's Perspective Using the International Classification of Functioning, Disability and Health (ICF) as a Reference. J Occup Rehabil 2011;21(2):167-78

Escorpizo R, Finger ME, Glassel A, Cieza A. An International Expert Survey on Functioning in Vocational Rehabilitation Using the International Classification of Functioning, Disability and Health. J Occup Rehabil 2011;21(2):147-55.

Finger ME, Escorpizo R, Glaessel A, Brinkel T, Erhart P, Stucki G, et al. Die Entwicklung von ICF Core Sets für die berufliche Rehabilitation. Suva Medical 2010(1):41-54.

Bürge E, Cieza A, Allet L, Finger ME, Stucki G, Huber EO. Intervention categories for physiotherapists treating patients with internal medicine conditions on the basis of the International Classification of Functioning Disability and Health. Int J Rehabil Res 2008;31(1):43-50.

Allet L, Cieza A, Burge E, Finger M, Stucki G, Huber EO. Intervention categories for physiotherapists treating patients with musculoskeletal conditions on the basis of the International Classification of Functioning, Disability and Health. Int J Rehabil Res 2007;30(4):273-80. 
Finger ME, Cieza A, Stoll J, Stucki G, Huber EO. Identification of intervention categories for physical therapy, based on the international classification of functioning, disability and health: a Delphi exercise. Phys Ther 2006;86(9):1203-20.

Ewert T, Grill E, Bartholomeyczik S, Finger M, Mokrusch T, Kostanjsek N, et al. ICF Core Set for patients with neurological conditions in the acute hospital. Disabil Rehabil 2005;27(7-8):367-73.

\section{Book Chapters}

Finger ME, De Bie R, Nowak D, Escorpizo R. Development and testing of an ICF based questionnaire to evaluate functioning in Vocational Rehabilitation - the Work Rehabilitation Questionnaire WORQ. In: Escorpizo R, Brage S, Homa D, Stucki G, editors. Contemporary issues in vocational rehabilitation and disability evaluation: Application and implementation of the ICF: Springer; 2014

Escorpizo R, Finger ME, Reneman MF. Integration and Application of the International Classification of Functioning, Disability and Health (ICF) in Return-to-Work. In: Schultz IZ, Gatchel R, editors. Handbook of Return to Work: Springer; 2014.

Finger ME, Luckenkemper M. Use Case 4: Applying the ICF Core Set for Vocational Rehabilitation in Long-Term Care. In: Bickenbach JE, Cieza A, Rauch A, Stucki G, editors. ICF core sets : manual for clinical practice. 1st ed. Göttingen: Hogrefe Publishing; 2012. p. 84-97. 